\title{
An Evaluation of Prior Residency and Habitat Effects on the Persistence of Settling Reef Fishes
}

by

Shane W. Geange

A thesis submitted to

Victoria University of Wellington

in fulfilment of the requirements for the degree of Doctor of Philosophy in Marine Biology.

Victoria University of Wellington

2010 


\section{An Evaluation of Prior Residency and Habitat Effects on the Persistence of Settling Reef Fishes}

by

Shane W. Geange

A thesis submitted to

Victoria University of Wellington

in fulfilment of the requirements for the degree of

Doctor of Philosophy in Marine Biology.

Victoria University of Wellington

2010 

This thesis was conducted under the supervision of:

Dr. Jeffrey S. Shima (Primary Supervisor)

Victoria University of Wellington,

Wellington, New Zealand

and

Prof. Craig W. Osenberg (Secondary Supervisor)

University of Florida

Gainesville, Florida, U.S.A 



\begin{abstract}
Both habitat complexity and competitive interactions can shape patterns of distribution and abundance of species. I evaluated the separate and joint effects of competitive interactions and habitat complexity on the survival of young fishes (Family Labridae) on coral reefs. First, I developed (in Chapter 2) a quantitative approach to evaluate potential resource (i.e., niche) overlap among groups of co-occurring species. Using appropriate transformations and probability models, I show that different types of data (e.g., categorical, continuous, count or binary data, as well as electivity scores) give rise to a standard measure of niche overlap, with the overlap statistic between two species defined as the overlapping area between the distributions for each species. Measurements derived from different types of data can be combined into a single multivariate analysis of niche overlap by averaging over multiple axes. I then describe null model permutation tests that differentiate between species occupying similar and different niches within my unified indices.

I then implemented this approach (in Chapter 3) to evaluate potential habitat overlap among eight species of wrasse (Gomphosus varius, Halichoeres hortulanus, H. trimaculatus, Pseudocheilinus hexataenia, Scarus sordidus, Stethojulis bandanensis, Thalassoma hardwicke and T. quinquevittatum), and used these results to inform my subsequent field experiments. In a field assay, I identified the presence of T. quinquevittatum as having the greatest negative effect on survival of transplanted $T$. hardwicke from a suite of three candidate species which were most similar in habitat use to T. hardwicke (the other two candidate species were G. varius and $P$. hexataenia). In a subsequent field experiment, I tested how competition
\end{abstract}


with T. quinquevittatum and structural refuge interact to influence the postsettlement survival of $T$. hardwicke. Competition with $T$. quinquevittatum and structural refuge both altered the survival of T. hardwicke, although their effects were not interactive, indicating that structural complexity did not mitigate the negative effects of competition. Survival of T. hardwicke was 2.3 times greater in treatments without $T$. quinquevittatum relative to those with T. quinquevittatum, and 2.8 times greater in treatments with structural refuge relative to treatments without structural refuge.

Thalassoma hardwicke and T. quinquevittatum often enter reef communities asynchronously, resulting in competitive pressures faced by earlyarriving individuals that potentially differ from those experienced by late-arriving individuals. In a series of field experiments, I investigated whether the strength of intra-cohort competitive interactions between recent T. hardwicke and T. quinquevittatum settlers were dependent upon the sequence and temporal separation of their arrival into communities. Survival rates for both species were greatest in the absence of competitors, but when competitors were present, survival rates were maximized when competitors arrived simultaneously. Survival rates declined as each species entered the community progressively later than its competitor. Further, reversals in the sequence of arrival reversed competitive outcomes. Results provide empirical evidence for competitive lotteries in the maintenance of species diversity in demographically open marine systems, while also highlighting the importance of temporal variation in the direction and magnitude of interaction strengths.

To further our understanding of how timing of arrival influences interaction strengths, I tested whether increasing the availability of complex habitat attenuates or enhances timing-of-arrival effects. Results from this field experiment indicated that aggression by early-arriving individuals towards late-arriving individuals increased as arrival times diverged. When aggression was weak, subordinate individuals were not displaced from complex habitat. Experimental increases in the availability 
of complex habitat resulted in increased survival of subordinates, presumably by disrupting predation pressure. However, when aggression was intense, competitive subordinates were displaced from complex habitat (regardless of the amount of complex habitat available), and this likely increased their exposure to predators.

Overall, the experimental and observational components of this thesis emphasise heterogeneity in competitive environments experienced by recently settled reef fishes. These results highlight the important role that priority effects and habitat complexity play in determining the persistence of reef fish settlers, and illustrate how ecological contexts can add considerable variation to realised interaction strengths. 


\section{Acknowledgments}

The completion of this dissertation was made possible foremost due to the guidance, support, encouragement, inspiration and patience of Jeff Shima and Craig Osenberg. I am also deeply indebted to many other people who have contributed directly and indirectly to both the completion of this dissertation, and my continued development as an ecologist.

I have received tremendous support and advice from friends and colleagues within the School of Biological Sciences at Victoria University of Wellington, and the Department of Zoology at the University of Florida. Deserving special mention are: Ben Bolker, Shirley Pledger, Adrian Stier, Jada-Simone White, Colette St. Mary, Nicole Phillips, Libby Liggins, Daniel "Snout" McNaughtan, Anna Smith, Kevin Burns, Angela Moles, John Poulsen, Gabriela Blohm and Seabird McKeon. All have provided critical reviews of this work in manuscripts or in seminars. I am also grateful to the Shima-Phillips lab-group at Victoria University, and the St Mary-Osenberg-Bolker lab-group at the University of Florida.

My examiners, Phil Lester (Victoria University of Wellington), Richard Taylor (Auckland University) and Geoff Jones (James Cook University), provided comments that greatly strengthened this thesis. Comments by Shirley Pledger and Kevin Burns strengthened Chapter 2. Kevin Burns supplied the alpine data set in Chapter 2. Nick Tolimieri, Nicole Phillips and three anonymous reviewers provided comments which greatly strengthened Chapter 3. Mark Carr, Todd Palmer, Joshua Idjadi and two anonymous reviewers provided comments which greatly strengthened Chapter 
4 (Published in Ecology 90(10) 2868-2878). Ross Alford and two anonymous reviewers provided comments which greatly strengthened Chapter 5 (Published in Oecologia DOI 10.1007/s00442-009-1554-z).

Much of the fieldwork was only possible with help from competent and enthusiastic field assistants, including Jada-Simone White, Natasha Dallin, Shelby Boyer, Anne Duplouy and Emily Hornett. Pete Edmunds, Andy Brooks, Keith Seydel, Hunter Lenihan, Hannah Stewart, Joshua Idjadi, Peggy Fong and Phil Munday provided advice on experimental design and logistics while in the field.

Invaluable logistical support was provided by the staff of U.C. Berkeleys Gump Research Station on Moorea, French Polynesia: Neil Davies, Frank Murphy, Hinano Teavai-Murphy, Tony and Jaques You-Sing, Valentine Brotherson, Irma You Sing.

I am grateful to my friends and collegues on Moorea for their support, especially Anne Duplouy, Matt-Jean McIlroy, Prince, Lez McIlroy, Michael Murray, Joshua Idjadi, Mairead Maheigan, David Hembry, Alice McLeod, Erica Spotswood, Alice Rodgers, Jenny Oates, Jimmy O'Donnell, Hollie Putnam, Nichole Price, Melissa Spitler, Shelby Boyer, William Goldenheim, Stephanie Talmage, Rachel Clausing, Natasha Dallin and the crew of the MV Braveheart (Matt, Brody, Neil and Nic).

A great many friends have also supported me throughout this process, including: Rebecca Spratt, Rowan \& Tamsin Haines, Elizabeth Elliott, Alice McNatty, Monique Crawford, Grant \& Abby Stowell, Simon Van Der Sluis, Katherine Lowe, Clayton Homer and Henry Campbell.

I would also like to thank Adrian Stier. We worked closely together in Moorea, assisting each other with logistics, conceptualization and fieldwork while conducting research for our respective dissertations. I would have gone mad at times without his support and friendship.

This dissertation was possible with financial support from various funding bodies: NSF (OCE-0242312) awarded to Osenberg, Bolker and St. Mary; Fulbright-Ministry of Research, Science and Technology Graduate 
Student Award 2007; VUW PhD Scholarship 2007-2009; New Zealand Post Graduate Study Abroad Award 2008 \& 2009; National Geographic International Ecostations Fellowship 2008; Sigma-Xi Grants in Aid of Research 2008 \& 2009.

Finally, I wish to thank my parents, Gail and Paul, my granddad Rob, and brother and sister, Andrew and Fiona for their encouragement. 
viii 


\section{Publications from this Thesis ${ }^{1}$}

\section{Published Articles}

Geange S.W. and A.C. Stier. (2010) Priority Effects and Habitat Complexity Affect the Strength of Competition. Oecologia DOI 10.1007/s00442-0091554-z

Author contribution: S.W.G designed and performed the experiments, analyzed the data and wrote the manuscript: A.C.S performed the experiments and edited the manuscript.

Geange S.W. and A.C. Stier. (2009) Order of Arrival Affects Competition in Two Reef Fishes. Ecology 90(10) 2868-2878

Author contribution: S.W.G designed and performed the experiments, analyzed the data and wrote the manuscript: A.C.S performed the experiments and edited the manuscript.

\section{Articles in Review/Preparation}

Geange S.W. (In Review) Effects of Habitat Complexity and Interspecific Competition on the Post-settlement Survival of a Coral Reef Fish. Marine Ecology Progress Series

Author contribution: S.W.G designed and performed the experi-

${ }^{1}$ As of 14th Jan 2010 
ments, analyzed the data and wrote the manuscript.

Geange S.W., Pledger S, Burns K.C. and Shima J.S. (In Prep) A Multivariate Analysis of Niche Overlap Incorporating Data of Different Types. Intended for submission to Oecologia

Author contribution: S.W.G, S.P, K.C.B and J.S.S conceptualized the theoretical approach. S.W.G and S.P conceptualized and implemented the statistical analysis. S.W.G wrote the manuscript. S.P, K.C.B and J.S.S edited the manuscript. 


\section{Contents}

1 General Introduction $\quad 1$

2 A Multivariate Analysis of Niche Overlap Incorporating Data of Different Types 9

2.1 Abstract ...................... 10

2.2 Introduction . . . . . . . . . . . . . 11

2.3 Methods . . . . . . . . . . . . . . . . . 14

2.3.1 Data transformations and probability models . . . . . 14

2.3.2 Constructing Multivariate Indices of Niche Overlap and their Graphical Representation . . . . . . . 18

2.3.3 Detecting Statistical Differences in Niche Overlap . . 19

2.3.4 Coral Reef Fish Illustration . . . . . . . . . . . . 20

22

2.4 Results ....................... 23

2.4.1 Coral Reef Fish Illustration . . . . . . . . . . . 23

2.4 .2 Alpine Plant Illustration . . . . . . . . . . . . 25

2.5 Discussion . . . . . . . . . . . . . . . . 27

3 The Effects of Structural Refuge and Interspecific Competition on the Survival of Thalassoma hardwicke 33

3.1 Abstract ...................... 34

3.2 Introduction . . . . . . . . . . . . . . 35

3.3 Methods . . . . . . . . . . . . . . . . 37 
3.3.1 Study system . . . . . . . . . . . . . 37

3.3.2 Surveys of habitat availability and association . . . . 39

3.3.3 Identifying potential T. hardwicke competitors . . . . 41

3.3.4 The influence of competition and habitat complexity on the survival of T. hardwicke . . . . . . . . . . . 44

3.4 Results . . . . . . . . . . . . . . . . . 46

3.4.1 Surveys of habitat availability and association . . . . 46

3.4.2 Identifying potential T. hardwicke competitors . . . . 48

3.4.3 The influence of competition and structural refuge on the survival of T. hardwicke . . . . . . . . . . . . 51

3.5 Discussion . . . . . . . . . . . . . . . . . 54

4 Order of Arrival Affects Competition in Two Reef Fishes 59

4.1 Abstract ...................... 60

4.2 Introduction . . . . . . . . . . . . . . . . 61

4.3 Methods ....................... . 64

4.3 .1 Study Species . . . . . . . . . . . . . . . . 64

4.3.2 Study Site . . . . . . . . . . . . . 65

4.3.3 Experimental Design and Execution . . . . . . . . . 71

4.3.4 Behavioural Observations . . . . . . . . . . 75

4.3.5 Data Analysis . . . . . . . . . . . . . 76

4.4 Results . . . . . . . . . . . . . . . . 78

4.4.1 Interspecific Priority Effects . . . . . . . . . . 78

4.4.2 Intraspecific Priority Effects . . . . . . . . . . . 80

4.5 Discussion ..................... 83

5 Intraspecific Priority Effects and Habitat Complexity Affect the Survival of Thalassoma quinquevittatum Settlers 89

5.1 Abstract ....................... 90

5.2 Introduction . . . . . . . . . . . . . . . 91

5.3 Methods . . . . . . . . . . . . . . . . . . . 94

5.3 .1 Study Species . . . . . . . . . . . . . . . . . 94 
5.3 .2 Study Site . . . . . . . . . . . . . . 95

5.3.3 Experimental Design and Execution . . . . . . . . . 99

5.3.4 Behavioural Observations . . . . . . . . . . . . . . 101

5.3 .5 Data Analysis . . . . . . . . . . . . . . 103

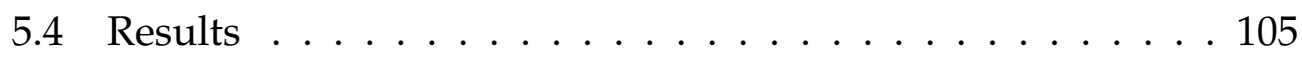

5.5 Discussion . . . . . . . . . . . . . . . 108

6 General Discussion 113

6.0.1 Interspecific Competition and Habitat Complexity . . 114

6.0.2 Intracohort Priority Effects . . . . . . . . . . 116

6.0.3 The Relationship Between Intracohort Priority Effects and Habitat Complexity . . . . . . . . . . . 119

6.0.4 Niche vs. Neutral Processes . . . . . . . . . . . . 120

6.0.5 Contribution to the Current State-of-Knowledge . . . 122

$\begin{array}{ll}\text { Appendices } & 123\end{array}$

A Evaluating the Performance of Visual Estimators 125

A.1 Introduction . . . . . . . . . . . . . . 126

A.2 Methods . . . . . . . . . . . . . . . . . 128

A.2.1 Study Site . . . . . . . . . . . . . . . 128

A.2.2 Study Species . . . . . . . . . . . . . . . . 128

A.2.3 Visual Estimation of Proportional Cover . . . . . . . . 128

A.2.4 Visual Estimation of Standard Length . . . . . . . . . 129

A.2.5 Visual Estimation of Fish Abundance . . . . . . . . . 129

A.2.6 Measuring Performance with Precision, Bias and Accuracy . . . . . . . . . . . . . . . 130

A.3 Results . . . . . . . . . . . . . . . . . 132

A.3.1 Visual Estimation of Proportional Cover . . . . . . . . 132

A.3.2 Visual Estimation of Standard Length . . . . . . . . 135

A.3.3 Visual Estimation of Abundance . . . . . . . . . . . 137

A.4 Discussion . . . . . . . . . . . . . . . . . . . 137 
A.4.1 Visual Estimation of Proportional Cover . . . . . . . 137

A.4.2 Visual Estimation of Standard Length . . . . . . . . . 140

A.4.3 Visual Estimation of Abundance . . . . . . . . . . . 141

A.4.4 Summary . . . . . . . . . . . . . . 142

B Geange and Stier (2009) Order of arrival affects competition in two reef fishes. Ecology 90(10) 2868-2878

C Geange and Stier (2010) Priority effects and habitat complexity affect the strength of competition. Oecologia 


\section{List of Figures}

2.1 Graphical representations of probability distributions constructed from categorical, ratio and electivity data . . . . . 24

2.2 Interspecific similarities in unified niche overlap between five species of reef fishes incorporating three functional traits 26

2.3 Interspecific similarities in unified niche overlap between five alpine plant species incorporating two functional traits . 28

3.1 Patterns of habitat association for eight species of coral reef fishes presented as Manlys Alpha values . . . . . . . . . . 49

3.2 Graphical representation of interspecific similarities in habitat association for eight species of coral reef fishes presented as: (A) a dendrogram; and (B) non-metric multidimensional

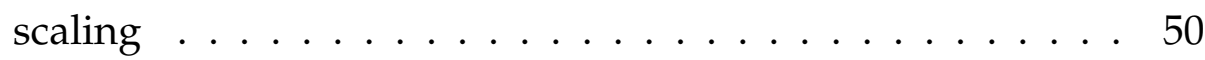

3.3 Observed proportional survival of Thalassoma hardwicke in the presence of Gomphosus varius, Pseudocheilinus hexataenia and T.quinquevittatum . . . . . . . . . . . . . 52

3.4 Proportional survival of Thalassoma hardwicke in the presence or absence of T. quinquevittatum (competitor: a deleterious effect) and Turbinaria ornata (complex habitat: a beneficial effect $) \ldots \ldots \ldots \ldots$. . . . . . . . . . . 53 
4.1 Standard lengths $(\mathrm{mm})$ of focal individuals and prior residents used in experiments examining Intra- and Interspecific priority effects between Thalassoma hardwicke and $T$. quinquevittatum ................... 74

4.2 Survival of focal individuals (either Thalassoma hardwicke or T. quinquevittatum) in response to presence, relative timing of arrival, and relative aggression of a competitor (either Thalassoma hardwicke or T. quinquevittatum) . . . . . . . . . . . 81

5.1 Standard lengths ( $\mathrm{mm}$ ) of Thalassoma quinquevittatum used in an experiment examining Intraspecific priority effects . . 102

5.2 Survival of, and aggression displayed towards Thalassoma quinquevittatum as a function of priority effects and habitat complexity . . . . . . . . . . . . . . . 109

A.1 Examples of: (A) low precision; and (B) systematic bias . . . 127

A.2 Model II linear regression of visual estimation of proportional habitat cover against fixed point contact estimates . . 134

A.3 Model II linear regression of visual estimates of standard length against standard length measured with calipers . . . 136

A.4 Model II linear regressions of visual estimates of abundance against the best estimate of Thalassoma hardwicke abundance 138

Note: in some instances captions are abbreviated from that in the figure 


\section{List of Tables}

2.1 Mean niche overlap between five species of reef fishes based on three functional traits . . . . . . . . . . . . . . 25

2.2 Mean niche overlap between five alpine plant species based on two functional traits . . . . . . . . . . . . . . . . . . 27

3.1 Counts of juvenile wrasses ( $<25 \mathrm{~mm}$ standard length) on 240 patch reefs within the northern lagoon of Moorea . . . . 38

3.2 Proportion of reefs with Manlys Alpha values greater than expected under conditions of random association . . . . . 47

3.3 Results from a generalized linear model modeling Thalassoma hardwicke survival against the presence of Gomphosus varius, Pseudocheilinus hexataenia and T. quinquevittatum . . . 48

3.4 Results from the best fitting generalized linear model modeling proportional Thalassoma hardwicke survival against the presence and absence of T. quinquevittatum (competitor: a deleterious effect) and Turbinaria ornata (structural refuge: a beneficial effect) . . . . . . . . . . . . . . . . 51

4.1 Non-manipulated fish community structure on experimental patch reefs used in a study examining intracohort priority effects between Thalassoma hardwicke and T. quinquevittatum 67 
4.2 Non-manipulated fish community structure on experimental patch reefs used in a study examining intraspecific, intracohort, priority effects between Thalassoma hardwicke individuals . . . . . . . . . . . . . . . . . . 69

4.3 Experimental design examining intra- and interspecific priority effects between Thalassoma hardwicke and T. quinquevittatum ......................... 72

4.4 Hazard ratios from a cox proportional hazard assessment examining survival of focal individuals (either Thalassoma hardwicke or T. quinquevittatum in response to presence and relative timing of arrival of a competitor (either Thalassoma hardwicke or T. quinquevittatum . . . . . . . . . . . . . 8

5.1 Non-manipulated fish community structure on experimental patch reefs in a study testing the effects of habitat complexity and priority effects on the post-settlement survival of Thalassoma quinquevittatum . . . . . . . . . . . . . . 97

5.2 Experimental design examining the effects of habitat complexity and intraspecific priority effects on the post-settlement survival of Thalassoma quinquevittatum . . . . . . . . . . . . . 101

5.3 Post-settlement survival of Thalassoma quinquevittatum in response to habitat complexity and intraspecific priority effects ....................... 106

5.4 Aggression towards Thalassoma quinquevittatum as a function of habitat complexity and intraspecific priority effects . 107

A.1 Performance of visual estimates of proportional cover contrasted against proportional cover measured with fixed point contact transects . . . . . . . . . . . . 133

A.2 Performance of visual estimates of standard length compared against standard length measured with calipers . . . . 135 
A.3 Performance of visual and capture estimates of Thalassoma hardwicke abundance against the best estimate of T. hardwicke abundance . . . . . . . . . . . . . . . . . 137

Note: in some instances captions are abbreviated from that in the table 
Chapter 1

General Introduction 
A central goal of community ecology is to explain spatio-temporal patterns in the distribution and abundance of organisms (Warner and Chesson, 1985; Chesson, 2000; Palmer et al., 2003; Schmitt and Holbrook, 2003; Munday, 2004; Roxburgh et al., 2004; Calcagno et al., 2006). Although recruitment (along with mortality, immigration and emigration) is one of the basic demographic processes bringing about changes in the distribution and abundance of organisms (Gaines and Roughgarden, 1985; Roughgarden et al., 1988; Underwood and Fairweather, 1989), the processes contributing to successful recruitment are not well understood. Recruitment can be defined as the input of juveniles to a population, and is the primary means by which many marine populations are replenished and persist over time (Ricker, 1975). In relatively closed systems, most recruits are a product of reproduction within the community, with the relative abundance of incoming recruits directly related to current community structure (Hixon et al., 2002). In contrast, demographically open systems (e.g., most marine communities, as well as plant and insect communities with dispersive life-history stages) depend on recruits largely derived from external sources (Hixon et al., 2002; Caley et al., 1996). Because the supply of recruits is often spatially and temporally unpredictable in open systems (due to variability in reproductive output, survival and dispersal of propagules, and successful transition of propagules to adult habitat), the relationship between the abundance of recruits and local adults is often decoupled (Hixon et al., 2002; Caley et al., 1996). A comprehensive understanding of role recruitment plays in maintaining patterns of distribution and abundance in open populations requires a detailed description of the processes occurring during recruitment.

The majority of coral reef fishes have two-phase life histories, consisting of a potentially dispersive pelagic larval phase, and benthic, reefassociated juvenile and adult phases. Consequently, reef fish communities are considered relatively open (Armsworth, 2002; Mora and Sale, 2002); 
however, see Jones et al. (1999), Swearer et al. (1999) and Cowen et al. (2000). Recruitment of reef fishes is generally assumed to represent the net product of settlement (the transition from the pelagic environment to benthic juvenile habitat) and post-settlement processes preceding the transition from juvenile to adult habitat (Ricker, 1975; Abrams, 1984; Beverton, 1991). Temporal and spatial variation in reef fish recruitment therefore depends upon several factors: (1) breeding phenology; (2) larger scale processes affecting larval dispersal and settlement; (3) the quality and quantity of appropriate settlement habitat; and (4) postsettlement interactions with established residents before the transition to adult habitat.

Breeding seasons of many reef fishes may be timed to coincide with optimal conditions for larval growth and survival (Qasim, 1956; Cushing, 1987). Consequently, the breeding phonologies of reef fishes typically vary with latitude. At lower latitudes, where favorable conditions for larval survival might extend throughout the year (Winemiller and Rose, 1992), longer breeding seasons are expected to be associated with lower fecundities which may reduce the potential for strong settlement cohorts (Luckhurst and Luckhurst, 1977; Robertson et al., 1993; Robertson et al., 1999; Srinivasan and Jones, 2006). Alternatively, on high latitude coral reefs, such the Great Barrier Reef, breeding periods are typically short, with strong settlement cohorts occurring during the summer (Russell et al., 1974; Russell et al., 1977; Talbot et al., 1978; Williams, 1983; Doherty and Williams, 1988b; Milicich and Doherty, 1994).

Following breeding, the duration of the pelagic larval phase in reef fishes is species-specific, flexible, and ranges from one week to over four months (Victor, 1986; Thresher et al., 1989). Although the dispersal of larvae is controlled by a combination of physical oceanographic processes (including circulation patterns, currents, and topography: Leis, 1991) and larval behavior (including orientating to visual, audio or olfactory cues: Montgomery et al., 2001; Simpson et al., 2004; Lecchini et al., 2005), 
exactly how larvae are dispersed, and the degree to which populations are open largely remains a black-box in our understanding of the recruitment dynamics of reef fishes. Despite this, there is ample evidence that populations of reef fish experience variable replenishment (Doherty and Williams, 1988a; Doherty, 1991), and that these variations can have lasting impacts on patterns of demography and abundance (Doherty, 1983; Victor, 1983; Victor, 1986).

As larvae within a cohort make the transition from pelagic to benthic habitat, they use sensory abilities (visual, audio or olfactory senses: Montgomery et al., 2001; Simpson et al., 2004; Lecchini et al., 2005) to detect settlement cues at small spatial scales (less than a few meters). Larvae may use these cues to orientate towards, and navigate to, settlement habitat. The availability of settlement habitat may determine community structure, with settler survival differing among habitats (e.g., Levin, 1994; Beukers and Jones, 1997), and similar assemblages of species developing in similar habitats (e.g., Syms and Jones, 1999; Syms and Jones, 2000). As larvae enter settlement habitat, they may encounter established residents that have settled in previous cohorts (i.e., establish residents) and other recently settled individuals from the same cohort. Established residents may facilitate, inhibit or have no effect on the successful settlement of reef fish larvae (Sale, 1976a; Jones, 1987b; Osman and Whitlatch, 1995; Risk, 1998; Tolimieri, 1998). For example, competitive interactions with established residents may affect post-settlement survival, and therefore alter initial patterns of abundance generated by larval supply (Shulman et al., 1983; Almany, 2003). Such "priority effects", in which established individuals affect those that arrive later, are a common feature of ecological communities, having been documented in plant (Kennedy and Burns, 2005), zooplankton (Louette and Meester, 2007), insect (Ehmann and MacMahon, 1996), sessile marine (Sutherland, 1974), amphibian (Lawler and Morin, 1993; Dayton and Fitzgerald, 2005) and reef fish communities (Shulman et al., 
1983; Sweatman, 1985; Almany, 2003; Almany, 2004c; Munday, 2004).

When priority effects operate in a species-specific manner, a communitys recruitment history can influence its future composition by setting-thestage for interactions between residents and settlers. Growing evidence suggests that such interactions are common in reef fishes, and can rapidly and substantially modify patterns established by variable larval supply (Webster, 2002; Webster, 2002; Almany, 2003; Almany, 2004c).

To date, the majority of research examining priority effects in coral reef fish has focused on intercohort effects of established predators and territorial species on the recruitment success of later arriving settlers (for examples see Shulman et al., 1983; Sweatman, 1985; Almany, 2003; Almany, 2004c; Munday, 2004), with little research examining intracohort priority effects (although see Jones, 1987b). While these studies demonstrate that prior residents can affect the recruitment success of later arrivals, they largely ignore intracohort effects and the influences of either: (1) reversals in the sequence of arrival; or (2) changes in the timing of arrival. Changes in the sequence (who arrives first) and timing (by how much) of arrival can add considerable variability to the direction and magnitude of interactions between prior residents and settlers. For example, the omission of sequence and timing effects in previous studies examining prior residency effects inhibits our ability to distinguish between priority effects versus competitive effects that are invariant with respect to prior residency.

Because many individuals with similar resource requirements settle within a single cohort, intracohort priority effects are a potentially important source of heterogeneity in the survival of reef fish settlers. When individuals within a single settlement pulse compete for limited resources (e.g., settlement habitat) and the outcome of competition is dependent upon size or experience advantages, subtle differences in arrival time may have large effects on recruitment success.

When priority effects (rather than species effects) determine compet- 
itive dominance, the composition of assemblages becomes a "lottery" because the outcome of competition depends only on who arrives first at a vacant site (Talbot et al., 1978; Victor, 1983; Sale, 1978; Sale, 1976b; Sale et al., 1984; Doherty and Williams, 1988a). Since space is limited, chance vacancies are quickly filled by settlers, with the unpredictability of the process preventing any one species from excluding the other. A strong prior residency affect allows any established recruit to hold space against all comers. Although this is consistent with the neutral theory of biodiversity, which explains coexistence with the equivalence of competitors (Hubbell, 2001), it is in direct contrast to traditional nichebased theories of coexistence that argue past interspecific competition has resulted in fine partitioning of resources among species, leading to stable coexistence (Pianka, 1966; Colwell and Fuentes, 1975). Theoretically, niche differences cause species to limit themselves more than they limit their competitors (Chesson, 2000), thus stabilizing competitor dynamics by giving species higher per capita population growth rates when rare than when common. Coexistence occurs when the stabilizing effects of niche differences overcome species differences in overall competitive ability (Levine and HilleRisLambers, 2009). Although many studies have found fish communities to be highly speciose assemblages whose members are relatively generalized in terms of diet and habitat association (e.g., Sale, 1975; Sale, 1977; Sale, 1978), the relative roles of niche-based versus neutral (e.g., lottery) processes in organizing reef fish communities continues to be debated.

Habitat complexity can also add considerable variation to the recruitment success of coral reef fishes. For example, increasing habitat complexity is expected to mitigate the negative effects of competition for predator free space (Almany, 2004a; Almany, 2004b; Forrester et al., 2006; Forrester and Steele, 2004; Holt, 1987) or reverse competitive dominance relationships (Ebersole, 1985). Consequently, the magnitude of timing of arrival effects during intercohort competition may be dependent upon 
habitat complexity.

This thesis incorporates both descriptive and experimental approaches to evaluate the separate and joint effects of the availability of settlement habitat and priority effects on the survival of reef fish settlers, with primary attention given to intracohort priority effects. The specific objectives of this thesis are to: (i) examine similarity in habitat use within a suite of eight sympatric wrasse species (focusing on settler/recruit stages) to determine which of these species have the greatest ecological similarity (i.e., overlap most in niche-space); (ii) determine the influence of sequence and timingof-arrival on the strength of intracohort priority effects between recent wrasse settlers; and (iii) determine whether increasing the availability of settlement habitat enhances or attenuates timing-of-arrival effects. These three objectives are mirrored in the basic structure of this thesis. Each chapter is written as a stand-alone manuscript; consequently, there is some repetition in the information contained in the introductions and methods of each chapter.

In chapter 2, I outline the construction of indices of niche overlap based on habitat use using electivity data. I expand this approach to allow the direct modeling of different types of data for inclusion within a unified multivariate analysis of niche overlap. Binary and categorical measures can be combined with continuous-variable quantitative functional traits, ratios, count data and electivity scores, using transformations and density estimations appropriate for each data type. Having constructed unified indices of niche overlap, I then describe the use of permutation tests to determine whether a group of species occupies the same niche, or whether there is evidence of some difference in their niches. I illustrate the approach with examples from reef fishes and alpine plants.

In Chapter 3, I use the approach developed in chapter 2, to evaluate potential overlap in the use of settlement habitat among eight species of wrasse. I use the resulting indices of overlap to inform subsequent 
field experiments. Using a field-based assay, I identify which species most similar in habitat use to Thalassoma hardwicke compete with $T$. hardwicke. In a subsequent field experiment, I test how competition and habitat complexity interact to influence the post-settlement survival of $T$. hardwicke.

In chapter 4, I use a field experiment to evaluate the influence of sequence (who arrives first) and timing of arrival (by how much) on the strength of intracohort priority effects between $T$. hardwicke and $T$. quinquevittatum settlers. In a second experiment, I assess the influence of timing-of-arrival on intraspecific priority effects between T. hardwicke settlers of the same cohort.

In Chapter 5, I examine potential interactive effects between timing of arrival and habitat complexity. Using a field experiment, I investigate whether increasing the availability of complex habitat attenuates or enhances timing-of-arrival effects between T. quinquevittatum settlers of the same cohort.

I conclude with a general discussion and synthesis of my work in chapter 6. Overall, this thesis suggests that the observed patterns of habitat use and survival in juvenile wrasses can be explained by a complex interplay between habitat preferences, competition, priority effects, habitat complexity and predation pressure. 


\section{Chapter 2}

\section{A Multivariate Analysis of Niche Overlap Incorporating Data of Different Types}




\subsection{Abstract}

Competition theory predicts that community structure may be shaped by resource partitioning between co-occurring species. As such, quantifying the degree of species overlap in resource utilization (i.e., niche overlap) is a key component of studies of both community structure and species coexistence. For many organisms, niche space is quantified by multiple resource axes. Each axis may be described by a different type of data (e.g., categorical, continuous, count or binary data, as well as electivity scores), with different data types requiring different statistical treatments. Therefore, incorporating multiple axes into a single measure of niche space is problematic. Here, I propose general methods for combining different data types within a unified multivariate analysis of niche overlap. Using appropriate transformations and probability models, I show that each data type can give rise to a standard measure of niche overlap, with the overlap statistic between two species defined as the overlapping area between the distributions for each species. Measurements derived from different types of data can be combined into a single multivariate analysis of niche overlap by averaging over multiple axes. I then describe null model permutation tests that differentiate between species occupying similar and different niches within my unified indices. To illustrate the use of these newly devised indices, I apply my these techniques to coral reef fish and alpine plant datasets. 


\subsection{Introduction}

Hutchinson (1957) defined the niche as a multidimensional hypervolume in which a species maintains a viable population. The related concept of niche overlap between species may be viewed as the multidimensional hypervolume within which two or more species maintain viable populations in the presence of one another. Descriptions of niche space often incorporate multiple axes, each of which may be an environmental condition (e.g., altitude, $\mathrm{pH}$ ); a type of resource (e.g., prey type, refuge type); a phenotypic trait indicating the type of resource used (e.g., gut length may be indicative of diet); or an index of electivity (e.g., Manlys Alpha). Multiple axes may be described by different data types, including: binary data (e.g., presence/absence of a prey type in the diet), categorical data (e.g., host size classes: small, medium or large), continuous data (e.g. soil $\mathrm{pH}$ ), ratio data (e.g., pectoral fin aspect ratio), count data (e.g., number of prey eaten per hour), or indices of electivity (e.g., habitat use relative to availability), with the most commonly studied niche axes incorporating food or habitat. When more than one niche dimension is relevant to species co-occurrence, a joint measure of niche overlap incorporating all of the relevant dimensions should be used (May, 1975); however, incorporating multiple axes described by different data types into a single measure of niche space is statistically challenging, because different data types cannot be dealt with in the same way. Here, I propose general statistical methods for combining different data types within a unified multivariate analysis of niche overlap.

Historically, niche overlap has been calculated using either: (1) continuous data (e.g., MacArthur and Levins, 1967); or (2) discrete categorical data (e.g., Pianka, 1973). Continuous data has often been modelled as the overlap of two normal curves (e.g., Cody, 1975), although this overlap index has two major problems: (1) it assumes that quantitative functional traits are normally distributed; and (2) it does not account for 
differences in variance between two normal distributions with the same mean. Although continuous data can be converted to categorical data to overcome these problems, there is a loss of information in replacing a measurement with ordered categories. Mouillot et al. (2005) provided a solution to these problems, describing an approach based on kernel distribution estimators that models niche overlap from continuous data independently of the underlying distribution of the data. Their approach extended niche overlap studies to allow the construction of broad, multivariate indices of niche overlap. Mouillot et al. (2005) constructed their indices from probability distributions of continuous measurements using density estimation to provide comparable metrics across different axes. However, this approach does not provide a framework for other types of data (e.g., electivity scores between 0 and 1 , or count data), which are often recorded by field workers, and might usefully be included in multivariate indices of niche overlap.

Here, I propose an extension of the work of Mouillot et al. (2005) that directly models different data types (binary, categorical, continuous, ratio, proportion, percent, count and electivity data) to provide comparable measures of niche overlap. Using appropriate transformations and density estimation techniques, each data type gives rise to a standard measure of niche overlap ranging from 0 (no overlap) to 1 (complete overlap). The use of a standard measure of niche overlap ensures that the geometric interpretation of the overlapping density functions or probability is the same for each data type. Once estimated probability distributions are available for each data type, the overlap statistic between two species is simply the overlapping area between the distributions for each species. It is then possible to create a composite output of niche overlap, derived from multivariate inputs of different types of data, by averaging over multiple axes.

A major objective of studies examining niche overlap is to determine if two or more species occupy the same niche. Niche comparisons must 
be done in a way that rules out detecting as different two niches which only differ due to sampling variation. I suggest the use of null models (Gotelli, 2000; Gotelli and Graves, 1996) to differentiate between species occupying similar and different niches. This approach uses permutation tests to produce a statistical null distribution (the distribution of the test statistic under the null hypothesis of no difference in niche overlap) by calculating pseudo-values of the test statistic which would arise if $H_{0}$ was true. The position of an emperically derived test statistic in relation to the pseudo-values generated by the null model provides the $P$-value for the test.

I begin by outlining methodology for combining binary, categorical, continuous, ratio, proportion, percent, count and electivity data into a multivariate analysis of niche overlap. Appropriate transformations and probability models for each data type give rise to estimated probability distributions, with the overlapping area between the probability distributions of two species the niche overlap statistic. I then outline how individual axes of niche overlap can be combined into a single multivariate measure of niche overlap. I illustrate the construction of composite measures of niche overlap first with an example from reef fishes that combines measurement, categorical and electivity data. Next I use an alpine plant example combining continuous and categorical data. I chose these examples as illustrations because they both include spatial data in one axis. Spatial resource partitioning is a common ecological phenomenon. For example, plants may partition their niches along various spatial gradients, including gradients of light, soil moisture and elevation (e.g., Silvertown, 2004), and reef fishes may partition resources by depth (e.g., Larson, 1980). For each illustration, I use permutation tests to identify groups of species occupying similar niches. 


\subsection{Methods}

\subsubsection{Data transformations and probability models}

\section{Binary Data}

Many measures of resource overlap are binary. An example is whether a habitat patch is colonized or not (e.g., Moilanen and Nieminen, 2002). For such data, I assume a Bernoulli (binary) distribution for the rsponse variable, with species $i$ having probability $p_{i}$ for success (value 1) and $q_{i}=1-p_{i}$ for failure (value 0 ). The proportion of individuals of species $i$ with indicator 1 is the estimate of $p_{i}$. Similarly, $p_{j}$ is estimated by the proportion of individuals of species $j$ with indicator value 1 . The niche overlap (NO) between species $i$ and $j$ (on axis $t$ ), is defined as:

$$
N O_{i j t}=\min \left(p_{i} p_{j}\right)+\min \left(q_{i} q_{j}\right)
$$

\section{Categorical Data}

An example of categorical data is prey types in stomach content analysis (e.g., pelagic teleosts, demersal teleosts, invertebrates, and chondrichthyans: Lucifora et al., 2008). There are $K$ categories all assumed to be equally available to species $i$. Proportional usage of category $k$ by species $i$ is written $p_{i k}$, assuming the sum of $p_{i k}$ across all $k$ categories equals 1 . For example, $p_{i k}$ might be estimated by the proportion of individuals of species $i$ consuming prey $k$. Similarly, species $j$ has proportions $p_{j k}$. In an extension from binary data (two categories) to $K$ categories, the niche overlap (NO) between species $i$ and $j$ (on axis $t$ ) is defined as:

$$
N O_{i j t}=\sum_{k=1}^{K} \min \left(p_{i k} p_{j k}\right)
$$


For a graphical representation, see Figure 2.1 a.

\section{Continuous Data}

Examples of continuous measures include many quantitative functional traits (e.g., specific leaf area: Beaumont and Burns, 2009) and environmental covariates (e.g., salinity: Clarke and Allaway, 1993). Using kernel density estimations, Mouillot et al. (2005) converted finite data sets into continuous probability densities of flexible shape, avoiding two problems: (1) the loss of information involved in replacing continuous measurements with discrete categories; and (2) the unwarranted assumption of normality (or some other particular shape of distribution) if a single continuous distribution is fitted to the data. Density estimation by the kernel method (Silverman, 1986) gives a smooth, flexible, nonparametric curve for a probability density function over the data points (although the choice of the kernel bandwidth is a critical issue, see discussions in: Mouillot et al., 2005; Stine and Heyse, 2001). Non-parametric kernel density functions of niche overlap $\left(N O_{K}\right)$ between species $i$ and $j$ is the overlap of kernel population density functions ( $f_{i t}$ and $f_{j t}$ for species $i$ and $j$ respectively) on axis $t$, defined as:

$$
N O_{K i j t}=1-\frac{1}{2} \int\left|f_{i t}(x)-f_{j t}(x)\right| d x
$$

Modeling observed data with a mixture of normal distributions, which do not observe a restriction to positive values, may result in the extension of density curves to $x<0$ when the data were positive measurements. Although this may be appropriate for data that can go below zero (e.g., minimum temperature), it is not appropriate for data that must be positive (e.g., fish standard length). In the later case, Silverman (1986) suggests it is preferable to estimate the density of $\log (x)$. 


\section{Ratio, Proportion and Percentage Data}

With appropriate transformations, ratio, proportion and percent data can be modeled in the same way as continuous data. Ratio data is a continuous positive measurement; therefore (as with continuous data), density estimation is appropriate. Ratio data requires one of two transformations depending on how the data is bounded. Ratio data that is bounded below by zero, but has no upper bounds (e.g., ratio of leaf area to leaf mass: see Figure $1 b$ ) requires density estimation on $\log (x)$. Ratio data that is bounded below by zero and above by one, i.e., proportion data (e.g., the proportion of tail length to total body length in lizards) requires density estimation on logit $(x)$. This transformation prevents the density estimation overflowing the $(0,1)$ bounds. The same approach is used for percentage data, which is bounded below by 0 and above by 100 .

\section{Count Data}

An example of count data is the number of prey items eaten by an individual during a period of observation (e.g., Jansen et al., 2002). For species $i$, there will be records from several individuals. Density estimations are created by taking a finite mixture of Poisson distributions, which is analogous to the mixture of normal distributions used in kernel density estimation for continuous data. Using non-parametric maximum likelihood estimation (NPMLE: see Norris and Pollock, 1998), a mixture of finitely many Poisson distributions can be fitted to count data, with Akaikes Information Criterion (Akaike, 1973) providing an objective choice of the number of components needed to provide a good fit (analogous to bandwidth selection in kernel density estimation of continuous data).

If the fitted distributions for species $i$ and $j$ have probabilities $p_{i x}, p_{j x}$ respectively for values $x=0,1,2,3$, and $x_{\max }$ is set high enough for the minimum probability to be almost zero, niche overlap (NO) for axis $t$ is 
calculated as:

$$
N O_{i j t}=\sum_{x=0}^{x_{\max }} \min \left\{p_{i x}, p_{j x}\right\}
$$

\section{Electivity Data}

An example of electivity data is patterns of habitat use relative to availability in reef fish (e.g., McDermott and Shima, 2006). Electivity scores are similar to proportion data (bounded below by 0 and above by 1 ), but they are not strictly continuous because there may be clusters of observations at 0 or at 1 . If axis $t$ is the usage of a resource, and all individuals of species $i$ associate with that resource, the electivity score (e.g., Manlys Alpha: Chesson, 1978; Manly et al., 1972) is 1. If no individuals of species $i$ associate with that resource, the electivity score is 0 ; however, between 0 and 1 , with partial usage of the resource, the electivity measure is continuous. This implies there is a composite, or mixed, statistical distribution, neither fully continuous nor fully discrete. Such a distribution is not easily represented as a density. If a continuous curve is used for the probability density function on $0<x<1$, there should be infinite spikes at 0 and 1 ; similarly, the bar charts used in discrete distributions cannot accommodate continuous density functions. I note that representation as the cumulative distribution function is possible, $y=F(x)=\operatorname{Prob}(X x)$. With discrete distributions, this rises from 0 to 1 in a step function, while a continuous distribution gives a continuously rising curve. A distribution with a mixture of discrete and continuous probability simply includes both steps and a continuous curve; however, it is not possible to display niche overlap on the cumulative probability graph. Instead, I illustrate such distributions in a triptych graph that has left and right panels to display the probabilities of 0 and 1 respectively, 
and a central panel for the continuous probability (see Figure $2.1 \mathrm{c}$ ). The density estimation for the central panel uses logit transformed data to avoid an overflow outside the lower bound of zero and the upper bound of one.

For species $i$, the estimated probability of 0 is the proportion of zeros, and the probability of 1 is the proportion of ones. The remaining observations have density estimation as for proportion data; however, the probabilities from the density estimation are downscaled by the proportion of 0 and 1 in the dataset to reduce the area under the density curve to its original proportion. The same procedure is used for species $j$. The combined overlap between species $i$ and $j$ in the three density estimates is then taken as the degree of niche overlap.

\subsubsection{Constructing Multivariate Indices of Niche Overlap and their Graphical Representation}

Having calculated overlap between species $i$ and $j$ for each data type, multivariate measures of niche overlap are obtained by averaging niche overlap (NO) between species $i$ and $j$ over the different axes $t$, where $T$ is the number of axes:

$$
N O_{i j}=\frac{1}{T} \sum_{t=1}^{T} N O_{i j t}
$$

$N O_{i j}$ tends to 0 when the two distributions are disjoint, and is 1 when they are perfectly similar. The associated variance is:

$$
s_{N O_{i j}}^{2}=\frac{\sum_{i=1}^{T}\left(N O_{i j t}-N O_{i j}\right)^{2}}{T}
$$

Mouillot et al. (2005) provide approaches for calculating niche overlap for traits that are related to similar functions. In this scenario, the degree 
of independence of each trait is discounted by down weighting highly correlated traits (see formulas 8-10: Mouillot et al., 2005).

Niche overlap may be viewed as a measure of association between species pairs, therefore, $d_{i j}=1-N O_{i j}$ may be viewed as a measure of distance between species $i$ and $j$. Using these distance measures, an $n$ $\mathrm{x} n$ distance matrix $D=d_{i j}$ can be constructed, where $n$ is the number of species in the study. From this matrix, non-metric multidimensional scaling (nMDS), which reduces the dimension of the data below $n$ (if justified by the stress levels in the scaling) can be used to graphically display, in two dimensions, niche relationships amongst a group of $n$ species (for example see Figure 2.1).

\subsubsection{Detecting Statistical Differences in Niche Overlap}

Even if two or more niches are identical, there will be some differences in the data purely by chance. To rule out detecting as different two niches which only differ due to sampling variation, niche comparisons between two species must be done statistically to determine whether the same probability distribution describes the niche of two (or more) species, or whether there is evidence of some difference. On any axis $t$, species $i$ has $n_{i}$ readings $\left\{x_{i 1}, x_{i 2}, \ldots x_{i n_{i}}\right\}$, which are realizations of the random variable $X_{i t}$; similarly, species $j$ has $n_{j}$ readings $\left\{x_{j 1}, x_{j 2}, \ldots x_{j n_{j}}\right\}$, from the random variable $X_{j t}$. The observed readings are used to estimate the parameters and hence the probability structure of each distribution; however, even if the random variables $X_{i t}$ and $X_{j t}$ are the same, sampling variation will almost certainly cause the sampled data values to differ, giving $N O_{i j t}<1$. The question of interest is whether $N O_{i j t}$ is sufficiently less than 1 to provide evidence of niche differentiation. The same argument applies to the combined NO measure, averaged over all the axes. Even with identical niches, sampling variation will probably ensure the observed $N O_{i j}$ is less than one. 
Because the assumptions of equal variance and normality are unlikely to be met, I recommend analysis using null models and their associated permutation tests (Gotelli, 2000; Gotelli and Graves, 1996). Null models use randomization or permutation tests which do not rely on distributional assumptions (Manly, 2007). Calculating pseudo-values of the test statistic that would arise if $H_{0}$ (no niche differentiation) were true generates the null distribution. This is achieved by permutating species labels over all species (i.e., average niche overlap over all species). The justification is that if all the species in question occupy the same niche, the actual labeling of each species is irrelevant; hence, permuting the labels to calculate pseudo-values generates the null distribution. This has the advantage of (1) retaining the total amount of each resource that is used; and (2) incorporates individual variation in resource use. If the set of species in the test is $A$, the test statistic is:

$$
N O=\operatorname{mean}_{i j \in A, i<j} N O_{i j}
$$

The $P$-value is the proportion of pseudo-values less than the data-based value. If an overall niche difference exists between species $i$ and $j$, details of which axes contribute to the difference may be obtained by comparing the data-based $N O_{i j t}$ with the pseudo-values of $N O_{i j t}$ and finding the $P$ value for each axis in turn; however, doing $t$-tests brings the problem of multiple comparisons, so an adjustment to the $P$-values is necessary to protect against false positives (detecting a difference which is not really there). I suggest a sequential Bonferroni adjustment (see Quinn and Keough, 2005).

\subsubsection{Coral Reef Fish Illustration}

To illustrate the use of overlap indices generated from multivariate data of different types, I use data from individuals less than $25 \mathrm{~mm}$ stan- 
dard length (SL) from five fish species found between the shore and barrier reef crest of the northern lagoon of Moorea, French Polynesia $\left(17^{0} 30^{\prime} S, 149^{0} 50^{\prime} \mathrm{W}\right)$ : Gomphosus varius; Pseudocheilinus hexataenia, Scarus sordidus, Thalassoma hardwicke and T. quinquevittatum. For each species, I quantified niche space along three axes, incorporating three different types of data. (1) Pectoral fin aspect ratio (ratio data bounded below by 0): leading edge $e^{2}$ / area (following Wainwright et al. 2002). Pectoral fin aspect ratio is related to manoeuvrability, swimming speed and efficiency of locomotion (Wainwright et al., 2002; Walker and Westneat, 1997). The use of individuals of different sizes can introduce allometric bias into shape analysis (McCoy et al., 2006). I examined each species for allometric bias by regressing pectoral fin aspect ratio against standard length, resulting in linear regressions described by $Y=a+\beta_{X}$. I tested the significance of the slope $(\beta)$ obtained in each regression in order to determine if the $Y$ variables showed isometric $(\beta=0)$ or allometric $(\beta \neq 0)$ growth in relation to standard length. I found no evidence of non-isometry ( $\beta \neq 0, P>0.05$ in all cases). Pectoral fin aspect ratio was determined for 19,14,17, 16 and 15 individuals for G. varius; P. hexataenia, S.sordidus, T. hardwicke and T. quinquevittatum respectively. (2) Habitat association (electivity data): quantified as Manlys Alpha (Chesson, 1978; Manly et al., 1972), the proportion of fish at a given reef, on a given habitat type, relative to the probability of the fish associating with that habitat type under conditions of random assortment. In March 2005, I established three transects within Mooreas northern lagoon. Each transect was approximately $800 \mathrm{~m}$ in length, and ran from shore to the barrier reef crest. I selected five equally spaced sites along each transect. Within each site, I haphazardly selected 16 patch reefs (hereafter reefs) of similar size $(n=240$ [= $3 \times 5 \times 16]$ reefs: average surface area $=7.98 \mathrm{~m}^{2}, S D$ $=3.79$; average height $=0.83 \mathrm{~m}, S D=0.22$ ). For each reef, and a onemeter halo surrounding the reef, I visually estimated percent cover of six substrate categories: Porites massive; branching corals; macroalgae; bare 
habitat; other and rubble. I also recorded the presence of all individuals of the study species less than $25 \mathrm{~mm} \mathrm{SL}$, and noted the substrate each individual was associated with at the time it was first observed. I made all observations between 0800 and $1600 \mathrm{~h}$ (time of peak activity of benthic fishes) from 27 May to 6 June 2005. Mean overlap in habitat association was calculated separately for each of six habitat categories on 240 reefs, and then combined into a single index of habitat association using formula 2.5 above. (3) Distribution across the lagoon (categorical data): using the dataset from (2) above, I calculated the density of each species on each reef at the five sites between the barrier reef crest and shore (crest, offshore, centre, inshore, shore).

For each axis (pectoral fin aspect ratio, habitat association and distribution within the lagoon), I calculated niche overlap between the five species using the appropriate modelling technique. I then constructed multivariate measures of mean niche overlap and associated variance over the three axes using formulas 2.5 and 2.6 above. I used nMDS to graphically display results. To identify pairs of species occupying similar niches, I constructed test statistics from 1000 permutations of species labels using formula 2.7.

\subsubsection{Alpine Plant Illustration ${ }^{1}$}

I also illustrate the use of overlap indices using data from five alpine plant species found along an elevational gradient in the Nelson Lakes National Park of New Zealands South Island $\left(41^{0} 49 S, 172^{0} 50 E\right)$ : Coprosma foetidissima; C. microcarpa; C. pseudociliata; C. pseudocuneata and C. rhamnoides. For each species, I quantified niche space along two axes incorporating two different types of data: (1) Distribution along an elevational gradient (categorical data) at 26 elevations (620, 655, 690, 730, 770, 795, 820, 860,

\footnotetext{
${ }^{1}$ Data courtesy of K. C. Burns, School of Biological Sciences, Victoria University of Wellington, New Zealand
} 
$885,925,960,1000,1030,1055,1075,1100,1125,1150,1195,1230,1270$, $1310,1345,1385,1420$ and 1460 meters above sea level), taken as the number of each species in five $10 \mathrm{~m}^{2}$ randomly situated plots at each elevation. (2) Specific leaf area (ratio data bounded below by 0); defined as the ratio between leaf blade area and its dry weight (Garnier et al., 2001). Specific leaf area is representative of different life-history strategies, ranging from low-cost, short-lived leaves that provide a quick return on their energetic investment, to long-lived, energetically costly leaves that offer slower returns relative to energetic investment (see Whitfield, 2006). Specific leaf area was determined for 4, 8, 5, 13 and 5 individuals for C. foetidissima, C. microcarpa, C. pseudociliata, C. pseudocuneata and C. rhamnoides respectively. For each axis (distribution along an elevational gradient and specific leaf area), I calculated niche overlap between the five species using the appropriate modelling technique, and then constructed multivariate measures of mean niche overlap and associated variance over the two axes using formulas 2.5 and 2.6 above. I used nMDS to graphically display results. To identify pairs of species occupying similar niches, I constructed test statistics from 1000 permutations of species labels using formula 2.7 .

\subsection{Results}

\subsubsection{Coral Reef Fish Illustration}

Of the five fish species, lowest niche overlap was between $P$. hexataenia and S. sordidus (0.484; Table 2.1). These species have distinct functional niches. Juveniles of the former over-associate with the structurally complex hard corals Pocillopora verrucosa and Porites rus (see Chapter 3), feeding on copedpods, amphipods, gastropods, shrimps and polychaete worms (Harmelin-Vivien, 1979). On the other hand, juveniles of $S$. 

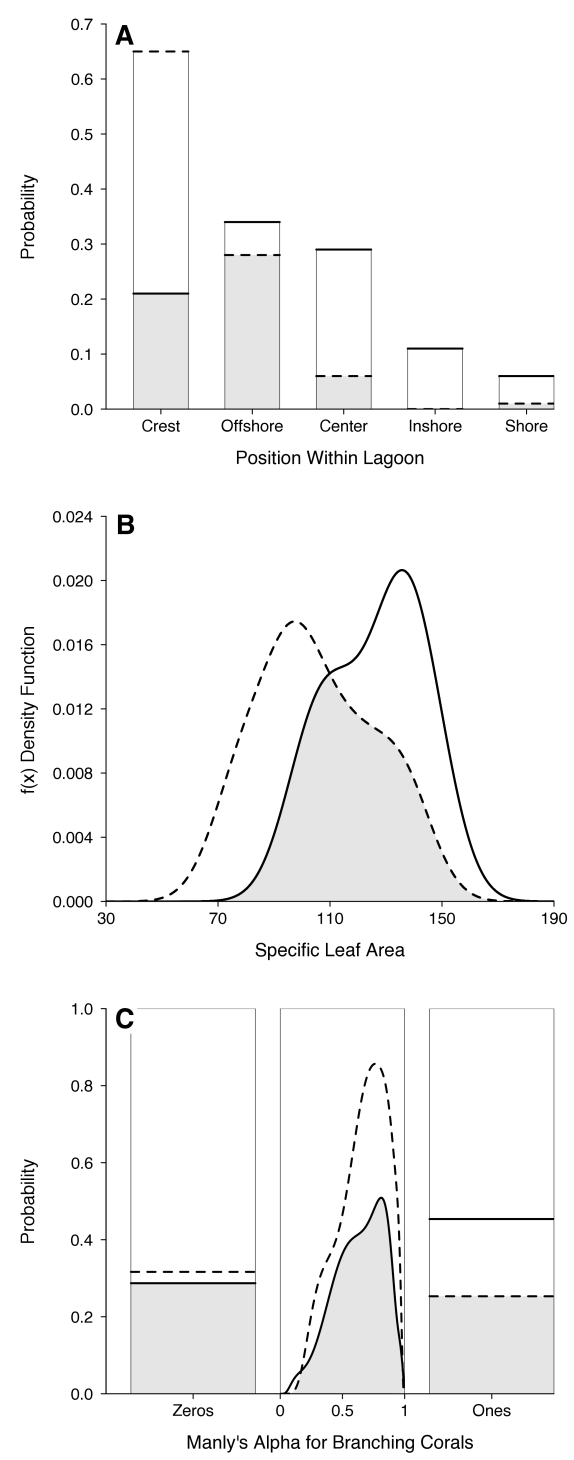

Figure 2.1: Overlapping probability distributions constructed using three different data types. Panel (A) represents probability distributions derived from categorical data detailing the occurrence of the wrasses Thalassoma hardwicke (solid horizontal lines) and T. quinquevittatum (dashed horizontal lines) across the northern lagoon of Moorea, French Polynesia. Panel (B) represents probability distributions derived from ratio data (bounded below by zero) for the specific leaf area of Coprosma pseudociliata (solid lines) and C. rhamnoides (dashed lines) from New Zealands Nelson Lakes district. Specific leaf area was log-transformed to prevent overflow below the lower bound of zero. Panel (C) represents probability distribution of the use of branching corals by T. hardwicke (solid lines) and T. quinquevittatum (dashed lines) based on electivity data (Manlys Alpha). The probability distribution of electivities is illustrated as a triptych graph with three panels. The left and right panels display the probabilities of zero (never using branching corals) and one (exclusively use of branching corals) respectively, and a central panel with intermediate continuous probabilities. The density estimation for the central panel uses logit transformed data to avoid an overflow outside the $(0,1)$ bounds. In each panel, grey shading indicates the area of overlapping distributions. Overlap was $0.562,0.624$ and 0.792 in panels (A), (B) and (C) respectively. In each panel (A, B and C), the area under the solid lines is 1 , as is the area under the dashed lines. 
sordidus over-associate with Porites rus, Turbinaria ornata (a structurally complex macroalgae) and coral rubble (see Chapter 3), feeding primarily on algae (Chen, 2002). The highest niche overlap was between $P$. hexataenia and T. hardwicke (0.822; Table 2.1). Like P. hexataenia, T. hardwicke juveniles feed primarily on small invertebrates (Myers, 1999) and overassociate with Pocillopora verrucosa and Porites rus (see Chapter 3).

Overall, my results did not group $S$. sordidus within the same niche space as any of the other species (Table 2.1; Figure 2.2). G. varius, $P$. hexataenia and T. hardwicke occupied similar niche space (Table 2.1; Figure 2.2). Although T. quinquevittatum also occupied similar niche space to $G$. varius, it grouped separately to P. hexataenia and T. hardwicke (Table 2.1; Figure 2.2).

Table 2.1: Mean $(S D)$ niche overlap between five species of reef fishes based on three functional traits: (1) pectoral fin aspect ratio (ratio data bound by 0 and 1); (2) habitat association (electivity data); and (3) distance from shore (categorical data). Species pairs occupying statistically different niches, as identified by null model tests, are indicated in bold $(P<0.01)$.

\begin{tabular}{|c|c|c|c|c|}
\hline & P. hexataenia & S. sordidus & T. hardwicke & T. quinquevittatum \\
\hline G. varius & $0.741(0.164)$ & $0.597(0.213)$ & $0.782(0.145)$ & $0.795(0.073)$ \\
\hline P. hexataenia & & $0.484(0.392)$ & $0.822(0.009)$ & $0.586(0.181)$ \\
\hline S. sordidus & & & $0.525(0.360)$ & $0.586(0.183)$ \\
\hline T. hardwicke & & & & $0.640(0.228)$ \\
\hline
\end{tabular}

\subsubsection{Alpine Plant Illustration}

Lowest niche overlap occurred between C. pseudocuneata and C. foetidissima (Table 2.2). These species have very different elevational distributions. C. pseudocuneata occupies higher montane to subalpine forest while C. foetidissima is restricted to lowland and lower montane forest and shrubland (Allan, 1961). Additionally, the leaves of C. pseudocuneata are thick and coriaceous, while those of $C$. foetidissima are membranous 


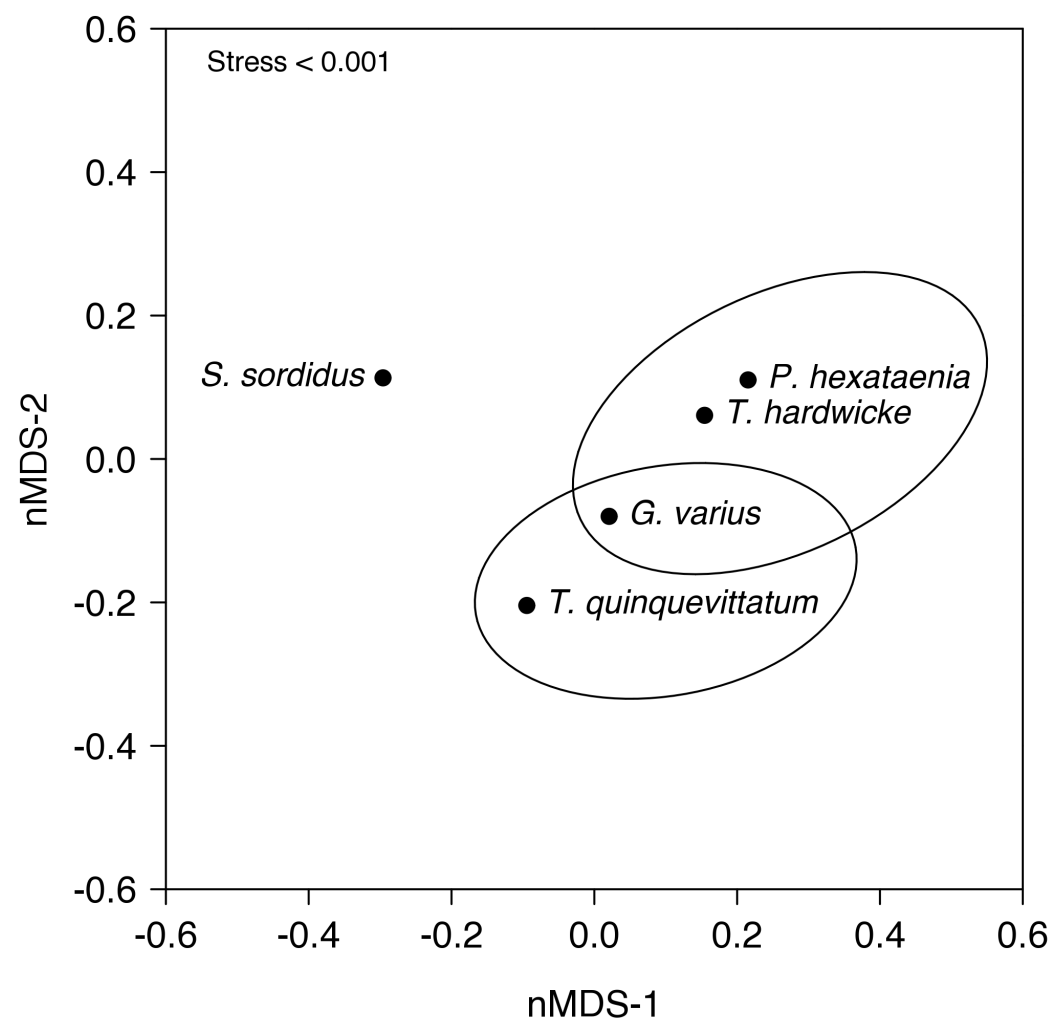

Figure 2.2: Interspecific similarities in unified niche overlap between five species of reef fishes incorporating three functional traits: (1) pectoral fin aspect ratio (measurement data); (2) habitat association (electivity data); and (3) distance from shore (categorical data). Similarities are represented graphically as non-metric multidimensional scaling. Ellipses encircle species occupying niches that were not identified as significantly different using null model tests. 
subcoriaceous leaves (Allan 1961), suggesting that these species have very different energetic investments in leaf production. Highest niche overlap occurred between C. foetidissima and C. rhamnoides (Table 2.2), both of which were found at lower elevations (the former inhabits coastal to subalpine forests: Allan, 1961). C. rhamnoides has waxy coriaceous leaves (Allan, 1961).

C. microcarpa occupied separate niche space to the other species (Table 2.2; Figure 2.3). C. pseudociliata and C. pseudocuneata occupied similar niche space, as did C. rhamnoides and C. foetidissima (Table 2.2; Figure 2.3).

Table 2.2: Mean (SD) niche overlap between five plant species based on two functional traits: (1) elevation (categorical data); and (2) surface leaf area (continuous). Species pairs occupying statistically different niches, as identified by null model tests, are indicated in bold $(P<0.01)$.

\begin{tabular}{|c|c|c|c|c|}
\hline & C. microcarpa & C. pseudociliata & C. pseudocuneata & C. rhamnoides \\
\hline C. foetidissima & $0.216(0.004)$ & $0.359(0.470)$ & $0.081(0.063)$ & $0.702(0.263)$ \\
\hline C. microcarpa & & $0.138(0.152)$ & $0.286(0.274)$ & $0.378(0.189)$ \\
\hline C. pseudociliata & & & $0.468(0.468)$ & $0.309(0.438)$ \\
\hline C. pseudocuneata & & & & $0.111(0.144)$ \\
\hline
\end{tabular}

\subsection{Discussion}

A major objective of studies examining niche overlap is to determine if two or more species occupy the same niche. This requires first identifying the position in niche space occupied by each species, and then determining if two or more species occupy the same portion of niche space. To the best of my knowledge, there are currently no formal indices capable of describing niche space using multiple axes described by different datatypes. This manuscript presents for the first time, indices which produce a composite measure of niche overlap derived from multivariate inputs incorporating 


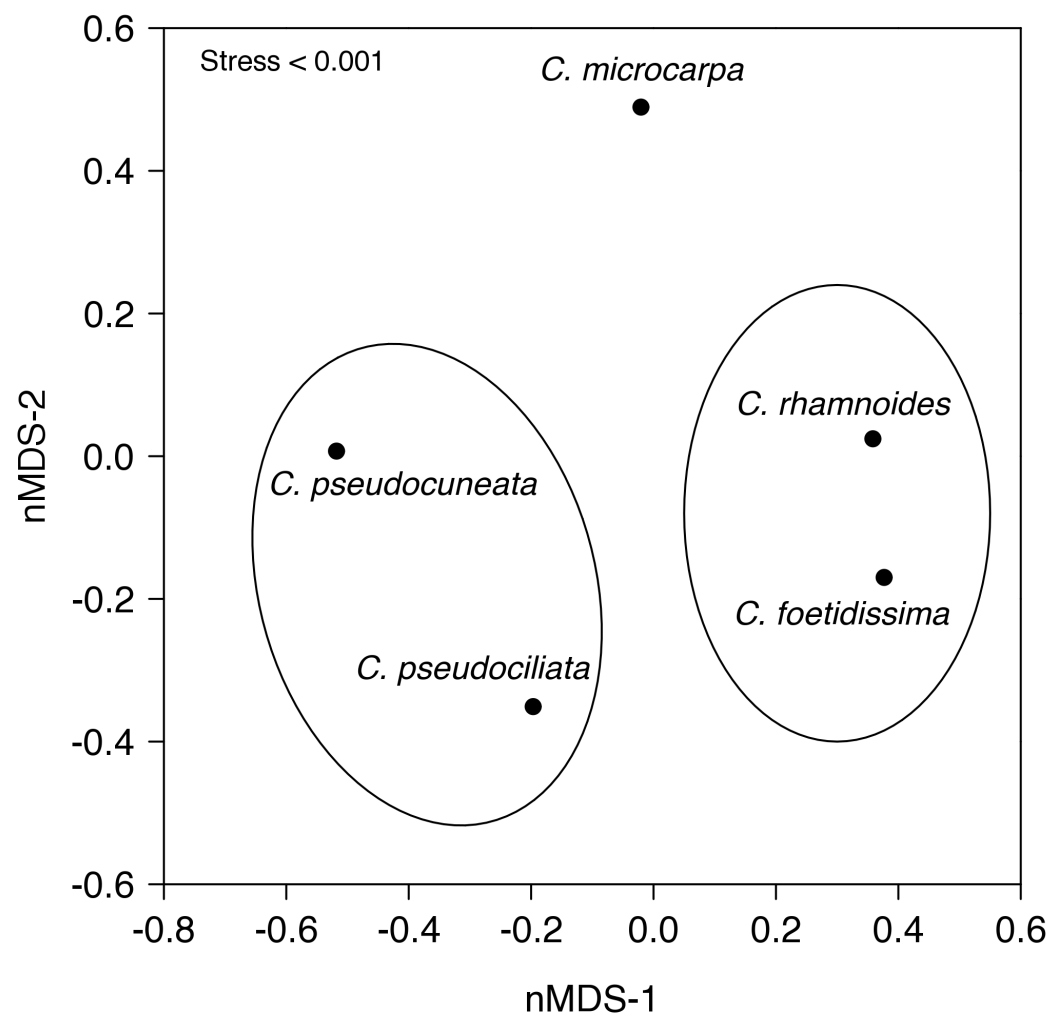

Figure 2.3: Interspecific similarities in unified niche overlap between five plant species incorporating two functional traits: (1) surface leaf area (continuous data); and (2) elevation (categorical data). Similarities are represented graphically as non-metric multi-dimensional scaling. Ellipses encircle species occupying niches that were not identified as significantly different using null model tests. 
binary, categorical, ratio, proportion, percent, count and electivity data. Also presented is a novel permutation test that discriminates between pairs of species displaying high and low overlap in multivariate niche space.

In the formal analysis of niche overlap between coral reef fishes, lowest overlap was 0.484 (S. sordidus and P. hexataenia), although overlaps were generally high. Of the five species examined, four are wrasses and one (S. sordidus) is a parrotfish. S. sordidus was the only species to show a significantly different niche from all the other species. S. sordidus likely stands apart from the other species because juvenile $S$. sordidus predominantly inhabit open pavement areas of shallow reef flats, and feed on benthic algae. Alternatively, juveniles of the four wrasse species associate with branching corals and macroalgae, and feed on planktonic crustaceans, small fishes and foraminiferans. S. sordidus was present in greater numbers closer to the shore, whereas the wrasse species were more abundant closer to the reef crest. I was therefore not surprised to find: (1) low overlap between $S$. sordidus and the wrasse species; or (2) high lowerlap between the wrasse species.

Using alpine plant species, C. microcarpa occupied a distinctly different niche from the other species. C. microcarpa has smooth leaves (Allan, 1961) which are thinner than the leaves of the other Coprosoma species in this study. This suggests C. microcarpa invests in leaf production differently than the other species examined here. Relative to the other species examined, C. microcarpa has a broad elevational distribution, from lowland to montane forests (Allan, 1961). The marked differences in leaf morphology between C. microcarpa and the other four species, coupled with the broad elevational distribution of $C$. microcarpa results in low overlap between this and the other species in my indices of niche overlap.

This new index of niche overlap involves averaging niche overlap over each niche axes. An alternative approach would be to model overlap in multidimensional space; however, multidimensional axes require 
continuous-type distributions. The use of multidimensional space is therefore not valid if one or more axes consist of either binary or categorical data. Importantly, there are two major differences between average niche overlap presented here and overlap in multidimensional space. First, both may provide different estimates of niche overlap because individual niche dimensions do not always reflect multidimensional niche overlap. For example, when overlap along two resources axes is independent, the product accurately reflects total overlap; however, when resource use is not independent, total overlap cannot be estimated from the use of individual resources alone (for example see figure 4.2: Gotelli and Graves, 1996). I illustrate this by considering the partitioning of food and time resources. Although food is considered a major resource axes for niche partitioning (Schoener, 1974), time is also a resource axes that can be partitioned on both daily and seasonal scales (Carothers and Jaksic, 1984; Case and Gilpin, 1974). In multidimensional space, I would obtain a zero overlap for two species with exactly the same diet but with different daily patterns, whereas averaging over niche axes provides a non-zero value. Second, compared to overlap along a single niche axes, increasing the number of niche axes will always produce the same or lower niche overlap in multidimensional space, although it may either increase or decrease average niche overlap. I suggest that the appropriate approach (average niche overlap vs. overlap in multidimensional space) depends in part on: (1) the questions being addressed; (2) the types of data being modeled; and (3) how completely the dataset being analyzed captures each axes of niche space.

A major objective of studies examining niche overlap is to determine whether a group of species occupy a similar niche, or whether there is evidence of some difference in their niches. I used null models to compare niche overlap between species. Although null models are viewed as a useful tool for revealing pattern (or lack thereof) in natural communities, the choice of appropriate null models has been highlighted 
as a critical issue (Gotelli, 2001). In practice, it is often difficult to decide what constitutes a truly null, purely statistical model. For example, it is difficult to be certain that some biological interactions that have shaped the data set are not woven into the null model (Harvey et al., 1983). Lawlor (1980) developed four randomization algorithms that are commonly used to construct null models. These algorithms differ in whether utilizations are reshuffled or replaced by a random number, and in whether the zeros in the matrix are retained or not. Both decisions have implications for the structure of the null community, and affect the power of the test (Gotelli and Graves, 1996). The properties of these randomization techniques have previously been explored (see Kobayashi, 1991; Winemiller and Pianka, 1990), and have identified RA3 (Lawlor, 1980) as the best existing algorithm for use in resource overlap null models. Like RA3 (Lawlor, 1980), my approach scrambles zeros, retaining the original total amount of each resource utilized; however, there is a fundamental difference between my randomization procedure and RA3. Lawlors RA3 reallocates pooled resource usages for each species, whereas my approach reallocates resource use for each individual. Because my approach does not assume all individuals of a species act alike (i.e., incorporates individual variation), it seems most powerful for tests determining if individuals of one species differ in resource use relative to individuals of a second species.

Although null models can be used to establish whether observed niche overlap is more or less than expected by chance, it is still difficult to infer the mechanism(s) responsible for such patterns. For example, high niche overlap may reflect intense competition for shared resources or, alternatively, a surplus of resources and the absence of competition (Glasser and Price, 1988). Both scenarios have been revealed in experimental field studies of competition (Schoener, 1983). It is not my intension to provide insights into the underlying causes of a given degree of niche overlap, but to outline and illustrate my approach to determining multivariate niche 
overlap based upon measures of different types.

Although I illustrated the implementation of my unified indices of niche overlap by examining interspecific overlap, it is also worth noting that my methodology can also be used to test for intraspecific temporal or spatial niche shifts by quantifying differences in niche overlap for a single species between different places or times. With this new approach, I have extended the indices of Mouillot et al. (2005) beyond continuous data to also incorporate binary, categorical, ratio, proportion, percent, count and electivity data. I have also devised a null model test to discriminate between pairs of species displaying high and low overlap in multivariate niche space. 


\section{Chapter 3}

The Effects of Structural Refuge and Interspecific Competition on the Survival of Thalassoma hardwicke 


\subsection{Abstract}

Structural refuge and competition can influence the survival of coral reef fishes; however, the effect of structural refuge on the outcome of competition remains unclear. In Moorea, French Polynesia, surveys were used to quantify habitat association for juvenile Thalassoma hardwicke and seven sympatric labroid species. Having identified the three species most similar to focal T. hardwicke in habitat association, a field assay was used to determine if their presence adversely affected the survival of focal individuals. Finally, a field experiment was used to test how competition and structural refuge interact to influence survival of transplanted $T$. hardwicke. Surveys demonstrated that Gomphosus varius, Pseudocheilinus hexataenia, and T. quinquevittatum were most similar to T. hardwicke in habitat association. In the field assay, the presence of T. quinquevittatum had the greatest negative effect on survival of transplanted T. hardwicke. The field experiment revealed that competition with T. quinquevittatum and structural refuge both altered the survival of T. hardwicke, although their effects were not interactive, indicating that structural complexity did not mitigate the negative effects of competition. Survival of T. hardwicke was 2.3 times greater in treatments without T. quinquevittatum relative to those with T. quinquevittatum, and 2.8 times greater in treatments with structural refuge relative to treatments without structural refuge. The additive effect may have occurred via the establishment of social dominance hierarchies between transplanted T. hardwicke and resident T. quinquevittatum independently of structural refuge, suggesting that it is important to account for interactions occurring independently of resources when examining resource competition. 


\subsection{Introduction}

Habitat specific survival may result from intrinsic differences in habitat quality, or because the effects of competitors and predators differ among habitat types (Ebersole, 1985; Holt, 1987; Rosenzweig, 1991; Gurevitch et al., 1992; Morris, 2003; Almany, 2004a; Almany, 2004b; Bonin et al., 2009). For example, asymmetric competition can lead to the exclusion of subordinates from mutually preferred habitats (Connell, 1983; Schoener, 1983). Competitive subordinates are expected to survive better when competitive dominants are removed (Colwell and Fuentes, 1975), or when competition is alleviated by a change in habitat composition (Ebersole, 1985; Rosenzweig, 1991). Increased habitat complexity is expected to mitigate the negative effects of competition and predation by providing a greater spectrum of resources (e.g., structural refuge) or decreasing encounter rates due to reduced manoeuvrability and/or the ability to visually detect competitors/prey (Anderson, 1984; Main, 1987; Persson and Eklov, 1995; Lindholm et al., 1999). Conversely, rates of predation may increase if habitat complexity increases predator encounter rates. For example, the efficiency of ambush predators may improve in structurally complex habitats that provide more sites from which predators can attack, or which decrease the visibility of predators to prey (Coen et al., 1981; Rilov et al., 2007). Consequently, natural heterogeneity in structural complexity or other habitat features may drive variability in the strength of competition and predation.

Competitive interactions have previously been shown to play a fundamental role in coral reef community dynamics, e.g., between algae and coral (McCook et al., 2001; Jompa and McCook, 2003), sponges and coral (Hill, 1998; Lopez-Victoria et al., 2006), vermetid gastropods (Gagern et al., 2008) and fishes (Holbrook and Schmitt, 2002; Forrester and Steele, 2004; Bonin et al., 2009). Coral reefs consist of structurally diverse microhabitats and the structural complexity of these microhabitats is capable 
of determining the magnitude of competitive interactions. Bonin et al. (2009) demonstrated that structural complexity and interspecific competition both influenced early post-settlement survival of a damselfish, with survival in the presence of competitors greatest on intricately-structured habitats. Alternatively, Almany (2004b) found that greater structural complexity increased the abundance of adults in the presence of predators and competitors, but did not affect the abundance of recruits. Thus, the phenomenon of post-settlement competitive effects being weakened by increasing the availability of structural refuge may be situation- or species-specific. For example, many reef fish are social, with competitive interactions (e.g., posturing, chases) occurring independently of resources during the establishment of social dominance hierarchies; therefore, the general expectation that increasing the availability of structural refuge will mitigate the negative effects of competition may not hold when social hierarchies dictate resource access.

This study examines the influence of structural refuge, competition and their interaction on the early post-settlement survival of transplanted Thalassoma hardwicke (the sixbar wrasse). Thalassoma hardwicke is a common resident of Indo-Pacific coral reefs that maintains tight associations with preferred habitats immediately following settlement (Shima, 2001b; Shima and Osenberg, 2003; Lecchini et al., 2007; Shima et al., 2008). To determine how competition for habitat influences post-settlement survival, quantitative surveys of habitat use and availability were first conducted to describe similarity in habitat use between T. hardwicke and seven sympatric labroid species. Then a field assay was used to determine whether the presence of the three species with the greatest degree of similarity in habitat association with $T$. hardwicke adversely affected postsettlement survival. Finally, a patch reef experiment was used to tease apart the effects of two factors potentially affecting the post-settlement survival of transplanted T. hardwicke: (1) the presence and absence of an interspecific competitor (T. quinquevittatum), and (2) the presence and 
absence of structural refuge (Turbinaria ornata). The provisioning of structural refuge was predicted to increase post-settlement survival; the presence of competitors was predicted to reduce post-settlement survival; and finally, the provisioning of structural refuge was predicted to reduce the influence of competitors.

\subsection{Methods}

\subsubsection{Study system}

This study was conducted in the northern lagoon of Moorea, French Polynesia $\left(17^{0} 30^{\prime} S, 149^{0} 50^{\prime} W\right)$. The northern lagoon is interspersed with patch reefs within a matrix of sand, fine coral rubble and coral pavement (Galzin and Pointer, 1985). Patch reefs are predominantly Porites spp., often surmounted by smaller colonies of branching corals, dead coral skeletons, patches of macroalgae, or lush stands of filamentous algae. The structure of patch reefs varies over small spatial scales (Galzin and Pointer, 1985).

There are 104 recognised wrasse species in Moorea ${ }^{1}$. Here, I focused on the eight most common species, which together comprise approximately $84 \%$ of juvenile wrasses within the lagoon (Table 3.1), and often co-occur: Gomphosus varius, Halichoeres hortulanus, H. trimaculatus, Pseudocheilinus hexataenia, Scarus sordidus, Stethojulis bandanensis, Thalassoma hardwicke and T. quinquevittatum. These species undergo pelagic larval development before settling in pulses to benthic reef habitat (Victor, 1986). Settlement occurs preferentially to microhabitats with high structural complexity, such as branching corals and macroalgae (Shima and Osenberg, 2003; Lecchini et al., 2007; Shima et al., 2008). Sequential settlement pulses

${ }^{1}$ Moorea Biocode Databases 2009. BSCIT University of California, Berkeley. Accessed 19 February. http : //biocode.berkeley.edu/ 
create populations of discrete, mixed-species cohorts. Interspecific aggressive interactions are common between and within these cohorts (see Chapters $4 \& 5$, and Geange and Stier, 2009). Following settlement, recruits generally remain site-attached for up to six months (unpublished data).

Table 3.1: Counts of juvenile wrasses ( $<25 \mathrm{~mm}$ standard length) on 240 patch reefs within the northern lagoon of Moorea. Each patch reef was counted once between 27 May and 6 June 2005. Displayed are separate totals for the focal species examined in this study ( $84 \%$ of total individuals) and other species. ${ }^{*}$ Includes multiple species.

\begin{tabular}{lr}
\hline Focal Species & Number \\
\hline Gomphosus varius & 123 \\
Halichoeres hortulanus & 13 \\
Halichoeres trimaculatus & 42 \\
Pseudocheilinus hexataenia & 61 \\
Scarus sordidus & 57 \\
Stethojulius bandanensis & 35 \\
Thalassoma hardwicke & 333 \\
Thalassoma quinquevittatum & 339 \\
\hline Total & 1003 \\
\hline \hline & \\
\hline Other Species & Number \\
\hline Cheilinus chlorourus & 16 \\
Cheilinus trilobatus & 7 \\
Cheilio inermis & 1 \\
Coris aygula & 7 \\
Coris gaimond & 3 \\
Epibulus insidiator & 4 \\
Halichoeres marginatus & 3 \\
Iniistius pavo & 1 \\
Labrid spp.* & 65 \\
Labroides bicolor & 32 \\
Novaculichthys taeniourus & 3 \\
Scarus altipinnis & 5 \\
Scarus spp.* & 22 \\
Thalassoma amblycephalum & 23 \\
\hline Total & 192 \\
\hline \hline
\end{tabular}




\subsubsection{Surveys of habitat availability and association}

In March 2005, I established three transects within Mooreas northern lagoon. Each transect was approximately 800 meters in length, and ran from shore to the barrier reef crest. I selected five equally spaced sites along each transect (90 $(S E=3), 180(S E=7), 289(S E=7), 409(S E=7)$ and $508(S E=11) \mathrm{m}$ from the reef crest). Within each site, I haphazardly selected 16 patch reefs (hereafter reefs) of similar size ( $n=240$ [ $=3 \times 5$ $x$ 16] reefs: average surface area $=7.98 \mathrm{~m}^{2}, S E=0.24$; average height $=$ $0.83 \mathrm{~m}, S E=0.01$ ). For each reef, and a one-meter halo surrounding the reef, I visually estimated percent cover of 16 substrate categories: Porites massive; Porites rus; Montipora spp.; Pocillopora spp.; Acropora spp.; other live coral; Turbinaria ornata; Dictyota spp.; Halimeda spp.; turf (a mixed filamentous red algal assemblage consisting predominately of Polysiphonia spp.); sponge; bare; other; sand; coral rubble; and pavement). For a subset of 45 reefs, I evaluated the accuracy of visual estimates of percent cover against Fixed Point Contact (FPC) estimates of percent cover (a commonly accepted standard; Floyd and Anderson, 1987). Visual estimates of percent cover were $84.8 \%$ accurate relative to FPC estimates (see Appendix A) and include better estimates of rare habitat than FPC (Meese and Tomich, 1992). Habitat surveys were conducted between 7 March and 29 April 2005.

On each reef, and the surrounding one-meter halo, I visually estimated the Standard Length (SL: to the nearest $\mathrm{mm}$ ) of all juvenile wrasses. I also recorded the substrate directly below each individual at the time it was first observed. I define juveniles as individuals less than $25 \mathrm{~mm}$ SL. I evaluated the accuracy of visual estimates of SL made in the field by capturing a subset of fish ( $n=298$ from 8 different species) and comparing visual estimates of SL for these individuals to SL measured in the lab with callipers. Based on mean absolute error (MAE), visual estimation of SL was 94.7\% accurate (see Appendix A). I made all observations between 0800 and 1600 hours (peak activity time for diurnal benthic fishes: Galzin, 
1987) from 27 May to 6 June 2005.

I quantified habitat association for each species by calculating Manlys Alpha (Manly et al., 1972; Chesson, 1978). Manlys Alpha measures the proportion of a species on a given habitat, relative to the availability of that habitat:

$$
\alpha_{i}=\frac{\frac{F_{i}}{H_{i}}}{\sum_{i=1}^{n} \frac{F_{i}}{H_{i}}} i=1, \ldots, n
$$

$H$ is the proportion of surveyed habitat of a given type and $F$ is the proportion of individuals censused on that habitat type. I evaluated habitat use $(\alpha)$ separately for each species, in each habitat type ( 1 through $n$ ), within a given replicate sampling unit (reef). $\alpha$ ranges between 0 and 1, 0 indicates habitat is never used, 1 indicates habitat is exclusively used, and $1 / n$ indicates random use. Not all habitat types were present on all reefs; therefore, $1 / n$ was reef specific. I determined the frequency of overassociation as the proportion of reefs for which $\alpha$ was greater than $1 / n$ (for each species on each habitat type). All reefs for which a focal fish was present were used to calculate the frequency of over-association.

To determine the degree to which each species shared habitat resources with T. hardwicke, I estimated probability distributions of the $\alpha$-values for each species habitat combination (see section 2.3.1 Chapter 2). I then calculated mean similarity in the probability distributions for all pairwise species combinations as:

$$
N O_{i j}=\frac{1}{T} \sum_{t=1}^{T} N O_{i j t}
$$

with associated variance: 


$$
s_{N O_{i j}}^{2}=\frac{\sum_{i=1}^{T}\left(N O_{i j t}-N O_{i j}\right)^{2}}{T}
$$

$N O_{i j t}$ is the overlap between species $i$ and $j$ for habitat $t$, and $T$ is the number of habitats. $N O_{i j}$ tends to 0 when the two distributions are disjoint, and is 1 when they are perfectly similar. This consistently estimates the true overlap in habitat use between two species without assumptions about shape of the distribution (i.e., it is non-parametric: Mouillot et al., 2005). Having calculated overlap between species $i$ and species $j$, which can be viewed as a measure of association between species pairs, I calculated a measure of distance as $1-N O_{i j}$. From these distance measures, I used a dendrogram and non-metric multidimensional scaling to graphically display in two dimensions, species pairs that have similar or dissimilar habitat use. I used the vegan package in R 2.7.0 (Team, 2008) to conduct multi-dimensional scaling.

I used null models (Gotelli and Graves, 1996; Gotelli, 2000) to determine if differences in interspecific habitat use were greater than those expected by chance. To achieve this, I compared the data-based $N O_{i j}$ with a null distribution of pseudo-based values of $N O_{i j}$ generated from 10,000 permutations of species labels over all species in the original dataset. I took the $P$-value as the proportion of pseudo-values less than the databased value.

\subsubsection{Identifying potential T. hardwicke competitors}

I used a field assay to identify whether the presence of each of three candidate species (G. varius, P. hexataenia and T. quinquevittatum; the three species most similar to T. hardwicke negatively effected the survival of transplanted T. hardwicke. I selected 32 reefs within $80 \mathrm{~m}$ of the reef crest. Reefs consisted of a live Porites base, surmounted by 1-2 Pocillopora 
verrucosa colonies and small patches $(<10 \%$ surface area) of macroalgae. Reefs had an average area of $5.43 \mathrm{~m}^{2}(S E=0.34)$, a mean height of $0.77 \mathrm{~m}$ $(S E=0.04)$, and were isolated from their nearest neighbour by $4.71 \mathrm{~m}(S E=$ $0.25)$. Of these 32 reefs, eight were inhabited by two to five (mean $=2.8 ; S E$ $=0.4$ ) T. quinquevittatum; eight were inhabited by two to five (mean $=3.4$; $S E=0.4)$ G. varius; and eight were inhabited by two to four (mean = 3; $S E$ = 0.3) P. hexataenia. The SL of individuals of all candidate species ranged between 12 and $30 \mathrm{~mm}$. All reefs lacked fish of the other species (e.g., reefs with $G$. varius did not have P. hexataenia or T. quinquevittatum). In addition, eight reefs lacked G. varius, P. hexataenia and T. quinquevittatum. All reefs were interspersed with each other within the lagoon. Before the field assay, I removed all resident $T$. hardwicke from all reefs.

Using the fish anaesthetic eugenol (clove oil) and hand nets, I collected T. hardwicke settlers from reefs approximately $600 \mathrm{~m}$ from the study site. All fish were held in tanks with running seawater for $12 \mathrm{~h}$, then individually tagged with different colors of Visible Implant Elastomer (VIE: Northwest Marine Technology, Shaw Island, Washington) forward of the caudal peduncle. VIE tags are clearly visible through the skin of the fish by observers in the field so it was not necessary to recapture individuals to determine their identity. VIE tags do not have adverse effects on other fishes (Beukers et al., 1995; Imbert et al., 2007; Simon, 2007), have been used to tag fish as small as $8 \mathrm{~mm}$ (Frederick, 1997), and my own preliminary study confirmed no tag-induced mortality of 20 tagged T. hardwicke held in aquaria for $72 \mathrm{~h}$. I therefore assume that tagging and handling effects were small. After tagging, I returned target fish to aerated aquaria for $12 \mathrm{~h}$ before measuring them to the nearest 0.1 $\mathrm{mm}$ SL. I then introduced three tagged T. hardwicke individuals $(14.8 \mathrm{~mm}$ SL; $S E=0.2$; approximately two weeks post-settlement age) onto each reef (which is representative of natural densities). I surveyed reefs daily (approximately 9 a.m.) for five days (beginning June 1 2005) after the introduction of $T$. hardwicke individuals to estimate their survival rates. 
At the same time, I recorded abundance of competitors and removed any untagged T. hardwicke smaller than $20 \mathrm{~mm}$ (two untagged T. hardwicke were removed, both $<10 \mathrm{~mm}$ ). I also searched neighbouring nonexperimental reefs for tagged immigrant T. hardwicke, and found none. Previous research has suggested that recent $T$. hardwicke settlers rarely move between reefs separated by as little as three meters (Shima, 2001a). I therefore assumed that the disappearance of a tagged fish was due to mortality rather than migration. The mean proportion of T. hardwicke remaining in each treatment on the last day of the assay was used as the response variable because by the end of the assay survival trajectories had stabilized (see Results).

I conducted statistical analysis using a generalized linear model (GLM) because my response variable was count data modeled as proportions (with unequal variance and non-normally distributed errors: (Crawley, 2007)). Using a GLM (specifying a binomial error distribution and a logit link function), I conducted an analysis of deviance to estimate T. hardwicke survival. I modelled proportional survival as a function of treatment, a categorical variable with four levels: (1) No competitors present; (2) G. varius present; (3) P. hexataenia present; and (4) T. quinquevittatum present. Because reefs varied in size, I used likelihood ratio tests to determine the significance of adding the additional terms of competitor density, the density of transplanted T. hardwicke, and the interactions between treatment, competitor density and the density of transplanted T. hardwicke to the model. None of the additional terms significantly contributed to the model ( $P>0.1$ in all cases); therefore I focus on the main effects of treatment only. Data were not overdispersed (residual deviance $=28.414$, residual $\mathrm{df}=28$ ). i calculated effect sizes using backtransformed mean proportions from the GLM model. 


\subsubsection{The influence of competition and habitat complexity on the survival of T. hardwicke}

Results from the field assay identified T. quinquevittatum as strongly competing with $T$. hardwicke. I used a factorial experiment to evaluate the effect of competition with T. quinquevittatum and structural refuge on the post-settlement survival of T. hardwicke. I increased structural refuge by adding Turbinaria ornata (a structurally complex, locally common, macroalga) to reefs. The thallus of $T$. ornata consists of a holdfast, a central stipe up to $33 \mathrm{~cm}$ in length, with rigid pyramid-shaped blades at its distal end encircled by rows of coarse teeth (Prathep et al., 2007). The spaces between closely packed blades provide cryptic habitat and structural refuge. Turbinaria ornata is easy to manipulate and juveniles of both T. hardwicke and T. quinquevittatum: (1) over-associate with T. ornata (see Results); and (2) shelter inside Turbinaria when threatened (personal observation).

I haphazardly selected 20 reefs, with an average surface area of $5.46 \mathrm{~m}^{2}$ $(S E=0.36)$, a mean height of $0.79 \mathrm{~m}(S E=0.03)$ and isolated from their nearest neighbour by $3.02 \mathrm{~m}(S E=0.19)$. All reefs initially had three to five (mean $=3.38 ; S E=0.16$ ) resident $T$. quinquevittatum $(22.1 \mathrm{~mm} \mathrm{SL}, S E$ $=0.56$ ) and lacked T. ornata. The presence/absence of T. ornata was crossfactored with the presence/absence of T. quinquevittatum and treatments were randomly assigned to reefs. On reefs assigned to the absence of $T$. quinquevittatum, I removed T. quinquevittatum. On reefs assigned to the presence of T. quinquevittatum, I conducted selective removals so that each reef had three, similarly sized, T. quinquevittatum individuals. For T. ornata present treatments, I attached whole Turbinaria plants to recipient reefs with cable ties, so that approximately $15 \%$ of habitat cover was T. ornata. Before the experiment, all resident $T$. hardwicke were removed from the reefs.

To each reef, I introduced three T. hardwicke individuals individuals 
(13.69 $\mathrm{mm} \mathrm{SL}, S E=0.51$ : collected and tagged as per the field assay), and surveyed their survival daily (approximately 9 a.m.) for five days. Each morning, I removed immigrant T. quinquevittatum (three immigrants were observed and removed) and new T. hardwicke that had settled the previous night (a total of eight settlers). I also searched neighbouring non-experimental reefs for tagged T. hardwicke immigrants. I found no tagged immigrants, and therefore assumed (as for the field assay), that the disappearance of a tagged fish was due to mortality rather than migration. Using the same reefs, I ran the experiment in two temporal blocks (beginning 12 June 2005 and 12 May 2007), yielding ten replicates (five in each temporal block) for each of the four treatments. Because by the end of each experimental run survival trajectories had stabilized (see Results) I used the mean proportion of T. hardwicke remaining in each treatment on the last day of the experiment as the response variable.

Using a GLM, I conducted a factorial analysis of deviance (specifying a binomial error distribution and a logit link function) to model survival of T. hardwicke after five days against the presence and absence of both T. quinquevittatum and T. ornata. The full model included four explanatory variables: (1) T. quinquevittatum (present/absent); (2) T. ornata (present/absent); (3) Run (2005/2007: a term for temporal block); and (4) reef area (continuous). Likelihood ratio tests were used to determine the significance of adding the additional terms of reef area, run (2005/2007: a term for temporal block) and the interactions between T. quinquevittatum, T. ornata, reef area and run. None of the additional terms significantly contributed to the model ( $P>0.1$ in all cases); therefore, results focus on the main effects of T. quinquevittatum and T. ornata only. Data were not overdispersed (residual deviance $=29.445, d f=37$ ). Effect sizes were calculated using back-transformed mean proportions from the reduced GLM.

All statistical analyses were conducted in R 2.7.0 (Team, 2008). 


\subsection{Results}

\subsubsection{Surveys of habitat availability and association}

I observed focal species on 11 of 16 habitat categories (fish were not enumerated in the other, other coral, Dictyota spp., Halimeda spp., or sponge categories). While most species (7 of 8 ) over-associated with the highly rugose coral P. rus (Figure 3.1), strong associations with other habitat types differed among species. Thalassoma hardwicke, T. quinquevittatum, G. varius and P. hexataenia were more similar in habitat association with one another (associating more with branching massive corals and macroalgae) than they were with Stethojulis bandanensis, Scarus sordidus, Halichoeres hortulanus and $H$. trimaculatus, which as a group showed stronger associations with macroalgae, rubble and sand (Figure 3.1). Thalassoma quinquevittatum was the species most similar to T. hardwicke in habitat association, with both species over-associating with $P$. rus, Pocillopora spp. and Turbinaria on more than $30 \%$ of reefs (Table 3.2). 
Table 3.2: Proportion of reefs with Manlys Alpha values greater than expected under conditions of random association (calculated as 1 / the number of available habitats). The total number of reefs upon which each species/substrate composition occurred is indicated within ( ). Note: the two measures are not directly comparable

\begin{tabular}{|c|c|c|c|c|c|c|c|c|}
\hline \multirow[b]{2}{*}{ Habitat } & \multicolumn{8}{|c|}{ Species } \\
\hline & T. hardwicke & T. quinquevittatum & G. varius & P. hexataenia & S. sordidus & S. bandanensis & H. hortulanus & H. trimaculatus \\
\hline Porites Massive & $0.229(118)$ & $0.273(88)$ & $0.143(49)$ & $0.057(35)$ & $0.080(25)$ & $0.130(23)$ & $0.000(9)$ & $0.000(25)$ \\
\hline Porites rus & $0.364(66)$ & $\mathbf{0 . 3 0 8}(39)$ & $0.414(29)$ & $0.346(26)$ & $0.400(20)$ & $0.364(11)$ & $0.000(5)$ & $0.176(17)$ \\
\hline Montipora spp. & $0.025(81)$ & $0.036(56)$ & $0.059(34)$ & $0.000(23)$ & $0.000(9)$ & $0.000(11)$ & $0.000(6)$ & $0.000(16)$ \\
\hline Pocillopora spp. & $\mathbf{0 . 6 8 8}(80)$ & $0.635(63)$ & $0.500(40)$ & $0.697(33)$ & $0.000(12)$ & $0.000(14)$ & $0.000(8)$ & $0.000(14)$ \\
\hline Acropora spp. & $0.192(26)$ & $0.053(19)$ & $0.000(14)$ & $0.000(13)$ & $0.000(5)$ & $0.000(5)$ & $0.000(4)$ & $0.000(4)$ \\
\hline Turf & $0.032(62)$ & $0.103(29)$ & $0.130(23)$ & $0.000(21)$ & $0.050(20)$ & $0.143(14)$ & $0.000(3)$ & $0.067(15)$ \\
\hline Turbinaria ornata & $0.302(63)$ & $0.351(37)$ & $0.048(21)$ & $0.133(15)$ & $0.375(16)$ & $0.412(17)$ & $0.000(2)$ & $0.100(10)$ \\
\hline Bare & 0.105 (114) & $0.141(85)$ & $0.213(47)$ & $0.029(35)$ & $0.160(25)$ & $0.000(22)$ & $0.111(9)$ & $0.143(21)$ \\
\hline Sand & $0.000(108)$ & $0.000(55)$ & $0.025(40)$ & $0.000(30)$ & $0.037(27)$ & $0.000(22)$ & $0.600(5)$ & $0.261(23)$ \\
\hline Rubble & $0.000(100)$ & $0.013(76)$ & $0.068(44)$ & $0.029(35)$ & $0.269(26)$ & $\mathbf{0 . 4 0 0}(20)$ & $0.778(9)$ & $0.440(25)$ \\
\hline Pavement & $0.000(34)$ & $0.000(34)$ & $0.000(15)$ & $0.000(7)$ & $0.000(5)$ & $0.000(11)$ & $0.000(5)$ & $0.200(5)$ \\
\hline
\end{tabular}


Each of the seven species examined highly overlapped in habitat use with T. hardwicke (Figure 3.2): G. varius (0.91), H. hortulanus (0.76), H. trimaculatus (0.79), P. hexataenia (0.91), S. sordidus (0.87), S. bandanensis (0.88) and T. quinquevittatum (0.94). Test statistics derived from permutation tests indicated that none of the species examined statistically differed from $T$. hardwicke in the habitats they associated with ( $P>0.05$ in all cases).

\subsubsection{Identifying potential T. hardwicke competitors}

Mortality of transplanted T. hardwicke was greatest in the first $3 \mathrm{~d}$, after which survival stabilized (Figure 3.3a). Relative to controls, mean survival of T. hardwicke was lower in the presence of each of the potential competitor species; however, T. quinquevittatum produced the only statistically significant negative effect (Table 3.3). Survival of T. hardwicke ranged between $8 \%(S E=5)$ in the presence of T. quinquevittatum and 50\% (SE $=9$ )in the control treatment (Figure 3.3b), thus survival of T. hardwicke was six times greater in controls than treatments with $T$. quinquevittatum competitors ( $P=0.004$; Table 2; Figure 3.3b).

Table 3.3: Results from a generalized linear model (specifying a binomial distribution and logit link function) modeling T. hardwicke survival against the presence of potential competitors: four levels; Control (no competitors), G. varius, $P$. hexataenia and T. quinquevittatum ( $n=8$ for each treatment). Significant $P$-values $(P<$ $0.05)$ are indicated in bold.

\begin{tabular}{lcccc}
\hline & Estimate & $S E$ & $z$-value & $P$ \\
\hline (Intercept) & 0.000 & 0.408 & 0.000 & 1.000 \\
G. varius & -0.337 & 0.582 & -0.579 & 0.563 \\
P. hexataenia & -0.887 & 0.607 & -1.462 & 0.144 \\
T. quinquevittatum & -2.398 & 0.844 & -2.842 & $\mathbf{0 . 0 0 4}$ \\
\hline \hline
\end{tabular}



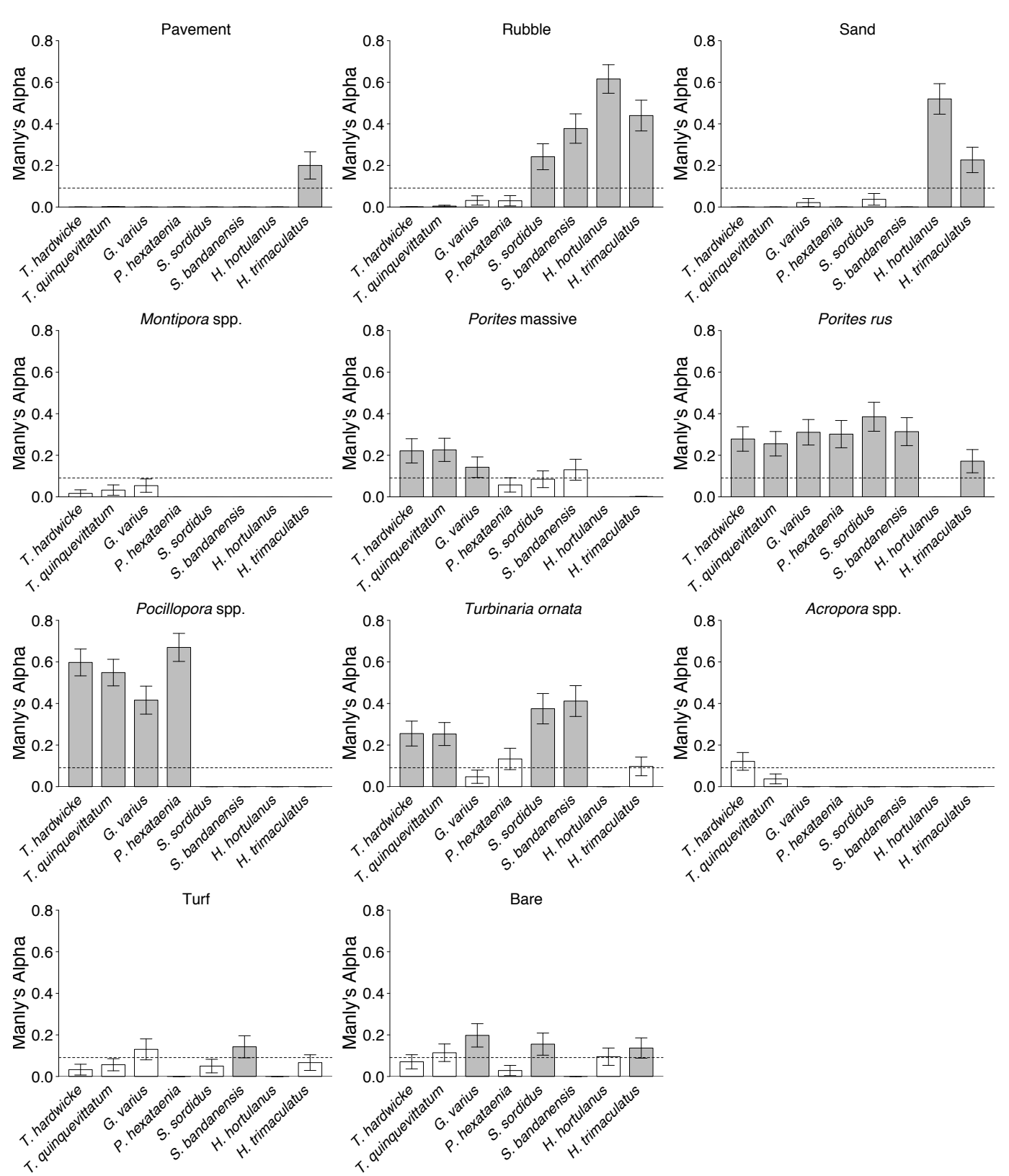

Figure 3.1: Patterns of habitat association (for the 11 habitat types fish were observed on) for eight species of coral reef fishes presented as Manlys Alpha values (means $\pm 95 \% \mathrm{CI}$ ). Alpha values range from 0 (least associated) to 1 (most associated). The dashed line represents expectations of random habitat association; values with error bars crossing this line are not statistically different from this expectation. Values with error bars above (grey bars) or below this line indicate over or under association (relative to availability) respectively. Species that do not overuse a habitat type (relative to availability) are depicted with white bars 

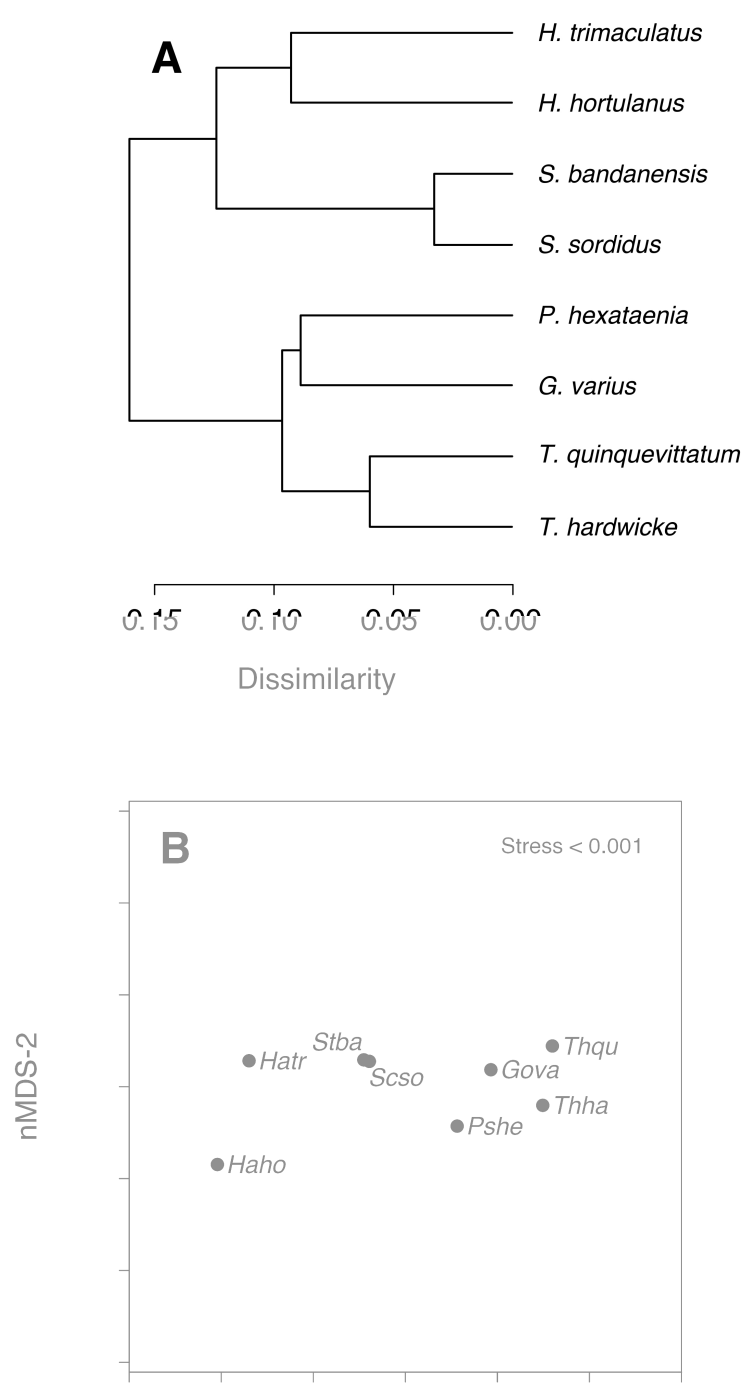

nMDS-1

Figure 3.2: Graphical representation of interspecific similarities in habitat association for eight species of coral reef fishes, presented as: (A) a dendrogram; and (B) non-metric multidimensional scaling (nMDS). Both representations are based upon dissimilarity matrices, calculated as 1 - the overlap in Manlys Alpha probability distributions between species $i$ and species $j$. Abbreviations in panel (B) are: Gova (Gomphosus varius); Haho (Halichoeres hortulanus); Hatr (H. trimaculatus); Pshe (Pseudocheilinus hexataenia); Scso (Scarus sordidus); Stba (Stethojulis bandanensis); Thha (Thalassoma hardwicke); and Thqu (T. quinquevittatum). 
Table 3.4: Results from the best fitting generalized linear model (specifying a binomial distribution and logit link function) modelling proportional T. hardwicke survival against the presence and absence of T. quinquevittatum (competitor: a deleterious effect) and Turbinaria ornata (structural refuge: a beneficial effect). Proportional survival is documented for two temporal blocks (June 2005, May 2007). $n=5$ sites per treatment, per block. Both the blocking term and interaction were nonsignificant. I therefore focus on the main effects of T. quinquevittatum and T. ornata. Significant $P$-values $(P<0.05)$ are indicated in bold.

\begin{tabular}{lcccc}
\hline & Estimate & $S E$ & $z$-value & $P$ \\
\hline (Intercept) & -1.774 & 0.461 & -3.850 & $<0.001$ \\
T. quinquevittatum (present) & -1.072 & 0.512 & -2.095 & $\mathbf{0 . 0 3 6}$ \\
Turbinaria (present) & 1.319 & 0.528 & 2.500 & $\mathbf{0 . 0 1 2}$ \\
\hline \hline
\end{tabular}

\subsubsection{The influence of competition and structural refuge on the survival of T. hardwicke}

Competitive effects occurred rapidly and then stabilized after $3 \mathrm{~d}$ (Figure 3.4a). Survival of $T$. hardwicke ranged between $3 \%(S E=3)$ when $T$. quinquevittatum was present and Turbinaria absent, and 37\% $(S E=8)$ when T. quinquevittatum was absent and Turbinaria present (Figure 3.4b). The minimum adequate GLM included the main effects of T. quinquevittatum and Turbinaria only (Table 3.4). Survival of T. hardwicke was 2.3 times greater in treatments without $T$. quinquevittatum competitors relative to those with $T$. quinquevittatum competitors $(P=0.036$; Table 3$)$ and 2.8 times greater in treatments with Turbinaria relative to treatments without Turbinaria ( $P=0.012$; Table 3 ). The effects of habitat complexity were therefore greater than the effects of competitors (the ratio of the effects of habitat complexity to competitive effects was 1.24). 

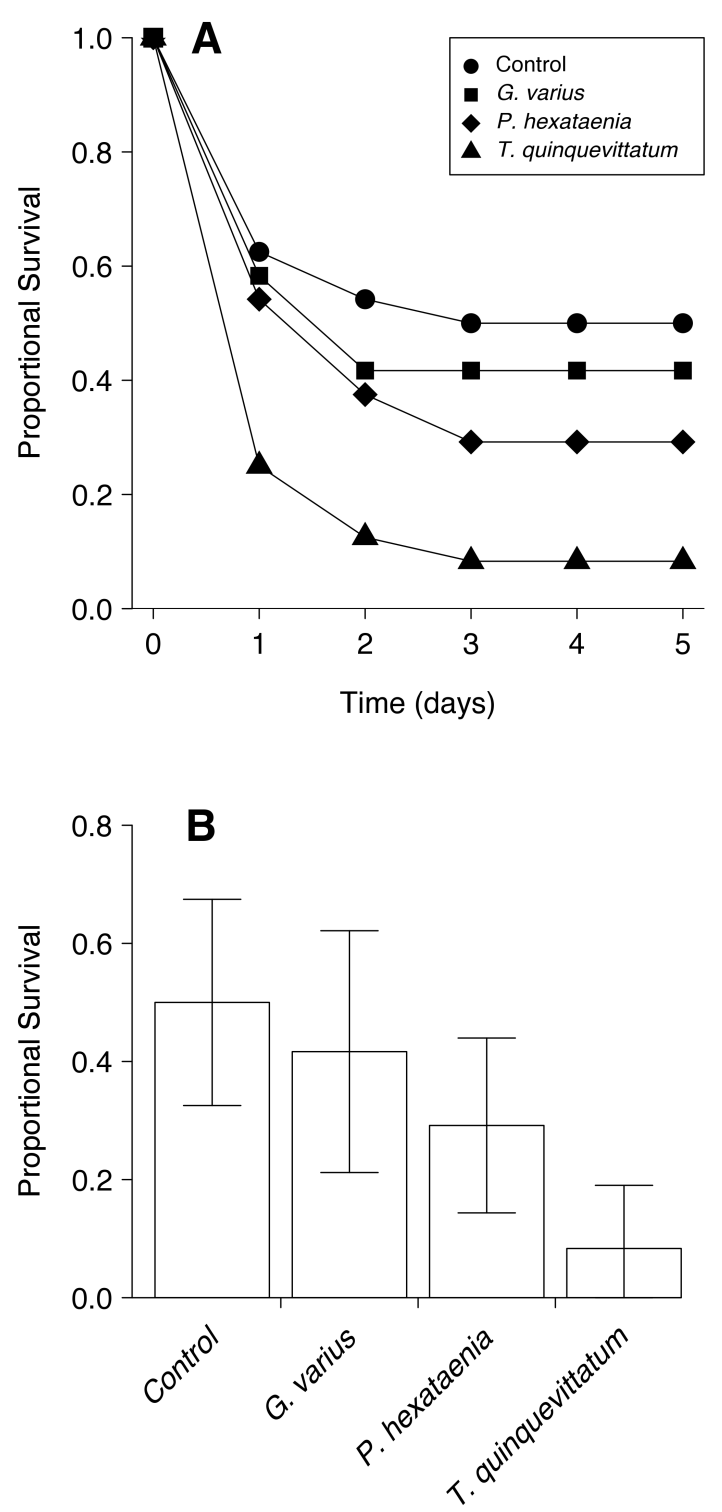

Figure 3.3: Observed proportional survival of Thalassoma hardwicke in the presence of Gomphosus varius, Pseudocheilinus hexataenia and T. quinquevittatum. T. hardwicke settlers were introduced to reefs in with one of four wrasse treatments: G. varius present; $P$. hexataenia present; T. quinquevittatum present; or Control (G. varius, P. hexataenia and T. quinquevittatum absent). (A) Survival trajectories of T. hardwicke over the five days the assay ran (error bars are omitted for clarity). (B) Proportional survival (means $\pm 95 \% \mathrm{CI}$ ) of T. hardwicke on day five of the assay. $n=8$ sites per treatment. 

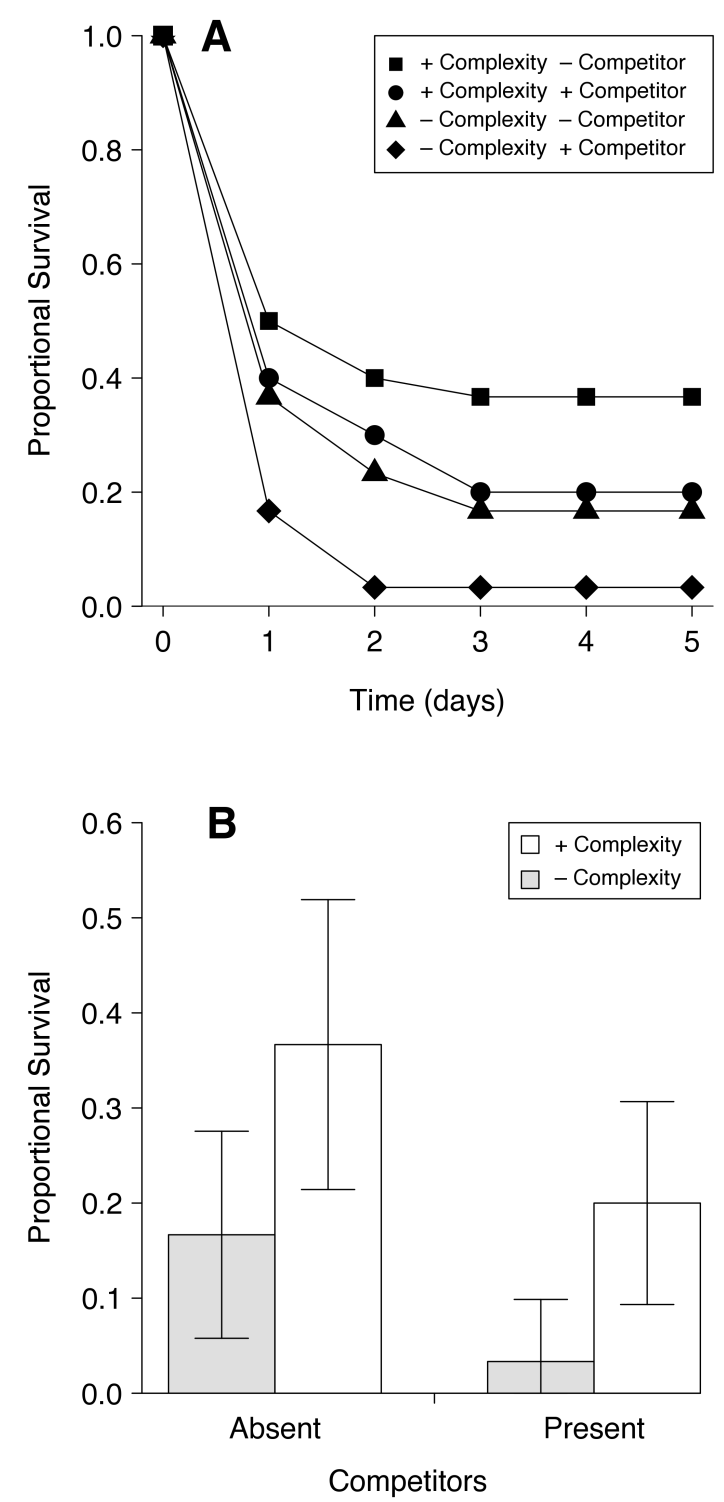

Figure 3.4: Proportional survival of Thalassoma hardwicke in the presence or absence of T. quinquevittatum (competitor: a deleterious effect) and Turbinaria ornata (complex habitat: a beneficial effect). (A) Survival trajectories of T. hardwicke over the five days the experiment ran (error bars are omitted for clarity). (B) Proportional survival (means $\pm 95 \% \mathrm{CI}$ ) of $T$. hardwicke on day five of the experiment. $n=10$ replicates per treatment. Proportional survival is pooled over two temporal blocks (June 2005, May 2007). 


\subsection{Discussion}

The importance of interspecific competition in structuring marine communities is well recognized (e.g., Byers, 2000; McCook et al., 2001; Munday et al., 2001; Connell et al., 2004; Turra and Denadai, 2004; LopezVictoria et al., 2006; Gagern et al., 2008); however, attributes of the current environment may influence the intensity of interspecific competition. For instance, structural refuge is generally expected to mitigate the negative effects of competition (Holt, 1987; Beukers and Jones, 1997; Almany, 2004b; Almany, 2004c). In the current study, T. hardwicke showed selectivity for complex habitats which provided structural refuge. Crossfactoring the presence and absence of T. ornata (structural refuge: a beneficial effect) with the presence and absence of T. quinquevittatum (competitor: a deleterious effect) produced additive effects. Thalassoma hardwicke survival significantly increased in the presence of $T$. ornata and significantly decreased in the presence of T. quinquevittatum. These results suggest that post-settlement survival of $T$. hardwicke will be greatest when structural refuge is present and competitors are absent; lowest when structural refuge is absent and competitors are present, and, in the presence of competitors, survival would be greatest when structural refuge is also present.

Classic competition theory suggests that competitive exclusion and niche diversification will lead to resource partitioning between species (Colwell and Fuentes, 1975; Diamond, 1978). Similar habitat associations between Thalassoma hardwicke, Gomphosus varius, Pseudocheilinus hexataenia and T. quinquevittatum suggest that juveniles of these species do not partition habitat. If niche models apply to this system, resource partitioning must therefore involve other resources (e.g., the differentiation of food resources, enemies or habitat use). Alternatively, similar habitat associations may be evidence that neutral processes are more important than functional differences in driving the population dynamics of these 
species (e.g., random variation in settlement: Bell, 2000; Hubbell, 2001; Chave, 2004; Leibold and McPeek, 2006; Adler et al., 2007).

Previous studies have demonstrated that aggressive interactions between reef fish can increase a subordinates exposure to predators via displacement from refuge habitat (Carr et al., 2002; Holbrook and Schmitt, 2002; Almany, 2003). Additionally, agonistic encounters (e.g., posturing and chases) may attract the attention of predators (e.g., Elkin and Baker, 2000) and/or be inversely proportional to vigilance, both of which may reduce survival. For example, Geange and Stier (2009) demonstrated that chases and fin bites by prior resident Thalassoma quinquevittatum forced subordinate T. hardwicke out of structural refuge (Pocillopora verrucosa), with the overall effect a reduction in T. hardwicke survival. In the present study, which examined a broader suite of species, the effects of prior residents were species-specific. The presence of Gomphosus varius and Pseudocheilinus hexataenia did not significantly affect the survival of T. hardwicke, although survival was 2.3 times less when T. quinquevittatum was present. However, because competitors were not randomly assigned to replicate reefs (rather, replicates on which potential competitors naturally occurred were used), reef-specific effects (e.g., lack of suitable habitat for the focal species or spatial variation in predation pressure) could also drive these patterns. Additionally, because small age and or size differences can have large impacts on competitive dominance hierarchies (Webster, 2004; Wilson, 2005; Samhouri et al., 2009) and this study used competitors that were larger and older than focal individuals, reversals in the relative sizes of competitors and focal individuals (e.g., due to priority effects) may alter the magnitude and direction of the effects observed here.

Increasing the availability of limiting resources is expected to mitigate the negative effects of resource limitation. Increased survival of $T$. hardwicke in the presence of T. ornata was consistent with this expectation and suggests structural refuge was a limiting resource. Increasing the availability of limiting resources is also expected to alleviate 
the deleterious effects of resource competition. Here, the effects of $T$. quinquevittatum and T. ornata were additive, not interactive, suggesting competition occurred independently of T. ornata. Competition may have either occurred for other limited resources (e.g., food), or independently of resources altogether (e.g., during the establishment of social dominance hierarchies). Many reef fish are social and form mixed-species groups (Lukoschek and McCormick, 2003). The establishment of social dominance hierarchies within groups may begin in early juvenile stages, with the relative position within social hierarchies, not resource availability, dictating resource access. This suggests the effect of increasing resource availability will vary according to group social structure. For groups where social dominance hierarchies do not occur, increasing the availability of limiting resources is likely to mitigate the negative effects of competition because all individuals have equal resource access. For groups of individuals where social dominant hierarchies are prevalent, increasing resource availability is unlikely to mitigate the negative effects of competition because competitive interactions occur independently of resources. In this study, both $T$. hardwicke and T. quinquevittatum form mixed species groups on patch reefs, with intense social interactions determining resource access (Geange and Stier, 2009); therefore, the non-interactive effect between competition and structural refuge may be explained by competition occurring independently of structural refuge during the assimilation of transplanted T. hardwicke into existing social hierarchies. Further, the ratio of the effects of structural refuge relative to competition was 1.24, indicating that the negative effects imposed by the presence T. quinquevittatum competitors were less than the negative effects of limited structural refuge. For T. hardwicke, it appears that the provisioning of structural refuge has a stronger influence on survival than competitive interactions that occur independently of structural refuge during the formation of social dominance hierarchies.

The establishment of dominance hierarchies between resident T. quin- 
quevittatum and transplanted T. hardwicke may also explain the rapid occurrence of competitive effects after transplantation. When individuals enter a community they come into contact with prior residents and must integrate into established dominance hierarchies. The steep drop in survival immediately following transplantation may reflect intense aggressive interactions during the assimilation of transplanted individuals, with survival trajectories stabilizing once social dominance hierarchies have been re-established. Although this study does not provide behavioural data to validate this interpretation, some support exists in the use of transplanted individuals that were approximately two weeks post-settlement and therefore likely had previous experience with competitors (including G. varius, P. hexataenia and T. quinquevittatum given their ubiquity). The steep drop in survival suggests that experiences with specific reefs or dominance hierarchies rather than experience with competitors per-se is an important determinant of post-settlement survival. This interpretation expands upon pervious research that cites the drivers of intense recruit mortality immediately after settlement as physical limitations of postsettlement reefs fishes due to energetic expenditure for metamorphosis (McCormick and Makey, 1997; McCormick et al., 2002).

Like Bonin et al. (2009), this study found (1) both competitive interactions and structural refuge can influence survival in reef fishes; and (2) the effects of structural refuge and competition were additive not interactive. In both of these studies, reef fishes form social groups, with competitive hierarchies potentially forming when relative position within the group determines resource access. This suggests that the lack of expected interactions between the availability of structural refuge and the presence of competitors may result from social interactions occurring independently of resource availability. If this is the case, it has important implications for ecologists attempting to evaluate the influence of resource limitation on the strength of competition, suggesting it is not only important to quantify resource limitation, but to also identify how 
individuals interact with one another independently of resources. Further work is needed to quantify the interplay between competition, resource availability and social hierarchies in reef fishes. 


\section{Chapter 4}

\section{Order of Arrival Affects Competition in Two Reef Fishes ${ }^{1}$}

${ }^{1}$ Publication: Geange S.W. and A.C. Stier. (2009) Order of Arrival Affects Competition in Two Reef Fishes. Ecology 90(10) 2868-2878 (see Appendix B). 


\subsection{Abstract}

Many communities experience repeated periods of colonization due to seasonally regenerating habitats or pulsed arrival of young-of-year. When an individuals persistence in a community depends on the strength of competitive interactions, changes in the timing of arrival relative to the arrival of a competitor can modify competitive strength and ultimately, establishment in the community. I investigated whether the strength of intracohort competitive interactions between recent settlers of the reef fishes Thalassoma hardwicke and T. quinquevittatum are dependent on the sequence, and temporal separation of their arrival into communities. To achieve this, I manipulated the sequence and timing of arrival of each species onto experimental patch reefs by simulating settlement pulses and monitoring survival and aggressive interactions. Both species survived best in the absence of competitors, but when competitors were present, did best when they arrived at the same time. Survival declined as each species entered the community progressively later than its competitor, and as aggression by its competitor increased. Intraspecific effects of resident T. hardwicke were similar to interspecific effects. This study shows that the strength of competition depends not only on the identity of competitors, but also on the sequence and timing of their interactions, suggesting that when examining interaction strengths, it is important to identify temporal variability in the direction and magnitude of their effects. Furthermore, my findings provide empirical evidence for the importance of competitive lotteries in the maintenance of species diversity in demographically open marine systems. 


\subsection{Introduction}

Many communities undergo repeated periods of development due to regenerating resources or pulsed arrival of young-of-year (e.g., Gibbs and Grant, 1987; Schauber et al., 2002). Because numerous species are highly fecund (e.g., many insects, plants, fishes and marine invertebrates), with females producing thousands of offspring, individuals often enter communities in large pulses. Further, species often enter communities asynchronously due to interspecific differences in phenology, with the competitive pressures faced by early-arriving individuals differing markedly from late-arriving individuals. In such instances, the degree to which one individual affects the success of another depends, in part, on both the sequence (who arrives first) and timing (by how much) of arrival of each individual into the community (i.e., priority effects). Priority effects may reflect interspecific differences in breeding phenology, which can be adaptive to, amongst other things, interspecific interactions. For example, competitive intensity may be less when a subordinate competitor breeds before or simultaneously as a superior competitor. In such cases, priority effects simply refer to interspecific interactions whose outcomes depend on the relative or absolute timing of arrival, breeding, or activity of the interacting species (Lawler and Morin, 1993).

There are at least two general types of priority effects; one in which per-capita competitive effects are constant but long-term dynamics are dependent on initial conditions, and the other in which timing of arrival alters the strength of per-capita competitive effects. The Lotka-Volterra competition model exemplifies the first type. When each species suffers more from inter- than intraspecific competition, the equilibrium outcome of competition is dependent upon initial conditions, with the species with a sufficiently large initial abundance having the advantage and excluding the other species. In this scenario, an early arriving species can build up to sufficiently high numbers that it excludes the invasion of the other species. 
Reversals in sequence of arrival can reverse the competitive outcome.

In the other type, the strength of competition varies according to conditions under which competition is occurring (i.e., the per-capita strength of competition is not constant). For example, if early arrival provides a competitive advantage due to differences in experience or size, then the competitive effect of the early arriving species on the later arriving species should increase as the arrival times diverge. In either case, knowledge of such temporal effects is critical to estimates and interpretation of realized interaction strengths of competitors in a community.

In this study, I was concerned with the second type of priority effect; how sequencing and timing of arrival change the strength of competition. The direction and magnitude of priority effects will depend on the underlying processes that give rise to the effect. For example, if initial size differences, or the time available for resource pre-emption confers an advantage upon a competitor arriving in a community early, performance of late arriving competitors should decline as they arrive progressively later than the early-arriving competitor (e.g., Lawler and Morin, 1993). Alternatively, when species are of similar size, differences in arrival time can affect the duration of head-to-head competition, in which case performance of late arriving competitors should increase as they arrive progressively later than the early-arriving competitor (Lawler and Morin, 1993).

Intracohort priority effects, which I define here as occurring within the same settlement season, have previously been shown to affect community dynamics, having been documented in protist (Price and Morin, 2004), zooplankton (Louette and Meester, 2007), insect (Benke, 1978; Shorrocks and Bingley, 1994) and amphibian communities (Lawler and Morin, 1993; Blaustein and Margali, 1996; Dayton and Fitzgerald, 2005). In marine systems, work on intracohort order-of-arrival has predominantly focused on sessile invertebrates (e.g., Sutherland and Karlson, 1977). However, 
reef fish communities are also a good platform for testing the influence of: (1) changes in the timing of arrival; and (2) reversals in the sequence of arrival, because they conform to repeated periods of development driven by pulsed arrival of young-of-the-year.

The majority of reef fishes have two-phase life histories, consisting of a dispersive planktonic larval phase, and benthic, reef-associated juvenile and adult phases. Given the dispersive nature of the planktonic larval phase, most reef fish communities are relatively open, relying on spatially and temporally unpredictable larval supply from external populations for colonising juveniles. At high latitudes $\left(>10^{\circ} \mathrm{N} / \mathrm{S}\right)$, recruitment patterns are typically seasonal, producing strong cohorts (Doherty and Williams, 1988b; Doherty, 1991; Srinivasan and Jones, 2006). Conversely, at low latitudes, longer breeding seasons are usually associated with lower fecundities (Winemiller and Rose, 1992), reducing the potential for strong cohorts. As individuals within a cohort make the transition from planktonic to benthic habitat, they encounter individuals that have settled in previous cohorts (i.e., established residents) and other recently settled individuals from the same cohort, with both intra- and intercohort interactions capable of determining the success of a newly arrived individual. To date, the majority of research examining priority effects in reef fishes has focused on intercohort effects of established residents on the success of later arriving individuals (for example see: Shulman et al., 1983; Sweatman, 1985; Almany, 2003; Almany, 2004c; Munday, 2004). These studies have demonstrated that the recruitment success of newly arrived juveniles is strongly influenced by interactions with established residents, and have for the most part concluded that strong interaction strengths add a degree of determinism to future community structure when the influence of prior residents on later arriving individuals is species-specific.

A fundamental endeavour of ecologists is evaluating interaction strengths among species, the consequences for community structure and dynamics, and how communities will respond to changes in the biotic environment. 
However, this type of information is only useful if we can identify the variability of interaction strengths across space and time. Here, I expand on previous research into the effects of established residents on new arrivals (i.e., intercohort effects) by examining the effect subtle differences in timing and order of arrival have on the recruitment success of individuals within the same cohort. Specifically, I examine intracohort priority effects between two competing reef fishes (Thalassoma hardwicke and T. quinquevittatum). Using experimental manipulations, I tested whether the strength of competitive interactions depends on the sequence and temporal separation of arrival of competing individuals. I predicted that: (1) when symmetrical intracohort priority effects occur (and not generic competitive effects), reversing the order of arrival should reverse the observed effects (i.e., effects should be a function of order of arrival and not species identity); and (2) when priority effects (rather than species effects) are most important, competitive effects should be weakest when competitors arrive simultaneously and increase in strength as temporal separation between competitor arrival increases.

\subsection{Methods}

\subsubsection{Study Species}

The wrasses (Labridae) Thalassoma hardwicke and T. quinquevittatum cooccur on reefs throughout the Indo-Pacific (Myers, 1999). At tropical latitudes $\left(\sim 14^{0} S\right)$, T. hardwicke and T. quinquevittatum spawn year round (Craig, 1998), with planktonic larval durations of approximately 47 and 56 days respectively (Victor, 1986). Both species settle in pulses around the new moon in the austral summer, at a standard length (SL) of $9-11$ $\mathrm{mm}$ (Geange personal observation). At my study site in Moorea, French Polynesia, a single pulse of reef fish settlement can last up to 14 days (Du- 
four and Galzin, 1993). Thalassoma hardwicke and T. quinquevittatum were highly similar in habitat use, strongly associating with massive Porites corals, Pocillopora verrucosa, Porites rus, and the macroalgae Turbinaria ornata (see Figure 3.1, Chapter 3). Both species also have similar diets, feeding predominantly on planktonic and benthic crustaceans (Randall 2005). Intra- and interspecific aggression, consisting of chases and fin bites, presumably for habitat, is common within and between these species (Geange unpublished data).

Given that settlement of T. hardwicke and T. quinquevittatum occurs in irregular pulses around the new moon, in which T. hardwicke and $T$. quinquevittatum settle asynchronously (Geange personal observation), I hypothesize that competitive dominance between individuals within a cohort will be determined by order of arrival.

\subsubsection{Study Site}

The study was conducted in the northern lagoon of Moorea, French Polynesia $\left(17^{0} 30^{\prime} S, 149^{0} 50^{\prime} W\right)$ between February and August 2007, on a grid of 28 live-coral patch reefs in water two to four meters deep. Reefs were located within a sand-flat, separated from each other and nearby natural reefs, by a minimum of 15 meters. I constructed reefs to minimize habitat variation by standardizing size, rugosity, and water depth. Each reef consisted of a base of live Porites lobata coral with an average area of $2.25 \mathrm{~m}^{2}(S D=0.57)$, and a mean height of $0.60 \mathrm{~m}(S D=0.10)$. I added two colonies of Pocillopora verrucosa, with an average area projected downward onto a 2D surface of $0.191 \mathrm{~m}^{2}(S D=0.057)$, onto the upper surface of each reef using Z-spar epoxy (Kopcoat, Pittsburgh, PA, USA). Reef quality for T. hardwicke increases as a function of Pocillopora cover (Osenberg et al., 2006; Shima et al., 2008). I removed all resident T. hardwicke and T. quinquevittatum, and manipulated the absolute and relative abundances of other resident fish species via selective removals and additions, so that 
the relative abundance of all species was similar among the 28 reefs (see Tables 4.1 and 4.2 for background community structure). I used the fish anaesthetic eugenol (clove oil), and hand nets to collect fish. 
Table 4.1: Non-manipulated fish community structure on experimental patch reefs used in a study examining intracohort priority effects between Thalassoma hardwicke and T. quinquevittatum. Means (and SE) are given for each of the seven treatments: (1) T. hardwicke without T. quinquevittatum; (2) T. hardwicke and T. quinquevittatum introduced simultaneously; (3) T. hardwicke with T. quinquevittatum introduced 5-days previously; (4) T. hardwicke with T. quinquevittatum introduced 12-days previously; (5) T. quinquevittatum without T. hardwicke; (6) T. quinquevittatum with T. hardwicke introduced 5-days previously, and (7) T. quinquevittatum with T. hardwicke introduced 12-days previously. Surveys were conducted the day immediately before deployment of prior residents in each of two temporal blocks (11 April and 2 May). Values for each treatment are calculated across both temporal blocks. Predator species we suspect as agents of mortality of focal individuals are highlighted in bold, but do not include transient species not captured in surveys that were observed visiting reefs during the course of the study, including Carangidae, Aulostomus chinensis, Botha spp., Cheilinus trilobatus, Saurida gracilis and Synodus binotatus.

\begin{tabular}{|c|c|c|c|c|c|c|c|c|c|}
\hline \multirow[b]{2}{*}{ Family } & \multirow[b]{2}{*}{ Species } & \multirow[b]{2}{*}{ Functional Group } & \multicolumn{7}{|c|}{ TREATMENT } \\
\hline & & & 1 & 2 & 3 & 4 & 5 & 6 & 7 \\
\hline \multirow[t]{3}{*}{ Acanthuridae } & Acanthurus olivaceus & Herbivore & - & - & - & - & - & - & $0.6(0.6)$ \\
\hline & Acanthurus triostegus & Herbivore & $1.5(0.5)$ & $1.3(0.4)$ & $1.5(0.6)$ & $1.3(0.4)$ & $1.5(0.7)$ & $1.6(0.5)$ & $2.3(0.6)$ \\
\hline & Naso annulatus & Planktivore/Herbivore & $0.3(0.2)$ & $0.1(0.1)$ & $1.3(0.7)$ & $0.6(0.4)$ & $0.5(0.4)$ & $0.1(0.1)$ & $0.4(0.3)$ \\
\hline \multirow[t]{3}{*}{ Apogonidae } & Apogon fraenatus & Planktivore & - & $0.4(0.3)$ & $0.1(0.1)$ & $0.3(0.2)$ & - & $0.1(0.7)$ & $0.1(0.1)$ \\
\hline & Arothron hispidus & Omnivore & - & - & $0.1(0.1)$ & - & - & - & - \\
\hline & Cheilodipterus quinquelineatus & Carnivore & $0.1(0.1)$ & $0.1(0.1)$ & $0.1(0.1)$ & $0.1(0.1)$ & $0.1(0.1)$ & $0.3(0.3)$ & - \\
\hline Balistidae & Balistapus undulatus & Omnivore & - & - & - & - & - & - & $0.1(0.1)$ \\
\hline Chaetodontidae & Chaetodon citrinellus & Omnivore & $0.9(0.3)$ & $0.9(0.4)$ & $1.0(0.5)$ & $1.5(0.5)$ & $1.1(0.5)$ & $1.5(0.5)$ & $2.3(0.5)$ \\
\hline Diodontidae & Diodon hystrix & Carnivore & - & - & $0.1(0.1)$ & - & - & - & - \\
\hline \multirow[t]{2}{*}{ Holocentridae } & Neoniphon argenteus & Carnivore & $0.1(0.1)$ & $0.1(0.1)$ & $0.1(0.1)$ & - & $0.3(0.2)$ & $0.1(0.1)$ & - \\
\hline & Neoniphon sammara & Carnivore & $0.1(0.1)$ & $0.5(0.3)$ & $0.5(0.3)$ & $0.1(0.1)$ & $0.3(0.2)$ & $0.3(0.2)$ & $0.1(0.1)$ \\
\hline \multirow[t]{3}{*}{ Labridae } & Halichoeres trimaculatus & Carnivore & $1.3(0.7)$ & $1.8(0.6)$ & $1.6(0.6)$ & $1.0(0.4)$ & $1.6(0.5)$ & $2.0(0.5)$ & $2.0(0.6)$ \\
\hline & Stethojulis bandanensis & Carnivore & $0.6(0.4)$ & $0.3(0.2)$ & $0.4(0.3)$ & $0.1(0.1)$ & $0.9(0.5)$ & $0.1(0.1)$ & $0.1(0.1)$ \\
\hline & Thalassoma amblycephalum & Planktivore & - & - & - & - & $0.1(0.1)$ & - & - \\
\hline
\end{tabular}


Table 4.1 - continued from previous page

\begin{tabular}{|c|c|c|c|c|c|c|c|c|c|}
\hline \multirow[b]{2}{*}{ Family } & \multirow[b]{2}{*}{ Species } & \multirow[b]{2}{*}{ Functional Group } & \multicolumn{7}{|c|}{ TREATMENT } \\
\hline & & & 1 & 2 & 3 & 4 & 5 & 6 & 7 \\
\hline Lethrinidae & Monotaxis grandoculis & Carnivore & - & - & $0.3(0.3)$ & - & - & - & - \\
\hline \multirow[t]{2}{*}{ Mullidae } & Mulloidichthys flavolineatus & Carnivore & - & - & - & $0.1(0.1)$ & - & $0.1(0.1)$ & $0.1(0.1)$ \\
\hline & Parupeneus multifasciatus & Carnivore & - & $0.5(0.5)$ & - & $0.4(0.3)$ & $0.1(0.1)$ & $0.1(0.1)$ & - \\
\hline \multirow[t]{2}{*}{ Muraenidae } & Echnidna nebulosa & Carnivore & $0.1(0.1)$ & - & - & - & - & - & - \\
\hline & Gymnothorax javanicus & Carnivore & - & - & $0.1(0.1)$ & - & - & - & - \\
\hline Pinguipedidae & Parapercis millepunctata & Carnivore & - & - & - & - & $0.1(0.1)$ & - & $0.1(0.1)$ \\
\hline \multirow[t]{6}{*}{ Pomacentridae } & Centropyge flavissimus & Herbivore & - & - & - & - & $0.1(0.1)$ & - & - \\
\hline & Chrysiptera brownriggii & Omnivore & $0.1(0.1)$ & - & $0.1(0.1)$ & $0.1(0.1)$ & $0.3(0.2)$ & $0.1(0.1)$ & $0.1(0.1)$ \\
\hline & Dascyllus aruanus & Planktivore/Herbivore & $0.3(0.2)$ & $0.5(0.3)$ & $0.4(0.3)$ & $0.4(0.2)$ & $0.5(0.3)$ & $0.6(0.4)$ & $0.4(0.2)$ \\
\hline & Dascyllus flavicaudus & Planktivore & $1.1(0.9)$ & $0.8(0.5)$ & $0.4(0.3)$ & $0.4(0.2)$ & $0.8(0.5)$ & $0.5(0.3)$ & $0.5(0.2)$ \\
\hline & Pomacanthus imperator & Omnivore & - & - & - & - & - & $0.1(0.1)$ & - \\
\hline & Pomacentrus pavo & Planktivore/Herbivore & $2.6(0.6)$ & $2.0(0.8)$ & $2.4(1.1)$ & $1.8(0.6)$ & $1.4(0.6)$ & $1.3(0.6)$ & $2.8(0.6)$ \\
\hline \multirow[t]{2}{*}{ Scaridae } & Scarus psittacus & Herbivore & $0.3(0.3)$ & $0.1(0.1)$ & $0.3(0.2)$ & $0.1(0.1)$ & $0.8(0.6)$ & $0.1(0.1)$ & $0.1(0.1)$ \\
\hline & Scarus sordidus & Herbivore & $1.6(0.6)$ & $0.6(0.3)$ & $0.1(0.1)$ & $0.5(0.2)$ & $1.0(0.4)$ & $0.1(0.1)$ & $1.0(0.5)$ \\
\hline \multirow[t]{2}{*}{ Scorpaenidae } & Scorpaenodes guamensis & Carnivore & - & - & - & - & - & - & $0.1(0.1)$ \\
\hline & Scorpaenopsis diabolus & Carnivore & $0.1(0.1)$ & - & - & - & - & - & - \\
\hline \multirow[t]{3}{*}{ Tetraodontidae } & Canthigaster bennetti & Omnivore & $3.1(1.4)$ & $3.8(1.2)$ & $3.4(0.9)$ & $2.1(0.7)$ & $1.8(0.6)$ & $2.1(1.1)$ & $3.9(1.3)$ \\
\hline & Canthigaster solandri & Omnivore & $0.3(0.3)$ & - & $0.1(0.1)$ & - & - & $0.1(0.1)$ & - \\
\hline & Canthigaster valantini & Omnivore & - & - & - & - & $0.1(0.1)$ & - & $0.3(0.2)$ \\
\hline
\end{tabular}


Table 4.2: Non-manipulated fish community structure on experimental patch reefs used in a study examining intraspecific, intracohort, priority effects between Thalassoma hardwicke individuals. Means (and SE) are given for each of our four treatments: (1) Focal T. hardwicke without resident T. hardwicke; (2) Focal and resident T. hardwicke introduced simultaneously; (3) Focal T. hardwicke with resident T. hardwicke introduced 5-days previously; (4) Focal T. hardwicke with resident T. hardwicke introduced 12-days previously. Surveys were conducted the day immediately before deployment of prior residents (6 June). Predator species we suspect as agents of mortality of focal individuals are highlighted in bold, but do not include transient species not captured in surveys that were observed visiting reefs during the course of the study, including Carangidae, Aulostomus chinensis, Botha spp., Cheilinus trilobatus, Saurida gracilis and Synodus binotatus.

\begin{tabular}{|c|c|c|c|c|c|c|}
\hline \multirow[b]{2}{*}{ Family } & \multirow[b]{2}{*}{ Species } & \multirow[b]{2}{*}{ Functional Group } & \multicolumn{4}{|c|}{ TREATMENT } \\
\hline & & & 1 & 2 & 3 & 4 \\
\hline \multirow[t]{3}{*}{ Acanthuridae } & Acanthurus olivaceus & Herbivore & $0.3(0.2)$ & $1.4(0.5)$ & $0.6(0.3)$ & - \\
\hline & Acanthurus triostegus & Herbivore & $0.4(0.2)$ & $1.1(0.3)$ & $0.7(0.4)$ & $0.3(0.2)$ \\
\hline & Naso annulatus & Planktivore/Herbivore & $0.1(0.1)$ & $0.3(0.2)$ & $0.6(0.4)$ & $0.1(0.1)$ \\
\hline \multirow[t]{2}{*}{ Apogonidae } & Apogon fraenatus & Planktivore & - & $0.1(0.1)$ & - & $0.3(0.2)$ \\
\hline & Cheilodipterus quinquelineatus & Carnivore & $0.3(0.2)$ & $0.3(0.2)$ & $0.3(0.2)$ & $0.1(0.1)$ \\
\hline Balistidae & Balistapus undulatus & Omnivore & $0.1(0.1)$ & $0.3(0.3)$ & $0.1(0.1)$ & - \\
\hline Chaetodontidae & Chaetodon citrinellus & Omnivore & $0.1(0.1)$ & $0.7(0.3)$ & $0.4(03)$ & $0.3(0.2)$ \\
\hline \multirow[t]{2}{*}{ Holocentridae } & Neoniphon argenteus & Carnivore & $1.0(0.5)$ & $2.1(0.6)$ & $0.9(0.4)$ & $0.7(0.4)$ \\
\hline & Neoniphon sammara & Carnivore & $0.7(0.3)$ & $0.6(0.3)$ & $0.1(0.1)$ & $0.7(0.3)$ \\
\hline \multirow[t]{4}{*}{ Labridae } & Cheilinus trilobatus & Carnivore & - & $0.1(0.1)$ & $0.1(0.1)$ & - \\
\hline & Halichoeres trimaculatus & Carnivore & $3.7(1.2)$ & $6.4(1.2)$ & $3.0(1.1)$ & $1.7(0.8)$ \\
\hline & Stethojulis bandanensis & Carnivore & $0.6(0.4)$ & $0.3(0.2)$ & $0.4(0.3)$ & $0.1(0.1)$ \\
\hline & Thalassoma amblycephalum & Planktivore & $0.1(0.1)$ & $0.1(0.1)$ & - & - \\
\hline Mullidae & Parupeneus multifasciatus & Carnivore & - & $0.1(0.1)$ & $0.2(0.2)$ & - \\
\hline
\end{tabular}


Table 4.2 - continued from previous page

\begin{tabular}{|c|c|c|c|c|c|c|}
\hline \multirow[b]{2}{*}{ Family } & \multirow[b]{2}{*}{ Species } & \multirow[b]{2}{*}{ Functional Group } & \multicolumn{4}{|c|}{ TREATMENT } \\
\hline & & & 1 & 2 & 3 & 4 \\
\hline Pinguipedidae & Parapercis millepunctata & Carnivore & $0.1(-)$ & $0.1(0.1)$ & - & - \\
\hline \multirow[t]{6}{*}{ Pomacentridae } & Chromis viridis & Planktivore & - & $0.1(0.1)$ & - & - \\
\hline & Chrysiptera brownriggii & Omnivore & - & $0.1(0.1)$ & - & - \\
\hline & Dascyllus aruanus & Planktivore/Herbivore & $0.6(0.3)$ & $0.3(0.2)$ & $0.1(0.1)$ & $0.3(0.2)$ \\
\hline & Dascyllus flavicaudus & Planktivore & $0.4(0.2)$ & $0.9(0.6)$ & $0.4(0.3)$ & $0.3(0.2)$ \\
\hline & Pomacanthus imperator & Omnivore & - & $0.3(0.2)$ & - & $0.1(0.1)$ \\
\hline & Pomacentrus pavo & Planktivore/Herbivore & $0.4(0.2)$ & $1.0(0.4)$ & $1(0.4)$ & $0.3(0.2)$ \\
\hline \multirow[t]{2}{*}{ Scaridae } & Scarus sordidus & Herbivore & $0.7(0.3)$ & $0.4(0.2)$ & $0.4(0.2)$ & $0.4(0.3)$ \\
\hline & Scarus psittacus & Herbivore & $0.3(0.2)$ & $0.1(0.1)$ & $0.3(0.2)$ & $0.1(0.1)$ \\
\hline Scorpaenidae & Scorpaenodes guamensis & Carnivore & - & $0.4(0.3)$ & $0.3(0.3)$ & - \\
\hline \multirow[t]{2}{*}{ Tetraodontidae } & Canthigaster bennetti & Omnivore & $1.3(0.5)$ & $1.9(0.6)$ & $1.7(0.9)$ & $2.7(0.7)$ \\
\hline & Canthigaster solandri & Omnivore & - & $0.1(0.1)$ & $0.3(0.3)$ & - \\
\hline
\end{tabular}

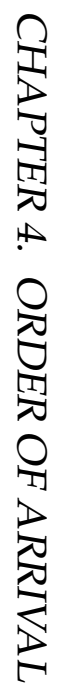




\subsubsection{Experimental Design and Execution}

To test for priority effects, I experimentally manipulated the sequence and timing of arrival of T. hardwicke and T. quinquevittatum onto reefs. I used recent settlers (13.8 mm SL; $S D=2.3$; approximately two weeks postsettlement) captured from reefs roughly $4 \mathrm{~km}$ from the study site. All captured fish were held in tanks with running seawater for 6-12 $\mathrm{h}$, then individually tagged with different colors of Visible Implant Elastomer (VIE: Northwest Marine Technology, Shaw Island, Washington, USA) forward of the caudal peduncle. Tags were readable through the skin of the fish by observers in the field, so it was not necessary to recapture individuals to determine their identity. VIE tags do not have adverse effects on other fishes (Beukers et al., 1995; Imbert et al., 2007; Simon, 2007), have been used to tag fish as small as $8 \mathrm{~mm}$ (Frederick, 1997), and a preliminary study I conducted showed no mortality of 12 tagged T. hardwicke and T. quinquevittatum held in aquaria for $48 \mathrm{~h}$. I therefore assumed that tagging and handling effects were small. After tagging, I returned fish to aerated aquaria for 6-12 $\mathrm{h}$ before measuring them to the nearest $0.1 \mathrm{~mm} \mathrm{SL}$, and deploying them in the field. I used tagged fish in two experiments. Experiment 1 examined interspecific priority effects between T. hardwicke and T. quinquevittatum. Experiment 2 examined intraspecific priority effects within T. hardwicke.

Experiment 1: Interspecific Priority Effects between T. hardwicke and T. quinquevittatum

I experimentally manipulated the sequence and timing of the arrival of $T$. hardwicke and T. quinquevittatum settlers; one portion of this experiment was designed to quantify effects of $T$. hardwicke (the prior resident) on T. quinquevittatum (the focal species); the other was designed to test the effects of T. quinquevittatum (as the prior resident) on T. hardwicke (as the focal species). For both cases, I simulated settlement pulses by introducing 
Table 4.3: Summary of Experiment 1 showing timing of prior resident introductions relative to focal introductions. $H$ represents $T$. hardwicke individuals and $Q$ represents $T$. quinquevittatum individuals. Focal individuals for each treatment are in bold. The seven treatments were as follows: (1) T. hardwicke without T. quinquevittatum; (2) T. hardwicke and T. quinquevittatum introduced simultaneously; (3) T. hardwicke with T. quinquevittatum introduced 5-days previously; (4) T. hardwicke with T. quinquevittatum introduced 12days previously; (5) T. quinquevittatum without T. hardwicke; (6) T. quinquevittatum with T. hardwicke introduced 5-days previously, and (7) T. quinquevittatum with T. hardwicke introduced 12-days previously. Note that treatment 2 served as the simultaneous arrival treatment for both species. Treatments 1-4 examine effects of prior T. quinquevittatum residency on T. hardwicke settlement. Treatments 2 and 5-6 examine effects of prior T. hardwicke residency on T. quinquevittatum settlement. Experiment 2 consisted of treatments $1-4$, replacing $\mathrm{Q}$ with $\mathrm{H}$ so that neighbor and focal individuals were both T. hardwicke.

\begin{tabular}{|c|c|c|c|c|c|c|c|c|c|c|c|c|c|c|}
\hline \multirow{3}{*}{$\frac{\text { TIMING }}{\text { 12-days }}$} & \multicolumn{14}{|c|}{ TREATMENT } \\
\hline & \multicolumn{2}{|c|}{$\mathbf{1}$} & \multicolumn{2}{|c|}{2} & \multicolumn{2}{|c|}{3} & \multicolumn{2}{|c|}{4} & \multicolumn{2}{|c|}{5} & \multicolumn{2}{|c|}{6} & \multicolumn{2}{|c|}{7} \\
\hline & - & - & - & - & - & - & $\mathrm{Q}$ & - & - & - & - & - & $\mathrm{H}$ & - \\
\hline 5-days & - & - & - & - & Q & - & - & - & - & - & $\mathrm{H}$ & - & - & - \\
\hline 0-days & - & $\mathbf{H}$ & $Q$ & $\mathbf{H}$ & - & $\mathbf{H}$ & - & $\mathbf{H}$ & - & $\mathbf{Q}$ & - & $Q$ & - & $Q$ \\
\hline
\end{tabular}


three fish of the focal species onto reefs where three tagged fish of the prior resident were either absent; had been introduced 12-days earlier than, 5-days earlier than, or simultaneously with (0-days) the focal species. Simulated settlement pulses of three fish are representative of natural settlement rates to reefs of the size used in this study. All fish were collected and tagged in the $24 \mathrm{~h}$ preceding their deployment in the field. I ran the experiment in two temporal blocks (11 - 30 April and $2-21$ May), randomly assigning treatments to reefs, and fish to treatments, yielding eight replicates (four in each temporal block) for each of my seven treatments: (1) T. hardwicke without T. quinquevittatum; (2) T. hardwicke and T. quinquevittatum introduced simultaneously; (3) T. hardwicke with T. quinquevittatum introduced 5-days previously; (4) T. hardwicke with T. quinquevittatum introduced 12-days previously; (5) T. quinquevittatum without T. hardwicke; (6) T. quinquevittatum with T. hardwicke introduced 5days previously, and (7) T. quinquevittatum with T. hardwicke introduced 12-days previously (Table 4.3). Note that treatment 2 served as the simultaneous arrival treatment for both species. For each experimental run, I size matched focal individuals and prior residents, so that all fish were the same size at the time they were added to reefs (see Figure 4.1). Size differences between prior residents and focal individuals were then a function of the length of prior residency (e.g., growth advantage conferred upon 12-day prior residents relative to 0 -day prior residents was 12 days). Fish on a given reef were not size matched, but sampled randomly from the pool of available sizes for that treatment.

Because recently settled fish often experience high rates of mortality (Almany and Webster, 2006), I initially introduced six prior residents to reefs in the 12-day and 5-day treatments. Prior to introducing focal fish to these treatments, I haphazardly removed excess residents when there were more than three residents (18 instances out of 32 reefs), and pressed residents (i.e., added individuals to sustain a constant number of three residents) at the same time as focal individuals were added when there 

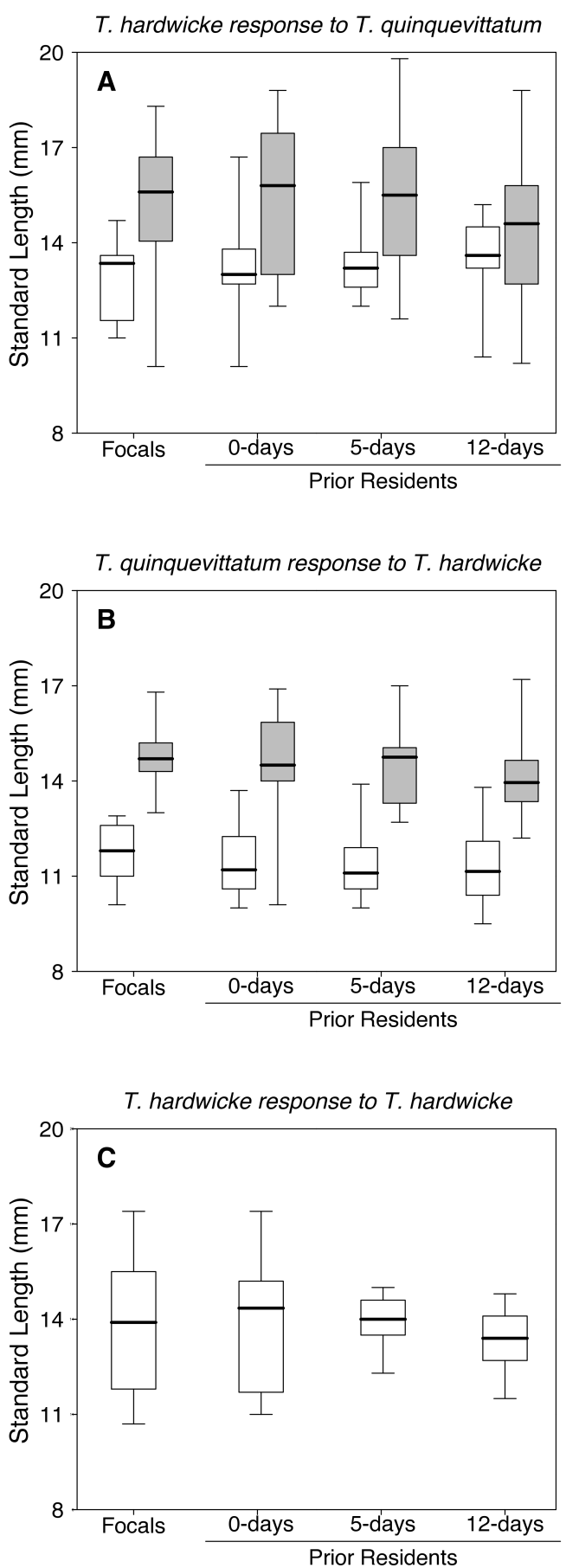

Figure 4.1: Standard lengths of focal individuals and prior residents. In panels (A) and (B), the standard lengths of individuals in experimental runs one and two are indicated by white and grey bars respectively. For each experimental run, a one-way ANOVA indicated that standard lengths of individuals at the time they were introduced to reefs did not statistically differ between treatments: (A) $F_{3,142}=2.526, P=0.060$ and $F_{3,139}=1.623, P=0.187$ for experimental runs one and two respectively; $(\mathrm{B}) F_{3,151}=1.838$, $P=0.143$ and $F_{3,153}=2.328, P=0.077$ for experimental runs one and two respectively; and $(C) F_{3,198}=1.012$ and $P=0.388$. 
were less than three residents (6 instances out of 32). Pressed residents were disproportionately distributed amongst treatments: T. hardwicke residents were pressed on four reefs (two individuals on two 12-day treatments, one individual on one 12-day treatment and two individuals on one 5-day treatment) and T. quinquevittatum were pressed on two reefs (two individuals each on one 12-day and one 5-day treatment). I used excess individuals removed from other experimental reefs to press residents.

I surveyed reefs twice daily (approximately 8 am and $4 \mathrm{pm}$ ) for seven days after I introduced focal individuals. I also searched neighboring non-experimental reefs for tagged immigrants. I found no immigrants or emigrants, and previous research has shown that small reef fish rarely move between reefs separated by as little as $15 \mathrm{~m}$ (Caselle, 1999; Shima, 2001a). I therefore assumed that the disappearance of an experimental fish was due to mortality rather than migration.

Experiment 2: Intraspecific Priority Effects between T. hardwicke Individuals

I used a similar experimental design to examine intraspecific priority effects for T. hardwicke (i.e., T. hardwicke recruits served as both focal individuals and prior residents: see Table 4.3). Because the intraspecific design had four instead of seven treatments, I conducted one experimental run (6 July to 25 July). I removed excess residents from 6 of 14 reefs, and added residents to 3 of 14 reefs (one 5-day treatment and two 12-days treatments) prior to adding focal individuals to reefs. All other aspects of Experiment 2 were identical to Experiment 1.

\subsubsection{Behavioural Observations}

To help elucidate the mechanisms driving priority effects I conducted fiveminute behavioral observations at the time I added focal individuals to 
reefs. After allowing fish to acclimate to my presence for approximately three minutes, I conducted behavioral observations at a distance of approximately two meters from the reef. I remained stationary, or moved slowly while conducting behavioral observations. This reduces the likelihood of herding or frightening fish onto or off reefs, or between substrates within reefs. I recorded three response variables: (1) The number of chases between focal individuals and both prior residents and the background community (in experiment 1,96\% and $89 \%$ of chases were inflicted by prior residents upon T. hardwicke and T. quinquevittatum respectively; in Experiment 2, 98\% of chases were inflicted by prior residents); (2) The number of fin bites inflicted during chases (all fin bites were inflicted by prior residents on focal individuals in both experiments); and (3) Time spent inside Pocillopora by focal individuals.

\subsubsection{Data Analysis}

\section{Survival Analysis}

I modeled time-to-disappearance for each treatment using Cox proportional hazard regression (Cox, 1972; Cox and Oakes, 1984). I modeled the underlying distribution of focal individual mortality against time of resident arrival. The probability distribution of mortality is specified as a hazard function, $h(t)$, the conditional or instantaneous mortality, expressed as a function of time, $t$ :

$$
h(t)=h_{0}(t) \exp ^{\beta_{1} \alpha_{1}+\beta_{2} \alpha_{2}+\ldots \beta_{p} \alpha_{p}}
$$

where $h_{0}(t)$ is the time dependent baseline hazard function which is dependent on a set of $p$ covariates $\left(\alpha_{1}, \alpha_{2}, \ldots, \alpha_{p}\right)$, whose impact is measured by the size of the respective coefficients $\left(\beta_{1}, \beta_{2}, \ldots, \beta_{p}\right)$. The 
density of prior residents slowly decreased through time after I added focal individuals. For prior resident present treatments, I controlled for decreasing resident densities through time by including density of residents as a time-dependent covariate in my model. For Experiment 1, I also included a strata term in the model to account for experimental run, which is similar to blocking terms in analysis of variance (Therneau and Grambsch, 2000). I right censored the data (i.e., analyzed data on minimal survival times), used the Efron approximation to handle tied data, used partial likelihood to derive regression coefficients $\left(\beta_{i}\right)$, converted these coefficients to a hazard ratio as $e^{\beta_{i}}$, and converted the hazard ratios into estimated percent changes in mortality rate (CMR) by subtracting 1 from the hazard ratio and multiplying by 100. I conducted model reduction using ANOVA.

I determined if the fitted Cox regression model adequately described the data using: (1) Schoenfeld residuals scaled by the Kaplan Meier estimate to test the assumption of proportional hazards; and (2) dfbeta values (the relative differences between the least squares and deleted estimates of the coefficients: Freund and Wilson, 1998) to test for influential data. Cox regressions were conducted using the survival package in R 2.5.1 (Team, 2007).

I ran three orthogonal survival analyses: (1) I tested competitive effects by contrasting survival of focal individuals between resident absent and resident present treatments (i.e., Absent vs. [0-days, 5-days, 12-days]); (2) I tested the effects of arriving later than residents by contrasting survival of focal individuals with simultaneous vs. later arrival (i.e., 0-days vs. [5days, 12-days]); (3) I tested the effects of arriving progressively later than residents by contrasting survival of focal individuals arriving 5-days vs. 12-days later than residents. 


\section{Behavior Analysis}

Because there were strong correlations among behavioral responses (e.g., fin bites only occurred during chases), I analyzed behavior data using Principal Components Analysis (PCA) to create a composite aggression score. I transformed data $(\ln (x+1))$ prior to analysis to improve normality. I conducted separate analyses for each of the three sub-studies (T. hardwicke with T. quinquevittatum; T. quinquevittatum with T. hardwicke; and T. hardwicke with T. hardwicke). Results were very similar for all three analyses. PCA-1 accounted for $63-68 \%$ of the total variation in aggression variables, and was driven by high positive loadings of total chases (64 - 68\%) and fin bites $(63-68 \%)$, and weak negative loadings of time-inPocillopora $(31-44 \%)$. Thus, I interpret this first PCA-axis as a gradient of overall aggression. I analyzed PCA-1 scores with a one-way analysis of variance (ANOVA), using a relaxed variance assumption (Dalgaard, 2002). For significant ANOVAs ( $P \leq 0.05)$, I used Bonferroni adjusted pairwise t-tests, with unequal variances, to compute all possible pairwise comparisons.

\subsection{Results}

\subsubsection{Interspecific Priority Effects}

Over the seven days that I monitored the survival of T. hardwicke focal individuals, average proportional survival was 46 ( $\pm 8.76 S E), 21( \pm 8.76$ $S E), 13( \pm 6.12 S E$ ) and 8 ( $\pm 5.44 S E$ ) percent, for Absent, 0-day, 5-day and 12-day treatments, respectively (Figure $4.2 \mathrm{a}, \mathrm{b}$ ). Average proportional survival of T. quinquevittatum after seven days was 46 ( \pm 8.77 SE), 46 ( \pm $10.78 S E), 21$ ( $\pm 8.76 S E$ ) and 21 ( $\pm 6.12 S E$ ) percent, for Absent, 0-day, 5-day and 12-day treatments respectively (Figure 4.2 c,d). 
Analysis of competitive effects (Absent vs. 0-day, 5-day, 12-day) indicated that the likelihood of mortality for T. hardwicke individuals entering reefs where T. quinquevittatum residents were present increased by $196 \%$, compared to reefs where T. quinquevittatum was absent (Figure $4.2 \mathrm{a}, \mathrm{b}$; Table 4.4). When arriving simultaneously, T. hardwicke had lower survival than T. quinquevittatum (mean proportional survival 0.208 ( \pm $0.059 S E)$ vs. $0.458( \pm 0.074 S E)$ for T. hardwicke and T. quinquevittatum respectively). Mortality of T. hardwicke increased as T. quinquevittatum were given greater residence times, but these effects were not significant (Figure $4.2 \mathrm{a}, \mathrm{b}$; Table 4.4).

Survival of T. hardwicke decreased with increases in the PCA-derived composite aggression score (Figure $4.2 \mathrm{~b}$ ). As T. hardwicke entered reefs progressively later than $T$. quinquevittatum, aggression from residents towards focal individuals increased $(P<0.001)$ and survival decreased $(P$ $<0.001)$. Aggression was significantly higher on reefs where T. quinquevittatum arrived either 5-days or 12-days prior to T. hardwicke, relative to reefs where T. quinquevittatum was absent (Figure $4.2 \mathrm{~b}$ ). Likewise, aggression was significantly higher on reefs where T. quinquevittatum arrived 12-days prior to T. hardwicke relative to reefs where T. quinquevittatum arrived simultaneously (Figure 4.2 b).

When the sequence of arrival was reversed, there was not a significant competitive effect of T. hardwicke on T. quinquevittatum (Figure $4.2 \mathrm{c}$,d; Table 4.4). However, when T. quinquevittatum arrived on reefs later than T. hardwicke mortality risk of T. quinquevittatum increased by $93 \%$ (Figure $4.2 \mathrm{c}$,d; Table 4.4). There was no demonstrable difference when T. hardwicke arrived 5-days vs. 12-days prior to arrival of T. quinquevittatum (Figure 4.2 c,d; Table 4.4).

Survival decreased with increase in the PCA-derived composite aggression score (Figure $4.2 \mathrm{~d}$ ). As T. quinquevittatum entered reefs later than T. hardwicke, aggression from residents towards focal individuals increased $(P<0.001)$ and survival decreased $(P=0.001)$. Aggression was 
significantly higher on reefs where T. hardwicke arrived either 5-days or 12days prior to T. quinquevittatum relative to reefs where T. hardwicke were absent, or arrived simultaneously as T. quinquevittatum (Figure $4.2 \mathrm{~d}$ ).

\subsubsection{Intraspecific Priority Effects}

Over the seven days that I monitored the survival of T. hardwicke, average proportional survival was 52 ( $\pm 8.35 S E), 29$ ( $\pm 5.91 S E), 24$ ( $\pm 6.47 S E$ ) and $5( \pm 3.23 S E)$ percent, for Absent, 0-day, 5-day and 12-day treatments, respectively (Figure $4.2 \mathrm{e}, \mathrm{f}$ ). Risk of $T$. hardwicke mortality increased by $133 \%$ when conspecific residents were present on reefs relative to when they were absent (Figure 4.2 e,f; Table 4.4). Mortality of focal T. hardwicke increased as competing conspecifics were given greater residence times, but these effects were not significant: (Figure 4.2 e,f; Table 4.4).

Survival decreased with increases in the PCA-derived composite aggression score (Figure $4.2 \mathrm{f}$ ). As T. hardwicke entered reefs progressively later than conspecifics, aggression from residents towards focal individuals increased $(P<0.001)$ and survival decreased $(P<0.001)$. Aggression was significantly higher on reefs where conspecifics arrived 12-days prior to T. hardwicke, relative to reefs where conspecifics were absent (Figure 4.2 f). 
$T$. hardwicke response to T. quinquevittatum

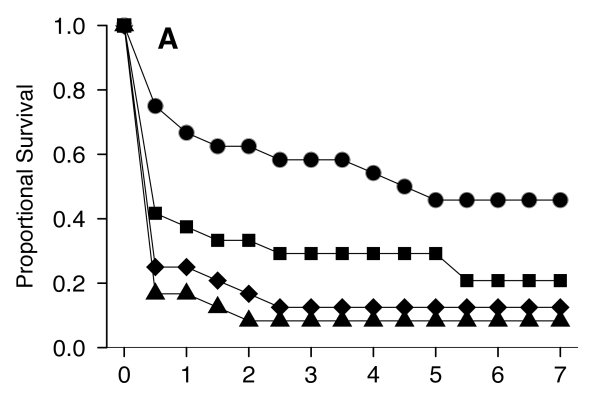

T. quinquevittatum response to T. hardwicke

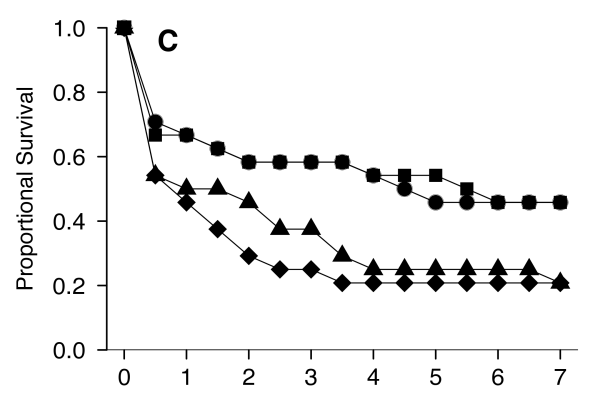

T. hardwicke response to T. hardwicke

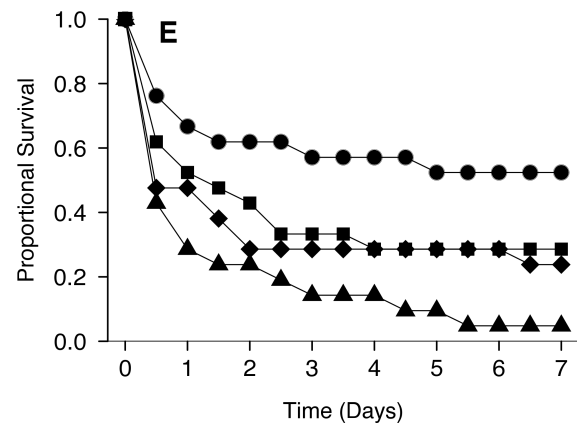

$T$. hardwicke response to T. quinquevittatum

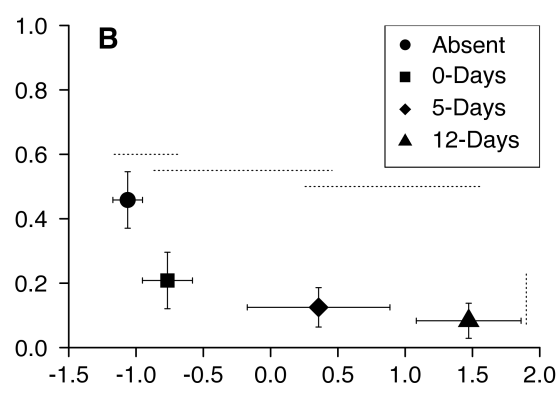

T. quinquevittatum response to T. hardwicke

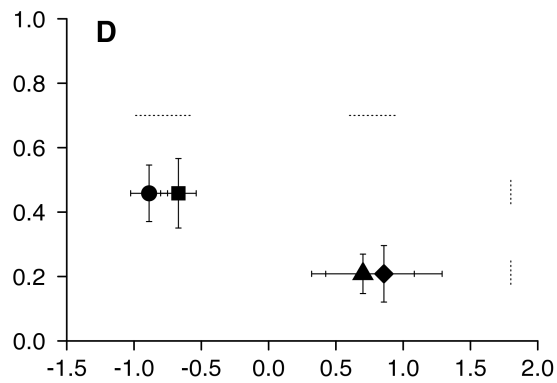

T. hardwicke response to T. hardwicke

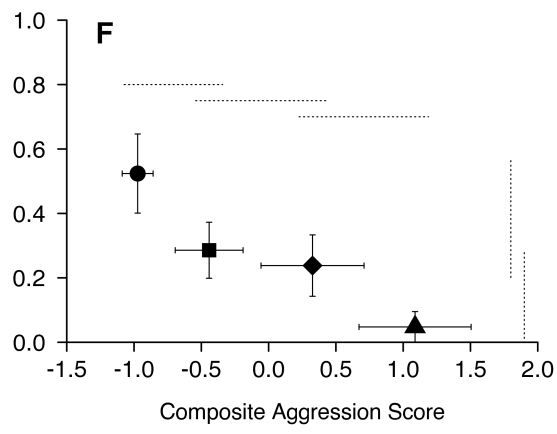

Figure 4.2: Survival of focal individuals in response to presence, relative timing of arrival, and relative aggression of a competitor. Left hand figures depict temporal trends of survival for (A) Thalassoma hardwicke in response to T. quinquevittatum, (C) T. quinquevittatum in response to T. hardwicke, and (E) T. hardwicke on itself. Error bars of temporal trends are omitted for clarity. Right hand figures show corresponding survival (proportion alive at the end of the experiment) in relation to composite aggression scores (modeling chases, fin bites and time spent inside Pocilliopora: see "Behavior Analysis") \pm $1 S E$. Dashed lines overlap treatments that are not significantly different. 
Table 4.4: Hazard Ratios from the Cox Proportional Hazard Assessment modeling survival of focal individuals relative to the arrival of prior residents. (A) Interspecific competition between Thalassoma hardwicke and T. quinquevittatum; and (B) Intraspecific competition between T. hardwicke. For each focal species, I ran three orthogonal survival analyses: (1) Competition (absent vs. [0-days 5-days \& 12-days]); (2) Priority (0-days vs. [5-days \& 12-days]); and (3) Degree of priority (5-days vs. 12-days).

\begin{tabular}{lccccc}
\hline Orthogonal Contrast & Coefficient $\left(\beta_{i}\right)$ & HR $\left(\exp \left(\beta_{i}\right)\right)$ & CMR & $95 \%$ CI & $P$ \\
\hline $\begin{array}{l}\text { A. INTERSPECIFIC EFFECT } \\
\text { T. } \text { hardwicke focal individuals }\end{array}$ & & & & & \\
Absent vs. (0-days, 5-days, 12-days) & 1.090 & 2.96 & $196 \%$ & $(1.61-5.45)$ & $<\mathbf{0 . 0 0 1}$ \\
0-days vs. (5-days, 12-days) & 0.506 & 1.66 & $66 \%$ & $(094-2.93)$ & 0.082 \\
5-days vs. 12 days & 0.173 & 1.19 & $19 \%$ & $(0.65-2.17)$ & 0.570 \\
& & & & & \\
T. quinquevittatum focal individuals & & & & & \\
Absent vs. (0-days, 5-days, 12-days) & 0.419 & 1.52 & $52 \%$ & $(0.83-2.80)$ & 0.180 \\
0-days vs. (5-days, 12-days) & 0.658 & 1.93 & $93 \%$ & $(1.02-3.64)$ & $\mathbf{0 . 0 4 2}$ \\
5-days vs. 12 days & -0.096 & 1.10 & $10 \%$ & $(0.48-1.72)$ & 0.770 \\
\hline & & & & & \\
B. INTRASPECIFIC EFFECTS & & & & & \\
T. hardwicke focal individuals & 0.844 & 2.33 & $133 \%$ & $(1.17-4.60)$ & $\mathbf{0 . 0 1 5}$ \\
Absent vs. (0-days, 5-days, 12-days) & 0.330 & 1.39 & $39 \%$ & $(0.76-2.55)$ & 0.290 \\
0-days vs. (5-days, 12-days) & 0.496 & 1.64 & $64 \%$ & $(0.84-2.22)$ & 0.150 \\
5-days vs. 12 days & & & & & \\
\hline \hline
\end{tabular}




\subsection{Discussion}

Formal analysis indicated strong inter- and intraspecific competitive effects, although strong support for priority effects only occurred in the response of $T$. quinquevittatum to the relative timing of arrival of $T$. hardwicke (Table 4.4, Figure 4.2 c). However, weaker priority effects are also evident for T. hardwicke (Figure 4.2 a,e). When both species arrived simultaneously, survival of T. quinquevittatum was similar to that when it arrived in communities devoid of T. hardwicke; whereas survival of T. hardwicke was lower than when it arrived in communities devoid of T. quinquevittatum. This suggests that when both species arrive simultaneously, T. quinquevittatum is competitively dominant over T. hardwicke.

My findings suggest that variability in the timing of settlement pulses of T. hardwicke relative to T. quinquevittatum can have dramatic effects on recruitment strength and success of both species. When both species arrived simultaneously, T. quinquevittatum survived better than T. hardwicke, which is indicative of an asymmetric competitive interaction between these species. However, when each species arrived at different times, reversals in sequence of arrival reversed the competitive advantage, indicating that competitive interactions were at least partially driven by priority effects, producing more symmetric competitive effects. The majority of short-term studies of interspecific competition between reef fishes have typically found competitive ability to be highly asymmetric, often resulting in local exclusion and habitat displacement (Hixon, 1980; Larson, 1980; Robertson and Gaines, 1986; Schmitt and Holbrook, 1986; Holbrook and Schmitt, 1989). However, these studies may not be representative of most competitive interactions as species pairs were selected in part because closely related species showed very different patterns of habitat use. While other studies have identified symmetric competitive interactions between reef fishes (Schmitt and Holbrook, 1990; 
Munday, 2004), my results expand these findings by suggesting that the direction and magnitude of competition may, in part, be determined by the sequence and timing of species interactions.

Classic competition theory predicts that over evolutionary time, intraspecific competition should be stronger than interspecific competition because competitive exclusion and niche diversification will lead to resource partitioning among species (Colwell and Fuentes, 1975; Diamond, 1978). Interspecific differences in distribution, resource use, environmental tolerances or natural enemies act as stabilizing processes, buffering per-capita population growth rates of a species in a community (Chesson, 2000), resulting in intraspecific effects being more negative than interspecific effects.

Alternatively, neutral theory (Bell, 2000; Hubbell, 2001) and the lottery model (Sale, 1976b; Sale, 1978) both predict that intra- and interspecific competition should be of equal magnitude. Neutral models suggest that the only drivers of population dynamics are random variation in births, deaths and dispersal (Adler et al., 2007), with species identity playing no role because species do not differ from one another in ways that distinguish their population dynamics (Chave, 2004; Leibold and McPeek, 2006). Likewise, the lottery model assumes that space is a limiting resource, vacant space is recolonised by the first-available settler, and that once recolonised the individual holds the space until it dies (i.e., there is a strong priority effect). Coexistence is favoured if arrival is higher for one species at some times or places, and higher for the other species at other times or places (Chesson and Warner, 1981). I found that the strength of competitive effects was primarily related to relative arrival time, and poorly explained by the identity of prior residents. This is consistent with both neutral theory and the lottery model: reversals in sequence of arrival reversed the direction of competition, and late arriving fish did poorer than fishes arriving simultaneously with their competitors, or before their competitors (as evidenced by the no competition treatment). 
Because I found order of arrival and not species identity to be important here, my results are more consistent with neutral processes structuring communities than niche-based theories.

Although I never explicitly tested mechanisms underlying priority effects in this study, I propose three. (1) A residency advantage, where if residents are able to deplete renewable resources to low levels, longer time in residency means that more depletion occurs, increasing the intensity of exploitative competition. (2) A size advantage in which larger (or older) fish (i.e., prior residents) induce stronger competitive effects than smaller (or younger) fish through either exploitative or interference competition (Jones, 1987a; Wilson, 2005). (3) An experience advantage, in which more experienced individuals (i.e., prior residents) gain knowledge of the local environment (e.g., greater awareness of established boundaries with neighbours and knowledge of hiding spaces), facilitating their ability (relative to later arriving fish) to acquire resources (i.e., exploitative competition), defend home ranges (i.e., interference competition) or evade predators. Of these three mechanisms, I have most evidence for the second and third. I found that aggression increased with increasing mortality risk and increasing temporal separation of species arrival, suggesting that aggressive behavior by residents towards focal individuals increased the mortality risk of focal individuals. This aggression gradient is suggestive of both size and experience advantages, which because larger individuals are often also more experienced, are not mutually exclusive. Previous research has shown that: (1) individuals less experienced with a site are less likely to engage in competitive interactions because they exhibit fear-like behaviours incompatible with aggression (Figler et al., 1976); and (2) larger individuals are often more successful in the acquisition and defence of food or cover, resulting in increased growth or reduced mortality (Robertson, 1984; Szabo, 2002). As individuals gain experience with a site they may also increase in confidence and more readily engage in aggressive interactions. Therefore, over time scales of minutes to hours 
when new arrivals exhibit fear like behaviours, experience advantages (or conversely an unwillingness by new arrivals to engage in aggressive interactions) may be determining factors in the outcome of interference competition. Over times scales of hours to days, when new arrivals have overcome any initial fear-like behaviours, size advantages may be critical as larger individuals are able to physically dominate smaller individuals during interference competition.

Based on previous work in coral reef fish communities, predation is likely the ultimate cause of mortality in recently settled reef fishes, with competition increasing a subordinates exposure to predators due to displacement of subordinates from refuge habitat (Carr et al., 2002; Holbrook and Schmitt, 2002; Almany, 2003). The ability to find (and defend) shelter sites may therefore increase competitive advantage. Shima (2002) found that the frequency of agonistic interactions between resident $T$. hardwicke scaled with density-and number-dependent losses to predation, suggesting that behavioural interactions (rather than proximate resource limitation) may underlie observed mortality. I have evidence that these patterns also hold true here (for both intra- and interspecific interactions), with the likely agents of mortality both resident (cardinalfish, eels, lizardfish, sandperch, triggerfish) and transient (jacks) predators (see Tables 4.1 and 4.2). I add a caveat to these interpretations. My experimental design effectively doubled the density of the experimental species when residents and focal individuals were present on the same reef relative to reefs where prior residents were absent. I acknowledge that this design does not distinguish competitive effects from apparent competition (i.e., the response of predators to overall increases in prey density) because neither competitor density nor predator effects were controlled for.

Communities are rarely devoid of established residents. Colonists and newborns immediately encounter a communitys current residents. Previous research has demonstrated that the degree to which residentsettler interactions affect the persistence of settlers can depend on the 
identity of both the resident and the settler (Shulman et al., 1983; Sweatman, 1985; Munday et al., 2001; Almany, 2003; Almany, 2004c; Hixon and Jones, 2005; Forrester et al., 2006). Here, I have expanded on this by showing that not only does the identity of the players in residentsettler interactions affect the outcome of these interactions, but so does the sequence and timing of these interactions. This has important implications for ecologists attempting to evaluate interaction strengths among species, suggesting that it is not only important to identify the direction and magnitude of interaction strengths, but also variability in the direction and magnitude of interaction strengths through time. 


\section{Chapter 5}

\section{Intraspecific Priority Effects and Habitat Complexity Affect the Survival of Thalassoma quinquevittatum Settlers ${ }^{1}$}

${ }^{1}$ Publication: Geange S.W. and A.C. Stier. (2010) Priority Effects and Habitat Complexity Affect the Strength of Competition. Oecologia (see Appendix C). 


\subsection{Abstract}

Both habitat complexity and priority effects can influence the strength of competitive interactions; however, the independent and synergistic effects of these processes are not well understood. In Moorea, French Polynesia, I conducted a factorial field experiment to quantify the independent and combined effects of priority effects and habitat complexity on the strength of intraspecific competitive interactions among recently settled individuals of a coral reef fish (Thalassoma quinquevittatum: Labridae). Simultaneous arrival of focal individuals with competitors resulted in a 2.89-fold increase in survival relative to reefs where focal individuals arrived 5-days later than competitors (i.e., a priority effect). Increasing habitat complexity, by doubling the availability of the branching coral Pocillopora verrucosa, resulted in a 1.55-fold increase in survivorship when focal individuals arrived simultaneously as, or before competitors. However, increasing habitat complexity did not effect the survivorship of focal individuals arriving 5-days later than competitors. Behavior observations showed that survivorship was negatively correlated with aggression. Aggression by prior residents towards focal individuals was significantly greater when focal individuals arrived 5-days later than competitors than when they arrived simultaneously. Increasing habitat complexity did not reduce aggression. My results suggest that when competitors arrive simultaneously, competitive interactions are weak and subordinates are not displaced from complex habitat; increasing habitat complexity increases survival by disrupting predation. Conversely, when competitors arrive at different times, aggression intensifies and increasing habitat complexity does not disrupt predation because competitive subordinates are excluded from habitat resources. This study demonstrates that the strength of competition can be context-dependent and may vary with the timing of competitive interactions and habitat complexity. 


\subsection{Introduction}

Historically, empirical and theoretical studies that quantify interaction strengths have been heavily biased towards predatory, competitive and top-down versus bottom-up interactions. Typically, these studies describe interaction strengths by constants or functions that depend on the densities of the interacting individuals, species, functional groups, or cohorts (Peacor and Werner, 2004). More recently, renewed calls have been made for more studies examining how the context within which interactions occur (e.g., disturbance regime (Gallet et al., 2007); higher-order interactions (Peacor and Werner, 2004); and environmental attributes (Chase, 2007; Crain et al., 2004)) shape interaction strengths (Agrawal et al., 2007). For example, the importance of competition in structuring rocky intertidal communities can vary spatially depending on levels of larval supply (Connolly and Roughgarden, 1999). The magnitude of competition may also vary depending upon the provisioning of structural refuge in complex habitats (e.g., Bonin et al., 2009), or the sequence in which competitors arrive in a community (i.e., priority effects; e.g., Alford and Wilbur, 1985). The intensity of priority effects can inturn depend upon the amount of time that separates the arrival of competitors in a community (Geange and Stier, 2009), or the presence of predators (Louette and Meester, 2007). Here, I examine the potential for variation in habitat complexity and priority effects to create context-dependent competitive outcomes. Understanding the independent and combined effects of priority effects and habitat complexity on the outcome of competitive interactions is of increasing importance as global climate change leads to widespread shifts in breeding phenology and habitat availability (Both et al., 2009; Durant et al., 2007; Hughes, 2000; Parmesan and Yohe, 2003; Visser and Both, 2005; Walther et al., 2002).

Habitat complexity can considerably influence interaction strengths (e.g., competition Bonin et al., 2009; Buenau et al., 2007; Ladd and 
Facelli, 2008) and predation (Beukers and Jones, 1997; Huffaker, 1958; Juliano, 2009)). Increasing habitat complexity is typically expected to mitigate the negative effects of competition for predator free space (e.g., (Almany, 2004b) or reverse competitive dominance relationships (e.g., Ebersole, 1985). More complex habitats often contain a greater diversity of food resources (e.g., Harmon et al., 1986) and refuges from predators (e.g., Beukers and Jones, 1997; Finke and Denno, 2002), thereby reducing the intensity of competition and predation. Increased structural complexity also may alter encounter rates between predators and prey, increasing predation risk if the structure decreases the visibility of predators to prey, or decreasing predation risk by providing enemy-free structural refuge or interfering with predator maneuverability and/or the ability to visually detect prey (Andruskiw et al., 2008; Janssen et al., 2007; Langellotto and Denno, 2004; Persson and Eklov, 1995; Rilov et al., 2007; Warfe and Barmuta, 2004).

Interaction strengths (e.g., competition and predation) can also be modified by the order (who arrives first) and timing (by how much) of arrival in a community (i.e., "priority effect": e.g., Chapter 4, Alford and Wilbur, 1985; Dayton and Fitzgerald, 2005; Geange and Stier, 2009; Lawler and Morin, 1993; Price and Morin, 2004; Shorrocks and Bingley, 1994). Early arrival may confer experience advantages if individuals gain knowledge of the local environment (e.g., greater awareness of established boundaries with neighbours and knowledge of predator-free space), facilitating their ability to acquire resources, defend home ranges, or evade predators. Alternatively, if larger size confers competitive advantages, early arriving individuals may have a growth advantage over late arriving individuals. When early arrival provides a competitive advantage due to differences in experience or size, the competitive effect of early arriving individuals on later arriving individuals should increase as arrival times diverge (Chapter 4, Alford and Wilbur, 1985; Geange and Stier, 2009). However, many species undergo extensive ontogenetic 
niche shifts which are often manifested as shifts in habitat use or diet with increasing size (Werner and Gilliam, 1984). Such shifts can substantially alter interaction strengths within communities (de Roos et al., 2002; Werner, 1992; Werner and Gilliam, 1984). For example, individuals arriving at different times may interact less intensely than individuals arriving at the same time because they are to some degree, acting as separate ecological species (Maiorana, 1978). As a result, priority effects will only be important if ontogenetic niche shifts occur slowly, so that late arriving individuals interact with larger, more experienced early arriving individuals. Conversely, when rapid ontogenetic niche shifts occur, the optimal strategy for an individual to avoid intracohort priority effects is to either: (1) enter the community before other settlers; or (2) enter the community late enough that prior settlers have undergone ontogenetic niche shifts and no longer pose a competitive threat.

Finally, habitat complexity and priority effects may interact, so that the effects of one process depend upon a second process. For example, although the magnitude of competition may increase as individuals arrive in a community progressively later than their competitors, late-arriving individuals may be released from competition or predation pressure in complex habitats that decrease encounter rates with early-arriving individuals. Understanding how both habitat complexity and priority effects independently and synergistically affect the strength of competitive interactions is essential to estimates and interpretation of the strength of competition.

The few studies that have examined the combined effects of habitat and arrival time on the strength of competition (see Fincke, 1999; Sunahara and Mogi, 2002) have identified habitat as capable of moderating inhibitory priority effects. In Chapter 4, which examined two labrid species that are closely related, both genetically and functionally (Thalassoma hardwicke and T. quinquevittatum), I identified strong intracohort priority effects. Aggression toward later arriving individuals by 
early arriving individuals increased as each species entered communities progressively later than its competitor. Additionally, aggression by earlyarriving individuals and the survival of late-arriving individuals was negatively correlated; suggesting that the timing of arrival relative to competitors results in context dependent competitive outcomes. Here, focussing on intraspecific competitive effects, I manipulated habitat complexity and timing of T. quinquevittatum settler arrival to: (i) determine the independent effects of timing of arrival and habitat complexity on intraspecific competition between T. quinquevittatum settlers; and (ii) address whether habitat complexity attenuates or enhances intraspecific interaction strengths among settlers arriving at different times. I hypothesized that: (1) when timing of arrival dictates the strength of competition, competitive effects should be weakest when competitors arrive simultaneously and increase in strength as temporal separation among competitor arrival increases; and (2) increasing habitat complexity would disrupt priority effects by releasing late arriving individuals from competitive interactions with early arriving individuals.

\subsection{Methods}

\subsubsection{Study Species}

Thalassoma quinquevittatum is a common wrasse throughout much of the Indo-Pacific. Thalassoma quinquevittatum spawns year round on Pacific coral reefs at latitudes of approximately $15^{0} S$ (Craig, 1998). Planktonic larval development takes 46-68 days (Victor, 1986) before competent larvae, 9-11 mm standard length (SL), settle to benthic reef habitat. At my study site, in Moorea, French Polynesia $\left(17^{0} 30^{\prime} S, 149^{0} 50^{\prime} \mathrm{W}\right)$, settlement occurs around new and full moons. A single T. quinquevittatum settlement pulse can last a few days to a week (Geange personal observation), 
meaning that, on a given patch reef, individuals in a given pulse often arrive asynchronously. Following settlement, T. quinquevittatum juveniles $(<25 \mathrm{~mm}$ SL) over-associate (relative to availability) with several coral species (e.g., Porites lobata, Pocillopora verrucosa, and Porites rus) and the macroalga Turbinaria ornata (see Figure 3.1, Chapter 3).

Mooreas northern lagoon consists of a matrix of sand and fine coral rubble interspersed with patch reefs. Patch reefs are predominantly massive Porites coral colonies, often surmounted by smaller colonies of other coral species (Pocillopora species, Montipora species, and Acropora species), patches of dead coral skeletons, macroalgae (Turbinaria species, Dictyota species, Sargassum species and Halimedia species) and filamentous algae (Polysiphonia species, and Sphacelaria species). Patch reefs are highly variable in their composition over small spatial scales; thus interactions between individuals within a settlement pulse are overlaid upon a background of variable habitat complexity. Previous research has demonstrated that variability in habitat complexity within this lagoon does affect post-settlement survival of reef fishes. For example, Shima et al. (2008) demonstrated that when density was held constant, mean post-settlement survival of T. hardwicke (a congener of T. quinquevittatum) increased with the abundance of the branching coral Pocillopora (a probable refuge from predation).

In this study, we used T. quinquevittatum individuals that were approximately two weeks post-settlement (13.3 mm SL; $S D=0.8)$.

\subsubsection{Study Site}

The study was conducted in the northern lagoon of Moorea between April and June 2008. I used an existing array of 28 isolated live-coral patch reefs separated by approximately $10 \mathrm{~m}$ in water $2-4 \mathrm{~m}$ deep (for a full description of the experimental array see Chapter 4). I added an additional two patch reefs to this array. 
In Chapter 4 (also see: Geange and Stier, 2009) I determined that juvenile T. hardwicke exclude T. quinquevittatum settlers: I therefore removed all resident $T$. hardwicke from patch reefs. I also removed resident T. quinquevittatum, and manipulated the relative abundances of other resident fish species via selective removals and additions, so that the relative abundance of all species was similar among the 30 reefs (see Table 5.1 for background community structure). I used the fish anaesthetic eugenol (clove oil) and hand nets to collect fish. 
Table 5.1: Non-manipulated fish community structure on experimental patch reefs in a study testing the effects of habitat complexity and priority effects on the post-settlement survival of Thalassoma quinquevittatum. The mean (SE) number of individuals for each species is given for each of my six treatments: (1) settlers without residents, with two P. verrucosa colonies; (2) settlers and residents introduced simultaneously, with two P. verrucosa colonies; (3) settlers with residents introduced 5-days previously, with two P. verrucosa colonies; (4) settlers without residents, with four P. verrucosa colonies; (5) settlers and residents introduced simultaneously, with four $P$. verrucosa colonies; and (6) settlers with residents introduced 5-days previously, with four $P$. verrucosa colonies. Surveys were conducted the day immediately prior to deployment of prior residents in each of two temporal blocks (17 April and 1 May). Values for each treatment are calculated across both temporal blocks. Predator species I suspect as agents of mortality of focal individuals are highlighted in bold, but do not include transient species not captured in surveys that were observed visiting reefs during the course of the study, including Carangidae, Aulostomus chinensis, Botha spp., Cheilinus trilobatus, Saurida gracilis and Synodus binotatus.

\begin{tabular}{|c|c|c|c|c|c|c|c|c|}
\hline \multirow[b]{2}{*}{ Family } & \multirow[b]{2}{*}{ Species } & \multirow[b]{2}{*}{ Functional Group } & \multicolumn{6}{|c|}{ TREATMENT } \\
\hline & & & 1 & 2 & 3 & 4 & 5 & 6 \\
\hline \multirow[t]{3}{*}{ Acanthuridae } & Acanthurus olivaceus & Herbivore & $0.9(0.9)$ & $0.2(0.2)$ & $0.1(0.1)$ & $0.1(0.1)$ & - & $0.1(0.1)$ \\
\hline & Acanthurus triostegus & Herbivore & $1.6(0.9)$ & $0.7(0.3)$ & $0.8(0.3)$ & $1.7(0.4)$ & $0.9(0.4)$ & $0.7(0.3)$ \\
\hline & Naso annulatus & Planktivore/Herbivore & $0.4(0.3)$ & $0.3(0.3)$ & - & $0.5(0.4)$ & - & $0.1(0.1)$ \\
\hline \multirow[t]{2}{*}{ Apogonidae } & Apogon fraenatus & Planktivore & - & - & - & $0.2(0.1)$ & $0.1(0.1)$ & $0.2(0.2)$ \\
\hline & Arothron hispidus & Omnivore & - & $0.1(0.1)$ & - & - & - & - \\
\hline Balistidae & Balistapus undulatus & Omnivore & - & - & - & $0.1(0.1)$ & - & - \\
\hline Chaetodontidae & Chaetodon citrinellus & Omnivore & $0.9(0.4)$ & $1.7(0.7)$ & $0.9(0.2)$ & $1.2(0.5)$ & $1.4(0.3)$ & $1.6(0.6)$ \\
\hline Diodontidae & Diodon hystrix & Carnivore & $0.1(0.1)$ & - & - & - & - & - \\
\hline Holocentridae & Neoniphon sammara & Carnivore & - & - & - & $0.2(0.1)$ & $0.1(0.1)$ & $0.4(0.4)$ \\
\hline \multirow[t]{3}{*}{ Labridae } & Halichoeres trimaculatus & Carnivore & $1.5(0.5)$ & $0.9(0.5)$ & $1.1(0.4)$ & $0.8(0.3)$ & $2.0(0.6)$ & $0.8(0.3)$ \\
\hline & Stethojulis bandanensis & Carnivore & $0.6(0.3)$ & $0.2(0.1)$ & $0.8(0.3)$ & $0.4(0.2)$ & $0.1(0.1)$ & $0.5(0.3)$ \\
\hline & Thalassoma amblycephalum & Planktivore & - & - & $0.1(0.1)$ & - & - & - \\
\hline
\end{tabular}


Table 5.1 - continued from previous page

\begin{tabular}{|c|c|c|c|c|c|c|c|c|}
\hline \multirow[b]{2}{*}{ Family } & \multirow[b]{2}{*}{ Species } & \multirow[b]{2}{*}{ Functional Group } & \multicolumn{6}{|c|}{ TREATMENT } \\
\hline & & & 1 & 2 & 3 & 4 & 5 & 6 \\
\hline Lethrinidae & Monotaxis grandoculis & Carnivore & - & - & - & - & - & $0.2(0.2)$ \\
\hline \multirow[t]{2}{*}{ Mullidae } & Mulloidichthys flavolineatus & Carnivore & - & - & - & - & $0.1(0.1)$ & - \\
\hline & Parupeneus multifasciatus & Carnivore & $0.1(0.1)$ & - & - & - & $0.1(0.1)$ & - \\
\hline \multirow[t]{2}{*}{ Muraenidae } & Echnidna nebulosa & Carnivore & $0.1(0.1)$ & - & - & - & - & - \\
\hline & Gymnothorax javanicus & Carnivore & - & - & $0.1(0.1)$ & - & - & - \\
\hline Pinguipedidae & Parapercis millepunctata & Carnivore & $0.2(0.1)$ & $0.2(0.1)$ & $0.2(0.1)$ & $0.2(0.1)$ & $0.2(0.1)$ & $0.2(0.1)$ \\
\hline \multirow[t]{6}{*}{ Pomacentridae } & Centropyge flavissimus & Herbivore & - & $0.1(0.1)$ & $0.1(0.1)$ & - & - & - \\
\hline & Chrysiptera brownriggii & Omnivore & $0.2(0.1)$ & $0.2(0.1)$ & $0.6(0.2)$ & - & $0.3(0.2)$ & $0.2(0.1)$ \\
\hline & Dascyllus aruanus & Planktivore/Herbivore & $0.3(0.1)$ & $0.7(0.3)$ & $0.6(0.2)$ & $0.5(0.2)$ & $0.2(0.1)$ & $0.6(0.3)$ \\
\hline & Dascyllus flavicaudus & Planktivore & $1.6(0.5)$ & $0.9(0.4)$ & $1.0(0.4)$ & $0.7(0.3)$ & $0.4(0.2)$ & $0.8(0.5)$ \\
\hline & Pomacanthus imperator & Omnivore & - & - & - & $0.1(0.1)$ & - & - \\
\hline & Pomacentrus pavo & Planktivore/Herbivore & $2.1(0.5)$ & $1.8(0.6)$ & $4.0(1.1)$ & $3.4(0.8)$ & $2.8(0.8)$ & $2.0(0.4)$ \\
\hline \multirow[t]{2}{*}{ Scaridae } & Scarus psittacus & Herbivore & $0.2(0.2)$ & - & - & - & $0.1(0.1)$ & - \\
\hline & Scarus sordidus & Herbivore & $2.0(0.4)$ & $1.2(0.6)$ & $2.1(0.6)$ & $0.9(0.3)$ & $0.9(0.4)$ & $1.0(0.4)$ \\
\hline \multirow[t]{3}{*}{ Tetraodontidae } & Canthigaster bennetti & Omnivore & $3.1(1.9)$ & $2.7(1.0)$ & $2.7(0.6)$ & $4.7(1.3)$ & $3.5(1.1)$ & $3.9(1.1)$ \\
\hline & Canthigaster solandri & Omnivore & $0.2(0.1)$ & - & - & - & - & $0.4(0.2)$ \\
\hline & Canthigaster valantini & Omnivore & - & - & - & $0.1(0.1)$ & $0.1(0.1)$ & - \\
\hline
\end{tabular}




\subsubsection{Experimental Design and Execution}

I examined the effects of habitat complexity and timing of arrival in the context of the survival of focal T. quinquevittatum settlers. I controlled habitat complexity by manipulating the availability of the branching coral Pocillopora verrucosa. This was achieved by drilling holes into the upper surface of patch reefs. Into these holes, I inserted stainless steel pins attached to P. verrucosa colonies with Z-Spar Splash Zone Compound (Kopcoat, Pittsburgh, Pa., USA). Mean colony surface area was $0.2 \mathrm{~m}^{2}(S D=0.07)$. I crossed the availability of $P$. verrucosa (two levels: two, or four colonies, which is representative of observed $P$. verrucosa cover within the lagoon: see Shima et al., 2008), with the presence of three tagged T. quinquevittatum competitors (three levels: absent, introduced simultaneously with (0-days), or 5-days earlier than the focal individuals). To each reef, I simulated settlement by introducing three tagged T. quinquevittatum focal individuals. Thus, my design had six treatments: (1) focal individuals without competitors, with two P. verrucosa colonies; (2) focal individuals and competitors introduced simultaneously, with two $P$. verrucosa colonies; (3) focal individuals with competitors introduced 5-days previously, with two $P$. verrucosa colonies; (4) focal individuals without competitors, with four P. verrucosa colonies; (5) focal individuals and competitors introduced simultaneously, with four P. verrucosa colonies; and (6) focal individuals with competitors introduced 5-days previously, with four P. verrucosa colonies (see Table 5.2). I ran the experiment in two temporal blocks (17 to 23-April and 1 to 7-May 2008), yielding ten replicates (five in each temporal block) for each of the six treatments.

I used T. quinquevittatum individuals captured from reefs adjacent to the reef crest, approximately $2 \mathrm{~km}$ from the study site. All captured fish were held in aquaria with running seawater for $24 \mathrm{~h}$ and then individually tagged with different colors of Visible Implant Elastomer (VIE: Northwest Marine Technology, Shaw Island, Washington, USA) 
anterior of the caudal peduncle. VIE tags were readable through the skin of the fish by observers in the field, so it was not necessary to recapture individuals to determine their identity. VIE tags do not have adverse effects on other fishes (Beukers et al., 1995; Imbert et al., 2007; Simon, 2007) or T. quinquevittatum (see Chapter 4 and Geange and Stier, 2009), and have been used to tag fish as small as $8 \mathrm{~mm}$ (Frederick, 1997). I therefore assumed that tagging and handling effects were minimal. After tagging, I returned fish to aerated aquaria for $24 \mathrm{~h}$ before measuring them to the nearest $0.1 \mathrm{~mm}$ SL. For each experimental run, I collected fish twice, once for the 5-day competitors, and once for the 0-day competitors and focal individuals. Each time I collected fish of the same size (see Figure 5.1). The difference between competitors and focal individuals was therefore their time on the reef and not their size. Fish on a reef were not size matched, but sampled randomly from the pool of available sizes for that treatment.

Because recently settled fish often experience high rates of mortality (Almany and Webster, 2006), I initially introduced six competitors to reefs in the 5-day treatments. At the same time as focal individuals were introduced to these treatments, I haphazardly removed excess competitors when there were more than three competitors (12 instances out of 20 reefs), and added competitors when there were less than three competitors ( 3 instances out of 20). I used excess individuals removed from other reefs to supplement competitors.

I surveyed reefs twice daily (approximately 8 am and $4 \mathrm{pm}$ ) for five days after the introduction of focal individuals. Day five was chosen to end the study because previous research found the first 36-48 $\mathrm{h}$ after settlement to be most critical (see Figures 3.3a and 3.4a Chapter 3, Figure 4.2 Chapter 4, and: Almany, 2003; Planes and Lecaillon, 2001; Webster, 2002; Webster and Almany, 2002). In a few instances, individuals not enumerated in one survey were enumerated in the subsequent survey (16 instances out of 570). When this occurred, these individuals were recorded 
as present at the times they were missed. During surveys, I searched neighboring non-experimental reefs for tagged immigrants. I found no immigrants or emigrants. Previous research has shown that small reef fish rarely move between reefs separated by as little as $15 \mathrm{~m}$ (Caselle, 1999; Shima, 2001a), and previous studies on my experimental array found no migration of similar sized T. quinquevittatum (see Chapter 4 and Geange and Stier, 2009). I therefore assume that the disappearance of an experimental fish was due to mortality rather than migration.

Table 5.2: Experimental Design examining the effects of habitat complexity and intraspecific priority effects on the post-settlement survival of Thalassoma quinquevittatum. $F$ represents focal individuals and $P$ represents prior residents. Each of the six treatments were as follows: (1) focal individuals without prior residents with two Pocillopora verrucosa colonies; (2) focal individuals and prior residents introduced simultaneously with two P. verrucosa colonies; (3) focal individuals with prior residents introduced 5-days previously with two P. verrucosa colonies; (4) focal individuals without prior residents with four $P$. verrucosa colonies; (5) focal individuals and prior residents introduced simultaneously with four $P$. verrucosa colonies; and (6) focal individuals with prior residents introduced 5-days previously with four $P$. verrucosa colonies.

\begin{tabular}{|c|c|c|c|c|c|c|c|c|c|c|c|}
\hline \multirow[b]{3}{*}{ TIMING } & \multicolumn{11}{|c|}{ TREATMENT } \\
\hline & 1 & & & 3 & & & & & & & \\
\hline & \multicolumn{5}{|c|}{2 Pocillopora colonies } & \multicolumn{6}{|c|}{4 Pocillopora colonies } \\
\hline 5-days & - & - & - & $\mathbf{P}$ & - & - & - & - & - & $\mathbf{P}$ & - \\
\hline 0-days & $\mathbf{F}$ & $\mathbf{P}$ & $\mathbf{F}$ & - & $\mathbf{F}$ & - & $\mathbf{F}$ & $\mathbf{P}$ & $\mathbf{F}$ & - & $\mathbf{F}$ \\
\hline
\end{tabular}

\subsubsection{Behavioural Observations}

To help elucidate the mechanisms driving interactions between focal individuals and competitors, I conducted five-minute behavioral observations at the time I added focal individuals to reefs. After allowing fish to acclimate to my presence for approximately three minutes, I identified 


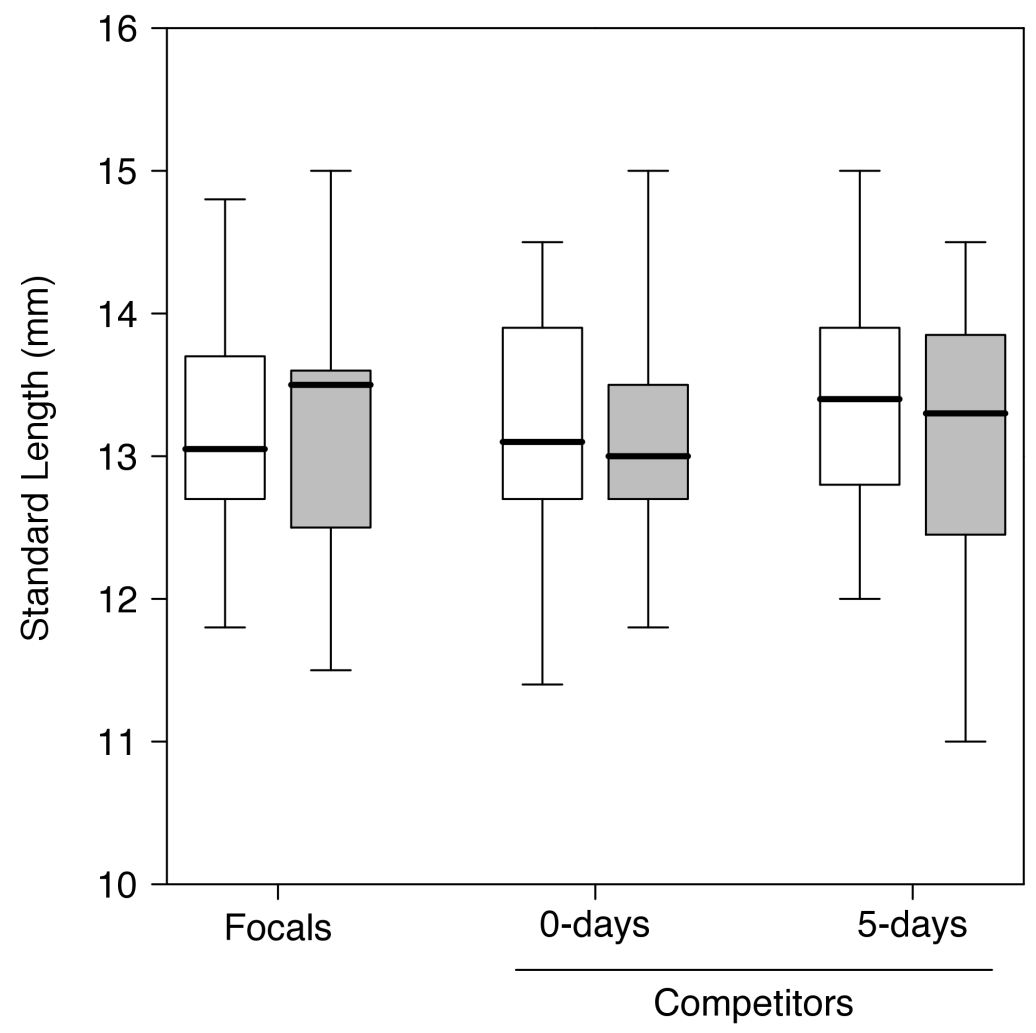

Figure 5.1: Standard lengths $(\mathbf{m m})$ of Thalassoma quinquevittatum. White and grey bars indicate the standard lengths of individuals in experimental runs one and two respectively. For each experimental run, a one-way ANOVA indicated that standard lengths of individuals at the time they were introduced to reefs did not statistically differ between treatments: $F_{2,117}=1.991, P=0.141$ and $F_{2,117}=0.165, P=0.848$ for experimental runs one and two respectively. 
one focal individual that was followed at a distance of approximately two meters from the reef. I recorded three response variables: (1) the number of chases between other fishes and focal individuals ( $80 \%$ of chases were by T. quinquevittatum competitors); (2) the number of fin bites inflicted upon focal individuals (all fin bites were inflicted by T. quinquevittatum competitors); and (3) time spent inside Pocillopora by focal individuals. I repeated this twice on each reef so that behavioral interactions were made for two focal individuals per reef.

\subsubsection{Data Analysis}

\section{Survival Analysis}

Using generalized linear models (GLM), I conducted an analysis of deviance with binomial error distributions and a logit link function to model the proportional survival of focal individuals five days after their introduction to reefs. I used an analysis of deviance to evaluate the statistical significance of the main effects and the interaction between the competition and habitat complexity treatments (i.e., the full model). Finding no interaction $\left(\chi^{2}=0.457, d f=2, P=0.796\right)$, I conducted four a priori contrasts: (1) Habitat effects without prior residents (Absent + 0-days low complexity vs. Absent + 0-days high complexity); (2) Competitive effects (control low and high complexity vs. 0-day low and high complexity); (3) Habitat effects with competitors (0-day and 5-day low complexity vs. 0-day and 5-day high complexity); and (4) timing of arrival effects (0-day low and high complexity vs. 5-day low and high complexity). I chose these contrasts to examine main effects of habitat and competition in the absence (contrasts 1 and 2) and presence (contrasts 3 and 4 ) of timing of arrival effects. Data were not overdispersed (residual deviance $=46.781$, residual $d f=54$ ). I calculated effect sizes as ratios using mean proportions from the raw data. 


\section{Behavior Analysis}

Because there were strong correlations among behavioral responses (e.g., fin bites only occurred during chases), I used Principal Components Analysis (PCA) to create a single composite aggression score. I transformed data $(\ln [x+1])$ prior to analysis to improve normality. PC1 accounted for $73 \%$ of the total variation in aggression variables, and was driven by high positive loadings of total chases $(64 \%)$ and fin bites $(60 \%)$, and weak negative loadings of time-in-Pocillopora (44\%). Thus, I interpret this first PC axis as a gradient of overall aggression.

I analyzed overall aggression with a two-way analyses of variance (ANOVA). I conducted two orthogonal contrasts; (1) I tested effects of competitors by contrasting aggression when competitors were absent versus present (i.e., Absent vs. [0-days and 5-days]); and (2) I tested the effects of arriving later than competitors by contrasting aggression with arrival simultaneous as versus later than competitors (i.e., 0-days vs. 5-days). In both analyses, I crossed the effects of competitors with habitat. I transformed data to meet assumptions of normality and equal variance: $1 /[X j+C]$; where $C$ is the largest negative value plus one (see: Rummel, 1970). LRT indicated that the inclusion of interaction terms did not improve model fit in either analysis, I therefore removed the interaction terms and focused on the main effects of habitat and competition. For significant main effects $(P<0.05)$, I used Tukeys Honest Significant Differences to compute pairwise comparisons.

I analyzed overall aggression with a two-way analyses of variance (ANOVA). I transformed data to meet assumptions of normality and equal variance (1 / $[X j+C]$; where $C$ is the largest negative value plus one, (see: Rummel, 1970). Finding no interaction $\left(F_{2,54}=0.012, P=0.987\right)$, I used overall aggression as the response variable to conduct four a priori contrasts equivalent to those described above for Survival Analysis.

All statistical analysis was conducted in R 2.8.0 (Team, 2008). 


\subsection{Results}

Increasing habitat complexity yielded a 1.50-fold increase in the proportional survival of focal individuals $(P=0.043$; Table 5.3; Figure 5.2). Relative to reefs where competitors were absent, arriving either simultaneously as, or 5-days later than competitors resulted in 1.15 and 3.34-fold decreases in survival, respectively $(P=0.001$; Table 5.3; Figure $5.2)$.

Increasing habitat from two to four P. verrucosa colonies on reefs where focal individuals arrived simultaneously or before competitors resulted in a 1.55-fold increase in the survival of focal individuals (Contrast $1 ; P=$ 0.024; Table 5.4). Arriving on reefs where competitors were absent yielded a 1.15-fold increase in survival relative to reefs where focal individuals arrived at the same time as competitors, although this effect was not statistically significant (Contrast 2; $P=0.448$; Table 5.4). When focal individuals arrived simultaneously with, or 5-days later than competitors, increasing habitat complexity increased survival, although this effect was not significant (Contrast 3; $P=0.953$; Table 5.4). Arriving at the same time as competitors yielded a 2.89 -fold increase in survival relative to reefs where focal individuals arrived five days later than competitors (Contrast 4; $P<0.001$; Table 5.4).

Survival of focal individuals decreased with increases in the PCAderived composite aggression score (slope $=-0.08, r^{2}=0.175, P=$ 0.001; Figure 5.2). Increasing habitat complexity did not significantly affect aggression $(P=0.959$; Table 5.3), although timing of arrival did $(P<0.001 ; 5.3)$. Aggression did not differ significantly between reefs where competitors were either absent or arrived simultaneously as focal individuals (Contrast 2; $P=0.088$; Table 5.4). Relative to when focal individuals arrived simultaneously as competitors, aggression was significantly greater when focal individuals arrived 5-days later than competitors (Contrast 4; $P<0.001$; Table 5.4). 
Table 5.3: Post-settlement survival of Thalassoma quinquevittatum in response to habitat complexity and intraspecific priority effects. Analysis of deviance and variance tables testing the significance of: (1) habitat (two levels: two (low), or four (high) Pocillopora verrucosa colonies); (2) timing of arrival (three levels: absent, introduced simultaneously with (0-days), or 5-days earlier than the focal individuals); and (3) the habitat:timing of arrival interaction. The response variables are: (i) proportional survival of focal T. quinquevittatum individuals (modeled using a generalized linear model with a logit link and assumed binomial error structure); and (ii) mean aggression towards focal individuals (modeled using an analysis of variance). Aggression is a PCA-derived composite of chases, fins bites and time spent inside P. verrucosa (see Behavior Analyses). Significant $P$-values $(<0.05)$ are highlighted in bold.

\begin{tabular}{lcccccccc}
\hline & \multicolumn{3}{c}{ Survival } & & \multicolumn{3}{c}{ Aggression } \\
\cline { 2 - 4 } \cline { 6 - 8 } & $d f$ & Deviance & $P$ & & $d f$ & $F$ & $P$ \\
\hline Habitat complexity & 1 & 4.090 & $\mathbf{0 . 0 4 3}$ & & 1,54 & 0.003 & 0.959 \\
Timing of arrival & 2 & 19.910 & $<\mathbf{0 . 0 0 1}$ & & 2,54 & 18.829 & $<\mathbf{0 . 0 0 1}$ \\
Habitat:Timing of arrival & 2 & 0.457 & 0.796 & & 2,54 & 0.012 & 0.987 \\
\hline \hline
\end{tabular}


Table 5.4: Aggression towards Thalassoma quinquevittatum as a function of habitat complexity and intraspecific priority effects. Results from four a priori contrasts testing the effects of intraspecific competitors (three levels: absent, introduced simultaneously with (0-days), or 5-days earlier than the focal individuals) and habitat complexity (two levels: two (low), or four (high) Pocillopora verrucosa colonies) on: (i) proportional survival of focal T. quinquevittatum individuals; and (ii) mean aggression towards focal individuals. Proportional survival and aggression are modeled using a generalized linear model and an analysis of variance respectively. Aggression is a PCA-derived composite of chases, fins bites and time spent inside P. verrucosa (see Behavior Analyses). The four contrasts presented are: 1 ) Habitat effects without prior residents (Absent +0 days low complexity vs. Absent + 0-days high complexity); 2) Competitive effects (control low and high complexity vs. 0-day low and high complexity); 3) Habitat effects with competitors (0-day and 5-day low complexity vs. 0-day and 5-day high complexity); and 4) timing of arrival effects (0-day low and high complexity vs. 5-day low and high complexity). Effect sizes are calculated as the ratio of mean proportions from the raw data. Significant $P$-values $(<0.05)$ are highlighted in bold.

\begin{tabular}{lcccccccc}
\hline & \multicolumn{3}{c}{ Survival } & & \multicolumn{3}{c}{ Aggression } \\
\cline { 2 - 4 } \cline { 7 - 9 } & Estimate & $z$-value & $P$ & & $d f$ & $F$ & $P$ \\
\cline { 1 - 5 } 1. Habitat effects without early competitors & -0.441 & -2.261 & $\mathbf{0 . 0 2 4}$ & & 1,58 & 0.001 & 0.973 \\
2. Competitive effects & -0.145 & -0.760 & 0.448 & & 1,58 & 3.004 & 0.088 \\
3. Habitat effects with early competitors & -0.440 & -1.601 & 0.109 & & 1,58 & 0.004 & 0.953 \\
4. Timing of arrival effects & 0.636 & 3.173 & $\mathbf{0 . 0 0 1}$ & & 1,58 & 12.331 & $<\mathbf{0 . 0 0 1}$ \\
\hline \hline
\end{tabular}




\subsection{Discussion}

Intraspecific competitive effects were demonstrably greater when focal individuals arrived after competitors. The large difference in survival and aggression between the treatments in which focal individuals arrived either simultaneously with or later than competitors provides direct quantitative evidence that interaction strengths may vary due to the relative timing of arrival of individuals. As with other studies (e.g., Lawler and Morin, 1993), this research suggests historical knowledge is important when estimating interaction strengths.

Increasing habitat complexity increased survivorship of settlers in the control and 0-day treatments. I predicted that increasing habitat complexity would release focal individuals from competitive interactions in 5-day treatments; however, my results did not support this prediction. Increasing habitat complexity did not significantly increase the survival of late arriving individuals. Similarly, increasing habitat complexity did not affect the level of aggression displayed towards focal individuals by competitors.

To understand the mechanisms driving the relationship between habitat complexity and survival, we need to consider the way in which prior residents affect the survival of late arriving settlers. Based on previous work in coral reef fish communities, predation is likely the ultimate cause of mortality in recently settled reef fishes (Almany, 2003; Carr et al., 2002), with competition forcing subordinates into less protective refugia (Holbrook and Schmitt, 2002) or displacing them from refuge habitat altogether (Munday et al., 2001). Interactions with more aggressive competitors may also distract subordinates, leading to reduced vigilance and increased conspicuousness to predators (Almany, 2003; Carr et al., 2002). In the current study this suggests that when aggression is weak (e.g., when focal individuals arrive before or simultaneously as competitors), subordinates are not displaced from complex habitat, and increasing habitat complexity 


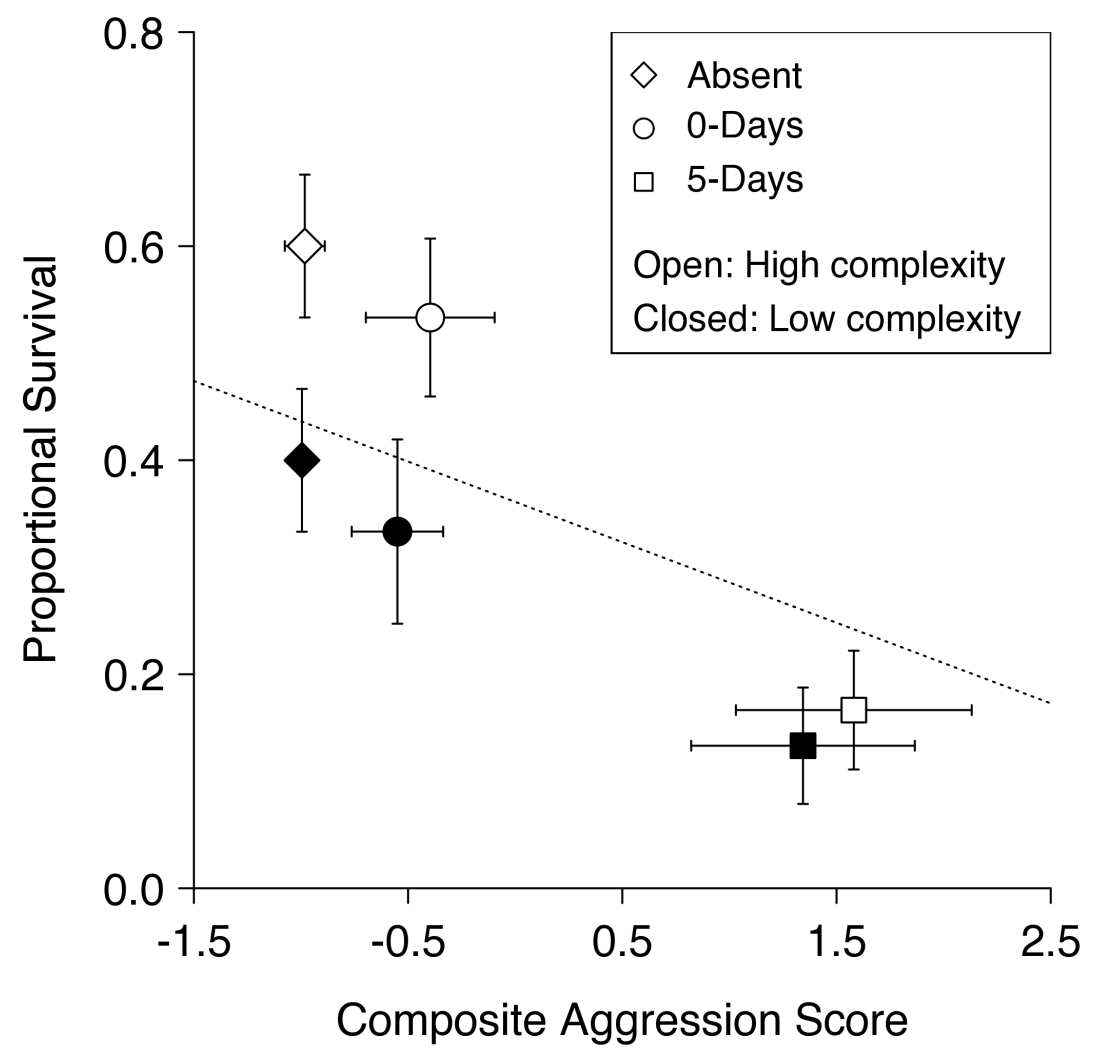

Figure 5.2: Survival of, and aggression displayed towards Thalassoma quinquevittatum as a function of priority effects and habitat complexity. The effects of intraspecific competitors (three levels: absent, introduced simultaneously with (0-days), or 5-days earlier than the focal individuals) and habitat complexity (two levels: two (low), or four (high) Pocillopora verrucosa colonies) on: (i) the proportional survival of focal $T$. quinquevittatum individuals (mean proportion alive at the end of the experiment; +/1 S.E.); and (ii) aggression towards focal individuals (+/- 1 S.E.). Aggression is a PCAderived composite of chases, fins bites and time spent inside P. verrucosa (see Behavior Analyses). The dashed line represents a linear regression between proportional survival and composite aggression based on the raw data (slope $=-0.08, r^{2}=0.175, P=0.001$ ). 
increases survival by reducing predation pressure (i.e., tight branching morphology of Pocillopora excludes the majority of predators I observe on my array); however, when aggression is intense (e.g., when focal individuals arrive later than competitors), increasing habitat complexity doesnt increase survival because competitive subordinates are displaced from refuge habitat. It therefore seems likely that a combination of the intensity of aggression (arising from the timing of arrival) and habitat complexity underlies observed survivorship of T. quinquevittatum engaged in intraspecific interactions.

I add three caveats to these interpretations. First, my experimental design effectively doubled the density of the experimental fish in 0-day and 5-day treatments relative to control treatments. Although I never observed aggregative responses of predators, I acknowledge that this design does not distinguish competitive effects from apparent competition (Holt, 1977) because neither T. quinquevittatum nor predator density were controlled for. However, during my surveys I did not see any evidence of aggregative responses of predators in either this, or a previous study (see Chapter 4 and Geange and Stier, 2009) that was conducted on the same set of reefs using the same focal species. Second, my study was conducted on small $\left(2.25 \mathrm{~m}^{2}\right)$ isolated patch reefs. On these reefs, I observed strong aggression towards focal individuals by early arriving competitors to the point that early arriving competitors pursued focal individuals across the entire reef. On larger reefs, I may see an effect of increasing habitat complexity on the survival of late arriving individuals if they are able to avoid contact with aggressive competitors, thereby avoiding exclusion from refuge habitat. Third, larval fish typically undergo rapid morphological and behavioral changes after settlement. Here, I simulated settlement using individuals that were approximately two weeks postsettlement. Consequently, the ecological divergence between the fish used in this study is likely to be far less than the ecological divergence between fish that are actually 0- and 5-days post-settlement. Therefore, although 
this study explores the general concept of how priority effects and habitat complexity interact, the specific relevance to this species and system is limited.

This is one of the first studies to examine the concurrent influence of habitat complexity and the timing of arrival on interaction strengths. My results suggest that the contexts within which interactions occur are important determinants of the strength of intraspecific competition. Studies encompassing multiple sources of variation are becoming increasingly imperative in the face of large-scale environmental disturbances that simultaneously impact multiple ecological processes. Indeed, simultaneous threats from global climate change, which has already caused shifts in the breeding phenology of many species (Both et al., 2009; Durant et al., 2007; Hughes, 2000; Parmesan and Yohe, 2003; Visser and Both, 2005; Walther et al., 2002) and habitat declines (Barel et al., 1985; Bellwood et al., 2004; Gardner et al., 2003; Silliman et al., 2005; Skole and Tucker, 1993), suggest the importance of understanding how habitat complexity and priority effects may interact could advance models predicting the responses of demographically open populations to global climate change. 
112 CHAPTER 5. PRIORITY EFFECTS AND HABITAT COMPLEXITY 
Chapter 6

General Discussion 
This investigation into the roles intracohort priority effects and habitat complexity play during settlement advances our understanding of the processes contributing towards the successful recruitment of coral reef fishes in open populations. Specifically, this study makes four contributions to reef fish ecology: (1) Chapter 2 describes a newly devised technique for combining different data types within a unified multivariate analysis of niche overlap, and the use of permutation tests to identify species pairs that occupy either similar or dissimilar niches; (2) Chapter 3 adds to a growing body of literature that suggests post-settlement mortality of reef fishes may be due to complex interactions between habitat preferences, habitat complexity, competition and predation pressure; (3) Chapter 4 expands upon Chapter 3 by suggesting that intracohort priority effects, driven by differences in the sequence and timing of arrival, can add considerable variation to the strength of interactions between reef fish settlers, and consequently post-settlement mortality; and (4) the examination of the effects habitat complexity and priority effects have on the post-settlement survival of reef fishes in Chapter 5 suggests that it is important to consider the context within which competitive interactions occur, and that in the case of competitive interactions between reef fish settlers, context should include the availability of complex habitat, the timing of competitive interactions and background predation pressure.

In this chapter, I will discuss the links between the empirical studies examining the effects of habitat complexity, interspecific competition and intracohort priority effects on recruitment success presented in Chapters 3-5.

\subsubsection{Interspecific Competition and Habitat Complexity}

Although there is some evidence that competition for preferred habitats can influence species distributions, the degree to which habitat complexity affects the outcome of competition is largely unknown. Increasing 
habitat complexity is typically expected to mitigate the negative effects of competition for predator free space, or reverse competitive dominance relationships. Ebersole (1985) found that on structurally complex habitat Eupomacentrus planiforms was dominant and could exclude E. leucosticus, but on less complex habitat competitive dominance was reversed. Whether increasing habitat complexity resulting in reversals of competitive dominance, or the easing the negative effects of competition is a general phenomenon is yet to be determined. The few studies that have examined the influence of habitat on the intensity and outcome of competitive interactions in coral reef fishes (Ebersole, 1985; Beukers and Jones, 1997; Almany, 2004a; Almany, 2004b; Bonin et al., 2009) have provided limited evidence that increasing habitat complexity mitigates the negative effects of interspecific competition. My research is concordant with this. I found that although both habitat complexity and interspecific competition did affect the post-settlement survival of Thalassoma hardwicke, their effects were not interactive. This research adds to a growing body of evidence that suggests, all else being equal, post-settlement mortality of recently settled reef fishes may be explained by a complex relationship between habitat preferences, competition and predation pressure. For example, species with similar habitat requirements may be attracted to communities where those habitat requirements are met. However, when habitat limitation occurs, individuals with similar habitat requirements may be more likely to engage in competitive interactions for limiting habitat, with competition increasing the exposure of subordinates to predators. Further, the extent to which competition will increase predation mortality may depend upon the structural complexity of the habitat within which competitive interactions occur, with increasing structural complexity either facilitating or inhibiting predators. 


\subsubsection{Intracohort Priority Effects}

In this thesis, I define intracohort priority effects as occurring within the same settlement season. My results suggest that the outcome of competition was primarily related to relative arrival time, and poorly explained by the identity of prior residents. Reversals in sequence of arrival reversed the direction of competition (Chapter 4), and late arriving fish did poorer than fishes arriving simultaneously with their competitors, or before their competitors (Chapters $4 \& 5$ ). Further, I found evidence for both asymmetric and symmetric competitive interactions between $T$. hardwicke and T. quinquevittatum. When T. hardwicke and T. quinquevittatum arrived on a reef simultaneously, T. quinquevittatum was competitively dominant (an asymmetric competitive effect; Chapter 4); however, when each species arrived at different times, reversals in the sequence of arrival reversed the competitive advantage, with the species arriving first competitively dominant (a symmetric competitive effect; Chapter 4).

The majority of short-term studies of interspecific competition between reef fish have found competitive ability to be highly asymmetric (Hixon, 1980; Larson, 1980; Robertson and Gaines, 1986; Schmitt and Holbrook, 1986; Holbrook and Schmitt, 1989); although see Schmitt and Holbrook (1990) and Munday (2004). The identification of symmetric competitive effects between reef fish settlers in this study, driven by sequence of arrival is consistent with the lottery model (Sale, 1976b; Sale, 1978). The lottery model proposes that competing species coexist through demographic mechanisms, without the need for resource partitioning. Essentially, coexistence of species with similar patterns of resource use is mediated by chance recolonization of vacant space rather than by mechanisms such as resource partitioning, provided there are temporal or spatial fluctuations in the relative abundance of recruits available to occupy vacant habitats (Chesson and Warner, 1981). The lottery model assumes that space is a limiting resource, the first-available recruit recolonises vacant space, and that once recolonised, there is no displacement (i.e., there is a strong 
priority effect). Coexistence is favoured if settlement is higher for one species at some times or places, and higher for the other species at other times or places (Munday, 2004).

Intracohort priority effects may be best viewed in terms of the mode and spread of settlement pulses within a settlement season. That is, high numbers of settlers are required for competition to be invoked (mode) (Levine, 1976), while timing effects rely on the spread of single settlement pulses (narrow $=$ all at once, wide $=$ through time), or bimodality during an entire settlement season resulting from multiple, sequential settlement events. Knowing something about the shape of settlement pulses allows the formulation of when intracohort priority effects are likely to affect recruitment success. When settlement pulses are small (i.e., have a low mode), intracohort priority effects may have limited or no influence on recruitment success (relative to other sources of variation) because individuals settling within the same pulse will have limited contact with one another due to low densities. When the spread of settlement pulses is wide, intracohort priority effects may be greater relative to settlement pulses with narrower spreads because size or experience advantages conferred upon early arriving individuals are large. Similarly, individuals arriving in sequential settlement pulses may have large negative impacts on one another. Variations in the mode and spread of settlement pulses, and interactions between individuals in sequential settlement pulses, add further levels of complexity to intracohort priority effects.

Individuals entering a community early often retain size or experience advantages over later arriving individuals. Larger, more experienced individuals that compete with smaller, less experienced individuals for shared resources are often competitively dominant, inhibiting the performance of subordinates via reductions in growth (Jones, 1987a) or survival (Wilson, 2005). However, as arrival times continue to diverge, profound ontogenetic shifts may decrease similarity in resource requirements between increasingly larger individuals and new settlers. For example, when $T$. 
hardwicke and T. quinquevittatum first settle to a reef they display strong associations with Pocillopora and Turbinaria (probable refuge habitats; Chapter 3) while they develop juvenile pigmentation. As these species increase in age and size, they become less dependent upon Pocillopora and Turbinaria as refuges, and increasingly associate with other habitat types. As resource requirements of prior residents change, competition with new settlers may become less intense. Ontogenetic shifts therefore define the point at which space becomes available for a new settler. As a result, the magnitude of competitive effects may initially increase as arrival times between competitors diverge, before weakening as early arriving individuals undergo ontogenetic shifts. In 2007, I ran a pilot field experiment that showed limited support for this ( $n=3$ for each treatment). T. quinquevittatum settlers (11.6 mm SL $\pm 0.764 S E$ ) survived better on reefs occupied by either small $(10.8 \mathrm{~mm}$ SL $\pm 0.086 \mathrm{SE})$ or large $T$. hardwicke residents $(24.1 \mathrm{~mm} \mathrm{SL} \pm 0.426 \mathrm{SE}$ ) relative to reefs with intermediate sized T. hardwicke residents (16.0 $\mathrm{mm}$ SL \pm 0.211 SE). Observations of high levels of aggression towards new settlers by medium sized prior residents, compared to relatively low levels of aggression displayed by either smaller or larger individuals during this pilot study provides additional anecdotal evidence of a Gaussian relationship between timing of arrival and the intensity of competition. This suggests that the optimal strategy for an individual to avoid strong intracohort priority effects is to either: (1) enter the community simultaneously as or before other settlers; or (2) enter the community late enough that other settlers have undergone ontogenetic shifts and no longer pose a competitive threat.

Traditionally, the view has been that intercohort priority effects weaken the influence of stochastic larval supply and add a degree of determinism to community structure. For example, the identity of new recruits may become predictably stable when residents facilitate the settlement of their own species while excluding others (Shulman et al., 1983), successional when residents replace each other in a transitive order (Shulman et al., 
1983), and cyclical if multi-species priority effects are nontransitive (Buss and Jackson, 1979). However, the existence of intracohort priority effects suggests that an unpredictable order of juvenile settlement may determine the identity of new recruits, reintroducing a stochastic element back into the identity of successful recruits.

Areas of research that this thesis opens up regarding the intensity of intracohort priority effects are: (1) the determination of what constitutes a significantly large difference in arrival time as to result in strong competitive effects; (2) whether ontogenetic shifts experienced by early arriving individuals alleviate the intensity of intracohort priority effects; and (3) the extent to which these results are broadly significant beyond the two Thalassoma species examined here?

\subsubsection{The Relationship Between Intracohort Priority Ef- fects and Habitat Complexity}

Having identified that the timing of arrival can add considerable variation to the magnitude and direction of interaction strengths, I examined how timing of arrival interacts with habitat complexity. Increasing habitat complexity increased the survival of $T$. quinquevittatum settlers when they arrived either before, or at the same time as their competitors; however, increasing habitat complexity had no affect on survival when $T$. quinquevittatum arrived after its competitor (Chapter 5). Results from the aggression analysis indicated that this may be because increasing habitat complexity did not weaken the intensity of aggression. Almany (2004b) identified similar responses, whereby fish settlers suffered high mortality immediately after settlement in the presence of residents (predatory basses and eels, and competitive damselfishes) regardless of habitat complexity; however, Almany (2004b) cited the lack of behavioral or physical capabilities during early post-settlement growth as a possible explanation for why increasing habitat complexity did not alleviate predation mortality. 
The degree with which habitat complexity interacts with timing of arrival effects to influence predation mortality of recently settled reef fishes may therefore depend upon the behavioral attributes of the individuals engaged in the interactions (including the amount of aggression displayed by prior residents, and the responses of late arriving individuals, which may be affected by experience or ability), and background predation pressure. Specifically, it appears that when multiple settlers colonize a reef, their timing of arrival relative to one another will influence the intensity of aggression displayed during competitive interactions. When individuals arrive at similar times, aggression is weak, subordinates are not displaced from complex habitat and increasing habitat complexity increases survival by disrupting predation pressure. Alternatively, when individuals arrive at different times, aggression is intense and competitive subordinates are displaced from complex habitat, increasing their exposure to predation. The complicated interplay between the benefits of habitat complexity, the timing of settler arrival, the intensity of aggression and background predation pressure begs the question: To what extent will background predation pressure, reef size, gradients in habitat complexity and interactions between these processes affect the intensity of intracohort priority effects?

\subsubsection{Niche vs. Neutral Processes}

Niche theory predicts that niche differences can cause species to limit their own populations more than they limit others, promoting coexistence (Chesson, 2000); however, despite the evidence for niche differences (reviewed in Rees et al., 2001; Wright, 2002), few studies have demonstrated the importance of niche differences in maintaining coexistence (Silvertown, 2004). Neutral theory (Hubbell, 2001), a competing explanation for the maintenance of coexistence, directly challenges the niche paradigm by proposing that species similarities, not differences, maintain 
coexistence. Neutral models are built on the assumption that all species are identical in their fitness and in their effects on one another. Niche mechanisms play no role in neutral models, with the only drivers of population dynamics random variation in births, deaths, and dispersal. An alternative rationalization is that both niche and neutral processes operate simultaneously (Hubbell, 2001; Gravel et al., 2006), although determining the relative importance of each has not yet been formalized.

Reef fish communities are generally composed of a small number of subsets of coexisting species (guild: sensuRoot, 1967) whose members often have a high degree of similarity in resource use (Sale, 1976b; Sale, 1977). Generalized resource requirements of individuals within these speciose groups suggest that niche mechanisms are probably relatively unimportant in maintaining coexistence, although the relative roles of niche vs. neutral processes in organizing reef fish communities continues to be debated.

This thesis contributes to the existing understanding of niche versus neutral processes by demonstrating that the co-occurrence of reef fishes with similar resource requirements can be maintained via variability in timing-of-arrival, a neutral process; however, a formal analysis incorporating the relative importance of niche versus neutral processes requires the replication of these experiments at the species level. Such an approach would examine the strength of timing-of-arrival affects for multiple species pairs that differ in the degree to which they overlap in niche space. The expected outcome from such a series of experiments would be that as niche overlap varies, so does the relative importance of niche and neutral processes. Neutral processes would be expected to be weakest when niche overlap is lowest because divergence in resource requirements between the two populations means each species limits its own population more than they do each other. 


\subsubsection{Contribution to the Current State-of-Knowledge}

In reef fish communities, most research has focused on the effects of established predators and territorial species on the recruitment success of later arriving individuals. For example, by factorially manipulating the presence and absence of resident predators and competitors, previous researchers have demonstrated that the recruitment success of newly arrived juveniles is strongly influenced by interactions with established predatory and competitor residents (Almany, 2003; Almany, 2004c; Shulman et al., 1983; Sweatman, 1985). While these types of studies provide an excellent demonstration of how the identity of prior residents can affect the recruitment success of later arrivals, they largely ignore how outcomes are influenced by either: (1) changes in the timing of arrival; or (2) reversals in the sequence of arrival. The ability of these types of studies to distinguish between priority effects versus competitive effects that are invariant with respect to prior residency is therefore limited. The experimental and observational components of this thesis expand the current understanding of prior residency effects in reef fish communities by demonstrating that variation in both sequence (who arrives first) and timing (by how much) of arrival can add considerable heterogeneity to the competitive environments experienced by recently settled reef fishes. These results have important implications for reef fish ecologists attempting to evaluate interaction strengths among species, suggesting that it is not only important to identify the direction and magnitude of interaction strengths, but also variability in the direction and magnitude of interaction strengths through time. 
Appendices 

Appendix A

Evaluating the Performance of

Visual Estimators 


\section{A.1 Introduction}

Ecologists often visually estimate the parameter(s) under investigation because, in the wider context of the study, more direct measures are considered too invasive. Visual estimators commonly belong to one of two classes: (1) Interval estimators, which attempt to estimate confidence intervals for a parameter or; (2) Point estimators, which attempt to estimate the exact value of a parameter. In the case of point estimators, the statistical concepts of precision, bias and accuracy are commonly used to evaluate performance. Precision (commonly referred to as variance or variability) refers to the absence of random error. Its magnitude is dependent on the estimated values and is completely independent of the actual value (see Figure A.1 and Thresher and Gunn, 1986). Precision varies due to error in the estimation procedure being used (Andrew 1987). Alternatively, bias is the difference between the estimated and the actual value of the parameter under investigation and results from either underor overestimation (Bainbridge 1985, Andrew 1987, Marriott 1990; see Figure A.1). Bias is commonly due to systematic error in estimating the parameter; therefore, increasing sampling effort does not reduce overall bias if all estimates are systematically biased away from the actual value (Marriott, 1990). Taken together, precision and bias define the accuracy of an estimator. The less precise and more biased an estimator is, the worse its overall ability to provide an accurate point estimation. Accuracy is therefore defined as the overall distance between estimated values and the actual value (Bainbridge, 1985; Andrew and Mapstone, 1987; Krebs, 1989). 

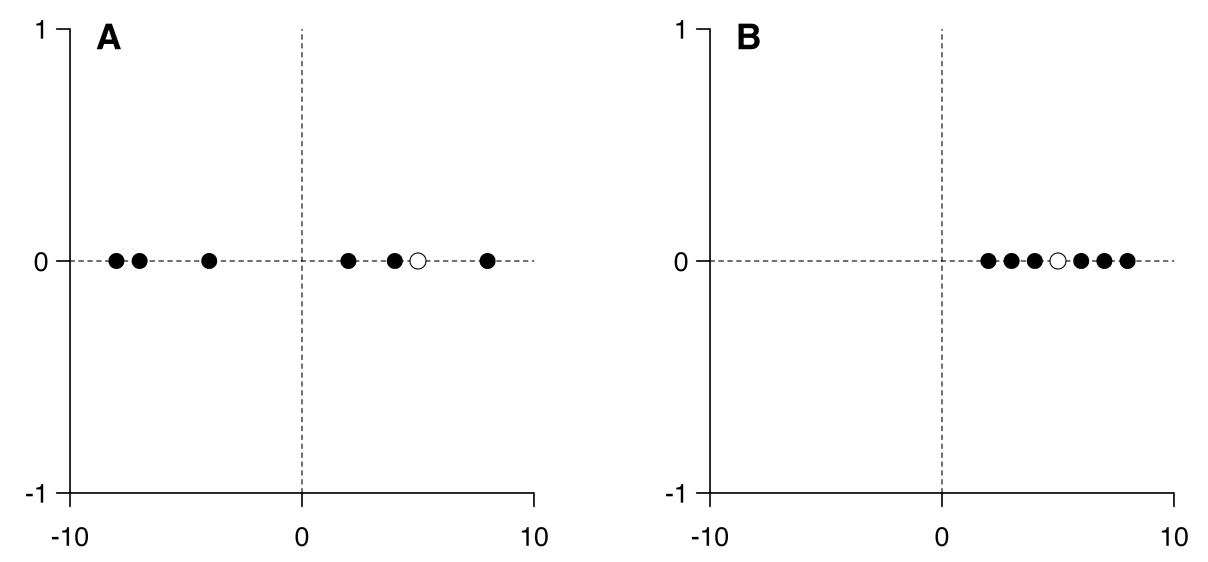

Figure A.1: Examples of: (A) low precision; and (B) systematic bias. In these examples the actual value is assumed to be 0 . An initial estimate (open circle) misses the actual value of 0 by five units. With just a single estimate it is impossible to attribute a source of the error. By obtaining further estimates (solid circles) we are able to hypothesise the cause of error. Panel (A) arises from low precision, panel (B) from systematic bias. Redrawn from (Walther and Moore, 2005)

Visual census has been an important tool for reef fish ecologists since Brock (1954) first proposed the use of visual transects to census reef fish populations. Visual census allows parameter estimation with relatively little expenditure of field time, and without the disadvantages inherent in the disturbance caused by mark-recapture, or destructive (e.g., ichthyocide) sampling procedures. Visual census is commonly used to estimate abundance (e.g., McCormick and Choat, 1987), size (e.g., Almany, 2004a), dispersal (e.g., Leis et al., 2002), recruitment (e.g., Shima, 2001a), mortality (e.g., Steele, 1997) and persistence (e.g., Shima and Osenberg, 2003). Here, using precision, bias and accuracy as measures of performance, I quantitatively evaluate the performance of visual estimation techniques that I have used throughout my research to determine: (1) habitat availability; (2) the standard length of juvenile reef fishes; and (3) the abundance of juvenile reef fishes. 


\section{A.2 Methods}

\section{A.2.1 Study Site}

Data for these analyses were collected in the northern lagoon of Moorea, French Polynesia $\left(17^{0} 30^{\prime} S, 149^{\circ} 50^{\prime} \mathrm{W}\right)$ between February 2005 and January 2006. For a site description, see Study Site in Chapter 3 of this thesis.

\section{A.2.2 Study Species}

For this study, I focused on: (1) 16 substrate categories (Porites massive; Porites rus; Montipora spp.; Pocillopora spp.; Acropora spp.; other live coral; Turbinaria ornata; Dictyota spp.; Halimedia spp.; Turf (a mixed filamentous red algal assemblage consisting predominately of Polysiphonia spp.); Sponge; Bare; Other; Coral sand; Coral rubble; and Pavement); and (2) eight species of co-occurring Labroids (Gomphosus varius, Halichoeres hortulanus, H. trimaculatus, Pseudocheilinus hexataenia, Scarus sordidus, Stethojulis bandanensis, Thalassoma hardwicke and T. quinquevittatum: for species descriptions, see section 3.3.1 in Chapter 3).

\section{A.2.3 Visual Estimation of Proportional Cover}

I evaluated the performance of visual estimates of proportional cover on 45 haphazardly selected patch reefs (hereafter reefs) of similar size (average surface area $=8.47 \mathrm{~m}^{2}, S E=0.50$; average height $=1.12 \mathrm{~m}, S E=$ $0.04)$. For each reef, I visually estimated proportional cover of 16 substrate categories (see A.2.2). I also recorded fixed point contact estimates of proportional cover by laying three evenly spaced (right side, middle, and left side) fibreglass transect tape measures over each reef parallel to the longest axis. Every $10 \mathrm{~cm}$ I recorded substrate categories. This procedure yielded a minimum of 50 fixed point contacts for every reef. Fixed 
point contact is a widely accepted method for characterizing proportional cover (Whitman and Siggeirsson, 1954; Floyd and Anderson, 1987; Meese and Tomich, 1992). Therefore I contrasted visual estimates of proportional cover against fixed point contact estimates to determine precision, bias and accuracy of visual estimates. I did this for each habitat category, and for all habitat categories pooled.

\section{A.2.4 Visual Estimation of Standard Length}

I evaluated the performance of visual estimates of standard length of 287 juvenile wrasses from eight species (see A.2.2). Immediately after visually estimating the standard length of an individual in-situ, that individual was collected using eugenol and handnets, euthanized with eugenol (as per Nickum et al., 2004) and preserved on ice until it was transported back to the laboratory. In the laboratory, I measured the standard length of each individual with vernier calipers. I contrasted visual estimates of standard length against caliper estimates to determine precision, bias and accuracy of visual estimates. I did this for each species, and for all species pooled.

\section{A.2.5 Visual Estimation of Fish Abundance}

I evaluated the performance of visual estimates of juvenile (defined as individuals $<30 \mathrm{~mm}$ standard length) T. hardwicke abundance on 62 reefs. After allowing fish to acclimate to my presence for approximately five minutes, I visually estimated abundance of T. hardwicke juveniles from a distance of two meters from the reef. I remained stationary or moved slowly while counting the most active and conspicuous individuals before moving closer, circling the reef and inspecting shelter sites and overhangs for more cryptic individuals. For each individual enumerated, I also recorded a visual estimate of standard length. Within two hours of the surveys, I collected all T. hardwicke recruits from these same reefs using 
handnets and eugenol. I preserved individuals on ice until they were transported back to the laboratory. In the laboratory, I measured the standard length of each individual with vernier calipers.

Following the assumption that all fish present on a given reef may not have been sampled by either technique alone (visual estimates or physical collections), but that any fish enumerated must have been present, the set of enumerations were combined to yield a single best estimate of T. hardwicke abundance on each reef during the census period. To combine the two datasets, individuals in each dataset were ranked by their standard length. Entries of the same rank and size $( \pm 2 \mathrm{~mm})$ between datasets were assumed to be a single individual. I took the number of individuals common to both datasets, plus the number of unique individuals in each dataset as being the actual abundance of T. hardwicke on a reef. Assuming that the combined measure is an accurate estimate of abundance, I determined the precision, bias and accuracy of visual and capture estimates by contrasting them against the combined estimate.

\section{A.2.6 Measuring Performance with Precision, Bias and Accuracy}

I calculated precision, bias and accuracy as the proportional difference between actual and estimated values. All analyses were conducted in the statistical package R (Team, 2008). I used the smatr package to conduct model II regressions (see below).

\section{Precision and Bias}

I calculated precision and bias using model II (standardized major axis) linear regressions, which allows for error in both the $x$ - and $y$-axes. I forced regressions through the origin as a base measure (Tiffin and Inouye, 2000; Brose et al., 2003). Using this technique, an estimator that exhibits perfect precision is characterized by data points falling directly on a straight regression line, producing an $R^{2}$ value of 1 .

A good estimator should be unbiased as well as precise. Typically, 
measures of bias take into account the difference between the estimated and the actual value of the parameter under investigation. Using a regression approach, all data points fall on a straight line with a slope of 1 for an unbiased and perfectly precise estimator. Bias is therefore calculated as the difference between the observed slope of the regression $\beta_{1}$, and the expected slope of 1 (i.e., bias $=1-\beta_{1}$ : Brose et al., 2003). Positive and negative bias indicate over- and under-estimation respectively (Brose et al., 2003); therefore, an even distribution of under- and overestimates leads to an overall bias of zero.

\section{Accuracy}

Accuracy incorporates both precision and bias. A good estimator should be accurate so that all estimates are as close to the actual value as possible. Like bias, accuracy examines the difference between the estimated and the actual value, but uses squared- or absolute values that eliminate directional information. Consequently, only the magnitude of the difference is evaluated. Commonly, accuracy is measured as mean square error (MSE) (e.g., Hellmann and Fowler, 1999; Foggo et al., 2003; Foggo et al., 2003) or the square root of the MSE (RMSE) (e.g., Casas et al., 2006; Davi et al., 2006; Maltamo et al., 2006); however, because both MSE and RMSE are calculated using squared differences, they tend to be dominated by outlying estimates far away from the actual value (Walther and Moore, 2005). This can be avoided by using Mean Absolute Error (MAE: the mean of the absolute difference between the observed and actual values; see Walther and Moore, 2005), calculated as:

$$
1-M A E=1-\left(\frac{1}{n} \sum_{j=1}^{n}\left|E_{j}-A\right|\right)
$$

where $E_{j}$ is the estimated value for the $j^{\text {th }}$ sample, $A$ is the actual value 
of the parameter being estimated and $n$ is the number of samples. The resulting value indicates how close the estimator is to the actual value. Highly accurate estimates approach a value of 1 . High precision and little bias lead to high accuracy. Alternatively inaccuracy may be due to low precision and / or large bias.

\section{A.3 Results}

\section{A.3.1 Visual Estimation of Proportional Cover}

Of the 16 habitat categories examined, regression analyses were restricted to the 11 habitat categories that were enumerated on three or more reefs in both datasets (Porites massive; Porites rus; Montipora spp.; Pocillopora spp.; Turbinaria spp.; Dictyota spp.; Turf; Bare; Coral sand; Coral rubble; and Pavement). The maximum number of estimates was 36 for Bare and Porites massive, the minimum was seven for Dictyota spp. (Table A.1). Dictyota, Montipora spp. and Pocillopora spp. never occupied more than ten percent of patch reef surface area (Table A.1).

Precision ranged between 0.23 (Dictyoya spp.) and 0.99 (Pavement) (Table A.1). Dictyota spp., Porites massive, Montipora spp., Pocillopora spp., and Turbinaria ornata all scored precision values of less than 0.8. With the exception of Porites massive, a large proportion $(>0.8)$ of enumerations for these species occupied less than ten percent of patch reef surface area (Table A.1).

Bias ranged between -0.38 (Dictyoya spp.) and 0.10 (Pavement) (Table A.1). Proportional cover of bare, Dictyoya spp., Porites massive, Porites rus, and Turbinaria ornata were all underestimated by visual estimates. Montipora, Pavement, Pocillopora spp., Coral Rubble, Sand and Turf (Table A.1) were all overestimated by visual estimates of proportional cover. Bias of visual estimates predicting proportional cover of Dictyota spp., Porites 
massive, Porites rus and Turbinaria ornata all exceeded \pm 0.1 .

Accuracy ranged between 0.44 (Bare) and 0.97 (Pavement) (Table A.1). Bare, Dictyota spp., Porites massive, Montipora spp., Pocillopora spp., Turbinaria ornata and Turf all scored accuracy values of less than 0.8 .

When all substrates were pooled, relative to proportional cover measured with FPC, visual estimates of proportional cover displayed high levels of precision (0.96), low positive bias (0.03) and high accuracy (0.95) (Table A.1; Figure A.2).

Table A.1: Performance of visual estimates of proportional cover contrasted against proportional cover measured with fixed point contact estimates. Precision $\left(R^{2}\right)$ and bias $\left(1-\beta_{1}\right)$ are calculated from model II linear regressions for 45 reefs. Accuracy is calculated as 1 - Mean Absolute Error. $n$ is the number of points in each regression; and $n<0.1$ is the number of fixed point contact estimates in each regression with proportional cover less than 0.1 .

\begin{tabular}{lccccc}
\hline Substrate & Precision & Bias & Accuracy & $n$ & $n<0.1$ \\
\hline Bare & 0.83 & -0.04 & 0.44 & 36 & 28 \\
Dictyota spp. & 0.23 & -0.38 & 0.71 & 7 & 7 \\
Porites massive & 0.69 & -0.13 & 0.64 & 36 & 6 \\
Montipora spp. & 0.61 & 0.07 & 0.68 & 12 & 12 \\
Pavement & 0.99 & 0.10 & 0.97 & 10 & 5 \\
Pocillopora spp. & 0.39 & 0.04 & 0.58 & 15 & 15 \\
Coral Rubble & 0.96 & 0.02 & 0.89 & 32 & 4 \\
Porites rus & 0.94 & -0.18 & 0.87 & 14 & 7 \\
Sand & 0.96 & 0.08 & 0.87 & 31 & 1 \\
Turbinaria ornata & 0.74 & -0.14 & 0.74 & 16 & 14 \\
Turf & 0.81 & 0.02 & 0.56 & 15 & 11 \\
\hline Pooled & 0.96 & 0.02 & 0.95 & 22 & 110 \\
\hline \hline
\end{tabular}




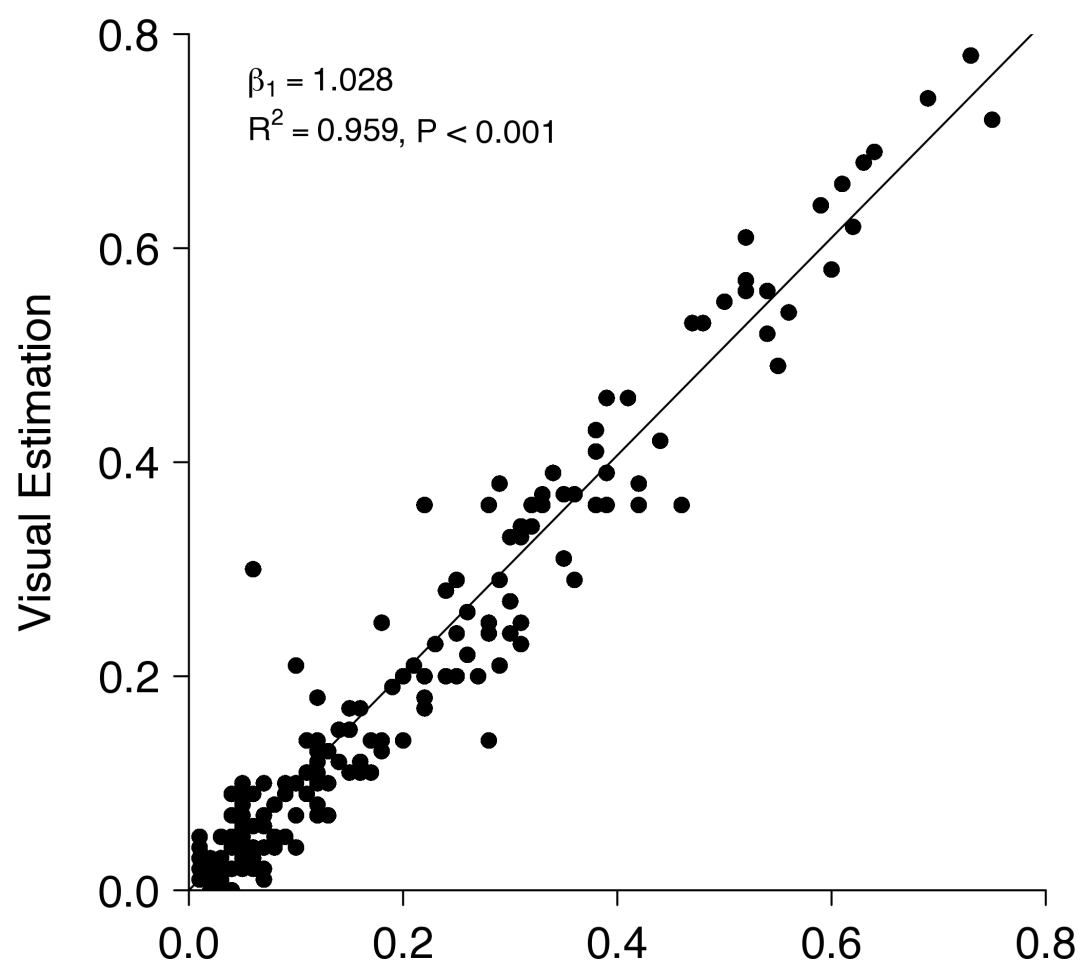

Fixed Point Contact

Figure A.2: Model II linear regression of fixed point contact against visual estimation of proportional habitat cover. The regression is forced through the origin as a base measure to calculate precision $\left(R^{2}\right)$ and bias $\left(1-\beta_{1}\right)$, and incorporates 224 data-points from 11 habitat categories (Porites massive; Porites rus; Montipora spp.; Pocillopora spp.; Turbinaria ornata; Dictyota spp.; Turf; Bare; Coral sand; Coral rubble; and Pavement). 


\section{A.3.2 Visual Estimation of Standard Length}

The maximum number of estimates was 164 for T. hardwicke, the minimum was six for P. hexataenia (Table A.2). Precision ranged between 0.67 ( $P$. hexataenia) and 0.97 (S. sordidus), with only P. hexataenia scoring a precision value of less than 0.8 (Table A.2).

Bias ranged between -0.02 (S. sordidus and T. quinquevittatum) and 0.02 (T. hardwicke). Visual estimates underestimated standard length for H. trimaculatus, S. sordidus, S. bandanensis and T. quinquevittatum, and overestimated standard length for G. varius, H. hortulanus, P. hexataenia and T. hardwicke.

Accuracy ranged between 0.88 (P. hexataenia) and 0.97 (S. sordidus), with only P. hexataenia having accuracy of less than 0.9 (Table A.2).

When all species were pooled, relative to standard length measured with calipers, visual estimation of standard length displayed high precision (0.95), low positive bias $(<0.00)$ and high accuracy (0.95) (Table A.2; Figure A.3).

Table A.2: Performance of visual estimation of standard length compared against standard length measured with calipers. Precision $\left(R^{2}\right)$ and bias $\left(1-\beta_{1}\right)$ are calculated from model II linear regressions forced through the origin. Accuracy is calculated as 1Mean Absolute Error; and $n$ is the number of points in each regression.

\begin{tabular}{lcccc}
\hline Species & Precision & Bias & Accuracy & $n$ \\
\hline Gomphosus varius & 0.86 & 0.01 & 0.93 & 18 \\
Halichoeres hortulanus & 0.89 & $<0.00$ & 0.93 & 7 \\
H. trimaculatus & 0.96 & -0.01 & 0.97 & 18 \\
Pseudocheilinus hexataenia & 0.67 & 0.01 & 0.88 & 6 \\
Scarus sordidus & 0.97 & -0.02 & 0.97 & 24 \\
Stethojulis bandanensis & 0.98 & -0.01 & 0.96 & 23 \\
Thalassoma hardwicke & 0.96 & 0.02 & 0.95 & 164 \\
T. quinquevittatum & 0.84 & -0.02 & 0.94 & 27 \\
\hline Pooled & 0.95 & $<0.00$ & 0.95 & 287 \\
\hline \hline
\end{tabular}




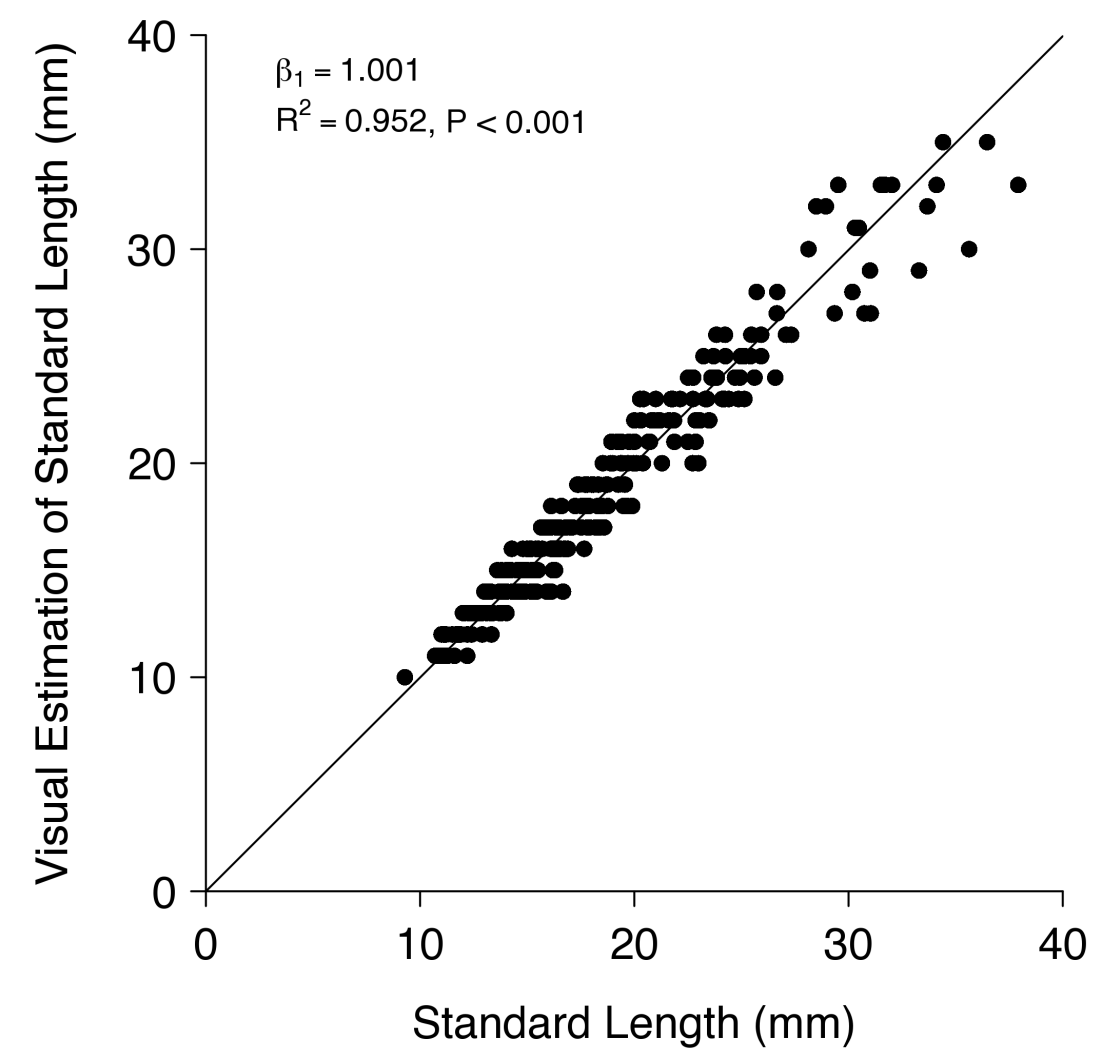

Figure A.3: Model II linear regression of visual estimation of standard length against standard length measured with calipers. The regression is forced through the origin as a base measure to calculate precision $\left(R^{2}\right)$ and bias $\left(1-\beta_{1}\right)$, and incorporates 287 datapoints from eight wrasse species (Gomphosus varius, Halichoeres hortulanus, H. trimaculatus, Pseudocheilinus hexataenia, Scarus sordidus, Stethojulis bandanensis, Thalassoma hardwicke and T. quinquevittatum). 


\section{A.3.3 Visual Estimation of Abundance}

On the 62 patch reefs surveyed, the abundance of T. hardwicke juveniles ranged between one and seven individuals. On average, visual and capture estimates sampled $88.8 \%( \pm 0.03 S E)$ and $87.4 \%( \pm 0.02 S E)$ of the best estimate of $T$. hardwicke abundance respectively.

Relative to the best estimate of abundance, both visual and capture estimates displayed high precision ( 0.87 and 0.88 respectively), low negative bias (-0.09 and -0.07 respectively) and high accuracy (0.89 and 0.87 respectively) (Table A.3; Figure A.4).

Table A.3: Performance of visual and capture estimates of Thalassoma hardwicke abundance against the best estimate of T. hardwicke abundance. Precision $\left(R^{2}\right)$ and Bias $\left(1-\beta_{1}\right)$ are calculated from model II linear regressions forced through the origin. Accuracy is calculated as 1- Mean Absolute Error; and $n$ is the number of points in each regression.

\begin{tabular}{lcccc}
\hline Sampling & Precision & Bias & Accuracy & $n$ \\
\hline Visual Estimation & 0.87 & -0.09 & 0.89 & 62 \\
Capture Estimation & 0.88 & -0.07 & 0.87 & 62 \\
\hline \hline
\end{tabular}

\section{A.4 Discussion}

\section{A.4.1 Visual Estimation of Proportional Cover}

Fixed point contact and visual estimates of proportional cover both incorporate estimation error which may not be present in more direct, quantitative procedures (e.g., image digitizing). Therefore, it seems most appropriate to: (1) evaluate the correlation between fixed point contact and visual estimates of proportional cover to determine the 

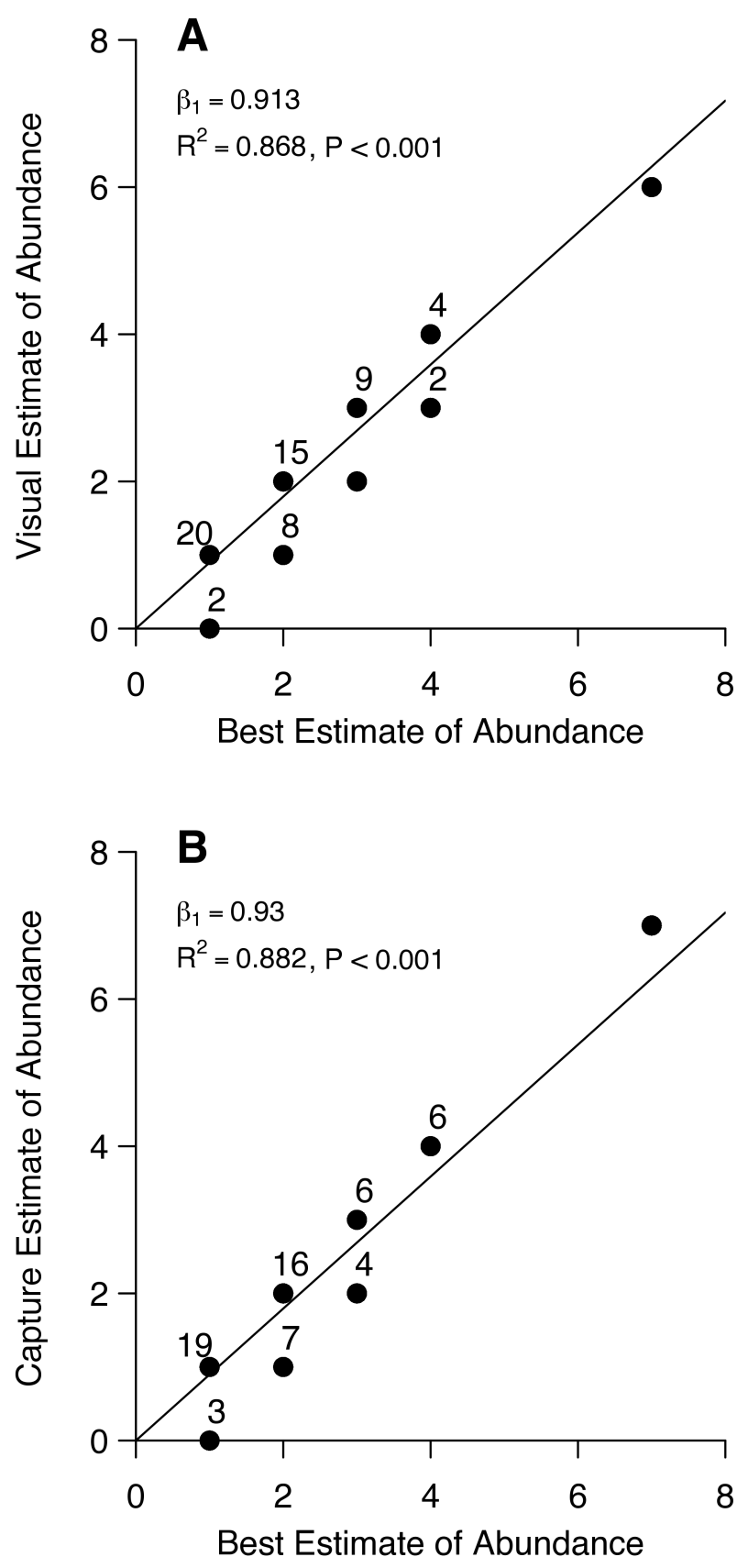

Figure A.4: Model II linear regressions of the best estimate of Thalassoma hardwicke abundance against: (A) visual estimation of abundance; and (B) capture estimation of abundance. Regressions are forced through the origin as a base measure to calculate precision $\left(R^{2}\right)$ and bias $\left(1-\beta_{1}\right) . n=62$ for each regression. Numbers indicate the number of overlapping data-points. 
appropriateness of substituting one for the other; and (2) evaluate the performance of visual estimates using high precision, or repeatability.

Precision was 0.95 when habitat categories were pooled. Keast and Harker (1977) suggest 0.9 as an ideal threshold for repeatability as a measure of performance in ecological studies. However, when each habitat was analyzed separately, only four of the 11 habitat categories met this threshold. Precision was less than 0.75 for Dictyota spp., Porites massive, Montipora spp., Pocillopora spp., and Turbinaria ornata. All of these species (with the exception of Porites massive) can be considered locally rare (constituting $<10 \%$ of substrate) on a large proportion ( $>$ 0.8) of reefs upon which they occurred. Previous researchers (Meese and Tomich, 1992; Miller and Ambrose, 2000) suggest that when habitat cover is proportionally low, fixed point contact is deficient in providing accurate estimations of proportional cover. Therefore, differences in the ability of fixed point contact and visual estimates to capture locally rare habitat may explain the low precision observed for those habitat categories.

In addition to local abundance, the performance of visual estimates of proportional cover may also be affected by: rugosity (highly rugose habitats may be harder to estimate than habitats with low rugosity); rigidity (structures with greater rigidity may be easier to estimate than less rigid structures); and color (habitats with high visual contrast may be easier to estimate than habitats with low visual contrast).

Visual estimates of proportional cover are often favoured over other techniques in the field such as point contact, line-transects and digitizing due to practicality, and because costs associated with visual estimation are lower, in terms of both time and resources. In the present study, I found visual estimation techniques to be on the order of five times faster than point contact methods in estimating proportional habitat cover.

It seems reasonable to substitute fixed point contact estimates with visual estimates of proportional cover given that: (1) precision was greater than 0.8 for locally abundant habitat; (2) visual estimates may better 
capture rare habitat than fixed point contact estimates and; (3) visual estimates are a more practical method of capturing percent cover in the field.

\section{A.4.2 Visual Estimation of Standard Length}

Precision, bias and accuracy indicated that visual estimation of standard length was an effective method for estimating the standard length of juvenile wrasses. Similarly, Bell et al. (1985) and Harvey et al. (2001) found that with a short sequence of practice surveyors can reliably estimate the standard length of fishes underwater. Additionally, Edgar et al. (2004) found that the ability to accurately estimate standard length was independent of species. Taking the results in the present study, together with previous research, visual estimation appears to be a viable technique for determining the standard length of fishes.

The ability to visually estimate the standard length of a focal individual accurately may vary due to a number of factors including: mobility (faster swimming individuals may be more difficult to estimate than slower individuals); morphology (e.g., dorso-ventrally versus laterally compressed fishes); behaviour (schooling species may be harder to estimate than sit-and-wait predators); and the size of focal individuals (larger individuals may be easier to estimate than smaller individuals). Additionally, estimating the standard length of cryptic individuals may be more difficult than estimating the standard length of non-cryptic individuals.

In the present study, all of the study species were small slow swimming wrasses with fusiform bodies. Accuracy of visual estimates of standard length was lowest for $P$. hexataenia, a shy species which maintains tight associations with the protection of branching corals. The shy nature of $P$. hexataenia may have inhibited accurate estimates of standard length. Aside from the attributes of the study species, observer experience may 
also affect the accuracy of visual estimates.

\section{A.4.3 Visual Estimation of Abundance}

Although visual and capture estimates were similar in their ability to sample the abundance of T. hardwicke, they both underestimated abundance. The combination of visual and capture estimates is likely to be a better predictor of $T$. hardwicke abundance than the use of a single estimator (given either estimator may not sample the entire assemblage); however, sources of error are possible. This includes the double counting of individuals, error in the visual estimation of standard length (although see Table A.2 and Figure A.3), mortality of focal individuals between visual and capture sampling, and the immigration or migration of focal individuals onto or off reefs between visual and capture censuses'. When visual and capture estimates are combined to produce the best estimate of abundance, the new estimate will incorporate any error present in both the visual and capture datasets.

Eighty-five percent of individuals were common to both the visual and capture datasets. It is likely that each technique (visual and capture estimates) sampled slightly different portions of the fish assemblage. Visual estimation techniques may miss smaller cryptic individuals hidden within shelter sites, or may be limited in their ability to distinguish between individuals in groups. Conversely, capture surveys may miss larger, faster individuals that are able to avoid eugenol clouds and nets. Therefore, although both visual and capture censuses display high repeatability, they probably seldom (if ever) completely sample the entire fish assemblage present at a site.

Generally, differences among visual surveys affecting the detectability of fish may include: water clarity and habitat characteristics (Thresher and Gunn, 1986); the number and variety of target groups counted 
simultaneously (Lincoln-Smith, 1989); observer presence (Chapman et al., 1974); swimming speed (De Girolamo and Mazzoldi, 2001); the size of the area being surveyed (Sale and Sharp, 1983); and the survey methodology utilized (Thresher and Gunn, 1986; Samoilys and Carlos, 2000). There are also substantial differences among distinct taxonomic or functional groups of fishes. For example, large, conspicuous, non-schooling fishes tend to be easier to count than small, schooling, highly mobile, or cryptic fishes (Samoilys and Carlos, 2000). Accuracy of visual estimates of fish abundance are therefore likely to vary as a function of technique, habitat and the species being sampled.

I found no difference in the performance of visual and capture estimates of $T$. hardwicke abundance. It therefore seems reasonable to conclude that visual estimates of $T$. hardwicke abundance are a suitable substitution for capture estimates when non-destructive sampling of $T$. hardwicke abundance is required.

\section{A.4.4 Summary}

In conclusion, measures of estimator performance should be viewed as suggestive, not prescriptive. Each measure should be adopted to explore an estimator's properties, but not be seen as the ultimate judgement tool, given that there is a virtually infinite number of ways of defining estimator performance. Each of the estimators examined here demonstrated utility, although no single estimator was, or should be expected to be one hundred percent accurate. Rather than attempt to generate correction factors to estimate, for example abundance or standard length, it seems best to accept the census data for what they are, reasonably accurate records of the parameters being estimated. 
Appendix B

Geange and Stier (2009) Order of arrival affects competition in two reef fishes. Ecology 90(10)

2868-2878 


\title{
Order of arrival affects competition in two reef fishes
}

\author{
Shane W. Geange ${ }^{1,3}$ and Adrian C. Stier ${ }^{2}$ \\ ${ }^{1}$ School of Biological Sciences, P.O. Box 600, Victoria University, Wellington, New Zealand \\ ${ }^{2}$ Department of Zoology, University of Florida, Gainesville, Florida 32611-8525 USA
}

\begin{abstract}
Many communities experience repeated periods of colonization due to seasonally regenerating habitats or pulsed arrival of young-of-year. When an individual's persistence in a community depends upon the strength of competitive interactions, changes in the timing of arrival relative to the arrival of a competitor can modify competitive strength and, ultimately, establishment in the community. We investigated whether the strength of intracohort competitive interactions between recent settlers of the reef fishes Thalassoma hardwicke and T. quinquevittatum are dependent on the sequence and temporal separation of their arrival into communities. To achieve this, we manipulated the sequence and timing of arrival of each species onto experimental patch reefs by simulating settlement pulses and monitoring survival and aggressive interactions. Both species survived best in the absence of competitors, but when competitors were present, they did best when they arrived at the same time. Survival declined as each species entered the community progressively later than its competitor and as aggression by its competitor increased. Intraspecific effects of resident $T$. hardwicke were similar to interspecific effects. This study shows that the strength of competition depends not only on the identity of competitors, but also on the sequence and timing of their interactions, suggesting that when examining interaction strengths, it is important to identify temporal variability in the direction and magnitude of their effects. Furthermore, our findings provide empirical evidence for the importance of competitive lotteries in the maintenance of species diversity in demographically open marine systems.
\end{abstract}

Key words: community dynamics; competition; competitive lotteries; coral reef fish; intracohort competitive interactions; Moorea, French Polynesia; priority effect; recruitment; settlement; Thalassoma spp.

\section{INTRODUCTION}

Many communities undergo repeated periods of development due to regenerating resources or pulsed arrival of young-of-year (e.g., Gibbs and Grant 1987, Schauber et al. 2002). Because numerous species are highly fecund (e.g., many insects, plants, fishes, and marine invertebrates), with females producing thousands of offspring, individuals often enter communities in large pulses. Further, species often enter communities asynchronously due to interspecific differences in phenology, with the competitive pressures faced by early-arriving individuals differing markedly from latearriving individuals. In such instances, the degree to which one individual affects the success of another depends, in part, on both the sequence (who arrives first) and timing (by how much) of arrival of each individual into the community (i.e., "priority effects"). Priority effects may reflect interspecific differences in breeding phenology, which can be adaptive to, among other things, interspecific interactions. For example, competitive intensity may be less when a subordinate compet-

Manuscript received 3 April 2008; revised 18 November 2008; accepted 7 January 2009. Corresponding Editor: M. H. Carr.

${ }^{3}$ E-mail: Shane.Geange@vuw.ac.nz itor breeds before or simultaneously with a superior competitor. In such cases, priority effects simply refer to interspecific interactions whose outcomes depend on the relative or absolute timing of arrival, breeding, or activity of the interacting species (Lawler and Morin 1993).

There are at least two general types of priority effects: one in which per capita competitive effects are constant but long-term dynamics are dependent on initial conditions and the other in which timing of arrival alters the strength of per capita competitive effects. The Lotka-Volterra competition model exemplifies the first type. When each species suffers more from inter- than from intraspecific competition, the equilibrium outcome of competition is dependent upon initial conditions, with the species with a sufficiently large initial abundance having the advantage and excluding the other species. In this scenario, an early-arriving species can build up to sufficiently high numbers that it excludes the invasion of the other species. Reversals in sequence of arrival can reverse the competitive outcome.

In the other type, the strength of competition varies according to conditions under which competition is occurring, i.e., the per capita strength of competition is not constant. For example, if early arrival provides a competitive advantage due to differences in experience or size, then the competitive effect of the early-arriving 
species on the later-arriving species should increase as the arrival times diverge. In either case, knowledge of such temporal effects is critical to estimates and interpretation of realized interaction strengths of competitors in a community.

In this study, we are concerned with the second type of priority effect, how sequencing and timing of arrival change the strength of competition. The direction and magnitude of priority effects will depend on the underlying processes that give rise to the effect. For example, if initial size differences or the time available for resource preemption confers an advantage upon a competitor arriving in a community early, performance of late-arriving competitors should decline as they arrive progressively later than the early-arriving competitor (e.g., Lawler and Morin 1993). Alternatively, when species are of similar size, differences in arrival time can affect the duration of head-to-head competition, in which case performance of late-arriving competitors should increase as they arrive progressively later than the early-arriving competitor (Lawler and Morin 1993).

Intracohort priority effects, which we define here as occurring within the same settlement season, have previously been shown to affect community dynamics, having been documented in protist (Price and Morin 2004), zooplankton (Louette and Meester 2007), insect (Benke 1978, Shorrocks and Bingley 1994), and amphibian communities (Lawler and Morin 1993, Blaustein and Margali 1996, Dayton and Fitzgerald 2005). In marine systems, work on intracohort order of arrival has predominantly focused on sessile invertebrates (e.g., Sutherland and Karlson 1977). However, reef fish communities are also a good platform for testing the influence of (1) changes in the timing of arrival and (2) reversals in the sequence of arrival, because they conform to repeated periods of development driven by pulsed arrival of young-of-the-year.

The majority of reef fishes have two-phase life histories, consisting of a dispersive planktonic larval phase and benthic, reef-associated juvenile and adult phases. Given the dispersive nature of the planktonic larval phase, most reef fish communities are relatively open, relying on spatially and temporally unpredictable larval supply from external populations for colonizing juveniles. At high latitudes $\left(>10^{\circ} \mathrm{N} / \mathrm{S}\right)$, recruitment patterns are typically seasonal, producing strong cohorts (Doherty 1988, 1991, Srinivasan and Jones 2006). Conversely, at low latitudes, longer breeding seasons are usually associated with lower fecundities (Winemiller and Rose 1992), reducing the potential for strong cohorts. As individuals within a cohort make the transition from planktonic to benthic habitat, they encounter individuals that have settled in previous cohorts (i.e., established residents) and other recently settled individuals from the same cohort, with both intra- and intercohort interactions capable of determining the success of a newly arrived individual. To date, the majority of research examining priority effects in reef fishes has focused on intercohort effects of established residents on the success of later-arriving individuals (for examples, see Shulman et al. 1983, Sweatman 1985, Almany 2003, 2004, Munday 2004). These studies have demonstrated that the recruitment success of newly arrived juveniles is strongly influenced by interactions with established residents and for the most part have concluded that strong interaction strengths add a degree of determinism to future community structure when the influence of prior residents on later-arriving individuals is species specific.

A fundamental endeavor of ecologists is evaluating interaction strengths among species and the consequences for community structure and dynamics and how communities will respond to changes in the biotic environment. However, this type of information is only useful if we can identify the variability of interaction strengths across space and time. Here, we expand on previous research into the effects of established residents on new arrivals (i.e., intercohort effects) by examining the effect subtle differences in timing and order of arrival have on the recruitment success of individuals within the same cohort. Specifically, we examine intracohort priority effects between two competing reef fishes (Thalassoma hardwicke and T. quinquevittatum). Using experimental manipulations, we tested whether the strength of competitive interactions depends on the sequence and temporal separation of arrival of competing individuals. We predicted that: (1) when symmetrical intracohort priority effects occur (and not generic competitive effects), reversing the order of arrival should reverse the observed effects (i.e., effects should be a function of order of arrival and not species identity); and (2) when priority effects (rather than species effects) are most important, competitive effects should be weakest when competitors arrive simultaneously and increase in strength as temporal separation between competitor arrival increases.

\section{Methods \\ Study species}

The wrasses (labridae) Thalassoma hardwicke (see Plate 1) and T. quinquevittatum co-occur on reefs throughout the Indo-Pacific (Myers 1999). At tropical latitudes $\left(\sim 14^{\circ} \mathrm{S}\right), T$. hardwicke and T. quinquevittatum spawn year round (Craig 1998), with planktonic larval durations of $\sim 47$ and $\sim 56 \mathrm{~d}$, respectively (Victor 1986). Both species settle in pulses around the new moon in the austral summer, at a standard length (SL) of 9-11 mm (S. W. Geange, personal observation). At our study site in Moorea, French Polynesia, a single pulse of reef fish settlement can last up to 14 d (Dufour and Galzin 1993). We determined habitat association for individuals of $T$. hardwicke and T. quinquevittatum $<25 \mathrm{~mm}$ by calculating mean Manly's alpha values (Manly et al. 1972, Chesson 1978) for 13 habitat categories across 240 patch reefs (surface area $=7.98 \pm 3.79 \mathrm{~m}^{2}[$ mean $\pm \mathrm{SD}]$ ). Manly's alpha measures the proportion of fish at a given 
reef on a given habitat type, relative to the probability of the fish associating with that habitat type under conditions of random assortment. Thalassoma hardwicke and $T$. quinquevittatum were highly similar in habitat use, strongly associating with massive Porites corals, Pocillopora verrucosa, Porites rus, and the macroalgae Turbinaria ornata (Fig. 1). Both species also have similar diets, feeding predominantly on planktonic and benthic crustaceans (Randall 2005). Intra- and interspecific aggression, consisting of chases and fin bites, presumably for habitat, is common within and between these species (S. W. Geange, unpublished data). Given that settlement of T. hardwicke and T. quinquevittatum occurs in irregular pulses around the new moon, in which $T$. hardwicke and $T$. quinquevittatum settle asynchronously (S. W. Geange, personal observation), we hypothesize that competitive dominance between individuals within a cohort will be determined by order of arrival.

\section{Study site}

The study was conducted in the northern lagoon of Moorea, French Polynesia $\left(17^{\circ} 30^{\prime} \mathrm{S}, 149^{\circ} 50^{\prime} \mathrm{W}\right)$ between February and August 2007, using a grid of 28 livecoral patch reefs in water $2-4 \mathrm{~m}$ deep. Reefs were located within a sand-flat, separated from one another and nearby natural reefs by a minimum of $15 \mathrm{~m}$. We constructed reefs to minimize habitat variation by standardizing size, rugosity, and water depth. Each reef consisted of a base of live Porites lobata coral with an area of $2.25 \pm 0.57 \mathrm{~m}^{2}$ (mean $\pm \mathrm{SD}$ ) and a height of 0.60 $\pm 0.10 \mathrm{~m}$. We added two colonies of Pocillopora verrucosa, with an average area projected downward onto a 2-D surface of $0.191 \pm 0.057 \mathrm{~m}^{2}$, onto the upper surface of each reef using Z-spar epoxy (Kopcoat, Pittsburgh, Pennsylvania, USA). Reef quality for $T$. hardwicke increases as a function of Pocillopora cover (Osenberg et al. 2006, Shima et al. 2008). We removed all resident $T$. hardwicke and $T$. quinquevittatum and manipulated the absolute and relative abundances of other resident fish species via selective removals and additions, so that the relative abundance of all species was similar among the 28 reefs (see Appendices A and B for background community structure). We used the fish anaesthetic eugenol (clove oil) and hand nets to collect fish.

\section{Experimental design and execution}

To test for priority effects, we experimentally manipulated the sequence and timing of arrival of T. hardwicke and $T$. quinquevittatum onto reefs. We used recent settlers (13.8 $\pm 2.3 \mathrm{~mm}$ SL [mean $\pm \mathrm{SD}$ ]; approximately two weeks post-settlement) captured from reefs roughly $4 \mathrm{~km}$ from the study site. All captured fish were held in tanks with running seawater for 6-12 h, then individually tagged with different colors of visible implant elastomer (VIE; Northwest Marine Technology, Shaw Island, Washington, USA) forward of the caudal peduncle. Tags were readable through the skin of the fish by observers in the field, so it was not necessary to recapture individuals to determine their identity. The VIE tags do not have adverse effects on other fishes (Beukers et al. 1995, Imbert et al. 2007, Simon 2007) and have been used to tag fish as small as $8 \mathrm{~mm}$ (Frederick 1997), and a preliminary study we conducted showed no mortality of 12 tagged T. hardwicke and T. quiqnuevittatum held in aquaria for $48 \mathrm{~h}$. We therefore assumed that tagging and handling effects were small. After tagging, we returned fish to aerated aquaria for 6-12 h before measuring them to the nearest $0.1 \mathrm{~mm} \mathrm{SL}$ and deploying them in the field. We used newly collected and tagged fish in two experiments. Experiment 1 examined interspecific priority effects between $T$. hardwicke and $T$. quinquevittatum. Experiment 2 examined intraspecific priority effects within $T$. hardwicke.

Experiment 1: interspecific priority effects between $\mathrm{T}$. hardwicke and T. quinquevittatum.-We experimentally manipulated the sequence and timing of the arrival of $T$. hardwicke and T. quinquevittatum settlers; one portion of this experiment was designed to quantify effects of $T$. hardwicke (as the prior resident) on $T$. quinquevittatum (as the focal species); the other was designed to test the effects of T. quinquevittatum (as the prior resident) on $T$. hardwicke (as the focal species). For both cases, we simulated settlement pulses by introducing three fish of the focal species onto reefs where three tagged fish of the prior resident were either absent, had been introduced 12 $\mathrm{d}$ earlier than, $5 \mathrm{~d}$ earlier than, or simultaneously with (0 d) the focal species. Simulated settlement pulses of three fish are representative of natural settlement rates to reefs of the size used in this study. All fish were collected and tagged in the $24 \mathrm{~h}$ preceding their deployment in the field. We ran the experiment in two temporal blocks (1130 April and 2-21 May), randomly assigning treatments to reefs and fish to treatments, yielding eight replicates (four in each temporal block) for each of our seven treatments: (1) T. hardwicke without T. quinquevittatum; (2) T. hardwicke and T. quinquevittatum introduced simultaneously; (3) T. hardwicke with T. quinquevittatum introduced $5 \mathrm{~d}$ previously; (4) $T$. hardwicke with $T$. quinquevittatum introduced $12 \mathrm{~d}$ previously; (5) $T$. quinquevittatum without T. hardwicke; (6) T. quinquevittatum with $T$. hardwicke introduced $5 \mathrm{~d}$ previously; and (7) T. quinquevittatum with T. hardwicke introduced $12 \mathrm{~d}$ previously (Table 1). Note that treatment 2 served as the simultaneous arrival treatment for both species. For each experimental run, we size matched focal individuals and prior residents, so that all fish were the same size at the time they were added to reefs (see Appendix C). Size differences between prior residents and focal individuals were then a function of the length of prior residency (e.g., growth advantage conferred upon $12-\mathrm{d}$ prior residents relative to $0-\mathrm{d}$ prior residents was $12 \mathrm{~d}$ ). Fish on a given reef were not size matched, but sampled randomly from the pool of available sizes for that treatment. 


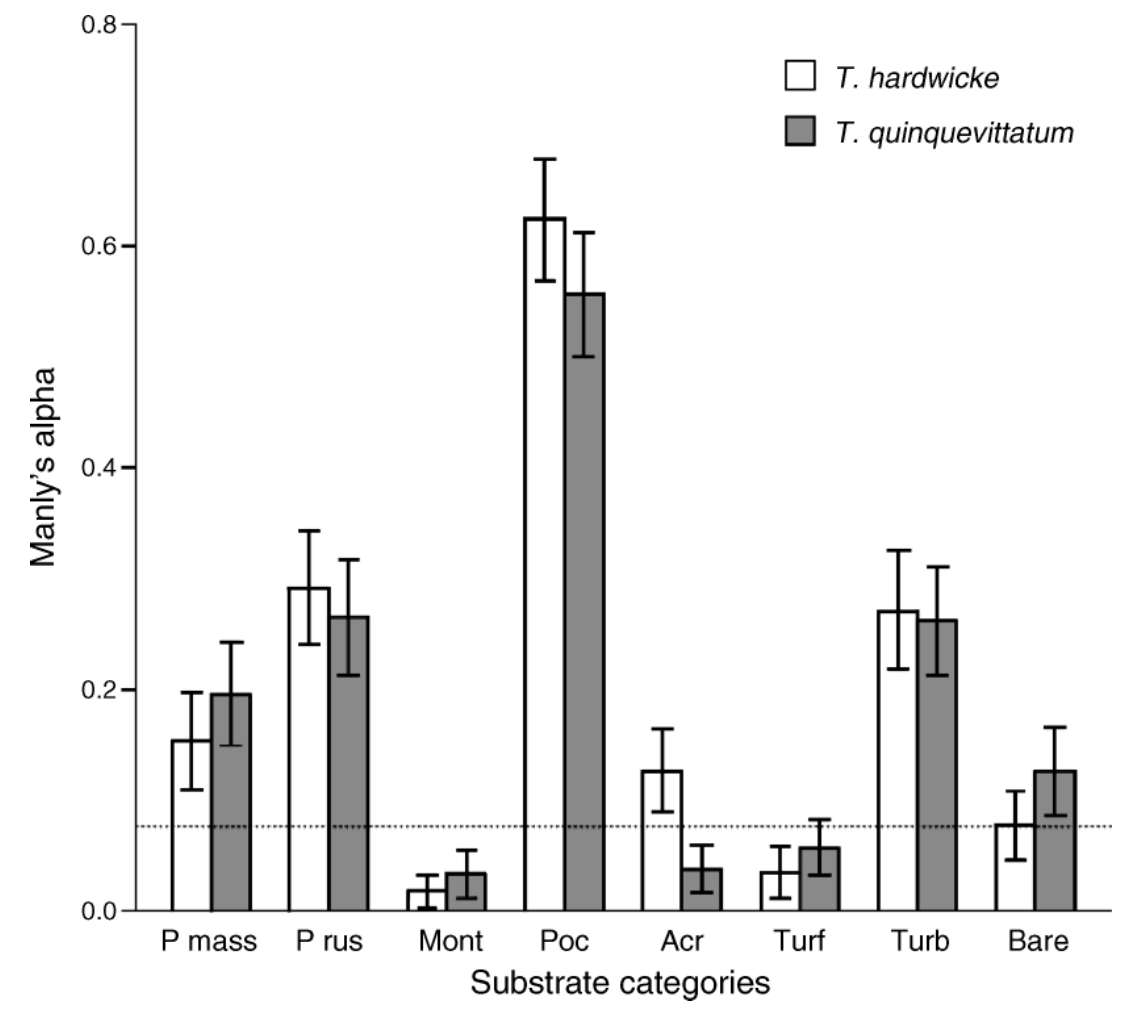

Fig. 1. Patterns of habitat association for the reef fishes Thalassoma hardwicke and T. quinquevittatum presented as Manly's alpha values (means with 95\% CI), which range from 0 (least associated) to 1 (most associated). The study was conducted on a coral reef off Moorea, French Polynesia. Results are presented for the eight (of 13) habitat categories with which fish associated. Abbreviations are: P mass, Porites massive; P rus, Porites rus; Mont, Montipora; Poc, Pocillopora spp.; Acr, Acropora spp.; Turf, a mixed filamentous red algal assemblage consisting predominately of Polysiphonia spp.; Turb, Turbinaria ornata; and Bare, reef substrate that did not comprise a significant biological component. Substrate categories that $T$. hardwicke and $T$. quinquevittatum did not associate with were other coral, Dictyota, Halimeda, and sponge. The broken line represents expectations of random habitat association; values with error bars crossing this line are not statistically different from this expectation; values with error bars above or below this line indicate over- or underuse (relative to availability), respectively.

Because recently settled fish often experience high rates of mortality (Almany and Webster 2006), we initially introduced six prior residents to reefs in the 12-d and 5-d treatments. Prior to introducing focal fish to these treatments, we haphazardly removed excess residents when there were more than three residents (18 instances out of 32 reefs) and pressed residents at the same time as focal individuals were added when there were less than three residents (six instances out of 32). Pressed residents were disproportionately distributed amongst treatments: T. hardwicke residents were pressed on four reefs (two individuals on two 12-d treatments, one individual on one 12-d treatment, and two individuals on one 5-d treatment) and T. quinquevitta-

TABLE 1. Summary of experiment 1 showing timing of neighbor introductions relative to focal introductions of reef fishes, where $\mathrm{H}$ represents Thalassoma hardwicke individuals and Q represents T. quinquevittatum individuals.

\begin{tabular}{|c|c|c|c|c|c|c|c|c|c|c|c|c|c|c|}
\hline \multirow[b]{2}{*}{ Timing } & \multicolumn{14}{|c|}{ Treatment } \\
\hline & & . & 2 & & 3 & & 4 & & & & & & & \\
\hline $12 \mathrm{~d}$ & $\ldots$ & $\ldots$ & $\ldots$ & $\ldots$ & $\ldots$ & $\ldots$ & $\mathrm{Q}(\mathrm{H})$ & $\ldots$ & $\ldots$ & $\ldots$ & & $\ldots$ & $\mathrm{H}$ & $\ldots$ \\
\hline $5 \mathrm{~d}$ & $\ldots$ & $\ldots$ & $\ldots$ & $\ldots$ & $\mathrm{Q}(\mathrm{H})$ & $\ldots$ & $\ldots$ & $\ldots$ & $\ldots$ & $\ldots$ & $\mathrm{H}$ & $\ldots$ & & $\ldots$ \\
\hline $0 \mathrm{~d}$ & $\ldots$ & H & Q (H) & H & $\ldots$ & H & & H & $\ldots$ & Q & $\ldots$ & Q & $\ldots$ & Q \\
\hline
\end{tabular}

Notes: Focal individuals for each treatment are in boldface. Each of our seven treatments were as follows: (1) T. hardwicke without T. quinquevittatum; (2) T. hardwicke and T. quinquevittatum introduced simultaneously (0 d); (3) T. hardwicke with T. quinquevittatum introduced $5 \mathrm{~d}$ previously; (4) T. hardwicke with $T$. quinquevittatum introduced $12 \mathrm{~d}$ previously; (5) $T$. quinquevittatum without $T$. hardwicke; (6) T. quinquevittatum with T. hardwicke introduced $5 \mathrm{~d}$ previously; and (7) $T$. quinquevittatum with $T$. hardwicke introduced $12 \mathrm{~d}$ previously. Note that treatment 2 served as the simultaneous arrival treatment for both species. Treatments 1-4 examine effects of prior $T$. quinquevittatum residency on $T$. hardwicke settlement. Treatments 2 and 5-7 examine effects of prior T. hardwicke residency on T. quinquevittatum settlement. Treatments 1-4 with "(H)" indicate experimental design for experiment 2 , where neighbor and focal individuals were both $T$. hardwicke. The study was conducted on a coral reef off Moorea, French Polynesia. 
tum were pressed on two reefs (two individuals each on one 12-d and one 5-d treatment). We used excess individuals removed from other experimental reefs to press residents.

We surveyed reefs twice daily (at approximately 08:00 and 16:00) for seven days after we introduced focal individuals. We also searched neighboring nonexperimental reefs for tagged immigrants. We found no immigrants or emigrants, and previous research has shown that small reef fish rarely move between reefs separated by as little as $15 \mathrm{~m}$ (Caselle 1999, Shima 2001). We therefore assumed that the disappearance of an experimental fish was due to mortality rather than migration.

Experiment 2: intraspecific priority effects between $\mathrm{T}$. hardwicke individuals.-We used a similar experimental design to examine intraspecific priority effects for $T$. hardwicke (i.e., T. hardwicke recruits served as both the focal and resident individuals; Table 1). Because the intraspecific design had four instead of seven treatments, all seven replicates of the four treatments were conducted together once (6-25 July). We removed excess residents from six of 14 reefs and added residents to three of 14 reefs (one 5-d treatment and two 12-d treatments) prior to adding focal individuals to reefs. All other aspects of experiment 2 were identical to experiment 1 .

\section{Behavioral observations}

To help elucidate the mechanisms driving priority effects we conducted 5-min behavioral observations at the time we added focal individuals to reefs. After allowing fish to acclimate to the observers' presence for -3 min, behavioral observations were conducted at a distance of $\sim 2 \mathrm{~m}$ from the reef. Observers remained stationary or moved slowly while conducting behavioral observations. This reduces the likelihood of "herding" or frightening fish onto or off reefs, or between substrates within reefs. We recorded three response variables: (1) the number of chases between focal individuals and both prior residents and the background community (in experiment $1,96 \%$ and $89 \%$ of chases were inflicted by prior residents upon T. hardwicke and T. quinquevittatum, respectively; in experiment $2,98 \%$ of chases were inflicted by prior residents); (2) the number of fin bites inflicted during chases (all fin bites were inflicted by prior residents on focal individuals in both experiments); and (3) the time spent inside Pocillopora by focal individuals.

\section{Data analysis}

Survival analysis.-We modeled time-to-disappearance for each treatment using Cox proportional hazard regression (Cox 1972, Cox and Oakes 1984). We modeled the underlying distribution of focal individual mortality against time of resident arrival. The probability distribution of mortality is specified as a hazard function, $h(t)$, the conditional or instantaneous mortality, expressed as a function of time, $t$ :

$$
h(t)=h_{0}(t) \exp \left(\beta_{1} x_{1}+\beta_{2} x_{2}+\cdots+\beta_{p} x_{p}\right)
$$

where $h_{0}(t)$ is the time-dependent baseline hazard function that is dependent upon a set of $p$ covariates $\left(x_{1}, x_{2}, \ldots, x_{p}\right)$, whose impact is measured by the size of the respective coefficients $\left(\beta_{1}, \beta_{2}, \ldots, \beta_{p}\right)$. The density of residents slowly decreased through time after we added focal individuals. For resident-present treatments, we controlled for decreasing resident densities through time by including density of residents as a time-dependent covariate in our model. For experiment 1 we also included a strata term in the model to account for experimental run, which is similar to effects of blocks in ANOVA (Therneau and Grambsch 2000). We rightcensored the data (i.e., analyzed data on minimal survival times), used the Efron approximation to handle tied data, used partial likelihood to derive regression coefficients $\left(\beta_{i}\right)$, converted these coefficients to a hazard ratio as $e^{\beta_{i}}$, and converted the hazard ratios into estimated percentage of changes in mortality rate (CMR) by subtracting 1 from the hazard ratio and multiplying by 100 . We conducted model reduction using ANOVA.

We determined whether the fitted Cox regression model adequately described the data using Schoenfeld residuals scaled by the Kaplan Meier estimate to test the assumption of proportional hazards, and df-beta values (the relative differences between the least squares and deleted estimates of the coefficients [Freund and Wilson 1998]) to test for influential data. Cox regressions were conducted using the survival package in R 2.5.1 ( $R$ Development Core Team 2007).

We ran three orthogonal survival analyses. (1) We tested competitive effects by contrasting survival of focal individuals between resident-absent and resident-present treatments (i.e., absent vs. $0 \mathrm{~d}, 5 \mathrm{~d}, 12 \mathrm{~d}$ ). (2) We tested the effects of arriving later than residents by contrasting survival of focal individuals with simultaneous vs. later arrival (i.e., 0 d vs. 5 d, 12 d). (3) We tested the effects of arriving progressively later than residents by contrasting survival of focal individuals arriving $5 \mathrm{~d}$ vs. $12 \mathrm{~d}$ later than residents.

Behavior analysis.-Because there were strong correlations among behavioral responses (e.g., fin bites only occurred during chases), we analyzed behavior data using principal components analysis (PCA) to create a composite aggression score. We transformed data $(\log [x$ $+1]$ ) prior to analysis to improve normality. We conducted separate analyses for each of the three substudies ( $T$. hardwicke with $T$. quinquevittatum, $T$. quinquevittatum with $T$. hardwicke, and $T$. hardwicke with $T$. hardwicke). Results were very similar for all three analyses. Principal components axis 1 (PCA 1) accounted for $63-68 \%$ of the total variation in aggression variables and was driven by high positive 
TABLE 2. Hazard ratios from the Cox proportional hazard assessment for: (A) interspecific competition between Thalassoma hardwicke and $T$. quinquevittatum and (B) intraspecific competition between $T$. hardwicke individuals.

\begin{tabular}{lccrrr}
\hline \hline \multicolumn{1}{c}{ Orthogonal contrast } & $\begin{array}{c}\text { Coefficient } \\
\left(b_{i}\right)\end{array}$ & $\begin{array}{c}\text { HR } \\
\left(\exp \left(b_{i}\right)\right)\end{array}$ & $\begin{array}{c}\text { CMR } \\
(\%)\end{array}$ & $95 \%$ CI & $P$ \\
\hline A) Interspecific effects & & & & & \\
T. hardwicke focal individuals & & & & & \\
$\quad$ Absent vs. (0 d, 5 d, 12 d) & 1.090 & 2.96 & 196 & $(1.61-5.45)$ & $<\mathbf{0 . 0 0 1}$ \\
0 d vs. (5 d, 12 d) & 0.506 & 1.66 & 66 & $(0.94-2.93)$ & 0.082 \\
5 d vs. 12 d & 0.173 & 1.19 & 19 & $(0.65-2.17)$ & 0.570 \\
T. quinquevittatum focal individuals & & & & & \\
Absent vs. (0 d, 5 d, 12 d) & 0.419 & 1.52 & 52 & $(0.83-2.80)$ & 0.180 \\
0 d vs. (5 d, 12 d) & 0.658 & 1.93 & 93 & $(1.02-3.64)$ & $\mathbf{0 . 0 4 2}$ \\
5 d vs. 12 d & -0.096 & 1.10 & 10 & $(0.48-1.72)$ & 0.770 \\
B) Intraspecific effects & & & & & \\
T. hardwicke focal individuals & & & & & \\
Absent vs. (0 d, 5 d, 12 d) & 0.844 & 2.33 & 133 & $(1.17-4.60)$ & $\mathbf{0 . 0 1 5}$ \\
0 d vs. (5 d, 12 d) & 0.330 & 1.39 & 39 & $(0.76-2.55)$ & 0.290 \\
5 d vs. 12 d & 0.496 & 1.64 & 64 & $(0.84-2.22)$ & 0.150 \\
\hline
\end{tabular}

Notes: For each focal species, we ran three orthogonal survival analyses: (1) competition (absent vs. $0 \mathrm{~d}$ and $5 \mathrm{~d}$ and $12 \mathrm{~d})$; (2) priority ( $0 \mathrm{~d}$ vs. $5 \mathrm{~d}$ and $12 \mathrm{~d})$; and (3) degree of priority $(5 \mathrm{~d}$ vs. $12 \mathrm{~d}$ ). See Table 1 for a description of the treaments. Abbreviations are: HR, hazard ratio; CMR, change in mortality rate; $\mathrm{CI}$, confidence interval.

loadings of total chases (64-68\%) and fin bites (63-68\%) and weak negative loadings of time-in-Pocillopora (31$44 \%$ ). Thus, we interpret this first PCA axis as a gradient of overall aggression. We analyzed PCA 1 scores with a one-way ANOVA, using a relaxed variance assumption (Dalgaard 2002). For significant ANOVAs $(P<0.05)$, we used Bonferroni-adjusted pairwise $t$ tests, with unequal variances, to compute all possible pairwise comparisons.

\section{RESUlTS}

\section{Interspecific priority effects}

Over the seven days that we monitored the survival of $T$. hardwicke focal individuals, percentage of survival was $46 \% \pm 8.76 \%$ (mean $\pm \mathrm{SE}), 21 \% \pm 8.76 \%, 13 \% \pm$ $6.12 \%$, and $8 \% \pm 5.44 \%$ for absent, $0-d, 5-d$, and $12-d$ treatments, respectively (Fig. 2a,b). Percentage of survival of $T$. quinquevittatum after seven days was $46 \% \pm 8.77 \%, 46 \% \pm 10.78 \%, 21 \% \pm 8.76 \%$, and $21 \% \pm$ $6.12 \%$, for absent, $0-\mathrm{d}, 5-\mathrm{d}$, and $12-\mathrm{d}$ treatments, respectively (Fig. 2c, d).

Analysis of competitive effects (absent vs. 0 d, 5 d, 12 d) indicated that the likelihood of mortality for $T$. hardwicke individuals entering reefs where T. quinquevittatum residents were present increased by $196 \%$, compared to reefs where T. quinquevittatum was absent $(P<0.001 ;$ Fig. 2a, b, Table 2). When arriving simultaneously, T. hardwicke had lower survival than T. quinquevittatum (proportional survival $0.208 \pm 0.059$ vs. $0.458 \pm 0.074$ for $T$. hardwicke and T. quinquevittatum, respectively). Mortality of $T$. hardwicke increased as $T$. quinquevittatum were given greater residence times, but these effects were not significant $(0 \mathrm{~d}$ vs. $5 \mathrm{~d}, 12 \mathrm{~d}, P$
$=0.082, \mathrm{CMR}=66 \% ; 5 \mathrm{~d}$ vs. $12 \mathrm{~d}, P=0.570, \mathrm{CMR}=$ 19\%; Fig. 2a, b; Table 2).

Survival of $T$. hardwicke decreased with increase in the PCA-derived composite aggression score (Fig. 2b). As $T$. hardwicke entered reefs progressively later than $T$. quinquevittatum, aggression from residents towards focal individuals increased $(P<0.001)$ and survival decreased $(P<0.001)$. Aggression was significantly higher on reefs on which $T$. quinquevittatum arrived either $5 \mathrm{~d}$ or $12 \mathrm{~d}$ prior to $T$. hardwicke relative to reefs on which $T$. quinquevittatum was absent (Fig. 2b). Likewise, aggression was significantly higher on reefs on which $T$. quinquevittatum arrived $12 \mathrm{~d}$ prior to $T$. hardwicke relative to reefs on which $T$. quinquevittatum arrived simultaneously (Fig. 2b).

When the sequence of arrival was reversed, there was not a significant competitive effect of $T$. hardwicke on $T$. quinquevittatum (absent vs. 0 d, 5 d, 12 d, $P=0.180$, $\mathrm{CMR}=52 \%$; Fig. 2c, d, Table 2). However, when $T$. quinquevittatum arrived on reefs later than T. hardwicke, mortality risk of $T$. quinquevittatum increased by $93 \%(0$ d vs. $12 \mathrm{~d}$ and $5 \mathrm{~d}, P=0.042$; Fig. $2 \mathrm{c}, \mathrm{d}$, Table 2). There was no demonstrable difference when $T$. hardwicke arrived $5 \mathrm{~d}$ vs. $12 \mathrm{~d}$ prior to arrival of $T$. quinquevittatum $(P=0.770, \mathrm{CMR}=10 \%$; Fig. 2c, d, Table 2).

Survival decreased with increase in the PCA-derived composite aggression score (Fig. 2d). As T. quinquevittatum entered reefs later than $T$. hardwicke, aggression from residents towards focal individuals increased $(P<$ $0.001)$ and survival decreased $(P=0.001)$. Aggression was significantly higher on reefs on which $T$. hardwicke arrived either $5 \mathrm{~d}$ or $12 \mathrm{~d}$ prior to $T$. quinquevittatum relative to reefs on which $T$. hardwicke were absent or arrived simultaneously with $T$. quinquevittatum (Fig. 2d). 
a) T. hardwicke response to $T$. quinquevittatum

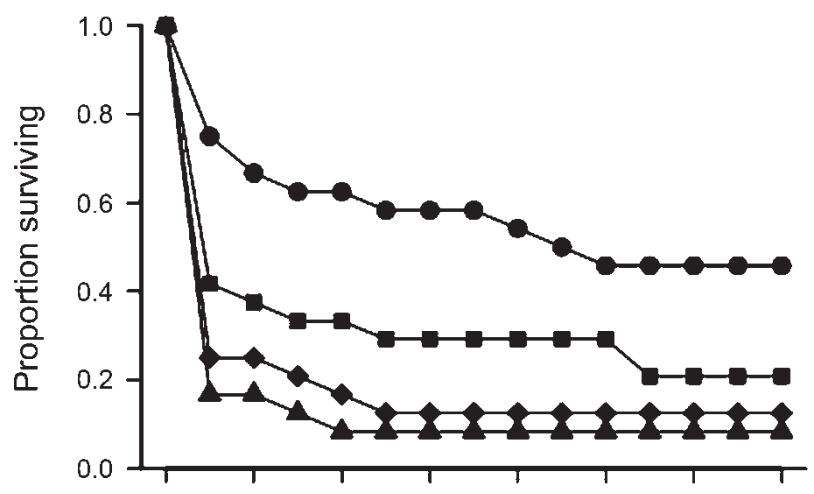

c) T. quinquevittatum response to T. hardwicke

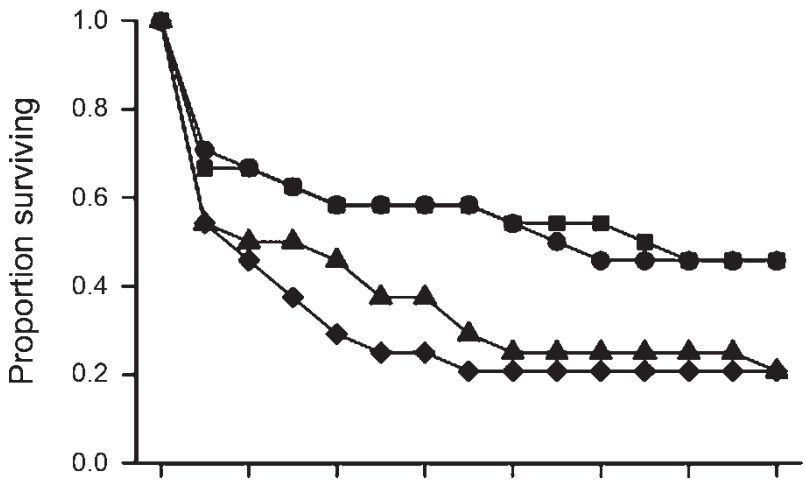

e) T. hardwicke response to T. hardwicke

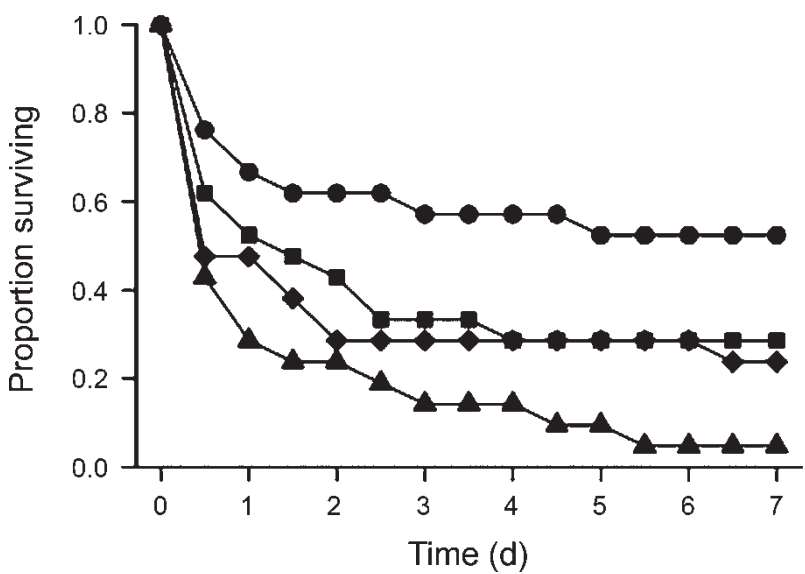

b) T. hardwicke response to T. quinquevittatum

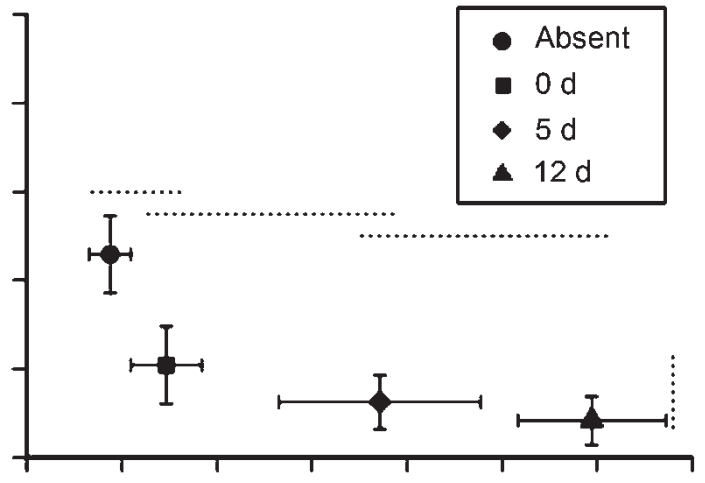

d) T. quinquevittatum response to T. hardwicke

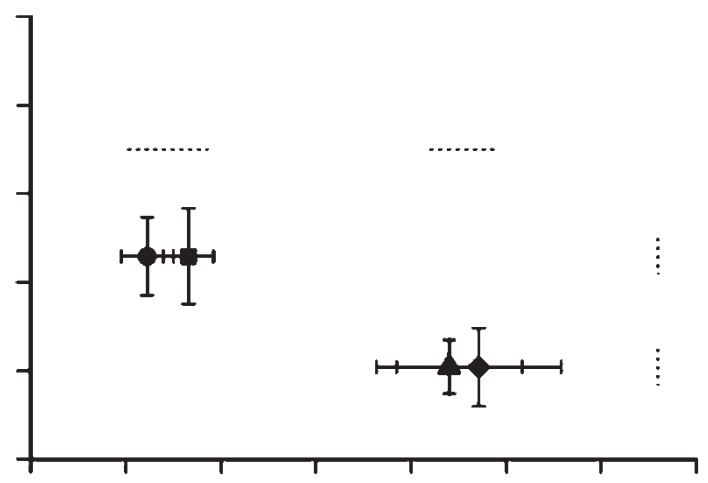

f) T. hardwicke response to T. hardwicke

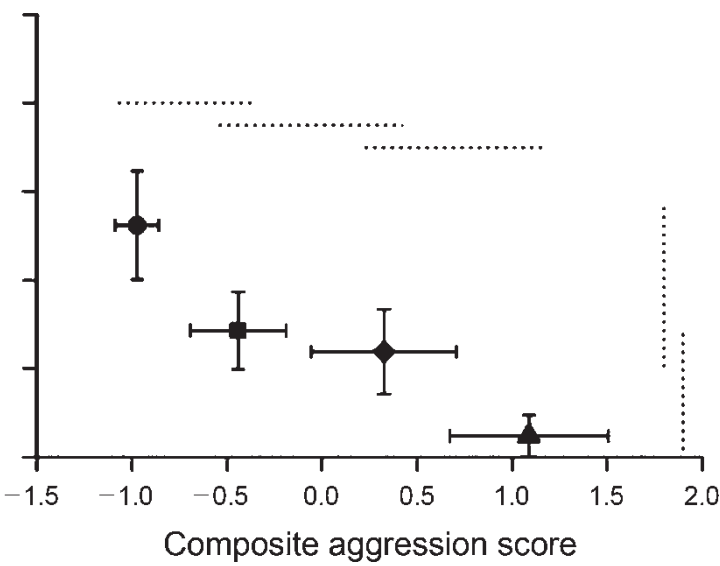

FIG. 2. Survival of focal individuals in response to presence, relative timing of arrival ( $0 \mathrm{~d}$ [the same time], $5 \mathrm{~d}$ prior, or $12 \mathrm{~d}$ prior), and relative aggression of a competitor. Temporal trends of survival are depicted for (a) Thalassoma hardwicke in response to T. quinquevittatum, (c) T. quinquevittatum in response to T. hardwicke, and (e) T. hardwicke intraspecific responses. Error bars of temporal trends are omitted for clarity. (b, d, f) Corresponding survival (proportion alive at the end of the experiment) in relation to composite aggression scores (modeling chases, fin bites, and time spent inside Pocillopora; see Methods: Behavioral observations; means $\pm \mathrm{SE}$ ). Broken lines overlap treatments that are not significantly different.

\section{Intraspecific priority effects}

Over the seven days that we monitored the survival of T. hardwicke, percentage of survival was $52 \% \pm 8.35 \%$ (mean $\pm \mathrm{SD}$ ), $29 \% \pm 5.91 \%, 24 \% \pm 6.47 \%$, and $5 \% \pm$ $3.23 \%$, for absent, $0-\mathrm{d}, 5-\mathrm{d}$, and $12-\mathrm{d}$ treatments, respectively (Fig. 2e, f). Risk of $T$. hardwicke mortality increased by $133 \%$ when conspecific residents were already present on reefs relative to conspecific-absent treatments (absent vs. 0 d, 5 d, 12 d, $P=0.015$; Fig. 2e, f, Table 2). Mortality of focal T. hardwicke increased as competing conspecifics were given greater residence times, but these effects were not significant: $(0 \mathrm{~d}$ vs. 5 


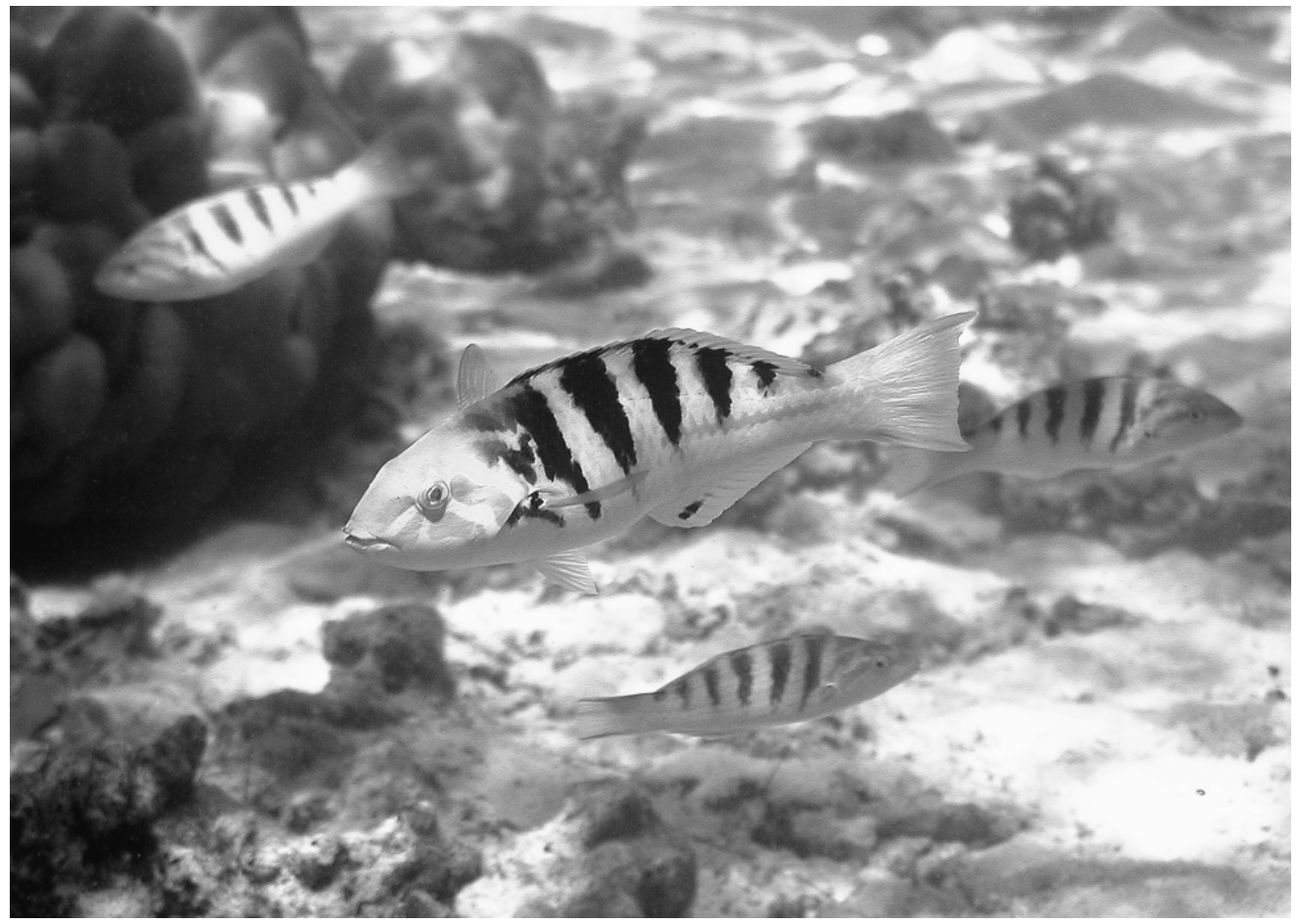

Plate 1. Adult sixbar wrasse (Thalassoma hardwicke) on the reef at Moorea, French Polynesia. Adult wrasse represent the product of intracohort competitive interactions between wrasse settlers. Photo credit: S. W. Geange.

d, $12 \mathrm{~d}, P=0.290, \mathrm{CMR}=39 \% ; 5 \mathrm{~d}$ vs. $12 \mathrm{~d}, P=0.150$, $\mathrm{CMR}=64 \%$; Fig. 2e, f; Table 2).

Survival decreased with increase in the PCA-derived composite aggression score (Fig. 2f). As T. hardwicke entered reefs progressively later than conspecifics, aggression from residents towards focal individuals increased $(P<0.001)$ and survival decreased $(P<$ 0.001). Aggression was significantly higher on reefs on which conspecifics arrived $12 \mathrm{~d}$ prior to T. hardwicke relative to reefs on which conspecifics were absent (Fig. 2f).

\section{DISCUSSION}

Formal analysis indicated strong inter- and intraspecific competitive effects, although strong support for priority effects only occurred in the response of $T$. quinquevittatum to the relative timing of arrival of $T$. hardwicke (Table 1, Fig. 2c). However, weaker priority effects are also evident for T. hardwicke (Fig. 2a, e). When both species arrived simultaneously, survival of $T$. quinquevittatum was similar to that when it arrived in communities devoid of $T$. hardwicke, whereas survival of $T$. hardwicke was lower than when it arrived in communities devoid of T. quinquevittatum. This suggests that when both species arrive simultaneously, $T$. quinquevittatum is competitively dominant over $T$. hardwicke.

Our findings suggest that variability in the timing of settlement pulses of $T$. hardwicke relative to $T$. quinquevittatum can have dramatic effects on recruit- ment strength and success of both species. When both species arrived simultaneously, T. quinquevittatum survived better than T. hardwicke, which is indicative of an asymmetric competitive interaction between these species. However, when each species arrived at different times, reversals in sequence of arrival reversed the competitive advantage, indicating that competitive interactions were at least partially driven by priority effects, producing more symmetric competitive effects. The majority of short-term studies of interspecific competition between reef fishes have typically found competitive ability to be highly asymmetric, often resulting in local exclusion and habitat displacement (Hixon 1980, Larson 1980, Robertson and Gaines 1986, Schmitt and Holbrook 1986, Holbrook and Schmitt 1989). However, these studies may not be representative of most competitive interactions as species pairs were selected in part because closely related species showed very different patterns of habitat use. While other studies have identified symmetric competitive interactions between reef fishes (Schmitt and Holbrook 1990, Munday 2004), our results expand these findings by suggesting that the direction and magnitude of competition may, in part, be determined by the sequence and timing of species interactions.

Classic competition theory predicts that over evolutionary time, intraspecific competition should be stronger than interspecific competition because competitive exclusion and niche diversification will lead to resource partitioning among species (Colwell and Fuentes 1975, 
Diamond 1978). Interspecific differences in distribution, resource use, environmental tolerances, or natural enemies act as stabilizing processes, buffering per capita population growth rates of a species in a community (Chesson 2000), resulting in intraspecific effects being more negative than interspecific effects.

Alternatively, neutral theory (Bell 2000, Hubbell 2001) and the "lottery model" (Sale 1976, 1978) both predict that intra- and interspecific competition should be of equal magnitude. Neutral models suggest that the only drivers of population dynamics are random variation in births, deaths, and dispersal (Adler et al. 2007), with species identity playing no role because species do not differ from one another in ways that distinguish their population dynamics (Chave 2004, Leibold and McPeek 2006). Likewise, the lottery model assumes that space is a limiting resource, vacant space is recolonized by the first available settler, and that once recolonized the individual holds the space until it dies (i.e., there is a strong "priority effect"). Coexistence is favored if arrival is higher for one species at some times or places and higher for the other species at other times or places (Chesson and Warner 1981). We found that the strength of competitive effects was primarily related to relative arrival time and poorly explained by the identity of prior residents. This is consistent with both neutral theory and the lottery model: reversals in sequence of arrival reversed the direction of competition, and latearriving fish did poorer than fishes arriving simultaneously with their competitors or before their competitors (as evidenced by the "no competition" treatment). Because we found order of arrival and not species identity to be important here, our results are more consistent with neutral processes structuring communities than niche-based theories.

Although we never explicitly tested mechanisms underlying priority effects in this study, we propose three: (1) a residency advantage, in which, if residents are able to deplete renewable resources to low levels, longer time in residency means that more depletion occurs, increasing the intensity of exploitative competition; (2) a size advantage in which larger (or older) fish (i.e., prior residents) induce stronger competitive effects than smaller (or younger) fish through either exploitative or interference competition (Jones 1987, Wilson 2005); (3) an experience advantage, in which more experienced individuals (i.e., prior residents) gain knowledge of the local environment (e.g., greater awareness of established boundaries with neighbors and knowledge of hiding spaces), facilitating their ability (relative to later-arriving fish) to acquire resources (i.e., exploitative competition), defend home ranges (i.e., interference competition) or evade predators. Of these three mechanisms, we have most evidence for the second and third. We found that aggression increased with increasing mortality risk and increasing temporal separation of species arrival, suggesting that aggressive behavior by residents toward focal individuals increased the mortality risk of focal individuals. This aggression gradient is suggestive of both size and experience advantages, which, because larger individuals are often also more experienced, are not mutually exclusive. Previous research has shown that: (1) individuals less experienced with a site are less likely to engage in competitive interactions because they exhibit fear-like behaviors incompatible with aggression (Figler et al. 1976); and (2) larger individuals are often more successful in the acquisition and defense of food or cover, resulting in increased growth or reduced mortality (Robertson 1984, Szabo 2002). As individuals gain experience with a site they may also increase in confidence and more readily engage in aggressive interactions. Therefore, over timescales of minutes to hours in which new arrivals exhibit fear-like behaviors, experience advantages (or conversely an unwillingness by new arrivals to engage in aggressive interactions) may be determining factors in the outcome of interference competition. Over timescales of hours to days, when new arrivals have overcome any initial fear-like behaviors, size advantages may be critical, as larger individuals are able to physically dominate smaller individuals during interference competition.

Based on previous work in coral reef fish communities, predation is likely the ultimate cause of mortality in recently settled reef fishes, with competition increasing a subordinate's exposure to predators due to displacement of subordinates from refuge habitat (Carr et al. 2002, Holbrook and Schmitt 2002, Almany 2003). The ability to find (and defend) shelter sites may therefore increase competitive advantage. Shima (2002) found that the frequency of agonistic interactions between resident $T$. hardwicke scaled with density- and number-dependent losses to predation, suggesting that behavioral interactions rather than proximate resource limitation may underlie observed mortality. We have evidence that these patterns also hold true here, for both intraspecific interactions between $T$. hardwicke and interspecific interactions between $T$. hardwicke and $T$. quinquevittatum, with the likely agents of mortality both resident (cardinalfish, eels, lizardfish, sandperch, triggerfish) and transient (jacks) predators (see Appendices A and B). We add a caveat to these interpretations. Our experimental design effectively doubled the density of the experimental species when residents and focal individuals were present on the same reef relative to reefs on which prior residents were absent. We acknowledge that this design does not distinguish competitive effects from apparent competition (i.e., the response of predators to overall increases in prey density) because neither competitor density nor predator effects were controlled for.

Communities are rarely devoid of established residents. Colonists and newborns immediately encounter a community's current residents. Previous research has demonstrated that the degree to which resident-settler interactions affect the persistence of settlers can depend 
on the identity of both the resident and the settler (Shulman et al. 1983, Sweatman 1985, Munday et al. 2001, Almany 2003, 2004, Hixon and Jones 2005, Forrester et al. 2006). Here we have expanded on this by showing that not only does the identity of the players in resident-settler interactions affect the outcome of these interactions, but so does the sequence and timing of these interactions. This has important implications for ecologists attempting to evaluate interaction strengths among species, suggesting that it is not only important to identify the direction and magnitude of interaction strengths, but also variability in the direction and magnitude of interaction strengths through time.

\section{ACKNOWLEDGMENTS}

Craig Osenberg, Jeff Shima, Jada-Simone White, Ben Bolker, Todd Palmer, and two anonymous reviewers provided many helpful comments on versions of this manuscript. Staff of the Richard B. Gump South Pacific Research Station provided invaluable logistical support, and Natasha Dallin, Shelby Boyer, and Anne Duplouy helped in the field and laboratory. This project was possible with financial support from NSF (OCE-0242312), a VUW Ph.D. Scholarship awarded to S. W. Geange, a Fulbright-Ministry of Research, Science and Technology Graduate Student Award to S. W. Geange, and a Three Seas Fellowship to A. C. Stier.

\section{Literature Cited}

Adler, P. B., J. HilleRisLambers, and J. M. Levine. 2007. A niche for neutrality. Ecology Letters 10:95-104.

Almany, G. R. 2003. Priority effects in coral reef fish communities. Ecology 84:1920-1935.

Almany, G. R. 2004. Priority effects in coral reef fish communities of the Great Barrier Reef. Ecology 85:28722880.

Almany, G. R., and M. S. Webster. 2006. The predation gauntlet: early post-settlement mortality in reef fishes. Coral Reefs 25:19-22.

Bell, G. 2000. The distribution of abundance in neutral communities. American Naturalist 155:606-617.

Benke, A. C. 1978. Interactions among coexisting predators-a field experiment with dragonfly larvae. Journal of Animal Ecology 47:335-350.

Beukers, J. S., G. P. Jones, and R. M. Buckley. 1995. Use of implant microtags for studies on populations of small reef fish. Marine Ecology Progress Series 125:61-66.

Blaustein, L., and J. Margali. 1996. Priority effects in temporary pools: nature and outcome of mosquito larvatoad tadpole interactions depend on order of entrance. Journal of Animal Ecology 65:77-84.

Carr, M. H., T. W. Anderson, and M. A. Hixon. 2002. Biodiversity, population regulation, and the stability of coralreef fish communities. Proceedings of the National Academy of Sciences (USA) 99:11241-11245.

Caselle, J. E. 1999. Early post-settlement mortality in a coral reef fish and its effect on local population size. Ecological Monographs 69:177-194.

Chave, J. 2004. Neutral theory and community ecology. Ecology Letters 7:241-253.

Chesson, J. 1978. Measuring preference in selective predation. Ecology 59:211-215.

Chesson, P. 2000. Mechanisms of maintenance of species diversity. Annual Review of Ecology and Systematics 31: 343-366.

Chesson, P., and R. Warner. 1981. Environmental variability promotes coexistence in lottery competitive systems. American Naturalist 117:923-943.
Colwell, R. K., and E. R. Fuentes. 1975. Experimental studies of the niche. Annual Review of Ecology and Systematics 6: 281-310.

Cox, D. R. 1972. Regression models and life-tables. Journal of the Royal Statistical Society Series B 34:187-220.

Cox, D. R., and D. Oakes. 1984. Analysis of survival data. Chapman and Hall, London, UK.

Craig, P. C. 1998. Temporal spawning patterns of several sugeonfishes and wrasses in American Samoa. Pacific Science 52:35-39.

Dalgaard, P. 2002. Introductory statistics with R. Springer, New York, New York, USA.

Dayton, G. H., and L. A. Fitzgerald. 2005. Priority effects and desert anuran communities. Canadian Journal of Zoology 83: 1112-1116.

Diamond, J. M. 1978. Niche shifts and the rediscovery of interspecific competition. American Scientist 66:322-331.

Doherty, P. J. 1988. Large-scale variability in the recruitment of a coral reef fish. Pages 667-672 in Proceedings of the Sixth International Coral Reef Symposium, Australia. Executive Committee, Townsville, Australia.

Doherty, P. J. 1991. Spatial and temporal patterns in recruitment. Pages 261-293 in P. F. Sale, editor. The ecology of fishes on coral reefs. Academic Press, San Diego, California, USA.

Dufour, V., and R. Galzin. 1993. Colonization patterns of reef fish larvae to the lagoon at Moorea Island, French Polynesia. Marine Ecology Progress Series 102:143-152.

Figler, M. H., R. M. Klein, and H. V. S. Peeke. 1976. The establishment and reversibility of dominance relationships in jewel fish, Hemichromis bimaculatus Gill (Pisces, Cichlidae): effects of prior exposure and prior residence situations. Behaviour 58:254-270.

Forrester, G. E., B. Evans, M. A. Steele, and R. R. Vance. 2006. Assessing the magnitude of intra- and interspecific competition in two coral reef fishes. Oecologia 148:632-640.

Frederick, J. L. 1997. Evaluation of fluorescent elastomer injection as a method for marking small fish. Bulletin of Marine Science 61:399-408.

Freund, R. J., and W. J. Wilson. 1998. Regression analysis: statistical modeling of a response variable. Academic Press, San Diego, California, USA.

Gibbs, H. L., and P. R. Grant. 1987. Ecological consequences of an exceptionally strong El Nino event on Darwin's Finches. Ecology 68:1735-1746.

Hixon, M. A. 1980. Competitive interactions between California reef fishes of the genus Embiotoca. Ecology 61:918-931.

Hixon, M. A., and G. P. Jones. 2005. Competition, predation, and density-dependent mortality in demersal marine fishes. Ecology 86:2847-2859.

Holbrook, S. J., and R. J. Schmitt. 1989. Resource overlap, prey dynamics, and the strength of competition. Ecology 70: 1943-1953.

Holbrook, S. J., and R. J. Schmitt. 2002. Competition for shelter space causes density-dependent predation mortality in damselfishes. Ecology 83:2855-2868.

Hubbell, S. P. 2001. The unified neutral theory of biodiversity and biogeography. Princeton University Press, Princeton, New Jersey, USA.

Imbert, H., L. Beaulaton, C. Rigaud, and P. Elie. 2007. Evaluation of visible implant elastomer as a method for tagging small European eels. Journal of Fish Biology 71: 1546-1554.

Jones, G. P. 1987. Competitive interactions among adults and juveniles in a coral reef fish. Ecology 68:1534-1547.

Larson, R. J. 1980. Competition, habitat selection, and the bathymetric segregation of two rockfish (Sebastes) species. Ecological Monographs 50:221-239. 
Lawler, S. P., and P. J. Morin. 1993. Temporal overlap, competition, and priority effects in larval anurans. Ecology 74:174-182.

Leibold, M. A., and M. A. McPeek. 2006. Coexistence of the niche and neutral perspectives in community ecology. Ecology 87:1399-1410.

Louette, G., and L. D. Meester. 2007. Predation and priority effects in experimental zooplankton communities. Oikos 116: 419-426.

Manly, B. F., P. Miller, and L. M. Cook. 1972. Analysis of a selective predation experiment. American Naturalist 106: 719-736.

Munday, P. L. 2004. Competitive coexistance of coral-dwelling fishes: the lottery hypothesis revisted. Ecology 85:623-628.

Munday, P., G. Jones, and M. Caley. 2001. Interspecific competition and coexistence in a guild of coral-dwelling fishes. Ecology 82:2177-2189.

Myers, R. F. 1999. Micronesian reef fishes. Coral Graphics, Guam.

Osenberg, C. W., J. S. Shima, and C. M. S. Mary. 2006. Habitat degredation and settlement behavior: effects on fish settlement, survival, and recruitment. Pages 257-263 in Y. Suzuki, T. Nakamori, M. Hidaka, H. Kayanne, B. E. Casareto, K. Nadaoka, H. Yamano, and M. Tsuchiya, editors. Proceedings of the 10th International Coral Reef Symposium, Okinawa, Japan. Japanese Coral Reef Society, Tokyo, Japan.

Price, J. E., and P. J. Morin. 2004. Colonization history determines alternate community states in a food web of intraguild predators. Ecology 85:1017-1028.

R Development Core Team. 2007. R: A language and environment for statistical computing. R Foundation for Statistical Computing, Vienna, Austria.

Randall, J. E. 2005. Reef and shore fishes of the South Pacific: New Caledonia to Tahiti and the Pitcairn Islands. University of Hawaii Press, Honolulu, Hawaii, USA.

Robertson, D. R. 1984. Cohabitation of competing territorial damselfishes on a Caribbean coral reef. Ecology 65:11211135.

Robertson, D., and S. G. Gaines. 1986. Interference competition structures habitat use in a local assemblage of coral reef surgeonfishes. Ecology 67:1372-1383.

Sale, P. F. 1976. Reef fish lottery. Natural History 85:60-65.

Sale, P. F. 1978. Coexistence of coral reef fishes - a lottery for living space. Environmental Biology of Fishes 3:85-102.

Schauber, E. M., D. Kelly, P. Turchin, C. Simon, W. G. Lee, R. B. Allen, I. J. Payton, P. R. Wilson, P. E. Cowan, and R. E. Brockie. 2002. Masting by eighteen New Zealand plant species: the role of temperature as a synchronizing cue. Ecology 83:1214-1225.
Schmitt, R. J., and S. J. Holbrook. 1986. Seasonally fluctuating resources and temporal variability of interspecific competition. Oecologia 69:1-11.

Schmitt, R., and S. Holbrook. 1990. Population responses of surfperch released from competition. Ecology 71:1653-1665.

Shima, J. S. 2001. Regulation of local populations of a coral reef fish via joint effects of density- and number-dependent mortality. Oecologia 126:58-65.

Shima, J. S. 2002. Mechanisms of density- and numberdependent population regulation of a coral-reef fish. Marine and Freshwater Research 53:175-179.

Shima, J. S., C. W. Osenberg, and C. M. S. Mary. 2008. Quantifying site quality in a heterogeneous landscape: recruitment of a reef fish. Ecology 89:86-94.

Shorrocks, B., and M. Bingley. 1994. Priority effects and species coexistence: experiments with fungal-breeding Drosophila. Journal of Animal Ecology 63:799-806.

Shulman, M., J. Ogden, W. McFarland, S. Miller, N. Wolf, and J. Ebersole. 1983. Priority effects in the recruitment of juvenile coral reef fishes. Ecology 64:1508-1513.

Simon, J. 2007. Evaluation of marking European silver eels with visible implant elastomer tags and alcian blue. Journal of Fish Biology 70:303-309.

Srinivasan, M., and G. P. Jones. 2006. Extended breeding and recruitment periods of fishes on a low latitude coral reef. Coral Reefs 25:673-682.

Sutherland, J. P., and R. H. Karlson. 1977. Development and stability of the fouling community at Beaufort, North Carolina. Ecological Monographs 47:425-446.

Sweatman, H. P. A. 1985. The influence of adults of some coral reef fishes on larval recruitment. Ecological Monographs 55: 469-485.

Szabo, A. R. 2002. Experimental tests of intercohort competition for food and cover in the tidepool sculpin (Oligocottus maculosus Girard). Canadian Journal of Zoology 80:137144.

Therneau, T. M., and P. M. Grambsch. 2000. Modeling survival data: extending the Cox model. Springer, New York, New York, USA.

Victor, B. C. 1986. Duration of the planktonic larval stage of one hundred species of Pacific and Atlantic wrasses (family Labridae). Marine Biology 90:317-326.

Wilson, J. A. 2005. Age class interactions in a marine goby, Elacatinus prochilos (Bohlke and Robins, 1968). Journal of Experimental Marine Biology and Ecology 327:144-156.

Winemiller, K. O., and K. A. Rose. 1992. Patterns of lifehistory diversification in North American Fishes: implications for population regulation. Canadian Journal of Fisheries and Aquatic Sciences 49:2196-2218.

\section{APPENDIX A}

Non-manipulated community structure in the interspecific study examining intracohort priority effects (Ecological Archives E090-203-A1).

\section{APPENDIX B}

Non-manipulated community structure in the intraspecific study examining intracohort priority effects (Ecological Archives E090-203-A2)

\section{APPENDIX C}

Standard lengths of focal individuals and prior residents (Ecological Archives E-090-203-A3). 
Appendix C

Geange and Stier (2010) Priority

effects and habitat complexity

affect the strength of competition.

Oecologia 


\title{
Priority effects and habitat complexity affect the strength of competition
}

\author{
Shane Wallace Geange $\cdot$ Adrian C. Stier
}

Received: 24 June 2009/ Accepted: 18 December 2009

(C) Springer-Verlag 2010

\begin{abstract}
Both habitat complexity and priority effects can influence the strength of competitive interactions; however, the independent and synergistic effects of these processes are not well understood. In Moorea, French Polynesia, we conducted a factorial field experiment to quantify the independent and combined effects of priority effects and habitat complexity on the strength of intraspecific competitive interactions among recently settled individuals of a coral reef fish (Thalassoma quinquevittatum: Labridae). Simultaneous arrival of focal individuals with competitors resulted in a 2.89-fold increase in survival relative to reefs where focal individuals arrived 5 days later than competitors (i.e., a priority effect). Increasing habitat complexity resulted in a 1.55-fold increase in survivorship when focal individuals arrived simultaneously with or before competitors. However, increasing habitat complexity did not affect the survivorship of focal individuals arriving 5 days later than competitors. Behavior observations showed that survivorship was negatively correlated with aggression. Aggression by prior residents towards focal individuals was significantly greater when focal individuals arrived 5 days
\end{abstract}

Communicated by Ross Alford.

Electronic supplementary material The online version of this article (doi:10.1007/s00442-009-1554-z) contains supplementary material, which is available to authorized users.

\footnotetext{
S. W. Geange ( $\square)$

School of Biological Sciences,

Victoria University of Wellington,

PO Box 600, Wellington, New Zealand

e-mail: shane.geange@vuw.ac.nz

A. C. Stier

Department of Biology, University of Florida,

Gainesville, FL 32611-8525, USA
}

later than competitors than when they arrived simultaneously. Increasing habitat complexity did not reduce aggression. Our results suggest that, when competitors arrive simultaneously, competitive interactions are weak and subordinates are not displaced from complex habitat; increasing habitat complexity increases survival by disrupting predation. Conversely, when competitors arrive at different times, aggression intensifies and increasing habitat complexity does not disrupt predation because competitive subordinates are excluded from habitat resources. This study demonstrates that the strength of competition can be context-dependent and may vary with the timing of competitive interactions and habitat complexity.

Keywords Competition - Habitat complexity · Interaction strengths · Priority effects - Reef fish

\section{Introduction}

Historically, empirical and theoretical studies quantifying interaction strengths have been heavily biased towards predatory, competitive and top-down versus bottom-up interactions. Typically, these studies describe interaction strengths by constants or functions that depend on the densities of the interacting individuals, species, functional groups, or cohorts (e.g., Peacor and Werner 2004). More recently, renewed calls have been made for more studies examining how the context within which interactions occur (e.g., disturbance regime: Gallet et al. 2007; higher-order interactions: Peacor and Werner 2004; and environmental attributes: Chase 2007; Crain et al. 2004) shapes interaction strengths (Agrawal et al. 2007). For example, the importance of competition in structuring rocky intertidal communities can vary spatially depending on levels of larval 
supply (Connolly and Roughgarden 1999). The magnitude of competition may also vary depending upon the provisioning of structural refuge in complex habitats (e.g., Bonin et al. 2009), or the sequence in which competitors arrive in a community (i.e., priority effects; e.g., Alford and Wilbur 1985). The intensity of priority effects can in turn depend upon the amount of time that separates the arrival of competitors in a community (Geange and Stier 2009), or the presence of predators (Louette and Meester 2007). Here, we examine the potential for variation in habitat complexity and priority effects to create context-dependent competitive outcomes. Understanding the independent and combined effects of priority effects and habitat complexity on the outcome of competitive interactions is of increasing importance as global climate change leads to widespread shifts in breeding phenology and habitat availability (Both et al. 2009; Durant et al. 2007; Hughes 2000; Parmesan and Yohe 2003; Visser and Both 2005; Walther et al. 2002).

Habitat complexity can considerably influence interaction strengths (e.g., competition: Bonin et al. 2009; Buenau et al. 2007; Ladd and Facelli 2008; and predation: Beukers and Jones 1997; Huffaker 1958; Juliano 2009). Increasing habitat complexity is typically expected to mitigate the negative effects of competition for predator free space (e.g., Almany 2004a) or reverse competitive dominance relationships (e.g., Ebersole 1985). More complex habitats often contain a greater diversity of food resources (e.g., Harmon et al. 1986) and refuges from predators (e.g., Beukers and Jones 1997; Finke and Denno 2002), thereby reducing the intensity of competition and predation. Increased structural complexity may also alter encounter rates between predators and prey, increasing predation risk if the structure decreases the visibility of predators to prey, or decreasing predation risk by providing enemy-free structural refuge or interfering with predator maneuvrability and/or the ability to visually detect prey (Andruskiw et al. 2008; Finke and Denno 2006; Janssen et al. 2007; Langellotto and Denno 2004; Persson and Eklov 1995; Rilov et al. 2007; Warfe and Barmuta 2004).

Interaction strengths (e.g., competition and predation) can also be modified by the order (who arrives first) and timing (by how much) of arrival in a community (i.e., "priority effects": e.g., Alford and Wilbur 1985; Dayton and Fitzgerald 2005; Geange and Stier 2009; Lawler and Morin 1993; Price and Morin 2004; Shorrocks and Bingley 1994). Early arrival may confer experience advantages if individuals gain knowledge of the local environment (e.g., greater awareness of established boundaries with neighbors and knowledge of predator-free space), facilitating their ability to acquire resources, defend home ranges, or evade predators. Alternatively, if larger size confers competitive advantages, early-arriving individuals may have a growth advantage over late-arriving individuals. When early arrival provides a competitive advantage due to differences in experience or size, the competitive effect of the earlyarriving individuals on the later-arriving individuals should increase as arrival times diverge (Alford and Wilbur 1985; Geange and Stier 2009). However, many species undergo extensive ontogenetic niche shifts which are often manifested as shifts in habitat use or diet with increasing size (Werner and Gilliam 1984). Such shifts can substantially alter interaction strengths within communities (de Roos et al. 2002; Werner 1992; Werner and Gilliam 1984). For example, individuals arriving at different times may interact less intensely than individuals arriving at the same time because they are, to some degree, acting as separate ecological species (Maiorana 1978). As a result, priority effects will only be important if ontogenetic niche shifts occur slowly, so that late-arriving individuals interact with larger, more experienced early-arriving individuals. Conversely, when rapid ontogenetic niche shifts occur, the optimal strategy for an individual to avoid intracohort priority effects is to either: (1) enter the community before other settlers; or (2) enter the community late enough that prior settlers have undergone ontogenetic niche shifts and no longer pose a competitive threat.

Finally, habitat complexity and priority effects may interact, so that the effects of one process depend upon a second process. For example, although the magnitude of competition may increase as individuals arrive in a community progressively later than their competitors, latearriving individuals may be released from competition or predation pressure in complex habitats that decrease encounter rates with early-arriving individuals. Understanding how both habitat complexity and priority effects independently and synergistically affect the strength of competitive interactions is essential to estimates and interpretation of the strength of competition.

The few studies that have examined the combined effects of habitat and arrival time on the strength of competition (see Fincke 1999; Sunahara and Mogi 2002) have identified habitat as capable of moderating inhibitory priority effects. In a previous study examining two labrid species that are closely related both genetically and functionally (Thalassoma hardwicke and T. quinquevittatum), we identified strong intracohort priority effects (Geange and Stier 2009). Aggression toward later-arriving individuals by early-arriving individuals increased as each species entered communities progressively later than its competitor. Additionally, aggression by early-arriving individuals and the survival of late-arriving individuals was negatively correlated, suggesting that the timing of arrival relative to competitors results in context-dependent competitive outcomes. Here, focussing on intraspecific competitive effects, we manipulated habitat complexity and timing of Thalassoma quinquevittatum settler arrival to: (1) determine the 
independent effects of timing of arrival and habitat complexity on intraspecific competition between $T$. quinquevittatum settlers; and (2) address whether habitat complexity attenuates or enhances intraspecific interaction strengths among settlers arriving at different times. We hypothesized that: (1) when timing of arrival dictates the strength of competition, competitive effects should be weakest when competitors arrive simultaneously and increase in strength as temporal separation among competitor arrival increases; and (2) increasing habitat complexity would disrupt priority effects by releasing late-arriving individuals from competitive interactions with early-arriving individuals.

\section{Materials and methods}

\section{Study species}

Thalassoma quinquevittatum is a common wrasse throughout much of the Indo-Pacific. T. quinquevittatum spawns year round on Pacific coral reefs at latitudes of approximately $15^{\circ} \mathrm{S}$ (Craig 1998). Planktonic larval development takes 46-68 days (Victor 1986) before competent larvae, 9-11 mm standard length (SL), settle to benthic reef habitat. At our study site, in Moorea, French Polynesia $\left(17^{\circ} 30^{\prime} \mathrm{S}, 149^{\circ} 50^{\prime} \mathrm{W}\right)$, settlement occurs around new and full moons. A single T. quinquevittatum settlement pulse can last a few days to a week (Geange, personal observation), meaning that, on a given patch reef, individuals in a given pulse often arrive asynchronously. Following settlement, T. quinquevittatum juveniles $(<25 \mathrm{~mm}$ SL) over-associate (relative to availability) with several coral species (e.g., Porites lobata, Pocillopora verrucosa, and Porites rus) and the macroalga Turbinaria ornata (Geange and Stier 2009).

Moorea's northern lagoon consists of a matrix of sand and fine coral rubble interspersed with patch reefs. Patch reefs are predominantly massive Porites coral colonies, often surmounted by smaller colonies of other coral species ( $P O$ cillopora spp., Montipora spp., and Acropora spp.), patches of dead coral skeletons, macroalgae (Turbinaria spp., Dictyota spp., Sargassum spp., and Halimedia spp.) and filamentous algae (Polysiphonia spp. and Sphacelaria spp.). Patch reefs are highly variable in their composition over small spatial scales; thus, interactions between individuals within a settlement pulse are overlaid upon a background of variable habitat complexity. Previous research has demonstrated that variability in habitat complexity within this lagoon does affect post-settlement survival of reef fishes. For example, Shima et al. (2008) demonstrated that when density was held constant, mean post-settlement survival of T. hardwicke (a congener of T. quinquevittatum) increased with the abundance of the branching coral Pocillopora (a probable refuge from predation).

In this study, we used $T$. quinquevittatum individuals that were approximately 2 weeks post-settlement $(13.3 \mathrm{~mm}$ $\mathrm{SL} ; \mathrm{SD}=0.8$ )

Study site

The study was conducted in the northern lagoon of Moorea between April and June 2008. We used an array of 30 isolated live-coral patch reefs separated by $\sim 10 \mathrm{~m}$ in water 2-4 m deep. Reefs were located within a sand-flat, separated from each other, and from nearby natural reefs, by a minimum of $15 \mathrm{~m}$. We constructed reefs to minimize habitat variation by standardizing size, rugosity, and water depth. Each reef consisted of a base of live Porites lobata coral with an average area of $2.23 \mathrm{~m}^{2}(\mathrm{SD}=0.56)$, and a mean height of $0.59 \mathrm{~m}(\mathrm{SD}=0.10)$.

Previous work by Geange and Stier (2009) determined that juvenile $T$. hardwicke exclude T. quinquevittatum settlers; we therefore removed all resident $T$. hardwicke from patch reefs. We also removed resident $T$. quinquevittatum, and manipulated the relative abundances of other resident fish species via selective removals and additions, so that the relative abundance of all species was similar among the 30 reefs (see electronic supplementary material, ESM, 1 for background community structure). We used the fish anaesthetic eugenol (clove oil) and hand nets to collect fish.

\section{Experimental design and execution}

We examined the effects of habitat complexity and timing of arrival in the context of the survival of focal T. quinquevittatum settlers. We controlled habitat complexity by manipulating the availability of the branching coral Pocillopora verrucosa. This was achieved by drilling holes into the upper surface of patch reefs. Into these holes, we inserted stainless steel pins attached to P. verrucosa colonies with Z-Spar Splash Zone Compound (Kopcoat, Pittsburgh, PA, USA). Mean colony surface area was $0.2 \mathrm{~m}^{2}$ $(\mathrm{SD}=0.07)$. We crossed the availability of $P$. verrucosa (two levels: two, or four colonies, which is representative of observed $P$. verrucosa cover within the lagoon (Shima et al. 2008)), with the presence of three tagged $T$. quinquevittatum competitors (three levels: absent, introduced simultaneously with (0 days), or 5 days earlier than the focal individuals). To each reef, we simulated settlement by introducing three tagged $T$. quinquevittatum focal individuals. Thus, our design had six treatments: (1) focal individuals without competitors, with two $P$. verrucosa colonies; (2) focal individuals and competitors introduced simultaneously, with two P. verrucosa colonies; (3) focal 
individuals with competitors introduced 5 days previously, with two $P$. verrucosa colonies; (4) focal individuals without competitors, with four $P$. verrucosa colonies; (5) focal individuals and competitors introduced simultaneously, with four $P$. verrucosa colonies; and (6) focal individuals with competitors introduced 5 days previously, with four $P$. verrucosa colonies. We ran the experiment in two temporal blocks (17-23 April and 1-7 May 2008), yielding ten replicates (five in each temporal block) for each of the six treatments.

We used T. quinquevittatum individuals captured from reefs adjacent to the reef crest, approximately $2 \mathrm{~km}$ from the study site. All captured fish were held in aquaria with running seawater for $24 \mathrm{~h}$ and then individually tagged with different colors of Visible Implant Elastomer (VIE; Northwest Marine Technology) anterior to the caudal peduncle. VIE tags were readable through the skin of the fish by observers in the field, so it was not necessary to recapture individuals to determine their identity. VIE tags do not have adverse effects on other fishes (Beukers et al. 1995; Imbert et al. 2007; Simon 2007) or on T. quinquevittatum (Geange and Stier 2009), and have been used to tag fish as small as $8 \mathrm{~mm}$ (Frederick 1997). We therefore assumed that tagging and handling effects were minimal. After tagging, we returned fish to aerated aquaria for $24 \mathrm{~h}$ before measuring them to the nearest $0.1 \mathrm{~mm}$ SL. For each experimental run, we collected fish twice, once for the 5day competitors, and once for the 0-day competitors and focal individuals. Each time we collected fish of the same size (see ESM 2). The difference between competitors and focal individuals was therefore their time on the reef and not their size.

Because recently settled fish often experience high rates of mortality (Almany and Webster 2006), we initially introduced six competitors to reefs in the 5-day treatments. At the same time as focal individuals were introduced to these treatments, we haphazardly removed excess competitors when there were more than three competitors (12 instances out of 20 reefs), and added competitors when there were less than three competitors ( 3 instances out of 20). We used excess individuals removed from other reefs to supplement competitors.

We surveyed reefs twice daily (approximately 0800 and 1600 hours) for 5 days after the introduction of focal individuals. Day 5 was chosen to end the study because previous research found the first 36-48 h after settlement to be most critical (Almany 2003, 2004b; Planes and Lecaillon 2001; Webster 2002; Webster and Almany 2002). In a few instances, individuals not enumerated in one survey were enumerated in the subsequent survey (16 instances out of 570). When this occurred, these individuals were recorded as present at the times they were missed. During surveys, we searched neighboring non- experimental reefs for tagged immigrants. We found no immigrants or emigrants. Previous research has shown that small reef fish rarely move between reefs separated by as little as $15 \mathrm{~m}$ (Caselle 1999; Shima 2001), and previous studies on our experimental array found no migration of similar-sized T. quinquevittatum (Geange and Stier 2009). We therefore assume that the disappearance of an experimental fish was due to mortality rather than migration.

\section{Behavioral observations}

To help elucidate the mechanisms driving interactions between focal individuals and competitors, we conducted 5-min behavioral observations at the time we added focal individuals to reefs. After allowing fish to acclimate to the observers' presence for approximately $3 \mathrm{~min}$, the observer identified one focal individual that was followed at a distance of approximately $2 \mathrm{~m}$ from the reef. The observer recorded three response variables: (1) the number of chases between other fishes and the focal individual (80\% of chases were by $T$. quinquevittatum competitors); (2) the number of fin bites inflicted upon the focal individual (all fin bites were inflicted by T. quinquevittatum competitors); and (3) time spent inside Pocillopora by the focal individual. This was repeated twice on each reef so that behavioral interactions were made for two focal individuals per reef.

\section{Data analysis}

\section{Survival analysis}

Using generalized linear models (GLM), we conducted an analysis of deviance with binomial error distributions and a logit link function to model proportional survival of focal individuals 5 days after their introduction to reefs. We used an analysis of deviance to evaluate the statistical significance of the main effects and the interaction between the competition and habitat complexity treatments (i.e., the full model). Finding no interaction $\left(\chi^{2}=0.457, d f=2\right.$, $P=0.796$ ), we conducted four a priori contrasts: (1) habitat effects without prior residents (absent +0 -day low complexity vs absent + 0-day high complexity); (2) competitive effects (control low and high complexity vs 0-day low and high complexity); (3) habitat effects with competitors (0-day and 5-day low complexity vs 0-day and 5-day high complexity); and (4) timing of arrival effects (0-day low and high complexity vs 5-day low and high complexity). We chose these contrasts to examine main effects of habitat and competition in the absence (contrasts 1 and 2) and presence (contrasts 3 and 4) of timing of arrival effects. Data were not overdispersed (residual 
deviance $=46.781$, residual $d f=54)$. We calculated effect sizes as ratios using mean proportions from the raw data.

\section{Behavior analyses}

Because there were strong correlations among behavioral responses (e.g., fin bites only occurred during chases), we used Principal Components Analysis (PCA) to create a single composite aggression score. We transformed data $[\ln (x+1)]$ prior to analysis to improve normality. PC1 accounted for $73 \%$ of the total variation in aggression variables, and was driven by high positive loadings of total chases $(64 \%)$ and fin bites $(60 \%)$, and weak negative loadings of time-in-Pocillopora (44\%). Thus, we interpret this first PC axis as a gradient of overall aggression.

We analyzed overall aggression with a two-way analyses of variance (ANOVA). We transformed data to meet assumptions of normality and equal variance $\left[1 /\left(X_{j}+C\right)\right.$; where $C$ is the largest negative value plus one; see Rummel $1970]$. Finding no interaction $\left(F_{2,54}=0.012, P=0.987\right)$, we used overall aggression as the response variable to conduct four a priori contrasts equivalent to those described above for survival analysis.

Because our previous work on this genus has shown correlations between aggression and the strength of competition (see Geange and Stier 2009), we used linear least squares regression to correlate survival and aggression across all treatments, treating each reef as an independent replicate and averaging multiple observations conducted within the same reef.

All statistical analysis was conducted in $\mathrm{R} 2.8 .0$ ( $\mathrm{R}$ Development Core Team 2008).

\section{Results}

Increasing habitat complexity yielded a 1.50-fold increase in the proportional survival of focal individuals $(P=0.043$; Table 1; Fig. 1$)$. Relative to reefs where competitors were absent, arriving either simultaneously with or 5 days later than competitors resulted in 1.15- and 3.34-fold decreases in survival, respectively $(P=0.001$; Table 1; Fig. 1).

Increasing habitat from two to four $P$. verrucosa colonies on reefs where focal individuals arrived simultaneously or before competitors resulted in a 1.55-fold increase in the survival of focal individuals (contrast 1; $P=0.024$; Table 2). Arriving on reefs where competitors were absent yielded a 1.15 -fold increase in survival relative to reefs where focal individuals arrived at the same time as competitors, although this effect was not statistically
Table 1 Analysis of deviance and variance tables testing the significance of low or high habitat complexity, timing of arrival of competitive reef fish and the interaction of these terms on survival of and aggression against focal fish, Thalassoma quinquevittatum

\begin{tabular}{|c|c|c|c|c|c|c|}
\hline & \multicolumn{3}{|c|}{ Survival } & \multicolumn{3}{|c|}{ Aggression } \\
\hline & $d f$ & Deviance & $P$ & $d f$ & $F$ & $P$ \\
\hline Habitat complexity & 1 & 4.090 & 0.043 & 1,54 & 0.003 & 0.959 \\
\hline Timing of arrival & 2 & 19.910 & $<\mathbf{0 . 0 0 1}$ & 2,54 & 18.829 & $<\mathbf{0 . 0 0 1}$ \\
\hline $\begin{array}{l}\text { Habitat: timing of } \\
\text { arrival }\end{array}$ & 2 & 0.457 & 0.796 & 2,54 & 0.012 & 0.987 \\
\hline
\end{tabular}

Low and high habitat complexity was comprised of two or four $P$. verrucosa colonies, respectively. Timing of arrival treatments for competitors of focal fish were absent (control; no competitors), simultaneous (0 days), or 5 days earlier. Proportional survival of focal individuals was modeled using a GLM with a logit link and assumed binomial error structure. Aggression is a PCA-derived composite of chases, fin bites and time spent inside $P$. verrucosa (see "Behavior analyses") modeled using ANOVA. Significant $P$ values $(<0.05)$ are highlighted in bold

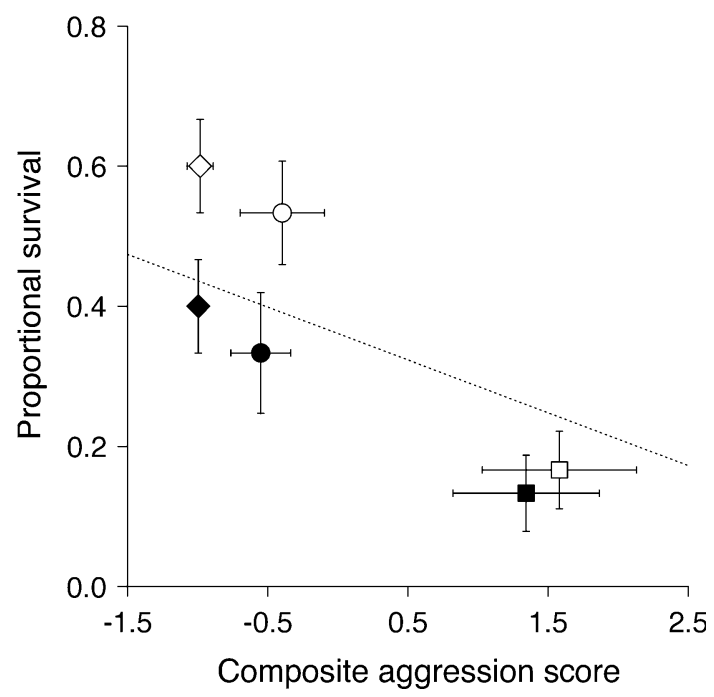

Fig. 1 The effects of habitat complexity and intraspecific competition on survival of focal Thalassoma quinquevittatum individuals (mean proportion alive at experiment end $\pm 1 \mathrm{SE}$ ) and aggression against focal fish (mean PCA-derived composite score of chases, fin bites, and time spent inside $P$. verrucosa reef $\pm 1 \mathrm{SE})$. Habitat complexity was either low (two $P$. verrucosa colonies, closed symbols) or high (four colonies, open symbols). Competition levels are based on the timing of competitor arrival: absent (diamonds), simultaneous (0 days, circles) or priority effects ( 5 days before focal fish, squares). Linear regression (dashed line) is based on the raw data, slope $=-0.08, r^{2}=0.175, P=0.001$

significant (contrast 2; $P=0.448$; Table 2). When focal individuals arrived simultaneously with or 5 days later than competitors, increasing habitat complexity increased survival, although this effect was not significant (contrast 3; $P=0.953$; Table 2). Arriving at the same time as competitors yielded a 2.89 -fold increase in survival relative to 
Table 2 Results from four a priori contrasts testing the effects of low or high habitat complexity and three levels of intraspecific competition (timing of competitor arrival treatments) on survival of and aggression against focal $T$. quinquevittatum individuals (see Table 1 for further explanation)

\begin{tabular}{|c|c|c|c|c|c|c|}
\hline & \multicolumn{3}{|l|}{ Survival } & \multicolumn{3}{|c|}{ Aggression } \\
\hline & Estimate & $Z$ value & $P$ & $d f$ & $F$ & $P$ \\
\hline 1. Habitat effects without early competitors & -0.441 & -2.261 & 0.024 & 1,58 & 0.001 & 0.973 \\
\hline 2. Competitive effects & -0.145 & -0.760 & 0.448 & 1,58 & 3.004 & 0.088 \\
\hline 3. Habitat effects with early competitors & -0.440 & -1.601 & 0.109 & 1,58 & 0.004 & 0.953 \\
\hline 4. Timing of arrival effects & 0.636 & 3.173 & 0.001 & 1,58 & 12.331 & $<0.001$ \\
\hline
\end{tabular}

The four contrasts presented are: (1) habitat effect without early competitors; (2) competitive effects; (3) habitat effects with early competitors; and (4) timing of arrival effects (see "Survival analysis" for contrast explanations). $Z$ values are from a generalized linear model; $F$ values are from an analysis of variance (see "Methods" for further explanation). Effect sizes are calculated as the ratio of mean proportions from the raw data. Significant $P$ values $(<0.05)$ are highlighted in bold

reefs where focal individuals arrived 5 days later than competitors (contrast 4; $P<0.001$; Table 2).

Survival of focal individuals decreased with increases in the PCA-derived composite aggression score (slope $=$ $-0.08, r^{2}=0.175, P=0.001$; Fig. 1). Increasing habitat complexity did not significantly affect aggression $(P=0.959 ;$ Table 1$)$, although timing of arrival did $(P<0.001$; Table 1). Aggression did not differ significantly between reefs where competitors were either absent or arrived simultaneously as focal individuals (contrast 2; $P=0.088$; Table 2). Relative to when focal individuals arrived simultaneously as competitors, aggression was significantly greater when focal individuals arrived 5-days later than competitors (contrast 4; $P<0.001$; Table 2).

\section{Discussion}

Intraspecific competitive effects were demonstrably greater when focal individuals arrived after competitors. The large difference in survival and aggression between the treatments in which focal individuals arrived simultaneously with and later than competitors provides direct quantitative evidence that interaction strengths may vary due to the relative timing of arrival of individuals. As with other studies (e.g., Alford and Wilbur 1985), this research suggests historical knowledge is important when estimating interaction strengths.

Increasing habitat complexity increased survivorship of settlers in the control and 0-day treatments. We predicted that increasing habitat complexity would release focal individuals from competitive interactions in 5-day treatments; however, our results did not support this prediction. Increasing habitat complexity did not significantly increase the survival of late-arriving individuals. Similarly, increasing habitat complexity did not affect the level of aggression displayed towards focal individuals by competitors.

To understand the mechanisms driving the relationship between habitat complexity and survival, we need to consider the way in which prior residents affect the survival of late arriving settlers. Based on previous work in coral reef fish communities, predation is likely the ultimate cause of mortality in recently settled reef fishes (Almany 2003; Carr et al. 2002), with competition forcing subordinates into less protective refugia (Holbrook and Schmitt 2002) or displacing them from refuge habitat altogether (Munday et al. 2001). Interactions with more aggressive competitors may also distract subordinates, leading to reduced vigilance and increased conspicuousness to predators (Almany 2003; Carr et al. 2002). In our study, this suggests that when aggression is weak (e.g., when focal individuals arrive before or simultaneously with competitors), subordinates are not displaced from complex habitat, and increasing habitat complexity increases survival by reducing predation pressure (i.e., tight branching morphology of Pocillopora excludes the majority of predators we observe on our array); however, when aggression is intense (e.g., when focal individuals arrive later than competitors), increasing habitat complexity does not increase survival because competitive subordinates are displaced from refuge habitat. It therefore seems likely that a combination of the intensity of aggression (arising from the timing of arrival) and habitat complexity underlies observed survivorship of T. quinquevittatum engaged in intraspecific interactions.

We add three caveats to these interpretations. First, our experimental design effectively doubled the density of the experimental fish in 0-day and 5-day treatments relative to control treatments. Although we never observed aggregative responses of predators, we acknowledge that this design does not distinguish competitive effects from apparent competition (Holt 1977) because neither T. quinquevittatum 
nor predator density were controlled for. However, during our surveys we did not see any evidence of aggregative responses of predators in either this or a previous study (Geange and Stier 2009) that was conducted on the same set of reefs using the same focal species. Second, our study was conducted on small $\left(2.25 \mathrm{~m}^{2}\right)$ isolated patch reefs. On these reefs, we observed strong aggression towards focal individuals by early-arriving competitors to the point that earlyarriving competitors pursued focal individuals across the entire reef. On larger reefs, we may see an effect of increasing habitat complexity on the survival of late-arriving individuals if they are able to avoid contact with aggressive competitors, thereby avoiding exclusion from refuge habitat. Third, larval fish typically undergo rapid morphological and behavioral changes after settlement. Here, we simulated settlement using individuals that were approximately 2 weeks post-settlement. Consequently, the ecological divergence between the fish used in this study is likely to be far less than the ecological divergence between fish that are actually 0 and 5 days post-settlement. Therefore, although this study explores the general concept of how priority effects and habitat complexity interact, the specific relevance to this species and system is limited.

This is one of the first studies to examine the concurrent influence of habitat complexity and the timing of arrival on interaction strengths. Our results suggest that the contexts within which interactions occur are important determinants of the strength of intraspecific competition. Studies encompassing multiple sources of variation are becoming increasingly imperative in the face of large-scale environmental disturbances that simultaneously impact multiple ecological processes. Indeed, simultaneous threats from global climate change, which has already caused shifts in the breeding phenology of many species (Both et al. 2009; Durant et al. 2007; Hughes 2000; Parmesan and Yohe 2003; Visser and Both 2005; Walther et al. 2002) and habitat declines (Barel et al. 1985; Bellwood et al. 2004; Gardner et al. 2003; Silliman et al. 2005; Skole and Tucker 1993), suggest understanding how habitat complexity and priority effects interact could advance models predicting the responses of demographically open populations to global climate change.

Acknowledgments C. W. Osenberg, J. S. Shima, L. Liggins and two anonymous reviewers provided many helpful comments on versions of this manuscript. Staff of the Richard B. Gump South Pacific Research Station provided invaluable logistical support. This project was possible with financial support from NSF (OCE-0242312), a VUW PhD Scholarship awarded to S.W.G., a Fulbright-Ministry of Research, Science and Technology Graduate Student Award to S.W.G., a New Zealand Post Graduate Study Abroad Award to S.W.G., a Three Seas Fellowship and a French American Cultural Exchange Grant to A.C.S., and National Geographic International Ecostations Fellowships awarded to S.W.G. and A.C.S. This is a contribution from UC Berkeley's Richard B. Gump South Pacific Research Station, Moorea, French Polynesia.

\section{References}

Agrawal AA et al (2007) Filling key gaps in population and community ecology. Front Ecol Environ 5:145-152

Alford RA, Wilbur HM (1985) Priority effects in experimental pond communities: competition between Bufo and Rana. Ecology 66:1097-1105

Almany GR (2003) Priority effects in coral reef fish communities. Ecology 84:1920-1935

Almany GR (2004a) Differential effects of habitat complexity, predators and competitors on abundance of juvenile and adult coral reef fishes. Oecologia 141:105-113

Almany GR (2004b) Priority effects in coral reef fish communities of the Great Barrier Reef. Ecology 85:2872-2880

Almany GR, Webster MS (2006) The predation gauntlet: early postsettlement mortality in reef fishes. Coral Reefs 25:19-22

Andruskiw M, Fryxell JM, Thompson ID, Baker JA (2008) Habitatmediated variation in predation risk by the American marten. Ecology 89:2273-2280

Barel CDN et al (1985) Destruction of fisheries in Africa's lakes. Nature 315:19-20

Bellwood DR, Hughes TP, Folke C, Nystrom M (2004) Confronting the coral reef crisis. Nature 429:827-833

Beukers JS, Jones GP (1997) Habitat complexity modifies the impact of piscivores on a coral reef fish population. Oecologia 114:50-59

Beukers JS, Jones GP, Buckley RM (1995) Use of implant microtags for studies on populations of small reef fish. Mar Ecol Prog Ser 125:61-66

Bonin MC, Srinivasan M, Almany GR, Jones GP (2009) Interactive effects of interspecific competition and microhabitat on early postsettlement survival in a coral reef fish. Coral Reefs 28:265-274

Both C, van Asch M, Bijlsma RG, van den Burg AB, Visser ME (2009) Climate change and unequal phenological changes across four trophic levels: constraints or adaptations? J Anim Ecol 78:73-83

Buenau KE, Rassweiler A, Nisbet RM (2007) The effects of landscape structure on space competition and alternative stable states. Ecology 88:3022-3031

Carr MH, Anderson TW, Hixon MA (2002) Biodiversity, population regulation, and the stability of coral-reef fish communities. Proc Natl Acad Sci USA 99:11241-11245

Caselle JE (1999) Early post-settlement mortality in a coral reef fish and its effect on local population size. Ecol Monogr 69:177-194

Chase JM (2007) Drought mediates the importance of stochastic community assembly. Proc Natl Acad Sci USA 104:1743017434

Connolly SR, Roughgarden J (1999) Theory of marine communities: competition, predation, and recruitment-dependent interaction strength. Ecol Monogr 69:277-296

Craig PC (1998) Temporal spawning patterns of several sugeonfishes and wrasses in American Samoa. Pac Sci 52:35-39

Crain CM, Silliman BR, Bertness SL, Bertness MD (2004) Physical and biotic drivers of plant distribution across estuarine salinity gradients. Ecology 85:2539-2549

Dayton GH, Fitzgerald LA (2005) Priority effects and desert anuran communities. Can J Zool 83:1112-1116

de Roos AM, Leonardsson K, Persson L, Mittelbach GG (2002) Ontogenetic niche shifts and flexible behavior in size-structured populations. Ecol Monogr 72:271-292 
Durant JM, Hjermann DO, Ottersen G, Stenseth NC (2007) Climate and the match or mismatch between predator requirements and resource availability. Clim Res 33:271-283

Ebersole JP (1985) Niche separation of two damselfish species by aggression and differential microhabitat utilization. Ecology 66:14-20

Fincke OM (1999) Organization of predator assemblages in Neotropical tree holes: effects of abiotic factors and priority. Ecol Entomol 24:13-23

Finke DL, Denno RF (2002) Intraguild predation diminished in complex-structured vegetation: implications for prey suppression. Ecology 83:643-652

Finke DL, Denno RF (2006) Spatial refuge from intraguild predation: implications for prey suppression and trophic cascades. Oecologia 149:265-275

Frederick JL (1997) Evaluation of fluorescent elastomer injection as a method for marking small fish. Bull Mar Sci 61:399-408

Gallet R et al (2007) Predation and disturbance interact to shape prey species diversity. Am Nat 170:143-154

Gardner TA, Cote IM, Gill JA, Grant A, Watkinson AR (2003) Longterm region-wide declines in Caribbean corals. Science 301:958960

Geange SW, Stier AC (2009) Order of arrival affects competition in two reef fishes. Ecology 90:2868-2878

Harmon ME et al (1986) Ecology of coarse woody debris in temperate systems. Adv Ecol Res 15:133-202

Holbrook SJ, Schmitt RJ (2002) Competition for shelter space causes density-dependent predation mortality in damselfishes. Ecology 83:2855-2868

Holt RD (1977) Predation, apparent competition, and the structure of prey communities. Theor Popul Biol 12:197-229

Huffaker CB (1958) Experimental studies on predation: dispersion factors and predator-prey oscillations. Hilgardia 27:343-383

Hughes L (2000) Biological consequences of global warming: is the signal already apparent? Trends Ecol Evol 15:56-61

Imbert H, Beaulaton L, Rigaud C, Elie P (2007) Evaluation of visible implant elastomer as a method for tagging small European eels. J Fish Biol 71:1546-1554

Janssen A, Sabelis MW, Magalhaes S, Montserrat M, Van Der Hammen T (2007) Habitat structure affects intraguild predation. Ecology 88:2713-2719

Juliano SA (2009) Species interactions among larval mosquitoes: context dependence across habitat gradients. Annu Rev Entomol 54:37-56

Ladd B, Facelli JM (2008) Priority effects produced by plant litter result in non-additive competitive effects. Oecologia 157:687696

Langellotto GA, Denno RF (2004) Responses of invertebrate natural enemies to complex-structured habitats: a meta-analytical synthesis. Oecologia 139:1-10

Lawler SP, Morin PJ (1993) Temporal overlap, competition, and priority effects in larval anurans. Ecology 74:174-182

Louette G, Meester LD (2007) Predation and priority effects in experimental zooplankton communities. Oikos 116:419-426

Maiorana VC (1978) An explanation of ecological and developmental constants. Nature 273:375-377

Munday P, Jones G, Caley M (2001) Interspecific competition and coexistence in a guild of coral-dwelling fishes. Ecology 82:2177-2189

Parmesan C, Yohe G (2003) A globally coherent fingerprint of climate change impacts across natural systems. Nature 421:37-42
Peacor SD, Werner EE (2004) How independent are species-pair interaction strengths on other species in the food web? Ecology 85:2754-2763

Persson L, Eklov P (1995) Prey refuges affecting interactions between piscivorous perch and juvenile perch and roach. Ecology 76:7081

Planes S, Lecaillon G (2001) Caging experiment to examine mortality during metamorphosis of coral reef fish larvae. Coral Reefs 20:211-218

Price JE, Morin PJ (2004) Colonization history determines alternate community states in a food web of intraguild predators. Ecology 85:1017-1028

R Development Core Team (2008) R: A language and environment for statistical computing. R Foundation for Statistical Computing, Vienna, Austria. ISBN 3-900051-07-0, http://www.R-project.org.

Rilov G, Figueira WF, Lyman SJ, Crowder LB (2007) Complex habitats may not always benefit prey: linking visual field with reef fish behavior and distribution. Mar Ecol Prog Ser 329:225238

Rummel RJ (1970) Applied factor analysis. Northwestern University Press, Evanston, Illinois

Shima JS (2001) Regulation of local populations of a coral reef fish via joint effects of density- and number-dependent mortality. Oecologia 126:58-65

Shima JS, Osenberg CW, Mary CMS (2008) Quantifying site quality in a heterogeneous landscape: recruitment of a reef fish. Ecology 89:86-94

Shorrocks B, Bingley M (1994) Priority effects and species coexistence: experiments with fungal-breeding Drosophila. J Anim Ecol 63:799-806

Silliman BR, van de Koppel J, Bertness MD, Stanton LE, Mendelssohn IA (2005) Drought, snails, and large-scale die-off of southern US salt marshes. Science 310:1803-1806

Simon J (2007) Evaluation of marking European silver eels with visible implant elastomer tags and alcian blue. J Fish Biol 70:303-309

Skole D, Tucker C (1993) Tropical deforestation and habitat fragmentation in the Amazon: satellite data from 1978 to 1988. Science 260:1905-1910

Sunahara T, Mogi M (2002) Priority effects of bamboo-stump mosquito larvae: influences of water exchange and leaf litter input. Ecol Entomol 27:346-354

Victor BC (1986) Duration of the planktonic larval stage of one hundred species of Pacific and Atlantic wrasses (family Labridae). Mar Biol 90:317-326

Visser ME, Both C (2005) Shifts in phenology due to global climate change: the need for a yardstick. Proc R Soc 272:2561-2569

Walther G-R et al (2002) Ecological responses to recent climate change. Nature 416:389-395

Warfe DM, Barmuta LA (2004) Habitat structural complexity mediates the foraging success of multiple predator species. Oecologia 141:171-178

Webster MS (2002) Role of predators in the early post-settlement demography of coral reef fishes. Oecologia 131:52-60

Webster MS, Almany GR (2002) Positive indirect effects in a coral reef fish community. Ecol Lett 5:549-557

Werner EE (1992) Individual behavior and higher-order species interactions. Am Nat 140:S5-S32

Werner EE, Gilliam JF (1984) The ontogenetic niche and species interactions in size-structured populations. Annu Rev Ecol Syst $15: 393-425$ 


\section{Bibliography}

Abrams, P., 1984: Recruitment, lotteries, and coexistence in coral reef fish. American Naturalist, 123, 44-55.

Adler, P. B., J. HilleRisLambers, and J. M. Levine, 2007: A niche for neutrality. Ecology Letters, 10, 95-104.

Agrawal, A. A., D. D. Ackerly, F. Adler, A. E. Arnold, C. Cceres, D. F. Doak, E. Post, P. J. Hudson, J. Maron, K. A. Mooney, M. Power, D. Schemske, J. Stachowicz, S. Strauss, M. G. Turner, and E. Werner, 2007: Filling key gaps in population and community ecology. Frontiers in Ecology and the Environment, 5, 145-152.

Akaike, H., 1973: Information theory as an extension of the maximum likelihood principle. In Second International Symposium on Information Theory, Petrov, B. N. and Csaki, F., editors, Academiai Kiado, Budapest, 267-281.

Alford, R. A. and H. M. Wilbur, 1985: Priority effects in experimental pond communities - competition between Bufo and Rana. Ecology, 66, 1097-1105.

Allan, H. H., 1961: Flora of New Zealand. Government Printer, Wellington.

Almany, G. R., 2003: Priority effects in coral reef fish communities. Ecology, 84, 1920-1935.

Almany, G. R., 2004a: Differential effects of habitat complexity, predators and competitors on abundance of juvenile and adult coral reef fishes. Oecologia, 141, 105-113.

Almany, G. R., 2004b: Does increased habitat complexity reduce predation and competition in coral reef fish assemblages? Oikos, 106, 275-284.

Almany, G. R., 2004c: Priority effects in coral reef fish communities of the Great Barrier Reef. Ecology, 85, 2872-2880. 
Almany, G. R. and M. S. Webster, 2006: The predation gauntlet: early postsettlement mortality in reef fishes. Coral Reefs, 25, 19-22.

Anderson, O., 1984: Optimal foraging by largemouth bass in structured environments. Ecology, 65, 851-861.

Andrew, N. L. and B. D. Mapstone, 1987: Sampling and the description of spatial pattern in marine ecology. Oceanography and Marine Biology Annual Review, 25, 39-90.

Andruskiw, M., J. M. Fryxell, I. D. Thompson, and J. A. Baker, 2008: Habitatmediated variation in predation risk by the American Marten. Ecology, 89, 22732280 .

Armsworth, P., 2002: Recruitment limitation, population regulation, and larval connectivity in reef fish metapopulations. Ecology, 83, 1092-1104.

Bainbridge, T. R., 1985: The committee on standards: precision and bias. ASTM Standardization News, 13, 44-46.

Barel, C. D. N., R. Dorit, P. H. Greenwood, G. Fryer, N. Hughes, P. B. N. Jackson, H. Kawanabe, R. H. Lowemcconnell, M. Nagoshi, A. J. Ribbink, E. Trewavas, F. Witte, and K. Yamaoka, 1985: Destruction of fisheries in Africa's lakes. Nature, $315,19-20$.

Beaumont, S. and K. C. Burns, 2009: Vertical gradients in leaf trait diversity in a New Zealand forest. Trees, 23, 339-346.

Bell, G., 2000: The distribution of abundance in neutral communities. The American Naturalist, 155, 606-617.

Bell, J., G. Craik, D. Pollard, and B. Russell, 1985: Estimating length frequency distributions of large reef fish underwater. Coral Reefs, 4, 41-44.

Bellwood, D. R., T. P. Hughes, C. Folke, and M. Nystrom, 2004: Confronting the coral reef crisis. Nature, 429, 827-833.

Benke, A. C., 1978: Interactions among coexisting predators - a field experiment with dragonfly larvae. The Journal of Animal Ecology, 47, 335-350.

Beukers, J., G. Jones, and R. Buckley, 1995: Use of implant microtags for studies on populations of small reef fish. Marine Ecology Progress Series, 125, 61-66.

Beukers, J. S. and G. P. Jones, 1997: Habitat complexity modifies the impact of piscivores on a coral reef fish population. Oecologia, 114, 50-59. 
Beverton, R. J. H., 1991: Recruitment in marine fish populations. Tree, 6, 64-65.

Blaustein, L. and J. Margali, 1996: Priority effects in temporary pools: nature and outcome of mosquito larva-toad tadpole interactions depend on order of entrance. The Journal of Animal Ecology, 65, 77-84.

Bonin, M. C., M. Srinivasan, G. R. Almany, and G. P. Jones, 2009: Interactive effects of interspecific competition and microhabitat on early post-settlement survival in a coral reef fish. Coral Reefs, 28, 265-274.

Both, C., M. v. Asch, R. G. Bijlsma, A. B. v. d. Burg, and M. E. Visser, 2009: Climate change and unequal phenological changes across four trophic levels: constraints or adaptations? Journal of Animal Ecology, 78, 73-83.

Brock, V. F., 1954: A preliminary report on a method of estimating reef fish populations. Journal of Wildlife Management, 18, 299-308.

Brose, U., N. D. Martinez, and R. J. Williams, 2003: Estimating species richness: sensitivity to sample coverage and insensitivity to spatial patterns. Ecology, 84, 2364-2377.

Buenau, K. E., A. Rassweiler, and R. M. Nisbet, 2007: The effects of landscape structure on space competition and alternative stable states. Ecology, 88, 30223031 .

Buss, L. W. and J. B. C. Jackson, 1979: Competitive networks: nontransitive competitive relationships in cryptic coral reef environments. The American Naturalist, 113, 223-234.

Byers, J. E., 2000: Competition between two estuarine snails: implications for invasions of exotic species. Ecology, 81, 1225-1239.

Calcagno, V., N. Mouquet, P. Jarne, and P. David, 2006: Coexistence in a metacommunity: the competition-colonization trade-off is not dead. Ecology Letters, 9, 897-907.

Caley, M. J., M. H. Carr, M. A. Hixon, T. P. Hughes, G. P. Jones, and B. A. Menge, 1996: Recruitment and the local dynamics of open marine populations. Annual Review of Ecology and Systematics, 27, 477-500.

Carothers, J. H. and F. M. Jaksic, 1984: Time as a niche difference: the role of interference competition. Oikos, 42, 403-406.

Carr, M. H., T. W. Anderson, and M. A. Hixon, 2002: Biodiversity, population regulation, and the stability of coral-reef fish communities. PNAS, 99, 1124111245 . 
Casas, A., G. Benito, V. R. Thorndycraft, and M. Rico, 2006: The topographic data source of digital terrain models as a key element in the accuracy of hydraulic flood modeling. Earth Surface Processes and Landforms, 31, 444-456.

Case, T. J. and M. E. Gilpin, 1974: Interference competition and niche theory. Proceeding of the National Academy of Science, U.S.A., 71, 3073-3077.

Caselle, J., 1999: Early post-settlement mortality in a coral reef fish and its effect on local population size. Ecological Monographs, 69, 177-194.

Chapman, C. J., A. D. F. Johnstone, J. R. Dunn, and D. J. Creasey, 1974: Reactions of fish to sound generated by divers' open-circuit underwater breathing apparatus. Marine Biology, 27, 357-366.

Chase, J. M., 2007: Drought mediates the importance of stochastic community assembly. PNAS, 104, 17430-17434.

Chave, J., 2004: Neutral theory and community ecology. Ecology Letters, 7, 241253.

Chen, L.-S., 2002: Post-settlement diet shift of Chlorurus sordidus and Scarus schlegeli (Pisces: Scaridae). Zoological Studies, 41, 47-58.

Chesson, J., 1978: Measuring preference in selective predation. Ecology, 59, 211215.

Chesson, P., 2000: Mechanisms of maintenance of species diversity. Annual Review of Ecology and Systematics, 31, 343-366.

Chesson, P. and R. Warner, 1981: Environmental variability promotes coexistence in lottery competitive systems. The American Naturalist, 117, 923 943.

Clarke, P. J. and W. G. Allaway, 1993: The regeneration niche of the Grey Mangrove (Avicennia marina): effects of salinity, light and sediment factors on establishment, growth and survival in the field. Oecologia, 93, 548-556.

Cody, M., 1975: Towards a theory of continental species diversities: bird distributions over Mediterranean habitat gradients. In Ecology and Evolution of Communities, Cody, M. and Diamond, J., editors. Harvard University Press, Cambridge, 214-257.

Coen, L. D., K. L. Heck, and L. G. Abele, 1981: Experiments on competition and predation among shrimps of seagrass meadows. Ecology, 62, 1484-1493. 
Colwell, R. K. and E. R. Fuentes, 1975: Experimental studies of the niche. Annual Review of Ecology and Systematics, 6, 281-310.

Connell, J. H., 1983: On the prevalence and relative importance of interspecific competition: evidence from field experiments. The American Naturalist, 122, 661696.

Connell, J. H., t. P. Hughes, C. C. Wallace, J. E. Tanner, K. E. Harms, and A. M. Kerr, 2004: A long-term study of competition and diversity of corals. Ecological Monographs, 74, 179-210.

Connolly, S. R. and J. Roughgarden, 1999: Theory of marine communities: competition, predation, and recruitment-dependent interaction strength. Ecological Monographs, 69, 277-296.

Cowen, R. K., K. M. M. Lwiza, S. Sponaugle, C. B. Paris, and D. B. Olson, 2000: Connectivity of marine populations: open or closed? Science, 287, 857.

Cox, D. R., 1972: Regression models and life-tables. Journal of the Royal Statistical Society. Series B (Methodological), 34, 187-220.

Cox, D. R. and D. Oakes, 1984: Analysis of survival data. Chapman and Hall, London.

Craig, P. C., 1998: Temporal spawning patterns of several sugeonfishes and wrasses in American Samoa. Pacific Science, 52, 35-39.

Crain, C. M., B. R. Silliman, S. L. Bertness, and M. D. Bertness, 2004: Physical and biotic drivers of plant distribution across estuarine salinity gradients. Ecology, 85, 2539-2549.

Crawley, M. J., 2007: The R Book. John Wiley \& Sons Ltd, Chichester, West Sussex.

Cushing, D. H., 1987: Population biology and the management of fisheries. Trends in Ecology \& Evolution, 2, 138-139.

Dalgaard, P., 2002: Introductory statistics with R. Statistics and Computing. Springer Science \& Business Media, New York.

Davi, H., K. Soudani, T. Deckx, E. Dufrene, V. Le Dantec, and C. Francois, 2006: Estimation of forest leaf area index from SPOT imagery using NDVI distribution over forest stands. International Journal of Remote Sensing, 27, 885-902.

Dayton, G. H. and L. A. Fitzgerald, 2005: Priority effects and desert anuran communities. Canadian Journal of Zoology-Revue Canadienne De Zoologie, 83, 11121116. 
De Girolamo, M. and C. Mazzoldi, 2001: The application of visual census on Mediterranean rocky habitats. Marine Environmental Research, 51, 1-16.

de Roos, A. M., K. Leonardsson, L. Persson, and G. G. Mittelbach, 2002: Ontogenetic niche shifts and flexible behavior in size-structured populations. Ecological Monographs, 72, 271-292.

Diamond, J. M., 1978: Niche shifts and the rediscovery of interspecific competition. American Scientist, 66, 322-331.

Doherty, P. J., 1983: Tropical territorial damselfishes: is density limited by aggression or recruitment? Ecology, 64, 176-190.

Doherty, P. J., 1991: Spatial and temporal patterns in recruitment. In The ecology of fishes on coral reefs, Sale, P. F., editor. Academic Press, San Diego, 261-293.

Doherty, P. J. and D. M. Williams, 1988a: Are local populations of coral reef fishes equilibrial assemblages? the empirical database. In Proceedings of the 6th International Coral Reef Symposium, volume 1, Australia, 131-140.

Doherty, P. J. and D. M. Williams, 1988b: The replenishment of coral reef fish populations. Oceanography and Marine Biology Annual Review, 26, 487-551.

Dufour, V. and R. Galzin, 1993: Colonization patterns of reef fish larvae to the lagoon at Moorea Island, French Polynesia. Marine Ecology Progress Series, 102, 143-152.

Durant, J. M., D. O. Hjermann, G. Ottersen, and N. C. Stenseth, 2007: Climate and the match or mismatch between predator requirements and resource availability. Climate Research, 33, 271-283.

Ebersole, J. P., 1985: Niche separation of two damselfish species by aggression and differential microhabitat utilization. Ecology, 66, 14-20.

Edgar, G. J., N. S. Barrett, and A. J. Morton, 2004: Biases associated with the use of underwater visual census techniques to quantify the density and sizestructure of fish populations. Journal of Experimental Marine Biology and Ecology, 308, 269-290.

Ehmann, W. J. and J. A. MacMahon, 1996: Initial tests for priority effects among spiders that co-occur on sagebrush shrubs. The Journal of Arachnology, 24, 173185.

Elkin, C. M. and R. L. Baker, 2000: Lack of preference for low-predation-risk habitats in larval damselflies explained by costs of intraspecific interactions. Animal Behaviour, 60, 511-521. 
Figler, M. H., R. M. Klein, and H. V. Peeke, 1976: The establishment and reversibility of dominance relationships in jewel fish, Hemichromis bimaculatus Gill (Pisces, Cichlidae): effects of prior exposure and prior residence situations. Behaviour, 58, 254-270.

Fincke, O. M., 1999: Organization of predator assemblages in neotropical tree holes: effects of abiotic factors and priority. Ecological Entomology, 24, 13-23.

Finke, D. L. and R. F. Denno, 2002: Intraguild predation diminished in complexstructured vegetation: implications for prey suppression. Ecology, 83, 643-652.

Floyd, D. A. and J. E. Anderson, 1987: A comparison of three methods for estimating plant cover. The Journal of Ecology, 75, 221-228.

Foggo, A., M. J. Attrill, M. T. Frost, and A. A. Rowden, 2003: Estimating marine species richness: an evaluation of six extrapolative techniques. Marine Ecology Progress Series, 248, 15-26.

Foggo, A., S. D. Rundle, and D. T. Bilton, 2003: The net result: evaluating species richness extrapolation techniques for littoral pond invertebrates. Freshwater Biology, 48, 1756-1764.

Forrester, G. and M. Steele, 2004: Predators, prey refuges, and the spatial scaling of density-dependent prey mortality. Ecology, 85, 1332-1342.

Forrester, G. E., B. Evans, M. A. Steele, and R. R. Vance, 2006: Assessing the magnitude of intra- and interspecific competition in two coral reef fishes. Oecologia, 148, 632-640.

Frederick, J., 1997: Evaluation of fluorescent elastomer injection as a method for marking small fish. Bulletin of Marine Science, 61, 399-408.

Freund, R. J. and W. J. Wilson, 1998: Regression analysis: statistical modeling of a response variable. Academic Press, San Diego, California, USA.

Gagern, A., T. Schuerg, N. K. Michiels, G. Schulte, D. Sprenger, and N. Anthes, 2008: Behavioural response to interference competition in a sessile suspension feeder. Marine Ecology Progress Series, 353, 131-135.

Gaines, S. and J. Roughgarden, 1985: Larval settlement rate: a leading determinant of structure in an ecological community of the marine intertidal zone. Proceeding of the National Academy of Science, U.S.A., 82, 3703-3711.

Gallet, R., S. Alizon, P. A. Comte, A. Gutierrez, F. Depaulis, M. v. Baalen, E. Michel, and C. D. M. Miller-Graf, 2007: Predation and disturbance interact to shape prey species diversity. American Naturalist, 170, 143-154. 
Galzin, R., 1987: Structure of fish communities of French Polynesian coral reefs. II. temporal scales. Marine Ecology Progress Series, 41, 137-145.

Galzin, R. and j. P. Pointer, 1985: Moorea Island, Society Archipelago. In 5th International Coral Reef Congress, Delesalle, B., Galzin, R., and Salvat, B., editors, volume 1, Tahiti, 73-102.

Gardner, T. A., I. M. Cote, J. A. Gill, A. Grant, and A. R. Watkinson, 2003: Longterm region-wide declines in Caribbean corals. Science, 301, 958-960.

Garnier, E., B. Shipley, C. Roumet, and G. Laurent, 2001: A standardized protocol for the determination of specific leaf area and leaf dry matter content. Functional Ecology, 15, 688-695.

Geange, S. W. and A. C. Stier, 2009: Order of arrival affects competition in two reef fishes. Ecology, 90, 2868-2878.

Gibbs, H. L. and P. R. Grant, 1987: Ecological consequences of an exceptionally strong El Nino event on Darwin's finches. Ecology, 68, 1735-1746.

Glasser, J. W. and H. J. Price, 1988: Evaluating expectations deduced from explicit hypotheses about mechanisms of competition. Oikos, 51, 57-70.

Gotelli, N. J., 2000: Null model analysis of species co-occurrence patterns. Ecology, 81, 2606-2621.

Gotelli, N. J., 2001: Research frontiers in null model analysis. Global Ecology $\mathcal{E}$ Biogeography, 10, 337-343.

Gotelli, N. J. and G. R. Graves, 1996: Null models in ecology. Smithsonian Institute Press, Washinton D.C.

Gravel, D., C. D. Canham, M. Beaudet, and M. Christian, 2006: Reconciling niche and neutrality: the continuum hypothesis. Ecology Letters, 9, 399-409.

Gurevitch, J., L. L. Morrow, A. Wallace, and J. S. Walsh, 1992: A meta-analysis of competition in field experiments. The American Naturalist, 140, 539-572.

Harmelin-Vivien, M., 1979: Ichtyofaune des recifs coralliens de Tulear (Madagascar). Ecologie et relations trophiques. PhD thesis, Universite Aix-Marseille II, France.

Harmon, M. E., J. F. Franklin, F. J. Swanson, P. Sollins, S. V. Gregory, J. D. Lattin, N. H. Anderson, S. P. Cline, N. G. Aumen, J. R. Sedell, G. W. Lienkamper, K. Cromack Jr, and K. W. Cummings, 1986: Ecology of coarse woody debris in temperate systems. Advances in Ecological Research, 15, 133-202. 
Harvey, E., D. Fletcher, and M. Shortis, 2001: A comparison of the precision and accuracy of estimates of reef-fish lengths determined visually by divers with estimates produced by a stereo-video system. Fishery Bulletin, 99, 63-71.

Harvey, P. H., R. K. Colwell, J. W. Silvertown, and R. M. May, 1983: Null models in ecology. Annual Review of Ecology and Systematics, 14, 189-211.

Hellmann, J. J. and G. W. Fowler, 1999: Bias, precision, and accuracy of four measures of species richness. Ecological Applications, 9, 824-834.

Hill, M. S., 1998: Spongivory on Caribbean reefs releases corals from competition with sponges. Oecologia, 117, 143-150.

Hixon, M., S. Pacala, and S. Dandin, 2002: Population regulation: historical context and contemporary challenges of open vs. closed systems. Ecology, 83, 1490-1508.

Hixon, M. A., 1980: Competitive interactions between California reef fishes of the genus Embiotoca. Ecology, 61, 918-931.

Hixon, M. A. and G. P. Jones, 2005: Competition, predation, and densitydependent mortality in demersal marine fishes. Ecology, 86, 2847-2859.

Holbrook, S. J. and R. J. Schmitt, 1989: Resource overlap, prey dynamics, and the strength of competition. Ecology, 70, 1943-1953.

Holbrook, S. J. and R. J. Schmitt, 2002: Competition for shelter space causes density-dependent predation mortality in damselfishes. Ecology, 83, 2855-2868.

Holt, R. D., 1977: Predation, apparent competition, and the structure of prey communities. Theoretical Population Biology, 12, 197-229.

Holt, R. D., 1987: Prey communities in patchy environments. Oikos, 50, 276-290.

Hubbell, S. P., 2001: The unified neutral theory of biodiversity and biogeography. Princeton University Press, Princeton, New Jersey.

Huffaker, C. B., 1958: Experimental studies on predation: dispersion factors and predator-prey oscillations. Hilgardia, 27, 343-383.

Hughes, L., 2000: Biological consequences of global warming: is the signal already apparent? Trends in Ecology E Evolution, 15, 56-61.

Hutchinson, G. E., 1957: Concluding remarks. Cold Spring Harbor Symposia on Quantitative Biology, 22, 415-427. 
Imbert, H., L. Beaulaton, C. Rigaud, and P. Elie, 2007: Evaluation of visible implant elastomer as a method for tagging small European eels. Journal of Fish Biology, 71, 1546-1554.

Jansen, P. A., H. Slettvold, A. G. Finstad, and A. Langeland, 2002: Niche segregation between Arctic Char (Salvelinus alpinus) and Brown Trout (Salmo trutta): an experimental study of mechanisms. Canadian Journal of Fisheries and Aquatic Science, 59, 6-11.

Janssen, A., M. W. Sabelis, S. Magalhaes, M. Montserrat, and T. Van Der Hammen, 2007: Habitat structure affects intraguild predation. Ecology, 88, 27132719.

Jompa, J. and L. J. McCook, 2003: Coral-algal competition: macroalgae with different properties have different effects on corals. Marine Ecology Progress Series, 258, 87-95.

Jones, G. P., 1987a: Competitive interactions among adults and juveniles in a coral reef fish. Ecology, 68, 1534-1547.

Jones, G. P., 1987b: Some interactions between residents and recruits in two coral reef fishes. Journal of Experimental Marine Biology and Ecology, 114, 169-182.

Jones, G. P., M. J. Milicich, M. J. Emslie, and C. Lunow, 1999: Self-recruitment in a coral reef fish population. Nature, $402,802$.

Juliano, S. A., 2009: Species interactions among larval mosquitoes: context dependence across habitat gradients. Annual Review of Entomology, 54, 37-56.

Keast, A. and J. Harker, 1977: Strip counts as a means of determining densities and habitat utilization patterns in lake fishes. Environmental Biology of Fish, 1, 181-188.

Kennedy, P. G. and T. D. Burns, 2005: Priority effects determine the outcome of ectomycorrhizal competition between two Rhizopogon species colonizing Pinus muricata seedlings. New Phytologist, 166, 631-638.

Kobayashi, S., 1991: Interpecific relations in forest floor Coleopteron assemblages: niche overlap and guild structure. Res. Popul. Ecol, 33, 345-360.

Krebs, C. J., 1989: Ecological methodology. Harper Colins, New York.

Ladd, B. and J. M. Facelli, 2008: Priority effects produced by plant litter result in non-additive competitive effects. Oecologia, 157, 687-696. 
Langellotto, G. A. and R. F. Denno, 2004: Responses of invertebrate natural enemies to complex-structured habitats: a meta-analytical synthesis. Oecologia, $139,1-10$.

Larson, R., 1980: Competition, habitat selection, and the bathymetric segregation of two Rockfish (Sebastes) species. Ecological Monographs, 50, 221239.

Lawler, S. P. and P. J. Morin, 1993: Temporal overlap, competition, and priority effects in larval Anurans. Ecology, 74, 174-182.

Lawlor, L. R., 1980: Structure and stability in natural and randomly constructed competitive communities. The American Naturalist, 116, 394-408.

Lecchini, D., C. W. Osenberg, J. S. Shima, C. M. S. Mary, and R. Galzin, 2007: Ontogenetic changes in habitat selection during settlement in a coral reef fish: ecological determinants and sensory mechanisms. Coral Reefs, 26, 423-432.

Lecchini, D., S. Planes, and R. Galzin, 2005: Experimental assessment of sensory modalities of coral-reef fish larvae in the recognition of their settlement habitat. Behavioral Ecology and Sociobiology, 58, 18-26.

Leibold, M. A. and M. A. McPeek, 2006: Coexistence of the niche and neutral perspectives in community ecology. Ecology, 87, 1399-1410.

Leis, J. M., 1991: The pelagic stage of reef fishes. In The Ecology of Fishes on Coral Reefs, Sale, P., editor. Academic Press, Inc., San Diego, CA, 182-229.

Leis, J. M., B. M. Carson-Ewart, and D. Cato, 2002: Sound detection in situ by the larvae of a coral-reef damselfish (Pomacentridae). Marine Ecology Progress Series, 232, 259-268.

Levin, P. S., 1994: Fine-scale temporal variation in recruitment of a temporate demersal fish: the importance of settlement versus post-settlement loss. Oecologia, 97, 124-133.

Levine, S. H., 1976: Competitive interactions in ecosystems. American Naturalist, 110, 903-910.

Levine, S. H. and J. HilleRisLambers, 2009: The importance of niches for the maintenance of species diversity. Nature, 461, 254-257.

Lincoln-Smith, M. P., 1989: Improving multispecies rocky reef fish censuses by counting different groups of species using different procedures. Environmental Biology of Fishes, 26, 29-37. 
Lindholm, J. B., P. J. Auster, and L. S. Kaufman, 1999: Habitat-mediated survivorship of juvenile (0-year) Atlantic cod Gadus morhua. Marine and Ecology Progress Series, 180, 247-255.

Lopez-Victoria, M., S. Zea, and E. Wei, 2006: Competition for space between encrusting excavating Caribbean sponges and other coral reef organisms. Marine Ecology Progress Series, 312, 113-121.

Louette, G. and L. D. Meester, 2007: Predation and priority effects in experimental zooplankton communities. Oikos, 116, 419-426.

Lucifora, L. O., V. B. Garca, R. C. Menni, A. H. Escalante, and N. M. Hozbor, 2008: Effects of body size, age and maturity stage on diet in a large shark: ecological and applied implications. Ecological Research, 24, 109-118.

Luckhurst, B. E. and K. Luckhurst, 1977: Recruitment patterns of coral reef fishes on the fringing reef of Curacao, Netherlands Antilles. Canadian Journal of Zoology, 55, 681-689.

Lukoschek, V. and M. I. McCormick, 2003: A review of multi-species foraging associations in fishes and their ecological significance. Proceedings of the 9th International Coral Reef Symposium.

MacArthur, R. and R. Levins, 1967: Limiting similarity, convergence, and divergence of coexisting species. American Naturalist, 101, 377-385.

Main, K. L., 1987: Predator avoidance in seagrass meadows: prey behavior, microhabitat selection, and cryptic coloration. Ecology, 68, 170-180.

Maiorana, V. C., 1978: An explanation of ecological and developmental constants. Nature, 273, 375-377.

Maltamo, M., J. Malinen, P. Packaln, A. Suvanto, and J. Kangas, 2006: Nonparametric estimation of stem volume using airborne laser scanning, aerial photography, and stand-register data. Canadian Journal of Forest Research, 36, 426-436.

Manly, B. F., P. Miller, and L. M. Cook, 1972: Analysis of a selective predation experiment. The American Naturalist, 106, 719-736.

Manly, B. F. J., 2007: Randomization, bootstrap and Monte Carlo methods in biology. Chapmann and Hall, London, 3 edition.

Marriott, F., 1990: A dictionary of statistical terms. Longman Scientific \& Technical, New york, 5 edition. 
May, R. M., 1975: Some notes on estimating the competition matrix. Ecology, 56, 737-741.

McCook, L. J., J. Jompa, and G. Diaz-Pulido, 2001: Competition between corals and algae on coral reefs: a review of evidence and mechanisms. Coral Reefs, 19, 400-417.

McCormick, M. and J. Choat, 1987: Estimating total abundance of a large temperate-reef fish using visual strip-transects. Marine Biology, 96, 469-478.

McCormick, M. and L. Makey, 1997: Post-settlement transition in coral reef fishes: overlooked complexity in niche shifts. Marine Ecology Progress Series, 153, 247-257.

McCormick, M., L. Makey, and V. Dufour, 2002: Comparative study of metamorphosis in tropical reef fishes. Marine Biology, 141, 841-853.

McCoy, M. W., B. M. Bolker, C. W. Osenberg, B. G. Miner, and J. R. Vonesh, 2006: Size correction: comparing morphological traits among populations and environments. Oecologia, 148, 547-554.

McDermott, C. J. and J. S. Shima, 2006: Ontogenetic shifts in microhabitat preference of the temperate reef fish Forsterygion lapillum: implications for population limitation. Marine Ecology Progress Series, 320, 259-266.

Meese, R. J. and P. A. Tomich, 1992: Dots on rocks: a comparison of percent cover estimation methods. Journal of Experimental Marine Biology and Ecology, $165,59-73$.

Milicich, M. J. and P. J. Doherty, 1994: Larval supply of coral reef fish populations: magnitude and synchrony of replenishment to Lizard Island, Great Barrier Reef. Marine Ecology Progress Series, 10, 121-134.

Miller, A. and R. Ambrose, 2000: Sampling patchy distributions: comparison of sampling designs in rocky intertidal habitats. Marine Ecology Progress Series, 196, $1-14$.

Moilanen, A. and M. Nieminen, 2002: Simple connectivity measures in spatial ecology. Ecology, 83, 1131-1145.

Montgomery, J. C., N. Tolimieri, and O. S. Haine, 2001: Active habitat selection by pre-settlement reef fishes. Fish Fisheries, 2, 261-277.

Mora, C. and P. Sale, 2002: Are populations of coral reef fish open or closed? Trends in Ecology and Evolution, 17, 422-428. 
Morris, D. W., 2003: Toward an ecological synthesis: a case for habitat selection. Oecologia, 136, 1-13.

Mouillot, D., W. Stubbs, M. Faure, O. Dumay, J. Tomasini, J. Wilson, and T. Chi, 2005: Niche overlap estimates based on quantitative functional traits: a new family of non-parametric indices. Oecologia, 145, 345-353.

Munday, P., G. Jones, and M. Caley, 2001: Interspecific competition and coexistence in a guild of coral-dwelling fishes. Ecology, 82, 2177-2189.

Munday, P. L., 2004: Competitive coexistance of coral-dwelling fishes: the lottery hypothesis revisted. Ecology, 85, 623-628.

Myers, R. F., 1999: Micronesian reef fishes: a field guide for divers and aquarists. Coral Graphics, Guam.

Nickum, J. G., H. L. Bart Jr, P. R. Bowser, I. E. Greer, C. Hubbs, J. A. Jenkins, J. R. MacMillan, J. W. Rachlin, J. D. Rose, P. W. Sorensen, and J. R. Tomasso, 2004: Guidelines for the use of fishes in research. American Fisheries Society, 53.

Norris, J. L. and K. H. Pollock, 1998: Non-parametric MLE for Poisson species abundance models allowing for heterogeneity between species. Environmental and Ecological Statistics, 5, 391-402.

Osenberg, C., J. Shima, and C. S. Mary, 2006: Habitat degradation and settlement behavior: effects on fish settlement, survival, and recruitment. In Proceedings of the 10th International Coral Reef Symposium, Okinawa, Japan, 257-263.

Osman, R. W. and R. B. Whitlatch, 1995: The influence of resident adults on recruitment: a comparison to settlement. Journal of Experimental Marine Biology and Ecology, 190, 169-198.

Palmer, T. M., M. L. Stanton, and T. P. Young, 2003: Competition and coexistence: exploring mechanisms that restrict and maintain diversity within mutualist guilds. The American Naturalist, 162, S63-S79.

Parmesan, C. and G. Yohe, 2003: A globally coherent fingerprint of climate change impacts across natural systems. Nature, 421, 37-42.

Peacor, S. D. and E. E. Werner, 2004: How independent are species-pair interaction strengths on other species in the food web? Ecology, 85, 2754-2763.

Persson, L. and P. Eklov, 1995: Prey refuges affecting interactions between piscivorous Perch and juvenile Perch and Roach. Ecology, 76, 70-81. 
Pianka, E. R., 1966: Latitudinal gradients in species diversity: a review of concepts. The American Naturalist, 910, 33-46.

Pianka, E. R., 1973: The structure of lizard communities. Annual Review of Ecology and Systematics, 4, 53-74.

Planes, S. and G. Lecaillon, 2001: Caging experiment to examine mortality during metamorphosis of coral reef fish larvae. Coral Reefs, 20, 211-218.

Prathep, A., B. Wichachucherd, and P. Thongroy, 2007: Spatial and temporal variation in density and thallus morphology of Turbinaria ornata in Thailand. Aquatic Botany, 86, 132-138.

Price, J. E. and P. J. Morin, 2004: Colonization history determines alternate community states in a food web of intraguild predators. Ecology, 85, 1017-1028.

Qasim, S., 1956: Time and duration of the spawning season in some marine teleosts in relation to their distribution. ICES Journal of Marine Science, 21, 144155.

Quinn, G. P. and M. J. Keough, 2005: Experimental design and data analysis for biologists. Cambridge University Press, Cambridge, UK, 4 edition.

Rees, M., R. Condit, M. Crawley, S. Pacala, and D. Tilman, 2001: Long-term studies of vegetation dynamics. Science, 293, 650-655.

Ricker, W. E., 1975: Computations and interpretation of biological statistics of fish populations. Technical report.

Rilov, G., W. F. Figueira, S. J. Lyman, and L. B. Crowder, 2007: Complex habitats may not always benefit prey: linking visual field with reef fish behavior and distribution. Marine Ecology Progress Series, 329, 225-238.

Risk, A., 1998: The effects of interactions with reef residents on the settlement and subsequent persistence of Ocean Surgeonfish, Acanthurus bahianus. Environmental Biology of Fishes, 51, 377-389.

Robertson, D. and S. G. Gaines, 1986: Interference competition structures habitat use in a local assemblage of coral reef surgeonfishes. Ecology, 67, 1372-1383.

Robertson, D. R., 1984: Cohabitation of competing territorial damselfishes on a Caribbean coral reef. Ecology, 65, 1121-1135.

Robertson, D. R., U. M. Schober, and J. D. Brawn, 1993: Comparative variation in spawning output and juvenile recruitment of some Caribbean reef fishes. Marine Ecology Progress Series, 94, 105-113. 
Robertson, D. R., S. E. Swearer, K. Kaufmann, and E. B. Brothers, 1999: Settlement vs. environmental dynamics in a pelagic-spawning reef fish at Caribbean Panama. Ecological Monographs, 69, 195-218.

Root, R., 1967: Niche exploitation pattern of Blue-gray Gnatcatcher. Ecological Monographs, 37, 317-350.

Rosenzweig, M. L., 1991: Habitat selection and population interactions: the search for mechanism. The American Naturalist, 137, S5-S28.

Roughgarden, J., S. Gaines, and H. Possingham, 1988: Recruitment dynamics in complex life cycles. Science, 241, 1460-1466.

Roxburgh, S., K. Shea, and J. Wilson, 2004: The intermediate disturbance hypothesis: patch dynamics and mechanisms of species co-existence. Ecology, 85, 359-371.

Rummel, R. J., 1970: Applied factor analysis. Northwestern University Press.

Russell, B. C., G. R. V. Anderson, and F. H. Talbot, 1977: Seasonality and recruitment of coral reef fishes. Australian Journal of Marine and Freshwater Research, 28, 521-528.

Russell, B. C., F. H. Talbot, and S. Domm, 1974: Patterns of colonization of artificial reefs by coral reef fishes. Proceedings of the Second International Coral Reef Symposium, 1, 207-215.

Sale, P., 1975: Patterns of use of space in a guild of territorial reef fishes. Marine Biology, 29, 89-97.

Sale, P. and B. Sharp, 1983: Correction for bias in visual transect censuses of coral reef fishes. Coral Reefs, 2, 37-42.

Sale, P. F., 1976a: The effect of territorial adult Pomacentrid fishes on the recruitment and survival of juveniles on patches of coral rubble. Journal of Experimental Marine Biology and Ecology, 24, 297-306.

Sale, P. F., 1976b: Reef fish lottery. Natural History, 85, 60-65.

Sale, P. F., 1977: Maintenance of high diversity in coral reef fish communities. The American Naturalist, 978, 337-359.

Sale, P. F., 1978: Coexistence of coral reef fishes - a lottery for living space. Environmental Biology of Fishes, 3, 85-102. 
Sale, P. F., P. J. Doherty, G. J. Eckert, W. A. Douglas, and D. J. Ferrell, 1984: Large scale spatial and temporal variation in recruitment to fish populations on coral reefs. Oecologia, 64, 191-198.

Samhouri, J. F., M. A. Steele, and G. E. Forrester, 2009: Inter-cohort competition drives density dependence and selective mortality in a marine fish. Ecology, 90, 1009-1020.

Samoilys, M. A. and G. Carlos, 2000: Determining methods of underwater visual census for estimating the abundance of coral reef fishes. Environmental Biology of Fishes, 57, 289-304.

Schauber, E., D. Kelly, P. Turchin, C. Simon, W. Lee, R. Allen, I. Payton, P. Wilson, P. Cowan, and R. Brockie, 2002: Masting by eighteen New Zealand plant species: the role of temperature as a synchronizing cue. Ecology, 83, 1214-1225.

Schmitt, R. and S. Holbrook, 1990: Population responses of surfperch released from competition. Ecology, 71, 1653-1665.

Schmitt, R. J. and S. J. Holbrook, 1986: Seasonally fluctuating resources and temporal variability of interspecific competition. Oecologia, 69, 1-11.

Schmitt, R. J. and S. J. Holbrook, 2003: Mutualism can mediate competition and promote coexistence. Ecology Letters, 6, 898-902.

Schoener, T., 1983: Field experiments on interspecific competition. American Naturalist, 122, 240-285.

Schoener, T. W., 1974: Resource partitioning in ecological communities. Science, $185,27-39$.

Shima, J., 2001a: Regulation of local populations of a coral reef fish via joint effects of density- and number-dependent mortality. Oecologia, 126, 58-65.

Shima, J. S., 2001b: Recruitment of a coral reef fish: roles of settlement, habitat, and postsettlement losses. Ecology, 82, 2190-2199.

Shima, J. S., 2002: Mechanisms of density- and number-dependent population regulation of a coral-reef fish. Marine and Freshwater Research, 53, 175-179.

Shima, J. S. and C. Osenberg, 2003: Cryptic density dependence: effects of covariation between density and site quality in reef fish. Ecology, 84, 46-52.

Shima, J. S., C. W. Osenberg, and C. M. S. Mary, 2008: Quantifying site quality in a heterogeneous landscape: recruitment of a reef fish. Ecology, 89, 86-94. 
Shorrocks, B. and M. Bingley, 1994: Priority effects and species coexistence: experiments with fungal-breeding Drosophila. The Journal of Animal Ecology, 63, 799-806.

Shulman, M., J. Ogden, W. McFarland, S. Miller, N. Wolf, and J. Ebersole, 1983: Priority effects in the recruitment of juvenile coral reef fishes. Ecology, 64, 15081513.

Silliman, B. R., J. van de Koppel, M. D. Bertness, L. E. Stanton, and I. A. Mendelssohn, 2005: Drought, snails, and large-scale die-off of southern US salt marshes. Science, 310, 1803-1806.

Silverman, B. W., 1986: Density estimation for statistics and data analysis. Chapman and Hall, London.

Silvertown, J., 2004: Plant coexistence and the niche. Trends in Ecology and Evolution, 19, 605-611.

Simon, J., 2007: Evaluation of marking european silver eels with visible implant elastomer tags and alcian blue. Journal of Fish Biology, 70, 303-309.

Simpson, S. D., M. G. Meekan, R. D. McCauley, and A. Jeffs, 2004: Attraction of settlement-stage coral reef fishes to reef noise. Marine Ecology Progress Series, 276, 263-268.

Skole, D. and C. Tucker, 1993: Tropical deforestation and habitat fragmentation in the Amazon - satellite data from 1978 to 1988. Science, 261, 1104-1104.

Srinivasan, M. and G. P. Jones, 2006: Extended breeding and recruitment periods of fishes on a low latitude coral reef. Coral Reefs, 25, 673-682.

Steele, M. A., 1997: Population regulation by post-settlement mortality in two temperate reef fishes. Oecologia, 112, 64-74.

Stine, R. A. and J. F. Heyse, 2001: Non-parametric estimates of overlap. Stat Med, 20, 215-236.

Sunahara, T. and M. Mogi, 2002: Priority effects of Bamboo-stump Mosquito larvae: influences of water exchange and leaf litter input. Ecological Entomology, $27,346-354$.

Sutherland, J. P., 1974: Multiple stable points in natural communities. The American Naturalist, 108, 859-873.

Sutherland, J. P. and R. H. Karlson, 1977: Development and stability of the fouling community at Beaufort, North Carolina. Ecological Monographs, 47, 425446. 
Swearer, S. E., J. E. Caselle, D. W. Lea, and R. R. Warner, 1999: Larval retention and recruitment in an island population of a coral-reef fish. Nature, 402, 799-802.

Sweatman, H. P. A., 1985: The influence of adults of some coral reef fishes on larval recruitment. Ecological Monographs, 55, 469-485.

Syms, C. and G. P. Jones, 1999: Scale of disturbance and the structure of a temperate fish guild. Ecology, 80, 921-940.

Syms, C. and G. P. Jones, 2000: Disturbance, habitat structure, and the dynamics of a coral-reef fish community. Ecology, 81, 2714-2729.

Szabo, A. R., 2002: Experimental tests of intercohort competition for food and cover in the tidepool sculpin (Oligocottus maculosus Girard). Canadian Journal of Zoology, 80, 137-144.

Talbot, F. H., B. C. Russell, and G. R. V. Anderson, 1978: Coral reef fish communities: unstable, high-diversity systems? Ecological Monographs, 48, 425440.

Team, R. D. C., 2007: R: a language and environment for statistical computing.

Team, R. D. C., 2008: R: a language and environment for statistical computing.

Therneau, T. M. and P. M. Grambsch, 2000: Modeling survival data: extending the Cox model. Statistics for Biology and Health. Springer, New York.

Thresher, R. E., P. L. Colin, and L. J. Bell, 1989: Planktonic duration, distribution and population structure of western and Central Pacific damselfishes (Pomacentridae). Copeia, 1989, 420-434.

Thresher, R. E. and J. S. Gunn, 1986: Comparative analysis of visual census techniques for highly mobile, reef-associated piscivores (Carangidae). Environmental Biology of Fishes, 17, 93-116.

Tiffin, P. and B. D. Inouye, 2000: Measuring tolerance to herbivory: accuracy and precision of estimates made using natural versus imposed damage. Evolution, 54, 1024-1029.

Tolimieri, N., 1998: Effects of substrata, resident conspecifics and damselfish on the settlement and recruitment of the Stoplight Parrotfish, Sparisoma viride. Environmental Biology of Fishes, 53, 393-404.

Turra, A. and M. Denadai, 2004: Interference and exploitation components in interspecific competition between sympatric intertidal hermit crabs. Journal of Experimental Marine Biology and Ecology, 310, 183-193. 
Underwood, A. J. and P. G. Fairweather, 1989: Supply-side ecology and benthic marine assemblages. Trends in Ecology \& Evolution, 4, 16-20.

Victor, B. C., 1983: Recruitment and population dynamics of a coral reef fish. Science, 219, 419-420.

Victor, B. C., 1986: Duration of the planktonic larval stage of one hundred species of Pacific and Atlantic wrasses (family Labridae). Marine Biology, 90, 317-326.

Visser, M. and C. Both, 2005: Shifts in phenology due to global climate change: the need for a yardstick. Proceedings of the Royal Society B-Biological Sciences, 272, 2561-2569.

Wainwright, P. C., D. R. Bellwood, and M. W. Westneat, 2002: Ecomorphology of locomotion in labrid fishes. Environmental Biology of Fishes, 65, 47-62.

Walker, J. A. and M. W. Westneat, 1997: Labriform propulsion in fishes: kinematics of flapping aquatic flight in the Bird Wrasse Gomphosus varius (Labridae). Journal of Experimental Biology, 200, 1549-1569.

Walther, B. A. and J. L. Moore, 2005: The concepts of bias, precision and accuracy, and their use in testing the performance of species richness estimators, with a literature review of estimator performance. Ecography, 28, 815-829.

Walther, G.-R., E. Post, P. Convey, A. Menzel, C. Parmesan, T. J. C. Beebee, J.-M. Fromentin, O. Hoegh-Guldberg, and F. Bairlein, 2002: Ecological responses to recent climate change. Nature, 416, 389-395.

Warfe, D. M. and L. A. Barmuta, 2004: Habitat structural complexity mediates the foraging success of multiple predator species. Oecologia, 141, 171-178.

Warner, R. and P. Chesson, 1985: Coexistence mediated by recruitment fluctuations: a field guide to the storage effect. American Naturalist, 125, 769787.

Webster, M., 2002: Role of predators in the early post-settlement demography of coral reef fishes. Oecologia, 131, 52-60.

Webster, M. and G. Almany, 2002: Positive indirect effects in a coral reef fish community. Ecology Letters, 5, 549-557.

Webster, M. S., 2004: Density dependence via intercohort competition in a coralreef fish. Ecology, 85, 986-994. 
Werner, E. E., 1992: Individual behavior and higher-order species interactions. American Naturalist, 140, S5-S32.

Werner, E. E. and J. F. Gilliam, 1984: The ontogenetic niche and species interactions in size-structured populations. Annual Review of Ecology and Systematics, 15, 393-425.

Whitfield, J., 2006: The cost of leafing. Nature, 444, 539-541.

Whitman, W. C. and E. I. Siggeirsson, 1954: Comparison of line intercept and point contact methods in the analysis of mixed grass range vegetation. Ecology, $35,431-436$.

Williams, D. M., 1983: Daily, monthly and yearly variability in recruitment of a guild of coral reef fishes. Marine Ecology Progress Series, 10, 231-237.

Wilson, J. A., 2005: Age class interactions in a marine goby, Elacatinus prochilos (Bohlke and Robins, 1968). Journal of Experimental Marine Biology and Ecology, 327, 144-156.

Winemiller, K. O. and E. R. Pianka, 1990: Organization in natural assemblages of desert lizards and tropical fishes. Ecological Monographs, 60, 27-55.

Winemiller, K. O. and K. A. Rose, 1992: Patterns of life-history diversification in North American fishes: implications for population regulation. Canadian Journal of Fisheries and Aquatic Sciences, 49, 2196-2218.

Wright, S., 2002: Plant diversity in tropical forests: a review of mechanisms of species coexistence. Oecologia, 130, 1-14. 